\title{
Enzymatic synthesis of diverse heterocycles by a noncanonical nonribosomal peptide synthetase
}

Gina L. Morgan, ${ }^{1,3}$ Kelin Li, ${ }^{2}$ Drake M. Crawford, ${ }^{1}$ Jeffrey Aubé,,${ }^{1,2}$ and Bo Li, ${ }^{1,4 *}$

${ }^{1}$ Department of Chemistry, The University of North Carolina at Chapel Hill, Chapel Hill, NC 27599, United States

${ }^{2}$ The Division of Chemical Biology and Medicinal Chemistry, UNC Eshelman School of Pharmacy, The University of North Carolina at Chapel Hill, Chapel Hill, North Carolina 27599, United States

${ }^{3}$ Current Address: Oerth Bio LLC, Durham, NC 27701, United States

${ }^{4}$ Department of Microbiology and Immunology, The University of North Carolina at Chapel Hill, Chapel Hill, NC 27599, United States

${ }^{*}$ Corresponding author: boli@email.unc.edu

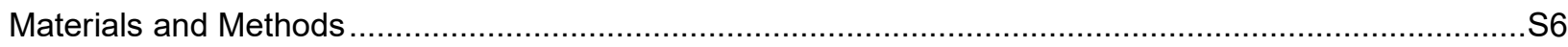

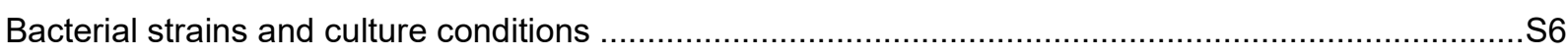

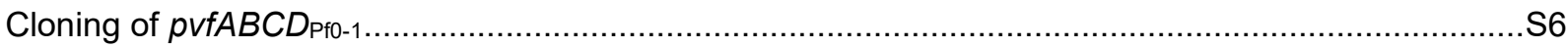

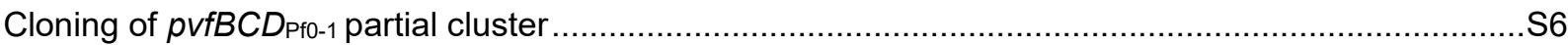

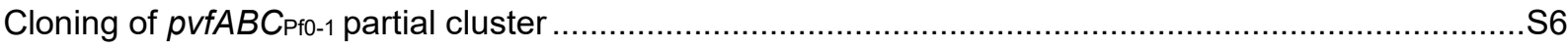

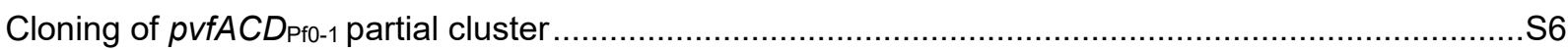

Transformation of plasmids into the heterologous host $P$. aeruginosa PAO1 ..................................... 6

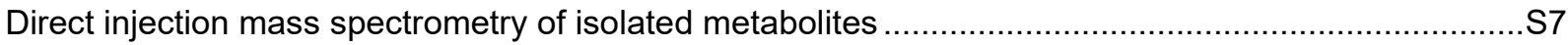

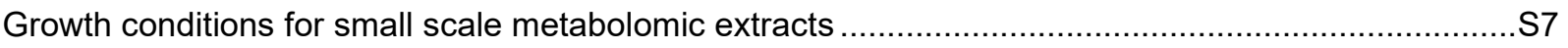

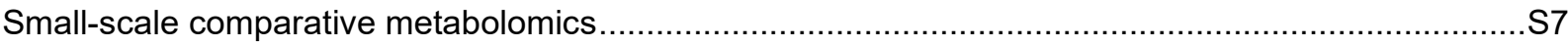

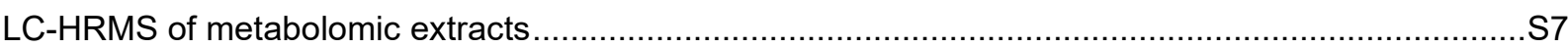

Purification and isolation of Leu-dPNO (1), Leu-PNO A (2), Leu-PNO B (4).......................................

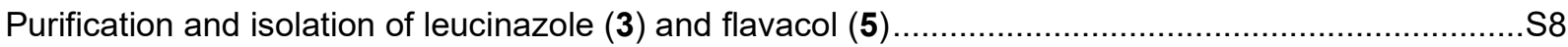

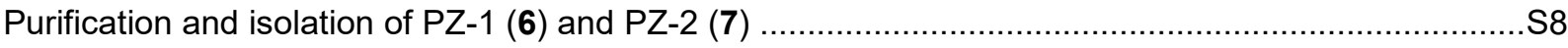

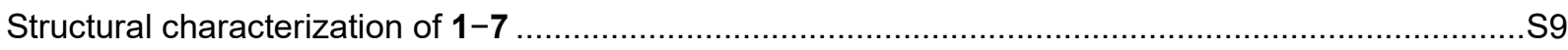

Synthesis of 3,6-diisobutylpyrazin-2(1H)-one standard (flavacol, 5) ............................................... 9

Synthesis of 1-(4(5)-isobutyl-1H-imidazol-2-yl)-3-methylbutan-1-one standard (leucinazole, 3) .........S10

Synthesis of 2,6-, 2,5-, and 2,3-diisobutylpyrazine standards ........................................................ 12

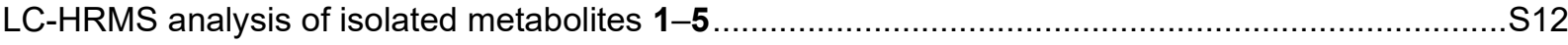

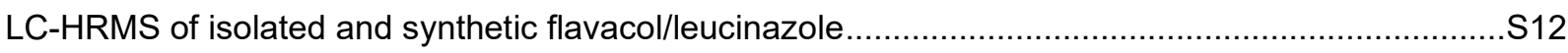

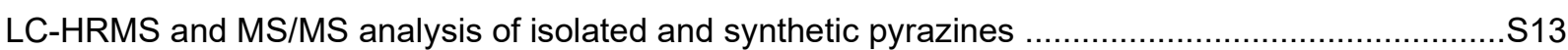

NMR analysis of PZ-1 (6) and PZ-2 (7) each mixed with their respective standard ............................ 13

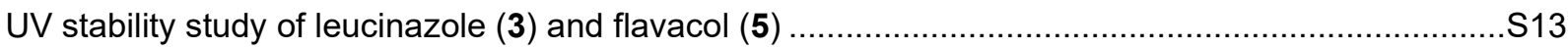

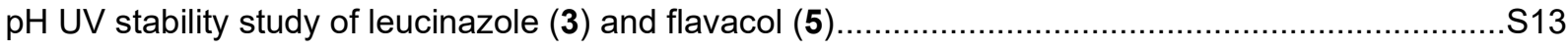

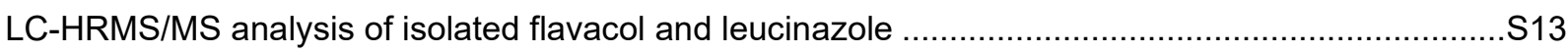

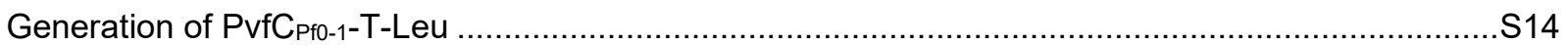




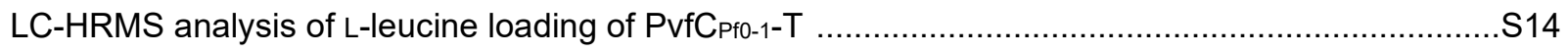

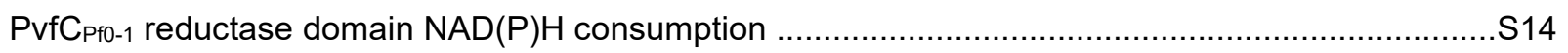

pH screen of in vitro production of leucinazole, flavacol, PZ-1, and PZ-2 ......................................S14

$\mathrm{PvfC}_{\llcorner 48}$ in vitro reactions to produce valine derivatives of leucinazole, flavacol, PZ-1, and PZ-2 .......S14

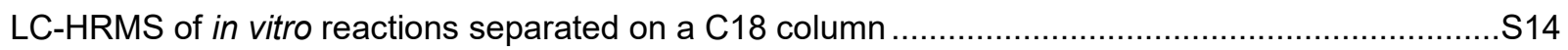

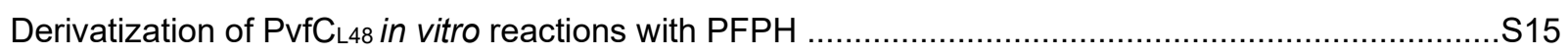

LC-HRMS and MS/MS analysis of $\mathrm{PvfC}_{\mathrm{L} 48}$ in vitro reactions ....................................................... 15

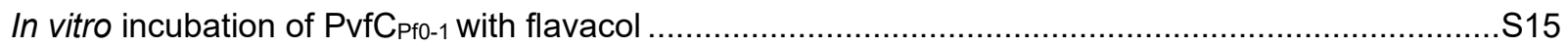

Inhibition studies towards Bacillus subtilis and Escherichia coli ................................................... 15

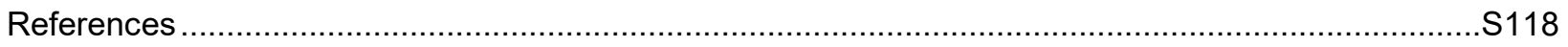

\section{Supplementary tables}

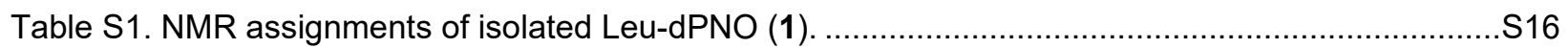

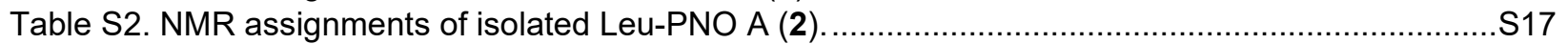

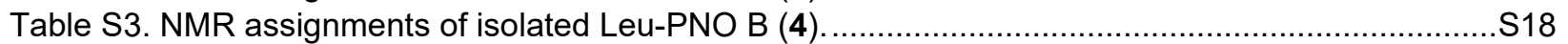

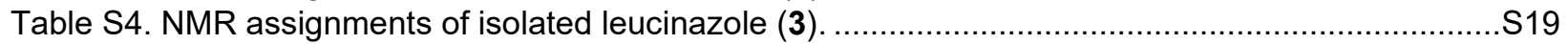

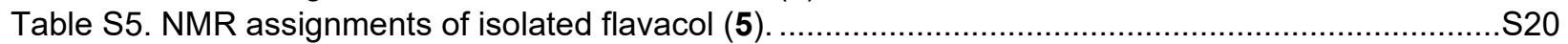

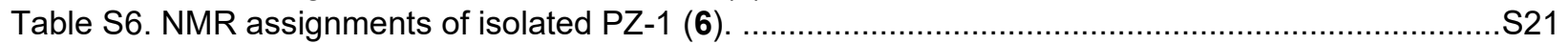

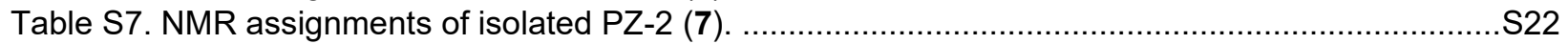

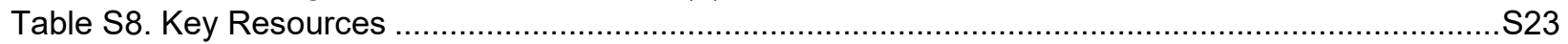

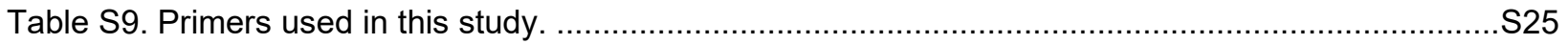

\section{Supplementary schemes}

Scheme S1. Synthesis of 3,6-diisobutylpyrazin-2(1H)-one (flavacol, 5) .............................................S9 Scheme S2. Synthesis of 1-(4(5)-isobutyl-1H-imidazol-2-yl)-3-methylbutan-1-one standard (leucinazole,

$3)$.

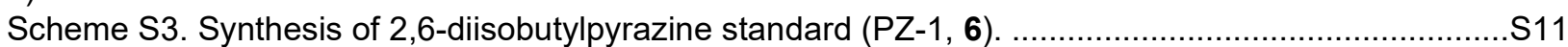

Scheme S4. Synthesis of 2,5-diisobutylpyrazine standard (PZ-2, 7) ...........................................

Scheme S5. Synthesis of 2,3-diisobutylpyrazine standard................................................................ 12

\section{Supplementary figures}

Figure S1. Production of Leu-dPNO, Leu-PNO A, and Leu-PNO B requires expression of $p v f C_{\mathrm{Pf0}-1}$ and pvfB $\mathrm{Pfo}_{1}$ and production of leucinazole, flavacol, $\mathrm{PZ}-1$, and $\mathrm{PZ}-2$ requires expression of $p v f C_{\mathrm{Pf0}-1}$ in $P$. aeruginosa PAO1 (black) and E. coli BAP1 (blue).

Figure S2. Mass spectra of isolated Leu-dPNO (1), Leu-PNO A (2), leucinazole (3), Leu-PNO B (4), flavacol (5), PZ-1 (6), and PZ-2 (7)

Figure S3. Mass spectra of isolated Leu-dPNO (1), Leu-PNO A (2), leucinazole (3), Leu-PNO B (4),

flavacol (5), PZ-1 (6), and PZ-2 (7) in metabolomic studies.

Figure S4. PvfC ${ }_{\mathrm{pfo}-1}$ produces more PZ-1, PZ-2, leucinazole, and flavacol with increasing $\mathrm{pH} . . . \ldots \ldots \ldots \ldots . . . . \mathrm{S} 30$

Figure S5. MS fragmentation of isolated leucinazole (3) and flavacol (5). ......................................... 32

Figure S6. Isolated flavacol, leucinazole, PZ-1, and PZ-2 elute at the same time as their synthetic standards.

Figure S7. MS fragmentation of isolated PZ-1 and PZ-2 and synthetic 2,6-, 2,3-, and 2,5diisobutylpyrazines. 
Figure S8. PvfC $\mathrm{Pf0}-1_{1}$ loads a single leucine on $\mathrm{PvfC}_{\mathrm{Pf0}-1-\mathrm{T}}$ and and utilizes an NADPH-dependent reductive

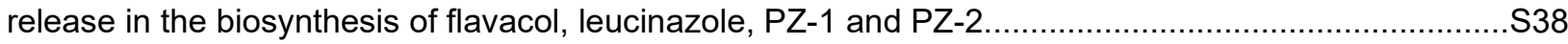
Figure S9. Elution profile of leucinazole, flavacol, PZ-1, PZ-2 in $\mathrm{PvfC}_{\mathrm{Pf0}-1}$ in vitro reaction changes based

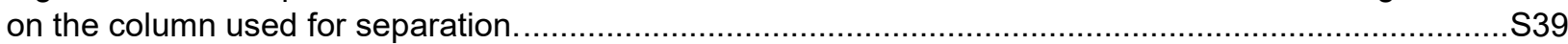
Figure S10. Leucinazole and flavacol are only produced by $\mathrm{PvfC}_{\mathrm{Pfo}-1}$ in the presence of NADPH. .........S40 Figure S11. PvfC $_{\mathrm{Pf0}-1}$ produces both PZ-1 (6) and PZ-2 (7) in vitro.................................................. 40 Figure S12. Leu-aldehyde is released by $\mathrm{PvfC}_{\mathrm{Pf0}-1}$ and derivatized by pentafluorophenylhydrazine

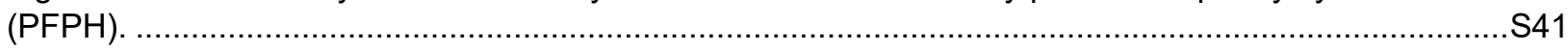
Figure S13. Leu-Leu-aldehyde (8) is released by $\mathrm{PvfC}_{\mathrm{Pf0}-1}$ and derivatized by $\mathrm{PFPH} . . . \ldots \ldots \ldots \ldots \ldots \ldots \ldots . . . . . . . . . . . . .242$

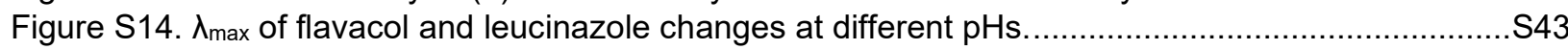
Figure S15. PvfC $\llcorner 48$ produces valine-derived molecules corresponding to Val-pyrazinone, Val-imidazole,

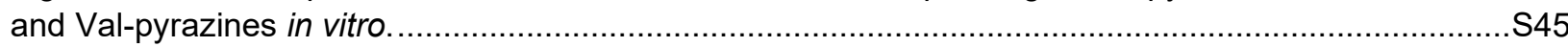

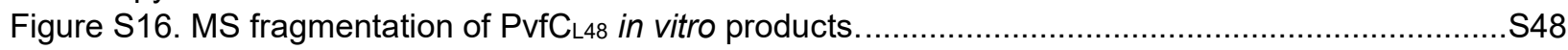
Figure S17. PvfC $\_48$ produces Val-Val-aldehyde in vitro. ................................................................. 49 Figure S18. Val-aldehyde is released from $\mathrm{PvfC}_{\llcorner 48}$ and captured by $\mathrm{PFPH}$ in vitro................................ 50 Figure S19. Leu-(d)PNOs, flavacol, leucinazole, PZ-1, PZ-2, and 2,3-diisobutylpyrazine do not inhibit growth of Bacillus subtilis or Escherichia coli.

\section{Supplementary Extended Data}

Extended Data 1. ${ }^{1} \mathrm{H}$ NMR spectrum of isolated Leu-dPNO (1) in $\mathrm{CDCl}_{3}(700 \mathrm{MHz})$..........................S52

Extended Data 2. ${ }^{13} \mathrm{C}$ NMR spectrum of isolated Leu-dPNO (1) in $\mathrm{CDCl}_{3}(176 \mathrm{MHz})$..........................53

Extended Data 3. $\left({ }^{1} \mathrm{H},{ }^{1} \mathrm{H}\right)$ COSY NMR spectrum of isolated Leu-dPNO (1) in $\mathrm{CDCl}_{3}(700 \mathrm{MHz}) \ldots \ldots \ldots . . .554$

Extended Data 4. $\left({ }^{1} \mathrm{H},{ }^{13} \mathrm{C}\right) \mathrm{HSQC}$ NMR spectrum of isolated Leu-dPNO (1) in $\mathrm{CDCl}_{3}\left({ }^{1} \mathrm{H}, 700 \mathrm{MHz},{ }^{13} \mathrm{C}\right.$,

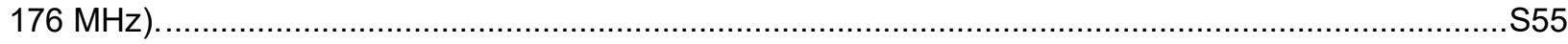

Extended Data 5. $\left({ }^{1} \mathrm{H},{ }^{13} \mathrm{C}\right) \mathrm{HMBC}$ NMR spectrum of isolated Leu-dPNO (1) in $\mathrm{CDCl}_{3}\left({ }^{1} \mathrm{H}, 700 \mathrm{MHz},{ }^{13} \mathrm{C}\right.$,

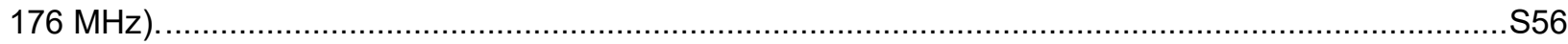

Extended Data 6. ${ }^{1} \mathrm{H}$ NMR spectrum of select peaks of isolated Leu-dPNO (1) in $\mathrm{CDCl}_{3}\left({ }^{1} \mathrm{H}, 850 \mathrm{MHz}\right)$ to

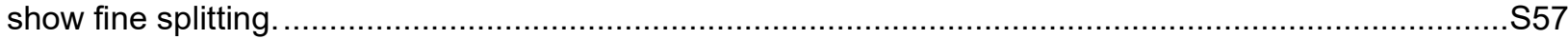

Extended Data 7. $\left({ }^{1} \mathrm{H},{ }^{1} \mathrm{H}\right)$ COSY NMR spectrum of isolated Leu-dPNO (1) in $\mathrm{CDCl}_{3}\left({ }^{1} \mathrm{H}, 850 \mathrm{MHz}\right) \ldots . .558$

Extended Data 8. ${ }^{1} \mathrm{H}$ NMR spectrum of isolated Leu-PNO A (2) in $\mathrm{CDCl}_{3}(700 \mathrm{MHz}) \ldots \ldots \ldots \ldots \ldots \ldots \ldots \ldots . . .559$

Extended Data 9. ${ }^{13} \mathrm{C}$ NMR spectrum of isolated Leu-PNO A (2) in $\mathrm{CDCl}_{3}(176 \mathrm{MHz}) \ldots \ldots \ldots \ldots \ldots \ldots \ldots \ldots . . . . . . . . . . . . .60$

Extended Data 10. $\left({ }^{1} \mathrm{H},{ }^{1} \mathrm{H}\right)$ COSY NMR spectrum of isolated Leu-PNO A (2) in $\mathrm{CDCl}_{3}(700 \mathrm{MHz})$.......S61

Extended Data 11. $\left({ }^{1} \mathrm{H},{ }^{13} \mathrm{C}\right) \mathrm{HSQC}$ NMR spectrum of isolated Leu-PNO A (2) in $\mathrm{CDCl}_{3}\left({ }^{1} \mathrm{H}, 700 \mathrm{MHz},{ }^{13} \mathrm{C}\right.$,

$176 \mathrm{MHz})$ ..S62

Extended Data 12. $\left({ }^{1} \mathrm{H},{ }^{13} \mathrm{C}\right) \mathrm{HMBC}$ NMR spectrum of isolated Leu-PNO A (2) in $\mathrm{CDCl}_{3}\left({ }^{1} \mathrm{H}, 700 \mathrm{MHz}\right.$,

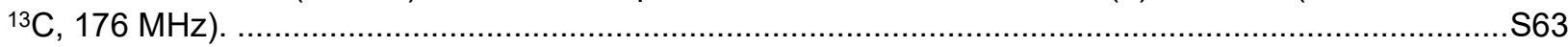

Extended Data 13. ${ }^{1} \mathrm{H}$ NMR spectrum of isolated Leu-PNO B (4) in $\mathrm{CDCl}_{3}(700 \mathrm{MHz})$.......................S64

Extended Data 14. ${ }^{13} \mathrm{C}$ NMR spectrum of isolated Leu-PNO B (4) in $\mathrm{CDCl}_{3}(176 \mathrm{MHz}) \ldots \ldots \ldots \ldots \ldots \ldots \ldots . . . . . . . . . .55$

Extended Data 15. $\left({ }^{1} \mathrm{H},{ }^{1} \mathrm{H}\right)$ COSY NMR spectrum of isolated Leu-PNO B (4) in $\mathrm{CDCl}_{3}(700 \mathrm{MHz}) \ldots \ldots . . .566$

Extended Data 16. $\left({ }^{1} \mathrm{H},{ }^{13} \mathrm{C}\right) \mathrm{HSQC}$ NMR spectrum of isolated Leu-PNO B (4) in $\mathrm{CDCl}_{3}\left({ }^{1} \mathrm{H}, 700 \mathrm{MHz},{ }^{13} \mathrm{C}\right.$,

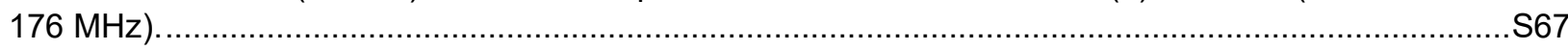

Extended Data 17. $\left({ }^{1} \mathrm{H},{ }^{13} \mathrm{C}\right) \mathrm{HMBC}$ NMR spectrum of isolated Leu-PNO B (4) in $\mathrm{CDCl}_{3}\left({ }^{1} \mathrm{H}, 700 \mathrm{MHz}\right.$,

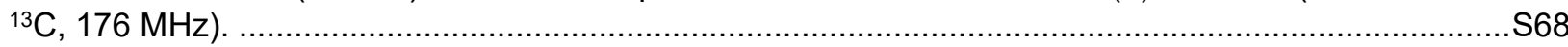

Extended Data 18. ${ }^{1} \mathrm{H}$ NMR spectrum of isolated leucinazole (3) in MeOD (700 MHz).....................S69

Extended Data 19. ${ }^{13} \mathrm{C}$ NMR spectrum of isolated leucinazole (3) in MeOD $(700 \mathrm{MHz}) \ldots \ldots \ldots \ldots \ldots \ldots \ldots . . . . . . . . . . .570$

Extended Data 20. $\left({ }^{1} \mathrm{H},{ }^{1} \mathrm{H}\right)$ COSY NMR spectrum of isolated leucinazole (3) in MeOD $(700 \mathrm{MHz})$......S71

Extended Data 21. $\left({ }^{1} \mathrm{H},{ }^{13} \mathrm{C}\right) \mathrm{HSQC}$ NMR spectrum of isolated leucinazole (3) in MeOD $\left({ }^{1} \mathrm{H}, 700 \mathrm{MHz},{ }^{13} \mathrm{C}\right.$,

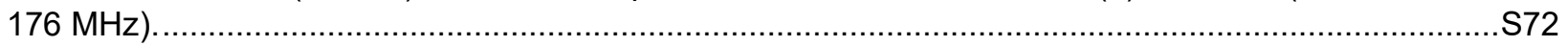
Extended Data 22. $\left({ }^{1} \mathrm{H},{ }^{13} \mathrm{C}\right) \mathrm{HMBC}$ NMR spectrum of isolated leucinazole (3) in MeOD $\left({ }^{1} \mathrm{H}, 700 \mathrm{MHz}\right.$,

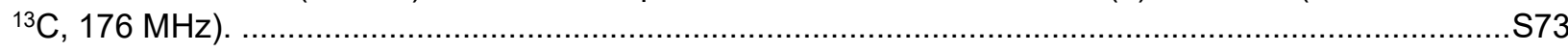

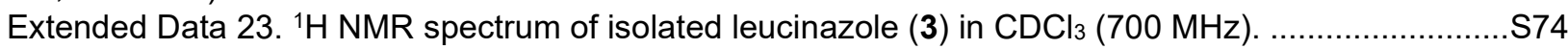


Extended Data 24. ${ }^{13} \mathrm{C}$ NMR spectrum of isolated leucinazole (3) in $\mathrm{CDCl}_{3}(700 \mathrm{MHz}) \ldots \ldots \ldots \ldots \ldots \ldots \ldots . . . . . . . .575$ Extended Data 25. $\left({ }^{1} \mathrm{H},{ }^{13} \mathrm{C}\right) \mathrm{HSQC}$ NMR spectrum of isolated leucinazole (3) in $\mathrm{CDCl}_{3}\left({ }^{1} \mathrm{H}, 700 \mathrm{MHz},{ }^{13} \mathrm{C}\right.$,

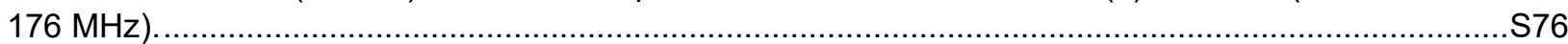
Extended Data 26. $\left({ }^{1} \mathrm{H},{ }^{13} \mathrm{C}\right) \mathrm{HMBC}$ NMR spectrum of isolated leucinazole (3) in $\mathrm{CDCl}_{3}\left({ }^{1} \mathrm{H}, 700 \mathrm{MHz},{ }^{13} \mathrm{C}\right.$,

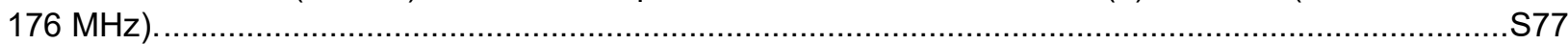

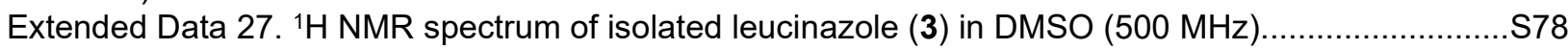

Extended Data 28. DEPT-135 ${ }^{13} \mathrm{C}$ NMR spectrum of isolated leucinazole (3) in DMSO $(500 \mathrm{MHz})$......S79 Extended Data 29. ${ }^{1} \mathrm{H}-{ }^{13} \mathrm{C}$ HSQC-TOCSY NMR spectrum of isolated leucinazole (3) in DMSO $(500 \mathrm{MHz})$.

Extended Data 30. ${ }^{1} \mathrm{H}$ NMR spectrum of isolated flavacol (5) in MeOD $(700 \mathrm{MHz}) \ldots$

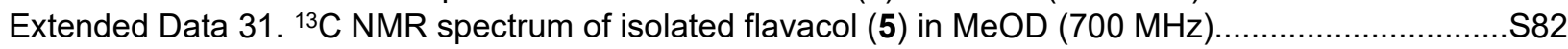

Extended Data 32. $\left({ }^{1} \mathrm{H},{ }^{1} \mathrm{H}\right)$ COSY NMR spectrum of isolated flavacol $(5)$ in MeOD $(700 \mathrm{MHz})$...........S83

Extended Data 33. $\left({ }^{1} \mathrm{H},{ }^{13} \mathrm{C}\right) \mathrm{HSQC}$ NMR spectrum of isolated flavacol $(5)$ in $\mathrm{MeOD}\left({ }^{1} \mathrm{H}, 700 \mathrm{MHz},{ }^{13} \mathrm{C}\right.$,

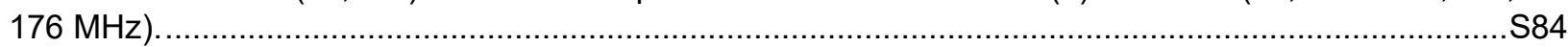
Extended Data 34. $\left({ }^{1} \mathrm{H},{ }^{13} \mathrm{C}\right) \mathrm{HMBC}$ NMR spectrum of isolated flavacol $(5)$ in $\mathrm{MeOD}\left({ }^{1} \mathrm{H}, 700 \mathrm{MHz},{ }^{13} \mathrm{C}\right.$,

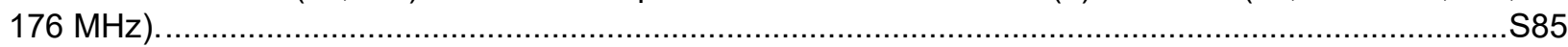

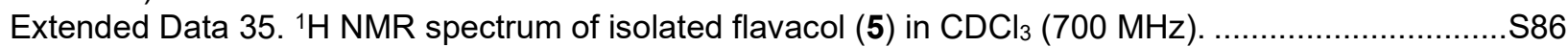

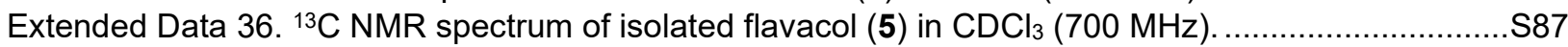

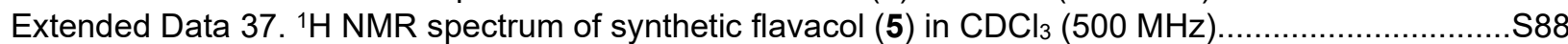

Extended Data 38. DEPT-135 ${ }^{13} \mathrm{C}$ NMR spectrum of synthetic flavacol (5) in $\mathrm{CDCl}_{3}(500 \mathrm{MHz}) \ldots \ldots \ldots . . .589$

Extended Data 39. $\left({ }^{1} \mathrm{H},{ }^{13} \mathrm{C}\right) \mathrm{HSQC}-T O C S Y$ NMR spectrum of synthetic flavacol (5) in $\mathrm{CDCl}_{3}(500 \mathrm{MHz})$.

Extended Data 40. ${ }^{1} \mathrm{H}$ NMR spectrum of isolated (top) and synthetic (bottom) flavacol in DMSO-d 6 (500

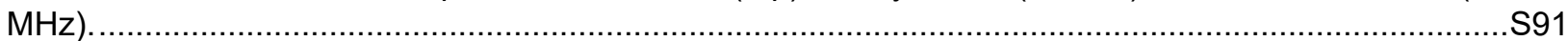

Extended Data 41. ${ }^{1} \mathrm{H}$ NMR spectrum of synthetic leucinazole (3) in DMSO $(500 \mathrm{MHz}) \ldots \ldots \ldots \ldots \ldots \ldots . . . . . . . . . .292$

Extended Data 42. DEPT $135{ }^{13} \mathrm{C}$ NMR spectrum of synthetic leucinazole (3) in DMSO $(500 \mathrm{MHz}) \ldots . . .593$

Extended Data 43. ${ }^{1} \mathrm{H}$ NMR spectrum of isolated (top) and synthetic (bottom) leucinazole in DMSO (500

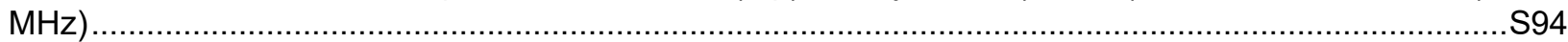

Extended Data 44. ${ }^{1} \mathrm{H}$ NMR spectrum of isolated PZ-1 (6) in $\mathrm{CDCl}_{3}(850 \mathrm{MHz})$. Solvent impurities were

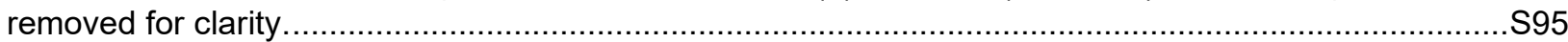

Extended Data 45. ${ }^{13} \mathrm{C}$ NMR spectrum of isolated PZ-1 (6) in $\mathrm{CDCl}_{3}(214 \mathrm{MHz}) \ldots \ldots \ldots \ldots \ldots \ldots \ldots \ldots \ldots . . . . . \ldots 96$

Extended Data 46. $\left({ }^{1} \mathrm{H},{ }^{1} \mathrm{H}\right)$ COSY NMR spectrum of isolated PZ-1 (6) in $\mathrm{CDCl}_{3}(700 \mathrm{MHz}) \ldots \ldots \ldots \ldots \ldots . . .597$

Extended Data 47. $\left({ }^{1} \mathrm{H},{ }^{13} \mathrm{C}\right) \mathrm{HSQC}$ NMR spectrum of isolated PZ-1 (6) in $\mathrm{CDCl}_{3}\left({ }^{1} \mathrm{H}, 850 \mathrm{MHz},{ }^{13} \mathrm{C}, 214\right.$

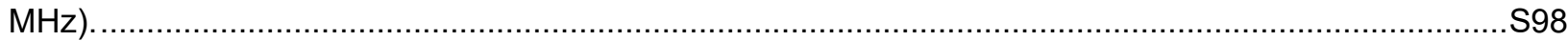

Extended Data 48. $\left({ }^{1} \mathrm{H},{ }^{13} \mathrm{C}\right) \mathrm{HMBC}$ NMR spectrum of isolated PZ-1 (6) in $\mathrm{CDCl}_{3}\left({ }^{1} \mathrm{H}, 850 \mathrm{MHz},{ }^{13} \mathrm{C}, 214\right.$

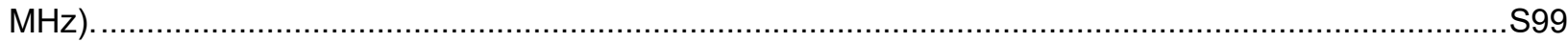

Extended Data 49. ${ }^{1} \mathrm{H}$ NMR spectrum of isolated PZ-2 (7) in $\mathrm{CDCl}_{3}(850 \mathrm{MHz})$. Solvent impurities were

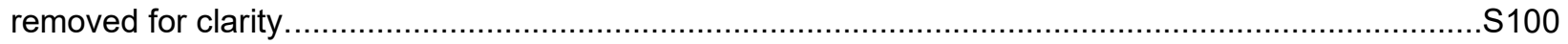

Extended Data 50. ${ }^{13} \mathrm{C}$ NMR spectrum of isolated PZ-2 (7) in $\mathrm{CDCl}_{3}(214 \mathrm{MHz}) \ldots \ldots \ldots \ldots \ldots \ldots \ldots \ldots \ldots . . . . . . . \ldots 101$

Extended Data 51. $\left({ }^{1} \mathrm{H},{ }^{1} \mathrm{H}\right)$ COSY NMR spectrum of isolated $\mathrm{PZ}-2(7)$ in $\mathrm{CDCl}_{3}(700 \mathrm{MHz})$..............S102

Extended Data 52. $\left({ }^{1} \mathrm{H},{ }^{13} \mathrm{C}\right) \mathrm{HSQC}$ NMR spectrum of isolated PZ-2 (7) in $\mathrm{CDCl}_{3}\left({ }^{1} \mathrm{H}, 850 \mathrm{MHz},{ }^{13} \mathrm{C}, 214\right.$

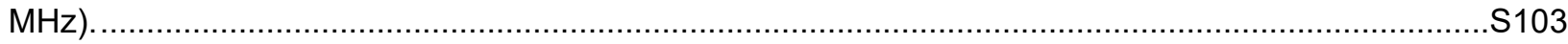

Extended Data 53. $\left({ }^{1} \mathrm{H},{ }^{13} \mathrm{C}\right) \mathrm{HMBC}$ NMR spectrum of isolated $\mathrm{PZ}-2(7)$ in $\mathrm{CDCl}_{3}\left({ }^{1} \mathrm{H}, 700 \mathrm{MHz},{ }^{13} \mathrm{C}, 176\right.$

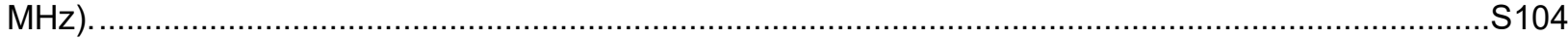

Extended Data 54. ${ }^{1} \mathrm{H}$ NMR spectrum of synthetic 2,3-diisobutylpyrazine in $\mathrm{CDCl}_{3}(850 \mathrm{MHz})$. Solvent

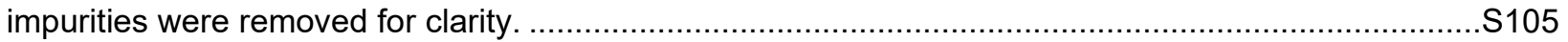

Extended Data 55. ${ }^{13} \mathrm{C}$ NMR spectrum of synthetic 2,3-diisobutylpyrazine in $\mathrm{CDCl}_{3}(214 \mathrm{MHz}) \ldots \ldots \ldots . . \mathrm{S} 106$

Extended Data 56. $\left({ }^{1} \mathrm{H},{ }^{13} \mathrm{C}\right) \mathrm{HSQC}$ NMR spectrum of synthetic 2,3-diisobutylpyrazine in $\mathrm{CDCl}_{3}\left({ }^{1} \mathrm{H}, 850\right.$

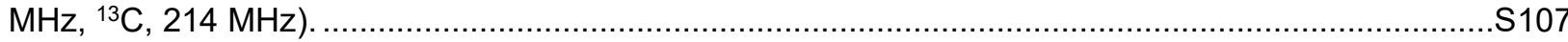

Extended Data 57. ${ }^{1} \mathrm{H}$ NMR spectrum of synthetic 2,5-diisobutylpyrazine (7) in $\mathrm{CDCl}_{3}(850 \mathrm{MHz})$. Solvent

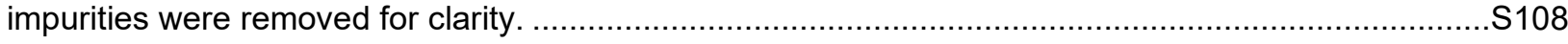

Extended Data 58. ${ }^{13} \mathrm{C}$ NMR spectrum of synthetic 2,5-diisobutylpyrazine (7) in $\mathrm{CDCl}_{3}(214 \mathrm{MHz})$....S109 
Extended Data 59. $\left({ }^{1} \mathrm{H},{ }^{13} \mathrm{C}\right) \mathrm{HSQC}$ NMR spectrum of synthetic 2,5-diisobutylpyrazine (7) in $\mathrm{CDCl}_{3}\left({ }^{1} \mathrm{H}\right.$, $\left.850 \mathrm{MHz},{ }^{13} \mathrm{C}, 214 \mathrm{MHz}\right)$...... S110 Extended Data 60. ${ }^{1} \mathrm{H}$ NMR spectrum of synthetic 2,6-diisobutylpyrazine in $\mathrm{CDCl}_{3}(850 \mathrm{MHz})$. Solvent impurities were removed for clarity.

Extended Data $61 .{ }^{13} \mathrm{C}$ NMR spectrum of synthetic 2,6-diisobutylpyrazine in $\mathrm{CDCl}_{3}(214 \mathrm{MHz})$..........S112 Extended Data 62. $\left({ }^{1} \mathrm{H},{ }^{13} \mathrm{C}\right) \mathrm{HSQC}$ NMR spectrum of synthetic 2,6-diisobutylpyrazine in $\mathrm{CDCl}_{3}\left({ }^{1} \mathrm{H}, 850\right.$ $\left.\mathrm{MHz},{ }^{13} \mathrm{C}, 214 \mathrm{MHz}\right)$.

Extended Data 63. ${ }^{1} \mathrm{H}$ NMR spectrum of a combined sample of isolated PZ-1 (6) and synthetic 2,6diisobutylpyrazine in $\mathrm{CDCl}_{3}(850 \mathrm{MHz})$.

Extended Data $64 .{ }^{13} \mathrm{C}$ NMR spectrum of a combined sample of isolated PZ-1 (6) and synthetic 2,6diisobutylpyrazine in $\mathrm{CDCl}_{3}(214 \mathrm{MHz})$. S115 Extended Data 65. ${ }^{1} \mathrm{H}$ NMR spectrum of a combined sample of isolated PZ-2 (7) and synthetic 2,5diisobutylpyrazine in $\mathrm{CDCl}_{3}(850 \mathrm{MHz})$. S116 Extended Data 66. ${ }^{13} \mathrm{C}$ NMR spectrum of a combined sample of isolated PZ-2 (7) and synthetic 2,5diisobutylpyrazine in $\mathrm{CDCl}_{3}(214 \mathrm{MHz})$. 


\section{Materials and Methods}

\section{Bacterial strains and culture conditions}

For cloning and transformations E. coli TOP 10 or BL21 was grown in Miller Luria Broth at $37{ }^{\circ} \mathrm{C}$. Kanamycin and gentamycin were used at a concentration of $50 \mu \mathrm{g} \mathrm{mL}^{-1}$ in both liquid and solid growth media.

Accession IDs of proteins used in this study

\begin{tabular}{|l|l|}
\hline Protein & UniProt Accession ID \\
\hline PvfC $_{\mathrm{Pf} 0-1}$ & Q3KK36 \\
\hline PvfC $_{\mathrm{L} 48}$ & Q1IGU3 \\
\hline
\end{tabular}

\section{Cloning of pvfABCD $D_{\mathrm{Pf0}-1}$}

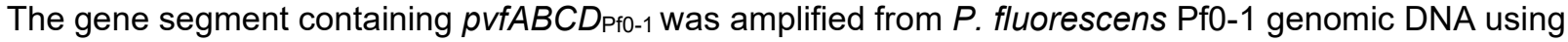
primers GM125 and GM128 and cloned into the pPSV35 vector. PCR products were digested with Xbal and $\mathrm{Kpnl}$ and ligated with pPSV35 that was digested with the same restriction enzymes. E. coli TOP10 cells were transformed with the resulting plasmid, pPSV35-pvfABCD $D_{\text {pfo-1, }}$ which was verified by sequencing. $P$. aeruginosa PAO1 or $E$. coli BAP1 cells were transformed with pPSV35-pvfABCD $\mathrm{Pf0}-1$ by electroporation for metabolomics.

\section{Cloning of $p v f B C D_{\text {Pf0-1 }}$ partial cluster}

The gene segment containing $p v f B C D$ Pfo-1 was amplified from $P$. fluorescens Pf0-1 genomic DNA using primers GM130 and GM131 and cloned into the pPSV35 vector. PCR products were digested with Xbal and Kpnl and ligated with pPSV35 that was digested with the same restriction enzymes. The resulting plasmid, pPSV35-pvfBCD $D_{\text {pfo-1 }}$, was transformed into $E$. coli TOP10 and verified by sequencing. $P$. aeruginosa PAO1 or $E$. coli BAP1 cells were transformed with pPSV35-pvfBCD $D_{\text {pf0-1 }}$ by electroporation for metabolomics.

\section{Cloning of pvfABC $C_{\mathrm{Pf0}-1}$ partial cluster}

The gene segment containing $p v f A B C_{\mathrm{PfO}-1}$ was amplified from $P$. fluorescens Pf0-1 genomic DNA using primers GM125 and GM129 and cloned into the pPSV35 vector. PCR products were digested with Xbal and $\mathrm{Kpnl}$ and ligated with pPSV35 that was digested with the same restriction enzymes. The resulting plasmid, pPSV35-pvfABC pf0-1, was transformed into $E$. coli TOP10 and verified by sequencing. $P$. aeruginosa PAO1 or E. coli BAP1 strains were transformed with pPSV35-pvfABC Pf0-1 $_{\text {by }}$ electroporation for metabolomics.

\section{Cloning of pvfACD $D_{\mathrm{Pf0}-1}$ partial cluster}

The pvfACD ${ }_{\mathrm{Pfo}-1}$ partial cluster was cloned using overlap extension PCR using $P$. fluorescens Pf0-1 genomic DNA as a template. Primers were designed to contain homologous regions overlapping the 3' end of $p v f A_{\text {pfo-1 }}$ with a 5' portion of $p v f C_{\text {pfo-1. }}$. Each DNA segment was amplified using primers GM132/GM134 and GM131/GM133, respectively. Reactions were then combined and the full DNA segment was amplified using a total of 35 cycles including ten two-step cycles before addition of primers GM131/GM132 for the remaining cycles. PCR products were digested with Xbal and Kpnl and ligated with pPSV35 that was digested with the same restriction enzymes. The resulting plasmid, pPSV35-

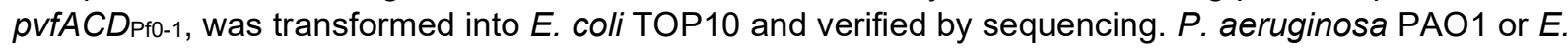
coli BAP1 cells were transformed with pPSV35-pvfACD pf0-1 $_{\text {by }}$ electroporation for metabolomics.

\section{Transformation of plasmids into the heterologous host $P$. aeruginosa PAO1} $P$. aeruginosa PAO1 was transformed with pPSV35-pvfABCD $D_{\text {ff0-1, }}$ pPSV35-pvfBCD $D_{\text {Pf0-1, }}$ pPSV35$p v f A B C_{\text {Pf0-1, }}$ pPSV35-pvfACD $D_{\text {Pf0-1, }}$ and the empty vector pPSV35 using the electroporation method described by Choi et al. ${ }^{2}$ Briefly, a sample of $6 \mathrm{~mL}$ overnight cultures of Pseudomonas were divided into 
four $1.5 \mathrm{~mL}$ microcentrifuge tubes and the cells were harvested at $6000 \times \mathrm{g}$ for 5 minutes. After removal of the supernatant, the cells were washed twice with $1 \mathrm{~mL}$ of $300 \mathrm{mM}$ sucrose per tube. The cell pellets were combined and resuspended in $200 \mu \mathrm{L}$ of $300 \mathrm{mM}$ sucrose to generate electrocompetent cells. An aliquot of $50 \mu \mathrm{L}$ cells in sucrose was gently mixed with $2 \mu \mathrm{L}$ of $100-200 \mathrm{ng} \mu \mathrm{L}^{-1}$ plasmid and transformed by electroporation ( $1 \mathrm{~mm}$ gap, $2.0 \mathrm{keV}$ ). Post electroporation, cells were recovered in $1 \mathrm{~mL}$ Lennox broth LB for 2 hours at $28^{\circ} \mathrm{C}$ while shaking at a speed of $225 \mathrm{rpm}$. A sample of $150 \mu \mathrm{L}$ of the cell suspension was plated on LB agar containing gentamycin and incubated at $28{ }^{\circ} \mathrm{C}$ for 1 day until colonies appeared.

\section{Direct injection mass spectrometry of isolated metabolites}

A sample of $5 \mu \mathrm{L}$ of each isolated molecule was analyzed by high resolution mass spectrometry via direct injection (Agilent Technologies 6520 Accurate Mass QTOF). Samples were directly injected onto the mass spectrometer using a mobile phase containing $50 \%$ acetonitrile and $0.1 \%$ formic acid at a flow rate of 0.4 $\mathrm{mL} \mathrm{min}^{-1}$ for 2 minutes. Electrospray ionization (ESI) mass spectrometry under positive ion mode was carried out using the following parameters: gas temperature $325{ }^{\circ} \mathrm{C}$, drying gas $10 \mathrm{~L} \mathrm{~min}^{-1}$, nebulizer 45 psi, fragmentor $175 \mathrm{~V}$, skimmer $65 \mathrm{~V}$.

\section{Growth conditions for small scale metabolomic extracts}

Overnight cultures of $P$. aeruginosa PAO1 or $E$. coli BAP1 that harbor pPSV35 plasmids containing various pvf $f_{\text {Pfo-1 }}$ constructs were grown in $5 \mathrm{~mL}$ LB containing gentamycin at $28{ }^{\circ} \mathrm{C}$ to saturation. A sample of 250 $\mu \mathrm{L}$ of overnight culture was used to inoculate $25 \mathrm{~mL}$ of LB containing gentamycin and incubated at $30^{\circ} \mathrm{C}$ (PAO1) or $37^{\circ} \mathrm{C}$ (BAP1) with shaking at $225 \mathrm{rpm}$. Expression of $p v f_{P f 0-1}$ genes was induced at an $\mathrm{OD}_{600}$ of $0.3-0.4$ by adding a final concentration of $0.5 \mathrm{mM}$ ITPG and all cultures were grown at $30^{\circ} \mathrm{C}$ and shaking at $225 \mathrm{rpm}$ for 24 hours total. Three biological replicates were grown for each strain.

\section{Small-scale comparative metabolomics}

Samples of $25 \mathrm{~mL}$ cultures were spun at $5000 \times \mathrm{g}$ to remove cells. Supernatant was collected and metabolites were extracted twice using one volume of ethyl acetate (EA) each time. The organic layers were pooled and dried with sodium sulfate. The extracts were evaporated to dryness in a round bottom flask, and the dried extracts were resuspended in $5 \mathrm{~mL}$ of methanol and transferred to a scintillation vial. This resuspension was evaporated to dryness and stored at $-20^{\circ} \mathrm{C}$.

\section{LC-HRMS of metabolomic extracts}

The extracted metabolites from each $25 \mathrm{~mL}$ of culture described in "Small-scale comparative metabolomics" were resuspended in $250 \mu \mathrm{L}$ of 50:50 water:acetonitrile mixture, centrifuged at maximum speed (>10,000 $\mathrm{x} \mathrm{g}$ ) for 10 minutes to remove any particulates, and diluted four-fold before analysis. A sample of $10 \mu \mathrm{L}$ extract was analyzed by liquid chromatography-high resolution mass spectrometry (LC-HRMS, Agilent Technologies 6520 Accurate Mass QTOF). Metabolites were separated on a Thermo Scientific $5 \mu \mathrm{m}$ Hypercarb $100 \times 2 \mathrm{~mm}$ column. Solvent A consisted of $0.1 \%$ formic acid in water, and solvent B consisted of $0.1 \%$ formic acid in acetonitrile. Using a flow rate of $0.5 \mathrm{~mL} \mathrm{~min}^{-1}$ the samples were eluted using $2 \% \mathrm{~B}$ for 2 minutes, followed by a linear gradient of $2-98 \%$ B over 16 minutes, and $98 \%$ B for another 2 minutes. All absorbances in the range of 190-450 nm were recorded. ESI mass spectrometry was carried out under positive ion mode using the following parameters: gas temperature $325^{\circ} \mathrm{C}$, drying gas $10 \mathrm{~L} \mathrm{~min}^{-1}$, nebulizer $45 \mathrm{psi}$, fragmentor $175 \mathrm{~V}$, skimmer $65 \mathrm{~V}$.

\section{Purification and isolation of Leu-dPNO (1), Leu-PNO A (2), Leu-PNO B (4)}

Round 1: 1, 2, and 4 were purified from a large-scale extraction of $P$. aeruginosa PAO1 containing pPSV35$p v f B C D_{P f o-1}$ using preparatory high-performance liquid chromatography (HPLC, Varian Prostar with 330 PDA variable wavelength detector). Dried EA extracts were resuspended in $75 \% \mathrm{ACN} /$ water $(4 \mathrm{~mL} / 1 \mathrm{~L}$ culture extracted) and injected on a C18 column (Phenomenex Luna) in $2 \mathrm{~mL}$ injections. Compounds of interest were separated using mobile phase $A$ (water, $0.1 \%$ TFA) and mobile phase $B$ (acetonitrile, $0.1 \%$ TFA) over a gradient of at $5 \%$ B for $5 \mathrm{~min}, 5-40 \%$ B over $10 \mathrm{~min}, 40-95 \%$ B over $20 \mathrm{~min}$, and at $95 \%$ for 6

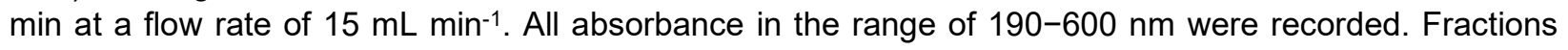


containing a compound of interest based on UV and subsequent MS analysis were combined separately and dried under high vacuum. The retention times were $21 \mathrm{~min}(1), 21 \mathrm{~min}(2)$, and $27 \mathrm{~min}$ (4).

Round 2a: 1 and 2 coeluted in the first round of purification and were separated using the same method outlined below. Fractions from round 1 were dissolved in $8 \mathrm{~mL}$ of $50 \%$ ACN/Water and injected on a Phenomenex Luna $\mathrm{C} 18$ column in $1 \mathrm{~mL}$ injections. Compounds of interest were separated using mobile phase A (water, $0.1 \%$ TFA) and mobile phase B (acetonitrile, $0.1 \%$ TFA) over a gradient of $5 \%$ B for 5 min, $5-41 \%$ B over $5 \mathrm{~min}, 41 \%$ B for $10 \mathrm{~min}, 41-42 \%$ B for $1 \mathrm{~min}, 42-95 \%$ B for $5 \mathrm{~min}$, and $95 \%$ B for 6 min at a flow rate of $15 \mathrm{~mL} \mathrm{~min}^{-1}$. All absorbance in the range of $190-600 \mathrm{~nm}$ were recorded. Fractions containing a compound of interest based on UV and subsequent MS analysis were combined separately and dried under high vacuum. Metabolites 1 and 2 have overlapping elution from $17.4 \mathrm{~min}(1)$ to 17.8 minutes (2). Pure fractions of metabolite 1 (RT = 17-17.4 $\mathrm{min}$ ) and metabolite 2 (RT = 17.8-18.2 $\mathrm{min}$ ) were collected separately. Fractions in between that contain both 1 and $2(R T=17.4-17.8)$ were collected and separated again using the same method until complete separation and purity was achieved.

Round 2b: Fractions of metabolite 4 from round 1 were dissolved in $4 \mathrm{~mL} 50 \%$ ACN/Water and injected on a Phenomenex Luna $\mathrm{C} 18$ column in $1 \mathrm{~mL}$ injections. Compounds of interest were separated using mobile phase A (water, $0.1 \%$ TFA) and mobile phase B (acetonitrile, $0.1 \%$ TFA) over a gradient of $5 \% \mathrm{~B}$ for $5 \mathrm{~min}$, $5-55 \%$ B over $5 \mathrm{~min}, 55 \%$ B for $10 \mathrm{~min}, 55-56 \%$ B over $1 \mathrm{~min}, 56-95 \%$ B over $5 \mathrm{~min}$, and $95 \%$ B for 6 min at a flow rate of $15 \mathrm{~mL} \mathrm{~min}^{-1}$. All absorbance in the range of 190-600 nm were recorded. Fractions containing a compound of interest based on UV and subsequent MS analysis were combined separately and dried under high vacuum. The retention time was $20.2 \mathrm{~min}(4)$.

\section{Purification and isolation of leucinazole (3) and flavacol (5)}

Round 1: $\mathbf{3}$ and $\mathbf{5}$ were purified from a large-scale extraction of $E$. coli BAP1 expressing $p v f A B C D$ Pfo-1 using preparatory HPLC. Dried EA extracts BAP1 was resuspended in $75 \% \mathrm{ACN} /$ water $(4 \mathrm{~mL} / 1 \mathrm{~L}$ culture extracted) and injected on a Phenomenex Luna C18 column in $2 \mathrm{~mL}$ injections. Compounds of interest were separated using mobile phase A (water, $0.1 \%$ TFA) and mobile phase B (acetonitrile, $0.1 \%$ TFA) over a gradient of $5 \%$ B for $5 \mathrm{~min}, 5-40 \%$ B over $10 \mathrm{~min}, 40-95 \%$ B over $20 \mathrm{~min}$, and $95 \%$ for $6 \mathrm{~min}$ at a flow rate of $15 \mathrm{~mL} \mathrm{~min}^{-1}$. All absorbance in the range of 190-600 nm were recorded. Fractions containing a compound of interest based on UV and subsequent MS analysis were combined separately and dried under high vacuum. The retention times were $20.5 \mathrm{~min} \mathrm{(3)}$ and $24.3 \mathrm{~min}$ (5).

Round 2a: Fractions from round 1 that contain 3 were dissolved in $2 \mathrm{~mL} \mathrm{50 \%} \mathrm{ACN/Water} \mathrm{and} \mathrm{injected} \mathrm{on}$ a Phenomenex Luna $\mathrm{C} 18$ column in $1 \mathrm{~mL}$ injections. Compounds of interest were separated using mobile phase $A$ (water, $0.1 \%$ TFA) and mobile phase $B$ (acetonitrile, $0.1 \%$ TFA) over a gradient of $5 \% \mathrm{~B}$ for $5 \mathrm{~min}$, $5-28 \%$ B over $5 \mathrm{~min}, 28 \%$ B for $10 \mathrm{~min}, 28-30 \%$ B over $1 \mathrm{~min}, 30-95 \%$ B over $5 \mathrm{~min}$, and $95 \%$ B for $6 \mathrm{~min}$ at a flow rate of $15 \mathrm{~mL} \mathrm{~min}^{-1}$. All absorbance in the range of 190-600 nm were recorded. Fractions containing a compound of interest based on UV and subsequent MS analysis were combined separately and dried under high vacuum. The retention time was $20.6 \mathrm{~min}(3)$.

Round 2b: Fractions from round 1 containing 5 were dissolved in $3 \mathrm{~mL} 66 \%$ ACN/Water and injected on a Phenomenex Luna $\mathrm{C} 18$ column in $1 \mathrm{~mL}$ injections. Compounds of interest were separated using mobile phase $A$ (water, $0.1 \%$ TFA) and mobile phase B (acetonitrile, $0.1 \%$ TFA) over a gradient of $5 \%$ B for $5 \mathrm{~min}$, 5-47.5\% B over $5 \mathrm{~min}, 47.5 \%$ B for $10 \mathrm{~min}, 47.5-49.5 \%$ B over $1 \mathrm{~min}, 49.5-95 \%$ B over $5 \mathrm{~min}$, and $95 \%$

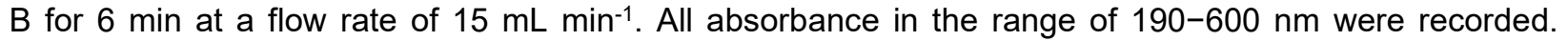
Fractions containing a compound of interest based on UV and subsequent MS analysis were combined separately and dried under high vacuum. The retention time was $18.7 \mathrm{~min}$ (5).

\section{Purification and isolation of PZ-1 (6) and PZ-2 (7)}

Round 1: 6 and 7 were purified from a large-scale extraction of $E$. coli BAP1 expressing $p v f A B C D_{\text {Pfo- } 1}$ using preparatory HPLC. Dried EA extracts BAP1 was resuspended in $50 \% \mathrm{ACN} /$ water $(1.5 \mathrm{~mL} / 1 \mathrm{~L}$ culture extracted) and injected on a Phenomenex Luna C18 column in $2 \mathrm{~mL}$ injections. Compounds of interest 
were separated using mobile phase $A$ (water, $0.1 \%$ TFA) and mobile phase $B$ (acetonitrile, $0.1 \%$ TFA) over a gradient of $5 \%$ B for $5 \mathrm{~min}, 5-40 \%$ B over $10 \mathrm{~min}, 40-95 \%$ B over $20 \mathrm{~min}$, and $95 \%$ for $6 \mathrm{~min}$, at a flow rate of $15 \mathrm{~mL} \mathrm{~min}^{-1}$. All absorbance in the range of 190-600 nm were recorded. Fractions containing a compound of interest based on UV and subsequent MS analysis were combined separately and dried under high vacuum. Because $\mathbf{6}$ and 7 are very volatile, ACN was removed from fractions by rotary evaporation, without removal of water. The retention times were $31.5 \mathrm{~min}(7)$ and $32.2 \mathrm{~min}(6)$.

Round 2: In round 1 purification, 6 and 7 eluted closely together from 31.25 min to 32.5 minutes, with overlapping elution from 31.75-32.2 min. Pure fractions of $7(R T=31.25-31.75 \mathrm{~min})$ and $6(R T=32.2-32.5$ $\mathrm{min}$ ) were collected separately. Fractions in between that contain both 6 and 7 (RT $=31.75-32.2 \mathrm{~min}$ ) were collected and repurified using the same method used in round 1 purification until full separation and purity was achieved. Again, ACN but not water was removed from the combined fractions. After reduction in volume, the fractions were brought up to $50 \%$ ACN/water for subsequent injections. After final round of purification, ACN was removed from fractions of interest by rotary evaporation and remaining water was extracted three times with 1 volume of diethyl ether. The organic layers were pooled, dried with $\mathrm{Na}_{2} \mathrm{SO}_{4}$, and concentrated in vacuo.

\section{Structural characterization of 1-7}

Purity of isolated 1-7 was analyzed by LC-HRMS. NMR experiments of 1-7 were conducted in deuterated chloroform. NMR experiments of $\mathbf{3}$ and $\mathbf{5}$ were also conducted in deuterated methanol. ${ }^{1} \mathrm{H},\left({ }^{1} \mathrm{H},{ }^{1} \mathrm{H}\right) \mathrm{COSY}$, $\left({ }^{1} \mathrm{H},{ }^{13} \mathrm{C}\right) \mathrm{HSQC},\left({ }^{1} \mathrm{H},{ }^{13} \mathrm{C}\right) \mathrm{HMBC}$, and ${ }^{13} \mathrm{C}$ NMR experiments were conducted for each compound using a Bruker $700 \mathrm{MHz}$ or $850 \mathrm{MHz}$ spectrometer equipped with a cryoprobe unless specified.

\section{Synthesis of 3,6-diisobutylpyrazin-2(1H)-one standard (flavacol, 5)}<smiles>CC(C)C[C@H](NC(=O)O)C(=O)O</smiles><smiles>CC(C)C[C@H](N)CO</smiles><smiles>CCOC(=O)c1ccccc1</smiles><smiles>CC(C)C[C@H](NC(=O)O)C(=O)N[C@@H](CO)CC(C)C</smiles>

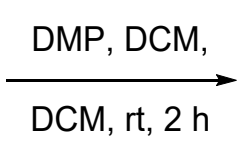<smiles>CC(C)C[C@H](NC(=O)OCc1ccccc1)C(=O)N[C@@H](C=O)CC(C)C</smiles>

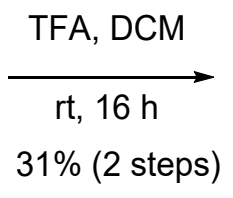<smiles>CC(C)Cc1cnc(CC(C)C)c(=O)[nH]1</smiles>

Scheme S1. Synthesis of 3,6-diisobutylpyrazin-2(1H)-one (flavacol, 5).

3,6-Diisobutylpyrazin-2(1H)-one (flavacol). Flavacol was synthesized from (tert-butoxycarbonyl)-Lleucine hydrate and $(R)$-2-amino-4-methylpentan-1-ol by adapting a reported procedure. ${ }^{3}$ Yield: $97.3 \mathrm{mg}$, 22\% (3 steps). ${ }^{1} \mathrm{H}$ NMR (600 MHz, $\left.\mathrm{CDCl}_{3}\right) \delta 12.89$ (s, br. $\left.1 \mathrm{H}\right), 7.21(\mathrm{~s}, 1 \mathrm{H}), 2.65$ (d, J = 7.2 Hz, 2H), 2.39 $(\mathrm{d}, J=7.3 \mathrm{~Hz}, 2 \mathrm{H}), 2.22-2.16(\mathrm{~m}, 1 \mathrm{H}), 2.08-2.03(\mathrm{~m}, 1 \mathrm{H}), 0.97-0.93(\mathrm{~m}, 12 \mathrm{H}) .{ }^{13} \mathrm{C} \mathrm{NMR}(151 \mathrm{MHz}$, $\left.\mathrm{CDCl}_{3}\right) \delta 158.8,156.7,138.5,123.1,41.6,39.6,28.4,27.2,22.8,22.3$. HRMS: $[\mathrm{M}+\mathrm{H}]^{+}$calcd for $\mathrm{C}_{12} \mathrm{H}_{21} \mathrm{~N}_{2} \mathrm{O}^{+}, 209.1648$; found, 209.1663. 
Synthesis of 1-(4(5)-isobutyl-1H-imidazol-2-yl)-3-methylbutan-1-one standard (leucinazole, 3)

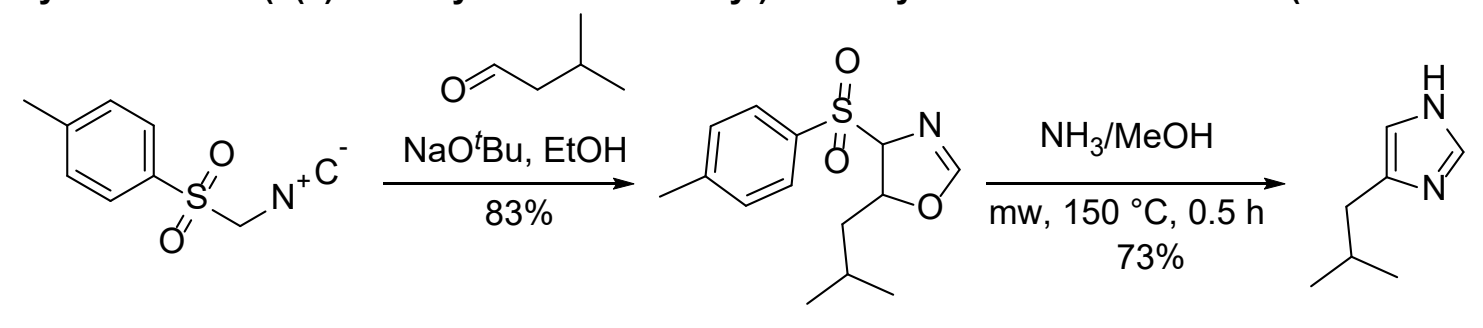<smiles>CC(C)CC(=O)c1ncc(CC(C)C)[nH]1</smiles>

3. $\mathrm{HCl} / \mathrm{MeOH}$

Scheme S2. Synthesis of 1-(4(5)-isobutyl-1H-imidazol-2-yl)-3-methylbutan-1-one standard (leucinazole, 3).<smiles>CC(C)Cc1c[nH]cn1</smiles>

4(5)-Isobutyl-1 $\boldsymbol{H}$-imidazole. ${ }^{4,5}$ To a suspension of 1 -((isocyanomethyl)sulfonyl)-4-methylbenzene (1.00 $\mathrm{g}, 5.12 \mathrm{mmol})$ and 3-methylbutanal $(566 \mu \mathrm{L}, 5.28 \mathrm{mmol})$ in ethanol $(26 \mathrm{~mL})$ at $0{ }^{\circ} \mathrm{C}$, was added sodium tert-butoxide $(24.6 \mathrm{mg}, 256 \mu \mathrm{mol})$. A clear solution was formed, and the reaction was allowed to warm up to rt. After $1 \mathrm{~h}$, solvent was removed and the residue was washed with DCM to afford 5-isobutyl-4-tosyl4,5-dihydrooxazole $(1.19 \mathrm{~g}, 83 \%)$ as a white solid, which was used without purification.

5-Isobutyl-4-tosyl-4,5-dihydrooxazole (300 mg, $1.07 \mathrm{mmol}$ ) was dissolved in ammonia (1.52 mL, 10.7 $\mathrm{mmol}, \mathrm{MeOH}$ solution) and heated at $150^{\circ} \mathrm{C}$ under microwave irradiation for $30 \mathrm{~min}$. Solvent was removed and the residue was purified via RP MPLC to give the desired product $(97.0 \mathrm{mg}, 73 \%)$ as a white amorphous solid. ${ }^{1} \mathrm{H}$ NMR $\left(600 \mathrm{MHz}, \mathrm{CDCl}_{3}\right) \delta 9.58(\mathrm{~s}, \mathrm{br} .1 \mathrm{H}), 7.56(\mathrm{~s}, 1 \mathrm{H}), 6.78(\mathrm{~s}, 1 \mathrm{H}), 2.48(\mathrm{~d}, J$ $=7.1 \mathrm{~Hz}, 2 \mathrm{H}), 1.99-1.79(\mathrm{~m}, 1 \mathrm{H}), 0.91(\mathrm{~d}, J=6.6 \mathrm{~Hz}, 6 \mathrm{H}) .{ }^{13} \mathrm{C} \mathrm{NMR}\left(151 \mathrm{MHz}, \mathrm{CDCl}_{3}\right) \delta 135.4,134.3$, $119.2,35.8,28.9,22.5$.<smiles>CC(C)Cc1cncn1[As]#[W]</smiles><smiles>[M]#Sn1cnc(CC(C)C)c1</smiles>

A

B

5-Isobutyl-1-((2-(trimethylsilyl)ethoxy)methyl)-1H-imidazole and 4-isobutyl-1-((2(trimethylsilyl)ethoxy)methyl)-1 $\mathrm{H}$-imidazole. To a solution of 5-isobutyl-1H-imidazole (84.4 mg, 680 $\mu \mathrm{mol})$ in DMF $(1.1 \mathrm{~mL})$ was added $\mathrm{NaH}(29.9 \mathrm{mg}, 60 \%, 748 \mu \mathrm{mol})$ and the solution was stirred at rt for 30 
min, at which time SEM-Cl (139 $\mu \mathrm{L}, 748 \mu \mathrm{mol})$ was added and the solution stirred at rt for an additional 16 h. Concentration afforded a residue, which was purified via RP MPLC to give a pure fraction of 5-isobutyl1-((2-(trimethylsilyl)ethoxy)methyl)-1H-imidazole (A, $32.2 \mathrm{mg}, 19 \%)$ and another fraction containing 4isobutyl-1-((2-(trimethylsilyl)ethoxy)methyl)-1H-imidazole (B) containing some isomer $\mathbf{A}$ (B:A = 6:1, 71.3 $\mathrm{mg}, 41 \%) .{ }^{6}$ Mixture of $\mathbf{B}$ and $\mathbf{A}:{ }^{1} \mathrm{H}$ NMR $\left(500 \mathrm{MHz}, \mathrm{CDCl}_{3}\right)$ of mixture. Major isomer $\mathbf{B}, \delta 7.48(\mathrm{~d}, J=1.5$ $\mathrm{Hz}, 1 \mathrm{H}), 6.72(\mathrm{~s}$, br. $1 \mathrm{H}), 5.18(\mathrm{~s}, 2 \mathrm{H}), 3.47-3.38(\mathrm{~m}, 2 \mathrm{H}), 2.40(\mathrm{~d}, J=7.1 \mathrm{~Hz}, 2 \mathrm{H}), 2.01-1.87(\mathrm{~m}, 1 \mathrm{H})$, $0.90(\mathrm{~d}, J=6.7 \mathrm{~Hz}, 6 \mathrm{H}), 0.86(\mathrm{t}, J=8.2 \mathrm{~Hz}, 2 \mathrm{H}),-0.03(\mathrm{~s}, 9 \mathrm{H})$. Minor isomer $\mathbf{A}$ (diagnostic peaks): $\delta 6.79$ (s, br. $1 \mathrm{H}), 2.46(\mathrm{~d}, J=7.2 \mathrm{~Hz}, 2 \mathrm{H}), 0.93(\mathrm{~d}, J=6.6 \mathrm{~Hz}, 6 \mathrm{H}) .{ }^{13} \mathrm{C} \mathrm{NMR}\left(126 \mathrm{MHz}, \mathrm{CDCl}_{3}\right)$ of mixture. Major isomer B, $\delta 143.0,136.6,115.6,75.9,66.2,37.7,28.6,22.5,17.8,-1.4$. Minor isomer A, $\delta 74.0$, 65.9, 32.9, 28.0, 22.6. Isolated isomer A: ${ }^{1} \mathrm{H}$ NMR $\left(500 \mathrm{MHz}, \mathrm{CDCl}_{3}\right) \delta 7.47(\mathrm{~s}, 1 \mathrm{H}), 6.79(\mathrm{~s}, 1 \mathrm{H}), 5.18(\mathrm{~s}$, 2H), $3.42(\mathrm{t}, J=8.2 \mathrm{~Hz}, 2 \mathrm{H}), 2.46(\mathrm{~d}, J=7.2 \mathrm{~Hz}, 2 \mathrm{H}), 1.95-1.83(\mathrm{~m}, J=6.8 \mathrm{~Hz}, 1 \mathrm{H}), 0.93(\mathrm{~d}, J=6.7 \mathrm{~Hz}$, $6 \mathrm{H}), 0.86(\mathrm{t}, J=8.2 \mathrm{~Hz}, 2 \mathrm{H}),-0.04(\mathrm{~s}, 9 \mathrm{H}) .{ }^{13} \mathrm{C} \mathrm{NMR}\left(126 \mathrm{MHz}, \mathrm{CDCl}_{3}\right) \delta 137.5,131.3,127.9,74.0,65.8$, $32.9,28.0,22.6,17.8,-1.4$.<smiles>CC(C)CC(=O)c1nc(CC(C)C)c[nH]1</smiles>

1-(4(5)-Isobutyl-1H-imidazol-2-yl)-3-methylbutan-1-one hydrochloride (leucinazole•HCl). ${ }^{6}$ The mixture of $\mathbf{B}$ and $\mathbf{A}$ as prepared above $(\mathbf{B}: \mathbf{A}=6: 1,56.1 \mathrm{mg}, 220 \mu \mathrm{mol})$ was dissolved in THF $(1.1 \mathrm{~mL})$ and cooled to $-78^{\circ} \mathrm{C}, n$-butyllithium $(88 \mu \mathrm{L}, 220 \mu \mathrm{mol})$ was added, and the solution was stirred for $30 \mathrm{~min}$. 3Methylbutanoyl chloride $(27 \mu \mathrm{L}, 220 \mu \mathrm{mol})$ was then added and the reaction allowed to warm up to rt. Solvent was removed and the residue was partially purified via RP MPLC to give a sample as a mixture of tautomers $(45.5 \mathrm{mg}, 61 \%)$ that was converted to the $\mathrm{HCl}$ salt without further purification. Thus, a sample of this mixture $(25.4 \mathrm{mg}, 75.0 \mu \mathrm{mol})$, was dissolved in $\mathrm{HCl}(1.00 \mathrm{~mL}, 3 \mathrm{~N}$ in $\mathrm{MeOH})$ and heated at $70{ }^{\circ} \mathrm{C}$ for $16 \mathrm{~h}$. Solvent was removed and the residue was purified via RP MPLC (basic, $0.1 \% \mathrm{NH}_{3} \cdot \mathrm{H}_{2} \mathrm{O}$ ) to give the neutral product, which was dissolved in $\mathrm{DCM}(1 \mathrm{~mL})$ and treated with $1 \mathrm{~mL}$ of $\mathrm{HCl}(2 \mathrm{~N}$ in ether) and stirred for $16 \mathrm{~h}$. Concentration afforded leucinazole $\cdot \mathrm{HCl}$ as a white solid $(12.1 \mathrm{mg}, 66 \%) .{ }^{1} \mathrm{H}$ NMR $(500$ $\mathrm{MHz}$, DMSO-d $)^{2} \delta 7.60(\mathrm{~s}, 1 \mathrm{H}), 3.02(\mathrm{~d}, J=6.9 \mathrm{~Hz}, 2 \mathrm{H}), 2.57(\mathrm{~d}, J=7.1 \mathrm{~Hz}, 2 \mathrm{H}), 2.23-2.06(\mathrm{~m}, 1 \mathrm{H})$, 2.04-1.89 (m, 1H), $0.94(\mathrm{~d}, J=6.7 \mathrm{~Hz}, 6 \mathrm{H}), 0.88(\mathrm{~d}, J=6.6 \mathrm{~Hz}, 6 \mathrm{H}) .{ }^{13} \mathrm{C}$ NMR $(126 \mathrm{MHz}, \mathrm{DMSO}) \delta$ 186.4, 139.2, 136.3, 120.2, 47.0, 33.0, 27.9, 24.3, 22.3, 21.9. HRMS: [M + H] $]^{+}$calcd for $\mathrm{C}_{12} \mathrm{H}_{21} \mathrm{~N}_{2} \mathrm{O}^{+}$, 209.1648; found, 209.1653.

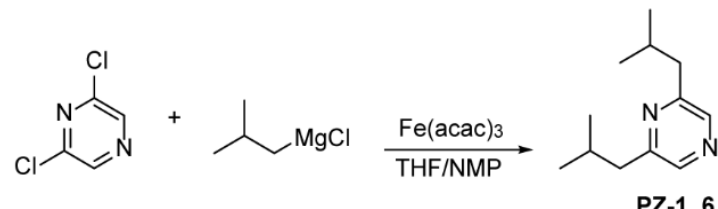

Scheme S3. Synthesis of 2,6-diisobutylpyrazine standard (PZ-1, 6).
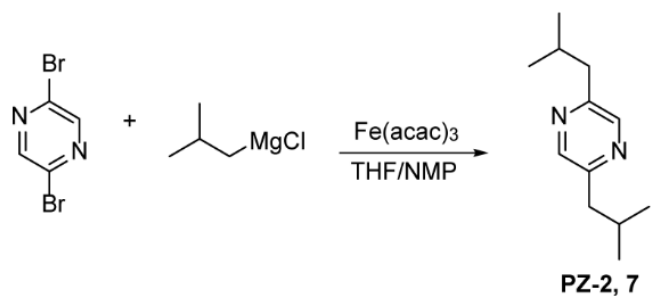
Scheme S4. Synthesis of 2,5-diisobutylpyrazine standard (PZ-2, 7).

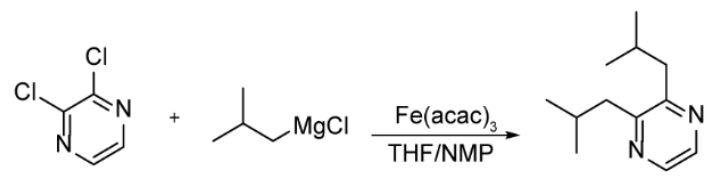

Scheme S5. Synthesis of 2,3-diisobutylpyrazine standard.

\section{Synthesis of 2,6-, 2,5-, and 2,3-diisobutylpyrazine standards}

Standards of 2,6-, 2,5-, and 2,3-diisobutylpyrazines were synthesized based on literature methods. ${ }^{7}$ For the synthesis of 2,6-diisobutylpyrazine, an oven-dried round bottom flask was charged with nitrogen. Dry THF $(4.5 \mathrm{~mL})$ and dry NMP $(450 \mu \mathrm{L})$ were added and cooled to $0{ }^{\circ} \mathrm{C}$. 2,6-dichloropyrazine (1 eq., 0.74 $\mathrm{mmol}$ ) and $\mathrm{Fe}(\mathrm{acac})_{3}(5 \mathrm{~mol} \%, 0.0375 \mathrm{mmol})$ were then added. A $2 \mathrm{M}$ Isobutylmagnesium chloride solution in THF (2.4 eq., $900 \mu \mathrm{L})$ was subsequently added dropwise. The reaction turned from red to dark brown and was stirred for 15 minutes at $0{ }^{\circ} \mathrm{C}$. Reaction was quenched with $4.5 \mathrm{~mL}$ water and extracted three times with diethyl ether. Organic layers were combined, dried with $\mathrm{Na}_{2} \mathrm{SO}_{4}$, and concentrated in vacuo. For the synthesis of 2,5-, or 2,3- diisobutylpyrazine, the reaction was set up as described for 2,6-diisobutylpyrazine with the exception that 2,5-dibromopyrazine or 2,3-dichloropyrazine was used in place of 2,6dichloropyrazine. All three compounds were purified according to the procedure in "Purification and isolation of PZ-1 (6) and PZ-1 (7)" with the following yields: 2,6-diisobutylpyrazine, $99 \mathrm{mg}, 69 \%$ yield, 2,6diisobutylpyrazine, $59 \mathrm{mg}, 41 \%$ yield, 2,3-diisobutylpyrazine, $80 \mathrm{mg}, 56 \%$ yield. In prep HPLC purification of the synthetic standards, 2,6-diisobutylpyrazine eluted at the same retention time as PZ-1 (6, $31.5 \mathrm{~min}$ ), 2,5-diisobutylpyrazine eluted at the same retention time as PZ-2 (7, $32.2 \mathrm{~min})$, and 2,3-diisobutylpyrazine eluted at $31.5 \mathrm{~min} .2,{ }^{1} \mathrm{H}$ NMR $\left(850 \mathrm{MHz}, \mathrm{CDCl}_{3}\right) \delta 8.63(\mathrm{~s}, 2 \mathrm{H}), 2.84(\mathrm{~d}, J=7.8 \mathrm{~Hz}, 4 \mathrm{H}), 2.17(\mathrm{dh}, J=$ 13.5, $6.7 \mathrm{~Hz}, 2 \mathrm{H}), 0.99-0.96(\mathrm{~m}, 12 \mathrm{H}) .2,5{ }^{1} \mathrm{H}$ NMR $\left(850 \mathrm{MHz}, \mathrm{CDCl}_{3}\right) \delta 8.55$ (s, 2H), 2.77 (d, J = $7.6 \mathrm{~Hz}$, $4 \mathrm{H}), 2.10(\mathrm{dq}, J=13.5,6.7 \mathrm{~Hz}, 2 \mathrm{H}), 0.98-0.95(\mathrm{~m}, 12 \mathrm{H}) .2,6{ }^{1} \mathrm{H} \mathrm{NMR}\left(850 \mathrm{MHz}, \mathrm{CDCl}_{3}\right) \delta 8.53(\mathrm{~s}, 2 \mathrm{H})$, $2.90(\mathrm{~d}, J=9.1 \mathrm{~Hz}, 4 \mathrm{H}), 2.18(\mathrm{~h}, J=6.7 \mathrm{~Hz}, 2 \mathrm{H}), 1.00(\mathrm{~d}, J=6.7 \mathrm{~Hz}, 12 \mathrm{H})$.

\section{LC-HRMS analysis of isolated metabolites 1-5}

\section{LC-HRMS of isolated and synthetic flavacol/leucinazole}

A $10 \mu \mathrm{L}$ sample of isolated leucinzaole or flavacol, or synthetic 3,6-diisobutylpyrazin-2(1H)-one or 1-(5isobutyl-1H-imidazol-2-yl)-3-methylbutan-1-one was analyzed by liquid chromatography high resolution mass spectrometry (LC-HRMS) using an Agilent Technologies 6520 Accurate Mass QTOF LC/MS.

Samples were separated on a Phenomenex Kinetex $5 \mu \mathrm{m}$ C18 $100 \AA$, $150 \times 4.60 \mathrm{~mm}$ column. Solvent A consisted of $0.1 \%$ formic acid in water, and solvent $B$ consisted of $0.1 \%$ formic acid in acetonitrile. Using a flow rate of $0.6 \mathrm{~mL} \mathrm{~min}^{-1}$, the samples were eluted by $2 \% \mathrm{~B}$ for 4 minutes, followed by a linear gradient of $2-95 \%$ B over 20 minutes, and $95 \%$ B for another 2 minutes. Positive ion mode ESI mass spectrometry was carried out using the following parameters: gas temperature $350^{\circ} \mathrm{C}$, drying gas $10 \mathrm{~L}$ $\mathrm{min}^{-1}$, nebulizer $45 \mathrm{psi}$, fragmentor $175 \mathrm{~V}$, skimmer $65 \mathrm{~V}$, absolute threshold of 200 for ions of interest. 


\section{LC-HRMS and MS/MS analysis of isolated and synthetic pyrazines}

A sample of $10 \mu \mathrm{L}$ of isolated PZ-1, PZ-2 or synthetic 2,3, 2,5, and 2,6-diisobutylpyrazine was analyzed by LC-HRMS and separated on a Thermo Scientific Hypercarb column $(5 \mu \mathrm{m}, 100 \times 4.6 \mathrm{~mm})$. Solvent A consisted of $0.1 \%$ formic acid in water, and solvent $B$ consisted of $0.1 \%$ formic acid in acetonitrile. Using a flow rate of $0.6 \mathrm{~mL} \mathrm{~min}-1$, samples were separated at $2 \% B$ for 2 minutes, followed by a linear gradient of $2-80 \%$ B over 16.8 minutes, followed by a linear gradient of $80-95 \%$ B over 6 minutes, and $95 \%$ B for 2 minutes. ESI mass spectrometry was carried out under positive ion mode using the following parameters: gas temperature $350^{\circ} \mathrm{C}$, drying gas $5 \mathrm{~L} \mathrm{~min}^{-1}$, nebulizer $20 \mathrm{psi}$, fragmentor $175 \mathrm{~V}$, skimmer $65 \mathrm{~V}$. MS/MS fragmentation was conducted using targeted fragmentation at a fragmentation voltage of $25 \mathrm{~V}$. For coinjection studies, isolated PZ-1 or isolated PZ-2 were mixed with 2,3-, 2,5-, or 2,6-diisobutylpyrazine at equimolar concentrations. A $15 \mu \mathrm{L}$ sample of these mixtures was analyzed using the method described above.

\section{NMR analysis of PZ-1 (6) and PZ-2 (7) each mixed with their respective standard}

Samples were made with equal amounts of PZ-1 and 2,6-diisobutylpyrazine (0.5 mg of each) or PZ-2 and 2,5-diisobutylpyrazine (1 mg of each) in a total volume of $600 \mu \mathrm{L}$ of $\mathrm{CDCl}_{3}$. Spectra were acquired using a Bruker $850 \mathrm{MHz}$ spectrometer equipped with a cryoprobe.

\section{UV stability study of leucinazole (3) and flavacol (5)}

Leucinazole (3) was diluted to $10 \mu \mathrm{M}$ and flavacol (5) was diluted to $20 \mu \mathrm{M}$ in water and left in ambient conditions. Scans were recorded every 7 days for 14 days from $800 \mathrm{~nm}$ to $200 \mathrm{~nm}$ using a Cary UV-Vis spectrophotometer.

\section{pH UV stability study of leucinazole (3) and flavacol (5)}

Leucinazole (3) was diluted to $25 \mu \mathrm{M}$ and flavacol (5) was diluted to $50 \mu \mathrm{M}$ in aqueous solutions ranging from $\mathrm{pH} 1-13$. Solutions were adjusted to $\mathrm{pH}$ with hydrochloric acid or sodium hydroxide. Solutions were incubated from 30 minutes at room temperature then measured. Scan was days from $800 \mathrm{~nm}$ to $200 \mathrm{~nm}$ using a Cary UV-Vis spectrophotometer. The cuvette used for this experiment had a larger sample volume than the UV stability study above, resulting in different absolute absorbance values.

\section{LC-HRMS/MS analysis of isolated flavacol and leucinazole}

A sample of $10 \mu \mathrm{L}$ isolated flavacol or leucinazole was analyzed by LC-HRMS. Samples were separated on a Phenomenex Gemini C18 column $(5 \mu \mathrm{m}, 50 \times 2 \mathrm{~mm})$. Solvent A consisted of $0.1 \%$ formic acid in water, and solvent $B$ consisted of $0.1 \%$ formic acid in acetonitrile. Using a flow rate of $0.6 \mathrm{~mL} \mathrm{~min} \mathrm{~m}^{-1}$, the samples were separated at $2 \%$ B for 2 minutes, followed by a linear gradient of 2-95\% B over 16 minutes, and $95 \%$ $\mathrm{B}$ for another 3 minutes. ESI mass spectrometry was carried out under positive ion mode using the following parameters: gas temperature $350{ }^{\circ} \mathrm{C}$, drying gas $10 \mathrm{~L} \mathrm{~min}^{-1}$, nebulizer $45 \mathrm{psi}$, fragmentor $175 \mathrm{~V}$, skimmer $65 \mathrm{~V}$. MS/MS fragmentation was conducted using targeted fragmentation at a fragmentation voltage of 20 or $25 \mathrm{~V}$.

\section{Expression and purification of $\mathrm{PvfC}_{\mathrm{Pf0}-1}, \mathrm{PvfC}_{\mathrm{Pf0}-1-\mathrm{T}}$, and $\mathrm{PvfC}_{\mathrm{L} 48}$}

$\mathrm{PvfC}_{\mathrm{Pf0}-1}, \mathrm{PvfC}_{\mathrm{Pf0}-1-\mathrm{T}}$, and $\mathrm{PvfC}_{\mathrm{L} 48}$ were purified according to literature protocol. ${ }^{8,9} \mathrm{~A}$ sample of $1 \mathrm{~L}$ of Luria Broth containing kanamycin was inoculated with $5 \mathrm{~mL}$ of overnight cultures and grown at $37^{\circ} \mathrm{C}$ until $\mathrm{OD}_{600}$ reached 0.5-0.6. Protein expression was induced with $0.5 \mathrm{mM}$ of IPTG and the cells were grown overnight at $16{ }^{\circ} \mathrm{C}$ post induction. Cells were harvested by centrifugation at $4500 \times \mathrm{g}$. His 6 -tagged proteins were purified by nickel affinity chromatography and size exclusion chromatography using an Akta FPLC. Cell pellet was resuspended in $15 \mathrm{~mL}$ of wash buffer and lysed using a Branson sonicator at $30 \%$ amplitude for $1.5 \mathrm{~min}$ of total 'on' time, cycling between $0.5 \mathrm{sec}$ on and $1.5 \mathrm{sec}$ off. Cell debris was pelleted at 15,000 $\mathrm{x}$ $\mathrm{g}$ and supernatant was filtered through a $0.45 \mu \mathrm{m}$ syringe filter and injected onto a GE $5 \mathrm{~mL}$ His Trap HP Column. The His6-tagged protein was eluted over a gradient of 5-300 mM imidazole. Fractions containing proteins of interest were identified by SDS-PAGE analysis, pooled, and concentrated with an Amicon centrifugal concentrator to $5 \mathrm{~mL}$ or less. The concentrated proteins were applied on a GE Superdex 200 
size exclusion column for further purification into storage buffer (Wash buffer with no imidazole). Protein was flash frozen in beads in liquid nitrogen and stored at $-80^{\circ} \mathrm{C}$.

Wash buffers for each protein are as follows:

PvfCpfo-1: (50 mM HEPES, $300 \mathrm{mM} \mathrm{NaCl}, 5 \mathrm{mM}$ imidazole, $10 \%$ glycerol, $\mathrm{pH}=8.0$ )

PvfC Pf0-1-T: (50 mM HEPES, $300 \mathrm{mM} \mathrm{NaCl}, 5 \mathrm{mM}$ imidazole, $10 \%$ glycerol, $\mathrm{pH}=8.0$ )

$\mathrm{PvfC}_{\llcorner 48}$ : (50 mM bicine, $5 \mathrm{mM}$ imidazole, $300 \mathrm{mM} \mathrm{NaCl}, 10 \%$ glycerol, $\mathrm{pH}=9.0$ )

\section{Generation of $\mathrm{PvfC}_{\mathrm{Pf0}-1}-\mathrm{T}$-Leu}

Loading leucine to $\mathrm{PvfC}_{\mathrm{Pf0}-1-\mathrm{T}}(150 \mu \mathrm{M})$ follows the same procedure as described above for generation of PvfC-T-Val with the exception that full length PvfC Pfo-1 $_{\text {was }}$ wsed instead of PvfC-A, $5 \mathrm{mM}$ of L-Leu was used as a substrate, and $25 \mathrm{mM}$ HEPES $(\mathrm{pH}=7.5)$ was used as a buffer.

\section{LC-HRMS analysis of L-leucine loading of $\mathrm{PvfC}_{\mathrm{Pf} 0-1-\mathrm{T}}$}

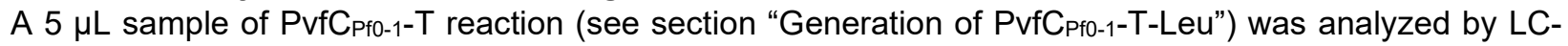
HRMS. Samples were separated on a Phenomenex bioZen Intact C4 column $(3.6 \mu \mathrm{m}, 150 \times 2 \mathrm{~mm})$. Solvent $A$ consisted of $0.1 \%$ formic acid in water, and solvent $B$ consisted of $0.1 \%$ formic acid in acetonitrile. Using a flow rate of $0.3 \mathrm{~mL} \mathrm{~min}-1$, the samples were separated at $5 \%$ B for 2 minutes, followed by a linear gradient of $2-35 \%$ B over 6 minutes, $35-60 \%$ B over 27 minutes, $60-95 \%$ B over 5 minutes, and $95 \%$ B for 2 minutes. ESI mass spectrometry was carried out under positive ion mode using the following parameters: gas temperature $350^{\circ} \mathrm{C}$, drying gas $12 \mathrm{~L} \mathrm{~min}^{-1}$, nebulizer $50 \mathrm{psi}$, fragmentor $250 \mathrm{~V}$, skimmer $65 \mathrm{~V}$. Untargeted MS/MS were conducted using a collision energy of $35 \mathrm{~V}$ and an absolute threshold of 200 for ions of interest. MS/MS chromatograms were smoothed for figure generation.

\section{$\mathrm{PvfC}_{\mathrm{Pf0}-1}$ reductase domain $\mathrm{NAD}(\mathrm{P}) \mathrm{H}$ consumption}

PvfC $_{\mathrm{PfO}-1}(2 \mu \mathrm{M})$ in $25 \mathrm{mM}$ phosphate buffer $(\mathrm{pH}=7.4)$ was incubated with $5 \mathrm{mM} \mathrm{MgCl} 2,8 \mu \mathrm{M} \mathrm{Sfp}, 1 \mathrm{mM}$ coenzyme A, $2.5 \mathrm{mM} \mathrm{ATP}$, and $5 \mathrm{mM}$ L-Leu. Reaction was initiated with the addition of $100 \mu \mathrm{M} \mathrm{NADPH}$ and measure by UV-vis spectroscopy. Scans were recorded from $800 \mathrm{~nm}$ to $200 \mathrm{~nm}$ every 30 seconds using a Cary UV-vis spectrophotometer. The control with no L-Leu was set up as described without L-Leu added. The control with NADH was set up as described with NADH instead of NADPH.

\section{pH screen of in vitro production of leucinazole, flavacol, PZ-1, and PZ-2}

Reactions were set up as described above for production of PZ-1, with the exception the buffers used were $25 \mathrm{mM}$ phosphate $(\mathrm{pH}=6.0,6.5,7.0,7.5,8.0)$ or $25 \mathrm{mM}$ bicine $(\mathrm{pH}=8.5,9.0)$. Reactions were analyzed using a Hypercarb column using the method described in "LC-HRMS of in vitro reactions separated on Hypercarb column" (main text methods).

$\mathrm{PvfC}_{\mathrm{L} 48}$ in vitro reactions to produce valine derivatives of leucinazole, flavacol, $\mathrm{PZ}-1$, and $\mathrm{PZ}-2$ $\mathrm{PvfC}_{\llcorner 48}(20 \mu \mathrm{M})$ in $25 \mathrm{mM}$ HEPES $(\mathrm{pH}=7.5)$ was incubated with $2 \mathrm{mM} \mathrm{MgCl}_{2}, 4 \mu \mathrm{M} \mathrm{Sfp}$, and $0.2 \mathrm{mM}$ coenzyme A for 30 minutes at room temperature. Samples of $1 \mathrm{mM} \mathrm{ATP,} 5 \mathrm{mM}$ L-Val (or ${ }^{15} \mathrm{~N}-\mathrm{L}-\mathrm{Val}$ ), and 2 $\mathrm{mM}$ NADPH were then added and incubated for 3 hours at room temperature. The reaction was quenched using $\mathrm{ACN}$ (one volume of enzyme reaction) and incubated at $-20^{\circ} \mathrm{C}$ for at least 20 minutes. Samples were centrifuged at $20,800 \times \mathrm{g}$ for 10 minutes to remove precipitated protein and analyzed by LC-HRMS in positive mode. The in vitro reactions were analyzed using a C18 column using the method described below in "LC-HRMS and MS/MS analysis of PvfC $\llcorner 48$ in vitro reactions".

\section{LC-HRMS of in vitro reactions separated on a C18 column}

A sample of $10 \mu \mathrm{L}$ of $\mathrm{PvfC}_{\mathrm{PfO}-1}$ reaction (see main text method "PvfC $\mathrm{Pf0}-1$ in vitro reactions to produce leucinazole, flavacol, PZ-1, and PZ-2") was analyzed by LC-HRMS. Samples were separated on a Phenomenex Gemini C18 column $(5 \mu \mathrm{m}, 50 \times 2 \mathrm{~mm})$. Solvent A consisted of $0.1 \%$ formic acid in water, and solvent $B$ consisted of $0.1 \%$ formic acid in acetonitrile. Using a flow rate of $0.6 \mathrm{~mL} \mathrm{~min}^{-1}$, the samples were separated at $2 \%$ B for 2 minutes, followed by a linear gradient of 2-95\% B over 16 minutes, and $95 \%$ 
B for another 3 minutes. ESI mass spectrometry was carried out under positive ion mode using the following parameters: gas temperature $350^{\circ} \mathrm{C}$, drying gas $10 \mathrm{~L} \mathrm{~min}^{-1}$, nebulizer $45 \mathrm{psi}$, fragmentor $175 \mathrm{~V}$, skimmer $65 \mathrm{~V}$.

\section{Derivatization of $\mathrm{PvfC}_{\mathrm{L} 48}$ in vitro reactions with $\mathrm{PFPH}$}

$P_{\text {vfC }} 488(6.5 \mu \mathrm{M})$ in $12.5 \mathrm{mM}$ HEPES buffer $(\mathrm{pH}=7.5)$ was incubated with $1 \mathrm{mM} \mathrm{MgCl}_{2}, 2 \mu \mathrm{M} \mathrm{Sfp}$, and 0.1 $\mathrm{mM}$ coenzyme A for 30 minutes at room temperature. Samples of $0.5 \mathrm{mM}$ ATP, $2.5 \mathrm{mM}$ L-Val (or ${ }^{15} \mathrm{~N}-\mathrm{L}-$ Val), $1 \mathrm{mM} \mathrm{NADPH}$, and $25 \mathrm{mM}$ PFPH were then added and incubated for 3 hours at room temperature. Reactions were quenched using $\mathrm{ACN}$ (one-half volume of enzyme reaction) and incubated at $-20{ }^{\circ} \mathrm{C}$ for at least 20 minutes. Samples were centrifuged at $20,800 \times \mathrm{g}$ for 10 minutes to remove precipitated protein and analyzed by LC-HRMS in positive mode. The in vitro reactions were analyzed using a $\mathrm{C} 18$ column using the method described below in "LC-HRMS and MS/MS analysis of PvfC $L 48$ in vitro reactions".

\section{LC-HRMS and MS/MS analysis of $\mathrm{PvfC}_{\mathrm{L} 48}$ in vitro reactions}

A $10 \mu \mathrm{L}$ sample of the $\mathrm{PvfC}_{\llcorner 48}$ reaction (see sections " $\mathrm{PvfC}_{\llcorner 48}$ in vitro reactions to produce valine derivatives of leucinazole, flavacol, PZ-1, and PZ-2" and "Derivatization of $\mathrm{PvfC}_{\llcorner 48}$ in vitro reactions with PFPH") was analyzed by liquid chromatography high resolution mass spectrometry (LC-HRMS) using an Agilent Technologies 6520 Accurate Mass QTOF LC/MS. Samples were separated on a Phenomenex Kinetex $5 \mu \mathrm{m}$ C18 $100 \AA, 150 \times 4.60 \mathrm{~mm}$ column. Solvent A consisted of $0.1 \%$ formic acid in water, and solvent $B$ consisted of $0.1 \%$ formic acid in acetonitrile. Using a flow rate of $0.6 \mathrm{~mL} \mathrm{~min}^{-1}$, the samples were eluted by $2 \%$ B for 4 minutes, followed by a linear gradient of $2-95 \%$ B over 20 minutes, and $95 \%$ B for another 2 minutes. Positive ion mode ESI mass spectrometry was carried out using the following parameters: gas temperature $350{ }^{\circ} \mathrm{C}$, drying gas $10 \mathrm{~L} \mathrm{~min}^{-1}$, nebulizer $45 \mathrm{psi}$, fragmentor $175 \mathrm{~V}$, skimmer $65 \mathrm{~V}$, absolute threshold of 200 for ions of interest. MS/MS was conducted using targeted fragmentation, $25 \mathrm{~V}$ collision energy, absolute threshold of 200 for ions of interest. MS and MS/MS chromatograms were smoothed for presentation purposes.

\section{In vitro incubation of $\mathrm{PvfC}_{\mathrm{Pf0}-1}$ with flavacol}

PvfC $_{\text {Pfo- } 1}(10 \mu \mathrm{M})$ in $25 \mathrm{mM}$ HEPES $(\mathrm{pH}=7.5)$ was incubated with $2 \mathrm{mM} \mathrm{MgCl}, 4 \mu \mathrm{M} \mathrm{Sfp}$, and $0.2 \mathrm{mM}$ coenzyme A for 30 minutes at room temperature. Samples of $1 \mathrm{mM}$ ATP and $5 \mathrm{mM}$ synthetic flavacol were then added and incubated for 30 minutes at room temperature. Finally, $2 \mathrm{mM} \mathrm{NADPH}$ was then supplemented to the reaction mixture and incubated for 2.5 hours at room temperature. The reaction was quenched using ACN (one volume of enzyme reaction) and incubated at $-20^{\circ} \mathrm{C}$ for at least 20 minutes. Samples were centrifuged at $20,800 \mathrm{xg}$ for 10 minutes to remove precipitated protein and analyzed by LCHRMS in positive mode using a C18 column using the method described below in "LC-HRMS and MS/MS analysis of $\mathrm{PvfC}_{\llcorner 48}$ in vitro reactions".

\section{Inhibition studies towards Bacillus subtilis and Escherichia coli}

Overnight cultures of Bacillus subtilis BSU168 or Escherichia coli BW25113 were grown to saturation in LB at $28{ }^{\circ} \mathrm{C}$ or $37^{\circ} \mathrm{C}$, respectively. Cultures were diluted to an $\mathrm{OD}_{600}$ of 0.5 and $100 \mu \mathrm{L}$ of diluted cultures was spread on an LB agar plate and let dry for 1 hour. Compounds ( $3 \mu \mathrm{L}$ in $\mathrm{MeOH}$ stock) were spotted on paper diffusion disks. Leu-dPNO (1), Leu-PNO A (2), leucinazole (3), Leu-PNO B (4), and flavacol (5), PZ-1 (6, synthetic), PZ-2 (7, synthetic) and 2,3-diisobutylpyrazine were all tested at $5 \mathrm{mM}, 2.5 \mathrm{mM}$, and $1.25 \mathrm{mM}$ concentrations along with a methanol control. Plates were incubated for a total of 24 hours at $28{ }^{\circ} \mathrm{C}$ for BSU168 and $37^{\circ} \mathrm{C}$ for BW25113. 


\section{Supplemental tables}

Table S1. NMR assignments of isolated Leu-dPNO (1).

Spectra were acquired on a $700 \mathrm{MHz}$ instrument. The last column represents proton spectra acquired on a $850 \mathrm{MHz}$ instrument to show fine splitting to distinguish the isobutyl groups.

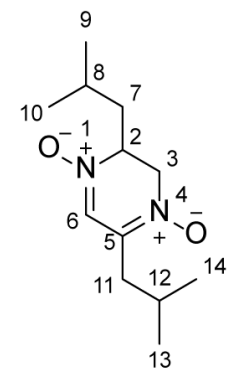

Leu-dPNO (1)

\begin{tabular}{|c|c|c|c|c|c|c|}
\hline & $\delta c$ & proton & $\begin{array}{c}\delta_{H} \\
\text { (multiplicity, } J[\mathrm{~Hz}] \text { ) }\end{array}$ & cosy & $\begin{array}{c}\left({ }^{1} \mathrm{H},{ }^{13} \mathrm{C}\right) \\
\mathrm{HMBC}\end{array}$ & $\begin{array}{c}\delta_{H}, 850 \mathrm{MHz} \\
\text { (multiplicity, } J[\mathrm{~Hz}] \text { ) }\end{array}$ \\
\hline \multicolumn{7}{|l|}{$1-\mathrm{N}$} \\
\hline 2 & 66 & $\mathrm{CH}$ & $\begin{array}{c}4.13 \\
(\mathrm{~m},[11.3,5.9,2.6])\end{array}$ & 3,7 & $3,6,7$ & $4.14(\mathrm{~m},[9.2,4.3,2.7,2.1]$ \\
\hline $3 a, b$ & 60.2 & $\mathrm{CH}_{2}$ & $\begin{array}{c}4.01,4.5 \\
(\mathrm{dd},[15.6,4.9])\end{array}$ & 2 & $2,5,6,7$ & $4.05,4.53$ (dd, [15.7, 4.9] \\
\hline \multicolumn{7}{|l|}{ 4-N } \\
\hline 5 & 140.64 & & & & & \\
\hline 6 & 128.2 & $\mathrm{CH}$ & $7.27(\mathrm{~s})$ & & $2,5,11$ & $7.25(\mathrm{~s})$ \\
\hline $7 a, b$ & 38.4 & $\mathrm{CH}_{2}$ & $\begin{array}{c}1.64,2.00 \\
(\mathrm{ddd},[14.3,8.6,6.2]) \\
\end{array}$ & 2,8 & $2,3,8$ & $\begin{array}{c}1.63,2.01 \\
(\mathrm{ddd},[13.9,8.70,6.13,2.0])\end{array}$ \\
\hline 8 & 24.4 & $\mathrm{CH}$ & $1.8(\mathrm{~m},[6.7])$ & $7,9,10$ & $2,7,9,10$ & $1.79(\mathrm{~m},[6.6,1.2])$ \\
\hline 9,10 & $\begin{array}{l}21.67 \\
22.77\end{array}$ & $\mathrm{CH}_{3}$ & $\begin{array}{l}0.98(\mathrm{~d},[6.5]), \\
1.05(\mathrm{~d},[6.5])\end{array}$ & 8 & 7,8 & $0.97(d,[6.5]), 1.04(d,[6.5])$ \\
\hline $11 a, b$ & 36.9 & $\mathrm{CH}_{2}$ & $\begin{array}{c}2.32,2.58 \\
(\mathrm{dd},[14.1,7.4])\end{array}$ & 12 & $\begin{array}{c}5,6,12 \\
13,14 \\
\end{array}$ & $\begin{array}{c}2.35,2.55 \text { (ddd, [14.09, } 7.4 \text {, } \\
14.1])\end{array}$ \\
\hline 12 & 26.2 & $\mathrm{CH}$ & $2.13(\mathrm{~m},[6.8])$ & $11,13,14$ & $\begin{array}{c}5,11,13 \\
14\end{array}$ & $2.11(\mathrm{~m},[6.8,2.0])$ \\
\hline 13,14 & 22.59 & $\mathrm{CH}_{3}$ & $1(\mathrm{~d},[6.0])$ & 12 & 11,12 & $0.99(\mathrm{~d}[6.5])$ \\
\hline
\end{tabular}


Table S2. NMR assignments of isolated Leu-PNO A (2).

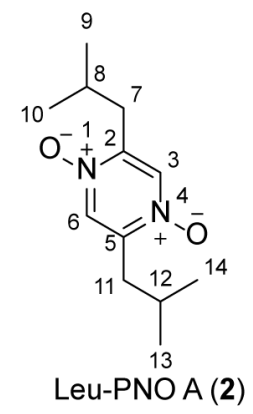

\begin{tabular}{|c|c|c|c|c|c|c|}
\hline & \multicolumn{2}{|c|}{ Literature $^{10}$} & \multicolumn{4}{|c|}{ This study } \\
\hline & $\begin{array}{c}\delta_{H} \\
\text { (multiplicity, } J \\
[H z])\end{array}$ & proton & $\delta_{c}$ & $\begin{array}{c}\delta_{H} \\
\text { (multiplicity, } J \\
{[\mathrm{~Hz}] \text { ) }}\end{array}$ & cosy & $\left({ }^{1} \mathrm{H},{ }^{13} \mathrm{C}\right) \mathrm{HMBC}$ \\
\hline \multicolumn{7}{|l|}{ 1-N, 4-N } \\
\hline 2,5 & & & 147.14 & & & \\
\hline 3,6 & $8.01(\mathrm{~s})$ & $\mathrm{CH}$ & 135.79 & $8.06(\mathrm{~s})$ & & 2,5 \\
\hline 7,11 & $2.64(\mathrm{~d},[6.5])$ & $\mathrm{CH}_{2}$ & 36.94 & 2.68 (d, [7.2]) & 8,12 & $\begin{array}{c}2,3,5,6,8-10 \\
12-14 \\
\end{array}$ \\
\hline 8,12 & $2.21(\mathrm{~m})$ & $\mathrm{CH}$ & 26.14 & $2.23(\mathrm{~m},[6.7])$ & $7,9,10,11,13,14$ & $7,9,10,11,13,14$ \\
\hline $\begin{array}{c}9,10,13 \\
14 \\
\end{array}$ & $0.98(\mathrm{~d},[6.5])$ & $\mathrm{CH}_{3}$ & 22.43 & $1.02(d,[6.7])$ & 8,12 & $7,8,11,12$ \\
\hline
\end{tabular}


Table S3. NMR assignments of isolated Leu-PNO B (4).

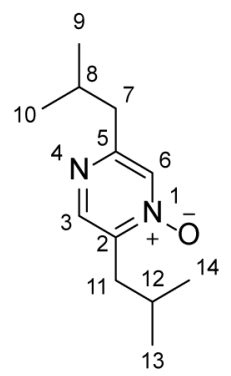

Leu-PNO B (4)

\begin{tabular}{|c|c|c|c|c|c|c|c|}
\hline & \multicolumn{3}{|c|}{ Literature $^{10,11}$} & \multicolumn{4}{|c|}{ This study } \\
\hline & $\delta c^{36}$ & Proton & $\delta_{H}^{35}$ & $\delta c$ & $\begin{array}{c}\delta_{H} \\
\text { (multiplicity, } J \\
{[H z] \text { ) }}\end{array}$ & cosy & $\begin{array}{c}\left({ }^{1} \mathrm{H},{ }^{13} \mathrm{C}\right) \\
\mathrm{HMBC}\end{array}$ \\
\hline \multicolumn{8}{|l|}{$1-\mathrm{N}$} \\
\hline 2 & 143.7 & & & 143.8 & & & \\
\hline 3 & 147.2 & $\mathrm{CH}$ & 8.27 & 147.14 & $8.32(\mathrm{~s})$ & 6 & $2,5,11$ \\
\hline \multicolumn{8}{|l|}{$4-\mathrm{N}$} \\
\hline 5 & 158.0 & & & 157.96 & & & \\
\hline 6 & 133.0 & $\mathrm{CH}$ & 7.97 & 133.05 & $8.01(\mathrm{~s})$ & 3 & $2,5,7$ \\
\hline 7 & 44.2 & $\mathrm{CH}_{2}$ & 2.56 & 44.2 & $2.59(\mathrm{~d},[7.2])$ & 8 & $5,6,8-10$ \\
\hline 8 & 28.5 & $\mathrm{CH}$ & 2.15 & 28.56 & $2.12(\mathrm{~m},[6.8])$ & $7,9,10$ & $5,7,9,10$ \\
\hline 9,10 & 22.3 & $\mathrm{CH}_{3}$ & 0.93 & 22.33 & $0.98(\mathrm{~d},[6.7])$ & 8 & 7,8 \\
\hline 11 & 36.6 & $\mathrm{CH}_{2}$ & 2.72 & 36.6 & $2.74(\mathrm{~d}, 7.2 \mathrm{]})$ & 12 & $2,3,12-14$ \\
\hline 12 & 25.4 & $\mathrm{CH}$ & 2.15 & 25.33 & $2.26(\mathrm{~m},[6.8])$ & $\begin{array}{c}11,13 \\
14\end{array}$ & $2,11,13,14$ \\
\hline 13,14 & 22.6 & $\mathrm{CH}_{3}$ & 0.94 & 22.58 & $0.99(\mathrm{~d},[6.7)$ & 12 & 11,12 \\
\hline
\end{tabular}




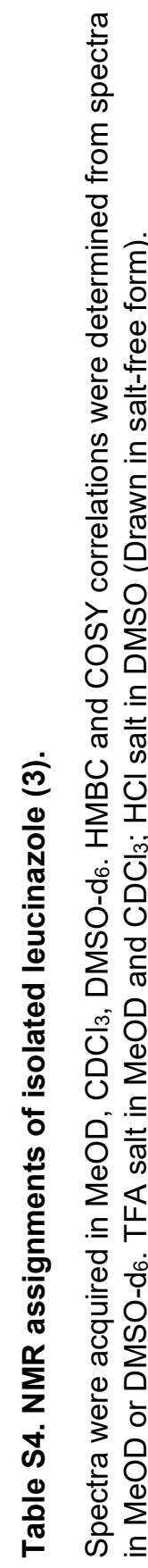

\begin{tabular}{|c|c|c|c|c|c|c|c|c|c|c|c|c|c|}
\hline \multirow{2}{*}{$\begin{array}{l}\text { के } \\
\text { के } \\
\text { के }\end{array}$} & 10 & & & $\begin{array}{l}\widehat{0} \\
0 \\
0 \\
\end{array}$ & & & & 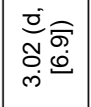 & 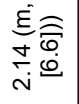 & 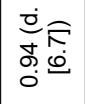 & $\begin{array}{l}\overrightarrow{0} \\
\hat{n} \\
\stackrel{5}{ \pm}\end{array}$ & 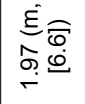 & $\begin{array}{l}0 \\
0 \\
\infty \\
\infty \\
0 \\
0 \\
0\end{array}$ \\
\hline & 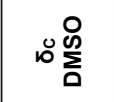 & & 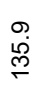 & @̊ & & $\begin{array}{l}\infty \\
\infty \\
\infty \\
\stackrel{2}{2}\end{array}$ & $\begin{array}{l}\hat{i} \\
\infty \\
\infty\end{array}$ & $\hat{F}$ & $\stackrel{m}{\sim}$ & $\stackrel{m}{\mathbb{N}}$ & 户户 & $\stackrel{+}{\infty}$ & $\stackrel{\circ}{\grave{N}}$ \\
\hline \multirow{10}{*}{ 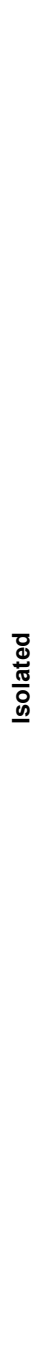 } & 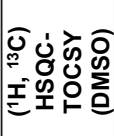 & & & $\begin{array}{l}n \\
\dot{5} \\
i \\
m\end{array}$ & & & & $\begin{array}{l}\sigma^{\circ} \\
\infty 0 \\
\text { 응 } \\
0\end{array}$ & $\begin{array}{l} \\
0 \\
\infty \\
\infty\end{array}$ & $\begin{array}{l}1 \\
\infty \\
0 \\
0\end{array}$ & 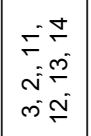 & 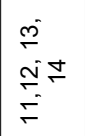 & 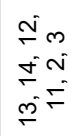 \\
\hline & İ ত্ల & & & $\begin{array}{l}n \\
i\end{array}$ & & & & $\begin{array}{l}\infty 0 \\
0 \% \\
0\end{array}$ & & $\begin{array}{l}\infty \\
N^{\prime}\end{array}$ & 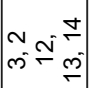 & & 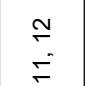 \\
\hline & خั. & & & & & & & $\infty$ & iే으 & $\infty$ & $\stackrel{\simeq}{\simeq}$ & $=\frac{\nabla}{\check{m}}$ & $\stackrel{\simeq}{\simeq}$ \\
\hline & Iิ & & & $\begin{array}{l}\frac{0}{0} \\
\hat{n} \\
\end{array}$ & & & & 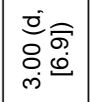 & 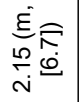 & 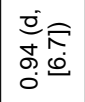 & 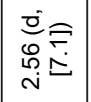 & $\begin{array}{l}\dot{\xi} \widehat{\sigma} \\
\infty \\
\stackrel{0}{\sigma} \dot{0}\end{array}$ & $\begin{array}{l}\stackrel{0}{0}=\bar{F} \\
\infty \\
\infty \\
0\end{array}$ \\
\hline & 10 & & & $\frac{\infty}{i} \infty$ & & & & 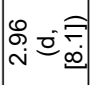 & Nָ & S. & 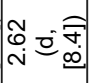 & مَّ & 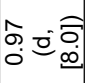 \\
\hline & 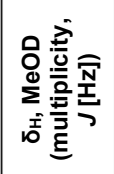 & & & $\begin{array}{l}\frac{\widehat{n}}{n} \\
\stackrel{m}{n}\end{array}$ & & & & 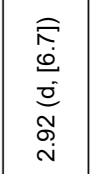 & 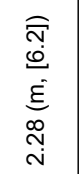 & $\begin{array}{l}\widehat{c} \\
0 \\
0 \\
0 \\
0 \\
0 \\
\dot{0} \\
\dot{r}\end{array}$ & 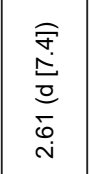 & 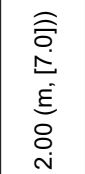 & $\begin{array}{l}\widehat{\sigma} \\
\dot{0} \\
\dot{0} \\
0 \\
\infty \\
0 \\
0 \\
0\end{array}$ \\
\hline & $\begin{array}{l}\text { 음 } \\
\text { 음 }\end{array}$ & & & I & & & & $\frac{T}{U}$ & I & $\stackrel{\text { I }}{\mathrm{U}}$ & $\frac{N}{U}$ & I & $\frac{m}{\mathrm{~m}}$ \\
\hline & ஸ் & & $\begin{array}{l}\stackrel{+}{0} \\
\stackrel{\varphi}{m}\end{array}$ & $\stackrel{\stackrel{ }{ }}{ }$ & & ִָ & $\begin{array}{l}0 \\
\dot{0} \\
\stackrel{\infty}{\circ}\end{array}$ & $\begin{array}{l}9 \\
\dot{q}\end{array}$ & $\stackrel{m}{\stackrel{N}{\sim}}$ & $\stackrel{\text { న్ }}{\text { N }}$ & $\overline{\ddot{m}}$ & ঐ̊ & $\stackrel{\leftrightarrow}{\grave{N}}$ \\
\hline & ن윰 & & 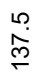 & $\stackrel{\stackrel{N}{N}}{\stackrel{N}{ }}$ & & 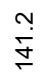 & $\begin{array}{l}\infty \\
\infty \\
\infty \\
\infty\end{array}$ & $\begin{array}{l}\stackrel{0}{\dot{f}} \\
\text { f }\end{array}$ & 官 & $\stackrel{๋}{N}$ & लें & $\begin{array}{l}L \\
\stackrel{\infty}{N}\end{array}$ & Ñ \\
\hline & $\sum_{0}^{0}$ & & $\begin{array}{l}\infty \\
\infty \\
\stackrel{\infty}{\sim}\end{array}$ & $\stackrel{\mathscr{N}}{\stackrel{N}{N}}$ & & $\begin{array}{l}0 \\
\stackrel{N}{Y}\end{array}$ & 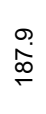 & 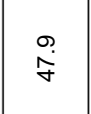 & 尽 & $\begin{array}{l}\infty \\
\stackrel{N}{N}\end{array}$ & 迎 & ஷ্ & $\stackrel{+}{\mathbb{N}}$ \\
\hline & & $z$ & $N$ & $m$ & $\underset{j}{z}$ & in & 0 & $\Lambda$ & $\infty$ & o은 & $\mp$ & ₹ & ๓士 \\
\hline
\end{tabular}




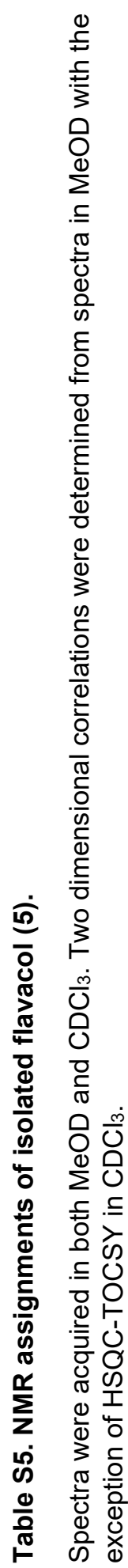

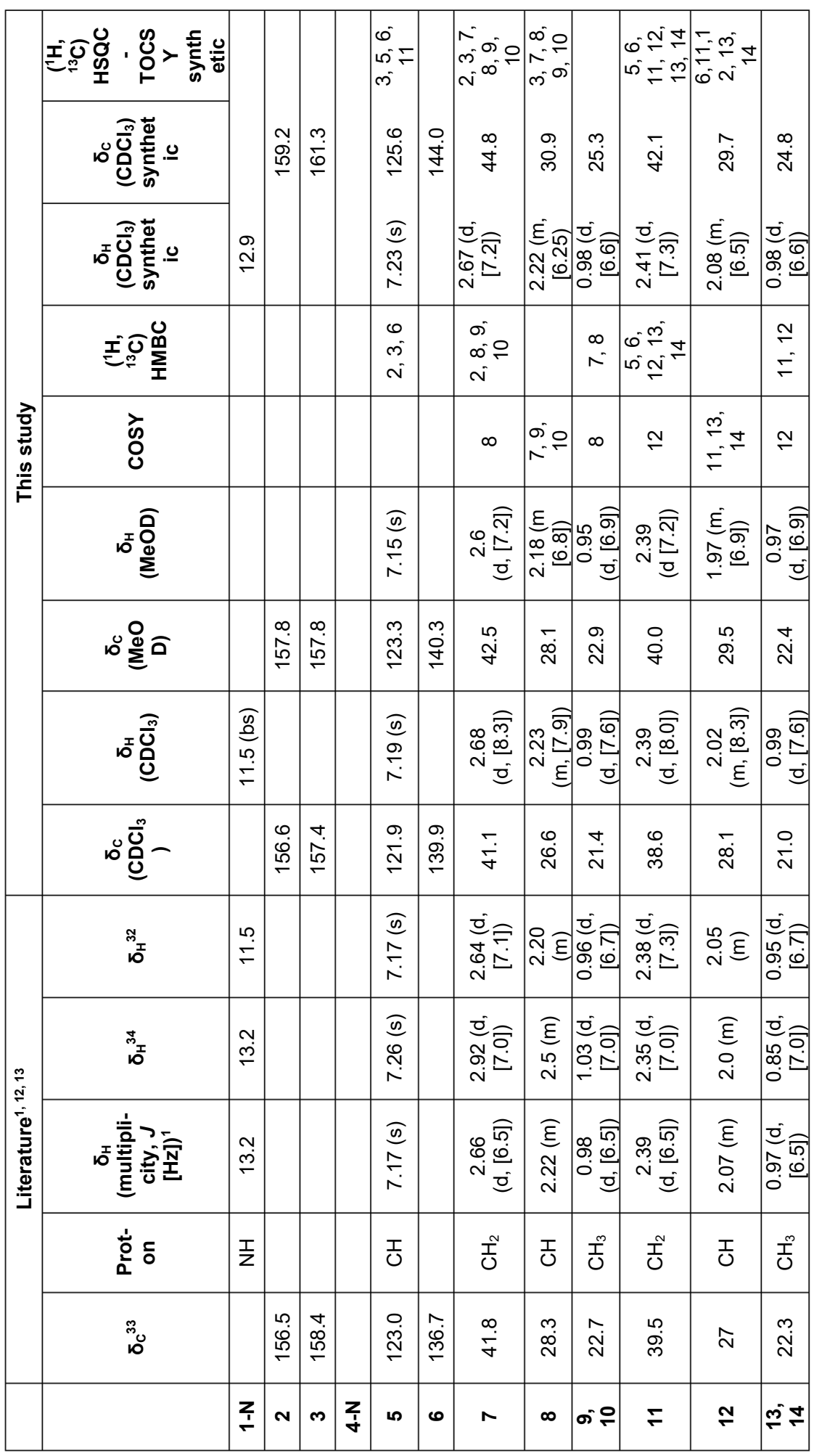


Table S6. NMR assignments of isolated PZ-1 (6).

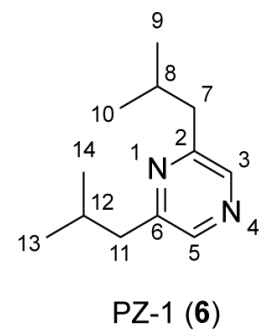

\begin{tabular}{|c|c|c|c|c|c|c|c|c|}
\hline & \multicolumn{4}{|c|}{ Isolated } & \multicolumn{2}{|c|}{ Synthetic } & \multicolumn{2}{|c|}{$\begin{array}{c}1: 1 \mathrm{mix} \\
\text { Synthetic:Isolated }\end{array}$} \\
\hline & $\delta c$ & $\begin{array}{c}\delta_{\mathrm{H}} \\
\text { (multiplicit } \\
y, J[\mathrm{~Hz}])\end{array}$ & cosy & $\begin{array}{c}\left({ }^{1} \mathrm{H},{ }^{13} \mathrm{C}\right) \\
\text { HMBC }\end{array}$ & $\delta c$ & $\begin{array}{c}\delta_{\mathrm{H}} \\
\text { (multiplicit } \\
y, J[\mathrm{~Hz}])\end{array}$ & $\delta_{c}$ & $\begin{array}{c}\delta_{H} \\
\text { (multiplicit } \\
y, J[H z])\end{array}$ \\
\hline \multicolumn{9}{|l|}{ 1-N, 4-N } \\
\hline 2,6 & 157.2 & & & & $\begin{array}{c}158 . \\
6\end{array}$ & & $\begin{array}{c}157 . \\
2\end{array}$ & \\
\hline 3,5 & 138.5 & $8.42(\mathrm{~s})$ & & 2,6 & $\begin{array}{c}135 . \\
8 \\
\end{array}$ & $8.53(\mathrm{~s})$ & $\begin{array}{c}140 . \\
0\end{array}$ & $8.30(\mathrm{~s})$ \\
\hline 7,11 & 44.7 & $\begin{array}{c}2.84(\mathrm{~d}, \\
[7.3])\end{array}$ & 8,12 & $\begin{array}{c}2,3,5,6,8- \\
10,12-14 \\
\end{array}$ & 43.3 & $\begin{array}{l}2.9(\mathrm{~d}, \\
[7.0])\end{array}$ & 43.2 & $\begin{array}{c}2.74(\mathrm{~d} \\
[7.1]) \\
\end{array}$ \\
\hline 8,12 & 29.2 & $\begin{array}{c}2.16(\mathrm{~m}, \\
[7.0])\end{array}$ & $\begin{array}{c}7,9,10 \\
11,13,14\end{array}$ & $\begin{array}{c}7,9,10,11 \\
13,14\end{array}$ & 29.7 & $\begin{array}{c}2.18(\mathrm{~m} \\
[6.5])\end{array}$ & 29.2 & $\begin{array}{l}2.14(\mathrm{~m} \\
[6.7])\end{array}$ \\
\hline $\begin{array}{c}9,10,13 \\
14\end{array}$ & 21.3 & $\begin{array}{l}0.99(\mathrm{~d}, \\
[6.7])\end{array}$ & 8,12 & $7,8,11,12$ & 23.5 & $\begin{array}{l}1.0(\mathrm{~d}, \\
[6.8])\end{array}$ & 22.3 & $\begin{array}{l}0.97(\mathrm{~d}, \\
[6.5])\end{array}$ \\
\hline
\end{tabular}


Table S7. NMR assignments of isolated PZ-2 (7).

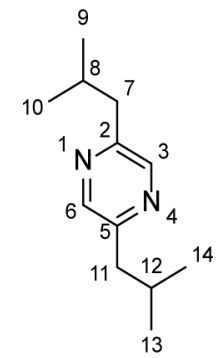

PZ-2 (7)

\begin{tabular}{|c|c|c|c|c|c|c|c|c|c|c|}
\hline & \multicolumn{2}{|c|}{ Literature $^{10}$} & \multicolumn{4}{|c|}{ This study } & \multicolumn{2}{|c|}{ Synthetic } & \multicolumn{2}{|c|}{ 1:1 mix Syn:Isolated } \\
\hline & $\delta c$ & Proton & $\delta c$ & $\begin{array}{c}\delta_{H} \\
\text { (multiplicity, } \\
J[\mathrm{~Hz}])\end{array}$ & cosy & $\begin{array}{c}\left({ }^{1} \mathrm{H},{ }^{13} \mathrm{C}\right) \\
\mathrm{HMBC}\end{array}$ & $\delta c$ & $\begin{array}{c}\delta_{H} \\
\text { (multiplicity, } \\
J[\mathrm{~Hz}])\end{array}$ & $\delta c$ & $\begin{array}{c}\delta_{H} \\
\text { (multiplicity } \\
, J[\mathrm{~Hz}] \text { ) }\end{array}$ \\
\hline \multicolumn{11}{|l|}{ 1-N, 4-N } \\
\hline 2,5 & 153.8 & & 154.1 & & & & 154 & & 153.9 & \\
\hline 3,6 & 144 & $\mathrm{CH}$ & 141.9 & $8.77(\mathrm{~s})$ & & 2,5 & 143.8 & $8.55(\mathrm{~s})$ & 143 & $8.53(\mathrm{~s})$ \\
\hline 7,11 & 44.2 & $\mathrm{CH}_{2}$ & 42.2 & $\begin{array}{c}2.91(\mathrm{~d}, \\
[7.4])\end{array}$ & 8,12 & $\begin{array}{c}2,3,5,6 \\
8-10,12- \\
14\end{array}$ & 43 & $2.77(\mathrm{~d},[7.7])$ & 43.2 & $\begin{array}{c}2.77(\mathrm{~d}, \\
[7.0])\end{array}$ \\
\hline 8,12 & 29 & $\mathrm{CH}$ & 29.5 & $\begin{array}{c}2.16(\mathrm{~m}, \\
[6.7])\end{array}$ & $\begin{array}{c}7,9, \\
10,11, \\
13,14\end{array}$ & $\begin{array}{c}7,9,10 \\
11,13,14\end{array}$ & 29.3 & $2.10(\mathrm{~m},[7.2])$ & 29.3 & $\begin{array}{c}2.12(\mathrm{~m}, \\
[6.8])\end{array}$ \\
\hline $\begin{array}{c}9,10,13, \\
14\end{array}$ & 22.4 & $\mathrm{CH}_{3}$ & 22.0 & $\begin{array}{c}1.01(\mathrm{~d}, \\
[6.9])\end{array}$ & 8,12 & $7,8,11,12$ & 22.2 & $0.97(\mathrm{~d},[7.3])$ & 22.2 & $\begin{array}{c}0.98(\mathrm{~d}, \\
[6.7])\end{array}$ \\
\hline
\end{tabular}


Table S8. Key Resources

\begin{tabular}{|c|c|c|}
\hline REAGENT or RESOURCE & SOURCE & IDENTIFIER \\
\hline \multicolumn{3}{|l|}{ Bacterial strains } \\
\hline P. fluorescens Pf0-1 & 14 & GM127 \\
\hline E. coli Top 10 pPSV35-pvfABCDpf0-1 & This study & GM222 \\
\hline P. aeruginosa PAO1 pPSV35-pvfABCD $\mathrm{pf0}-1$ & This study & GM229 \\
\hline E. coli BAP1 pPSV35-pvfABCDPf0-1 & This study & GM224 \\
\hline E. coli Top 10 pPSV35-pvfBCD pfo-1 & This study & GM236 \\
\hline P. aeruginosa $\mathrm{PAO} 1 \mathrm{pPSV} 35-p v f B C D$ pfo-1 & This study & GM245 \\
\hline E. coli BAP1 pPSV35-pvfBCD pfo-1 & This study & GM242 \\
\hline E. coli Top 10 pPSV35-pvfABCpfo-1 & This study & GM235 \\
\hline P. aeruginosa PAO1 pPSV35-pvfABC & This study & GM244 \\
\hline E. coli BAP1 pPSV35-pvfABC Pf0-1 & This study & GM241 \\
\hline E. coli Top 10 pPSV35-pvfACD $D_{\text {pfo-1 }}$ & This study & GM237 \\
\hline P. aeruginosa PAO1 pPSV35-pvfACD $D_{\mathrm{Pf0}-1}$ & This study & GM246 \\
\hline E. coli BAP1 pPSV35-pvfACD $D_{\mathrm{Pf0}-1}$ & This study & GM242 \\
\hline E. coli BL21 pET30a-pvfC $C_{\mathrm{Pf0}-1-T}$ & 9 & GM223 \\
\hline E. coli BL21 pET28a-pvfC pfo-1 & 8 & GM144 \\
\hline Pseudomonas aeruginosa PAO1 & $\begin{array}{l}\text { Chris Walsh (Harvard } \\
\text { Medical School) }\end{array}$ & GM053 \\
\hline Bacillus subtilis BSU168 & $\begin{array}{l}\text { Chris Walsh (Harvard } \\
\text { Medical School) }\end{array}$ & GM129 \\
\hline E. coli BW25113 & $\begin{array}{l}\text { Chris Walsh (Harvard } \\
\text { Medical School) }\end{array}$ & GM132 \\
\hline \multicolumn{3}{|l|}{ Chemicals and reagents } \\
\hline BOC-L-serine hydrate (tert-Butoxycarbonyl-L-serine & Acros & AC275660250 \\
\hline D-Leucinol ((R)-2-Amino-4-methylpentan-1-ol) & Alfa Aesar & L13243-03 \\
\hline N,N'-Diisopropylcarbodiimide (DIC) & Oakwood Chemical & M02889 \\
\hline 4-(Dimethylamino)pyridine (DMAP) & Aldrich & 107700 \\
\hline 1-Hydroxybenzotriazole hydrate (HOBt) & Oakwood Chemical & M02875 \\
\hline $\begin{array}{l}\text { 1,1,1-Tris(acetyloxy)-1,1-dihydro-1,2-benziodoxol-3(1H)- } \\
\text { one (DMP) }\end{array}$ & Matrix Scientific & 076222 \\
\hline Trifluoroacetic acid (TFA) & Acros & AC293811000 \\
\hline 1-((Isocyanomethyl)sulfonyl)-4-methylbenzene & Oakwood Chemical & 043405 \\
\hline Isovaleraldehyde (3-methylbutanal) & Aldrich & 146455 \\
\hline Ethanol & Acros & AC615100010 \\
\hline Sodium tert-butoxide & $\mathrm{TCl}$ & S0450 \\
\hline Ammonia $7 \mathrm{~N}$ solution in methanol & Acros & AC428381000 \\
\hline Sodium hydride $(\mathrm{NaH})$ & $\mathrm{TCl}$ & S0481 \\
\hline Dimethylformamide (DMF) & Sigma-Aldrich & 227056 \\
\hline
\end{tabular}




\begin{tabular}{|c|c|c|}
\hline 2-(Trimethylsilyl)ethoxymethyl chloride (SEM-Cl) & Matrix Scientific & 086097 \\
\hline$n$-Butyllithium $2.5 \mathrm{M}$ solution in hexanes & Acros & AC213351000 \\
\hline Isovaleryl chloride (3-Methylbutanoyl chloride) & Supelco & 157422 \\
\hline $\mathrm{HCl}$ (2 $\mathrm{N}$ in diethyl ether) & Acros & AC368471000 \\
\hline Pentafluorophenylhydrazine & Sigma & 156388 \\
\hline L-Leucine & Sigma & L8000 \\
\hline L-Leucine ${ }^{15} \mathrm{~N}$ & $\begin{array}{l}\text { Cambridge Isotope } \\
\text { Labs }\end{array}$ & NLM-142-PK \\
\hline $\begin{array}{l}\beta \text {-Nicotinamide adenine dinucleotide phosphate reduced } \\
\text { tetrasodium salt hydrate }\end{array}$ & Alfa Aesar & J60387 \\
\hline Acetyl coenzyme A sodium salt & Sigma & A2056 \\
\hline HEPES free acid & Fisher & BP301-1 \\
\hline Isobutyl magnesium chloride & Sigma & 479683 \\
\hline 2,5-Dibromopyrazine & Sigma & 796603 \\
\hline 2,6-Dichloropyrazine & Sigma & 132497 \\
\hline 2,3-Dichloropyrazine & Sigma & 465208 \\
\hline L-Valine & Sigma & V0500 \\
\hline L-Valine ${ }^{15} \mathrm{~N}$ & $\begin{array}{l}\text { Cambridge Isotope } \\
\text { Laboratories }\end{array}$ & NLM-316 \\
\hline Iron (III) acetylacetonoate & Aldrich & F300-25G \\
\hline Tetrahydrofuran, 99.9\%, extra dry, stabilized, anhydrous & Acros & AC610911000 \\
\hline $0.1 \% \mathrm{FA}$ in acetonitrile & Fisher & LS120-4 \\
\hline $0.1 \% \mathrm{FA}$ in water & Fisher & LS118-4 \\
\hline Diethyl ether & Acros & AC615080010 \\
\hline Ethyl acetate & Fisher & E124-20 \\
\hline Q5 DNA polymerase & New England Biolabs & M0491L \\
\hline T4 DNA ligase & New England Biolabs & M0202S \\
\hline Gentamicin sulfate & Gold Bio & G-400-1 \\
\hline Kanamycin sulfate & Fisher & $\mathrm{K}-120-25$ \\
\hline Isopropyl- $\beta$-D-thiogalactopyranoside (IPTG) & Fisher & BP1755100 \\
\hline \multicolumn{3}{|l|}{ Oligonucleotides } \\
\hline Table S8 & $\mathrm{N} / \mathrm{A}$ & $\mathrm{N} / \mathrm{A}$ \\
\hline \multicolumn{3}{|l|}{ Software and algorithms } \\
\hline GraphPad & Prism & $\mathrm{N} / \mathrm{A}$ \\
\hline MassHunter & Agilent & $\mathrm{N} / \mathrm{A}$ \\
\hline
\end{tabular}


Table S9. Primers used in this study.

\begin{tabular}{|c|c|c|}
\hline Description & Name & $5^{\prime}$ to $3^{\prime}$ sequence \\
\hline $\begin{array}{l}p v f C_{\mathrm{PfO}-1}-T \text { fwd } \\
\text { (BamHI) }\end{array}$ & GM123 & $\begin{array}{l}\text { GATCGATCGGATCCGCCAACGGCAAAGTCGACCG } \\
\text { TAAG }\end{array}$ \\
\hline $\begin{array}{l}\text { pvfC } C_{\mathrm{Pf0}-1}-T \text { rev } \\
\text { (Notl) }\end{array}$ & GM124 & $\begin{array}{l}\text { GATCGATCGCGGCCGCTCAGATGTGCACACCGAC } \\
\text { AAAACTGTTGG }\end{array}$ \\
\hline $\begin{array}{l}\text { pvfABCD } D_{\text {Pfo-1 }} \text { fwd } \\
\text { (Kpnl, start of } \\
\text { pvfA) }\end{array}$ & GM125 & $\begin{array}{l}\text { ATGATTACGAATTCGAGCTCGGTACCATGCCAACC } \\
\text { AAAGAGCAACTTA }\end{array}$ \\
\hline $\begin{array}{l}p v f A B C D_{\text {Pfo-1 }} \text { rev } \\
\text { (Xbal, end of } \\
\text { pvfD) }\end{array}$ & GM128 & $\begin{array}{l}\text { GCATGCCTGCAGGTCGACTCTAGATTACACAAACA } \\
\text { GCTTCAGCACA }\end{array}$ \\
\hline $\begin{array}{l}\text { pvfABC } \text { Pfo-1 rev } \\
\text { (Xbal, end of } \\
\text { pvfC) }\end{array}$ & GM129 & $\begin{array}{l}\text { GCATGCCTGCAGGTCGACTCTAGATCAGATGAAGT } \\
\text { TGATTTCTTTCAGGTAG }\end{array}$ \\
\hline $\begin{array}{l}\text { pvfBCD } D_{\text {pfo-1 fwd }} \\
\text { (Kpnl, start of } \\
\text { pvfB) }\end{array}$ & GM130 & $\begin{array}{l}\text { ATGATTACGAATTCGAGCTCGGTACCATGAACGCC } \\
\text { GCCGACTACC }\end{array}$ \\
\hline $\begin{array}{l}\text { pvfBCD } \text { Pfo-1 rev } \\
\text { (Xbal, end of } \\
\text { pvfD) }\end{array}$ & GM131 & $\begin{array}{l}\text { GCATGCCTGCAGGTCGACTCTAGATTACACAAACA } \\
\text { GCTTCAGCACATTGC }\end{array}$ \\
\hline $\begin{array}{l}\text { pvfACD } D_{\text {pfo- } 1} \\
\text { fragment } 1 \text { fwd } \\
\text { (Kpnl, start of }\end{array}$ & GM132 & $\begin{array}{l}\text { ATGATTACGAATTCGAGCTCGGTACCATGCCAACC } \\
\text { AAAGAGCAACTTACACTA }\end{array}$ \\
\hline $\begin{array}{l}\text { pvfACD } \text { pfo-1 } \\
\text { fragment } 1 \text { rev }\left(3^{\prime}\right. \\
\text { of pvfA into } 5\end{array}$ & GM134 & $\begin{array}{l}\text { GACGTCTCATGTCAGCCTCCTTGTCATTGGGCCAC } \\
\text { CTCCGC }\end{array}$ \\
\hline $\begin{array}{l}\text { pvfACD } \text { pfo-1 } \\
\text { fragment } 2 \text { fwd }(3 \text { ' } \\
\text { of pvfA into } 5\end{array}$ & GM133 & $\begin{array}{l}\text { GCGGAGGTGGCCCAATGACAAGGAGGCTGACATG } \\
\text { AGACGTC }\end{array}$ \\
\hline $\begin{array}{l}\text { pvfACD } D_{\text {Pfo-1 }} \\
\text { fragment } 2 \text { rev } \\
\text { (Xbal, end of }\end{array}$ & GM128 & $\begin{array}{l}\text { GCATGCCTGCAGGTCGACTCTAGATTACACAAACA } \\
\text { GCTTCAGCACA }\end{array}$ \\
\hline
\end{tabular}




\section{Supplemental Figures}

A

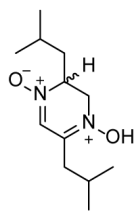

Leu-dPNO (1) $[M+H]^{+}: 227.1754$

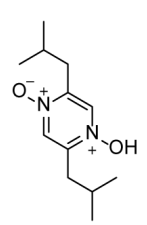

Leu-PNO A (2) $[M+H]^{+}: 225.1598$

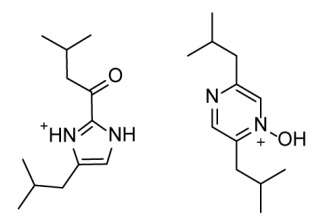

Leucinazole (3) Leu-PNO B(4) $[M+H]^{+}: 209.1648$

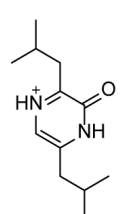

Flavacol (5)

$[M+H]^{+}: 209.1648$

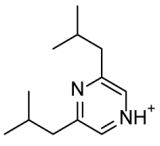

$\mathrm{PZ}-1$ (6) $[M+\mathrm{H}]^{+}: 193.1699$

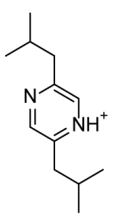

$\mathrm{PZ}-2$ (7) $[M+H]^{+}: 193.1699$
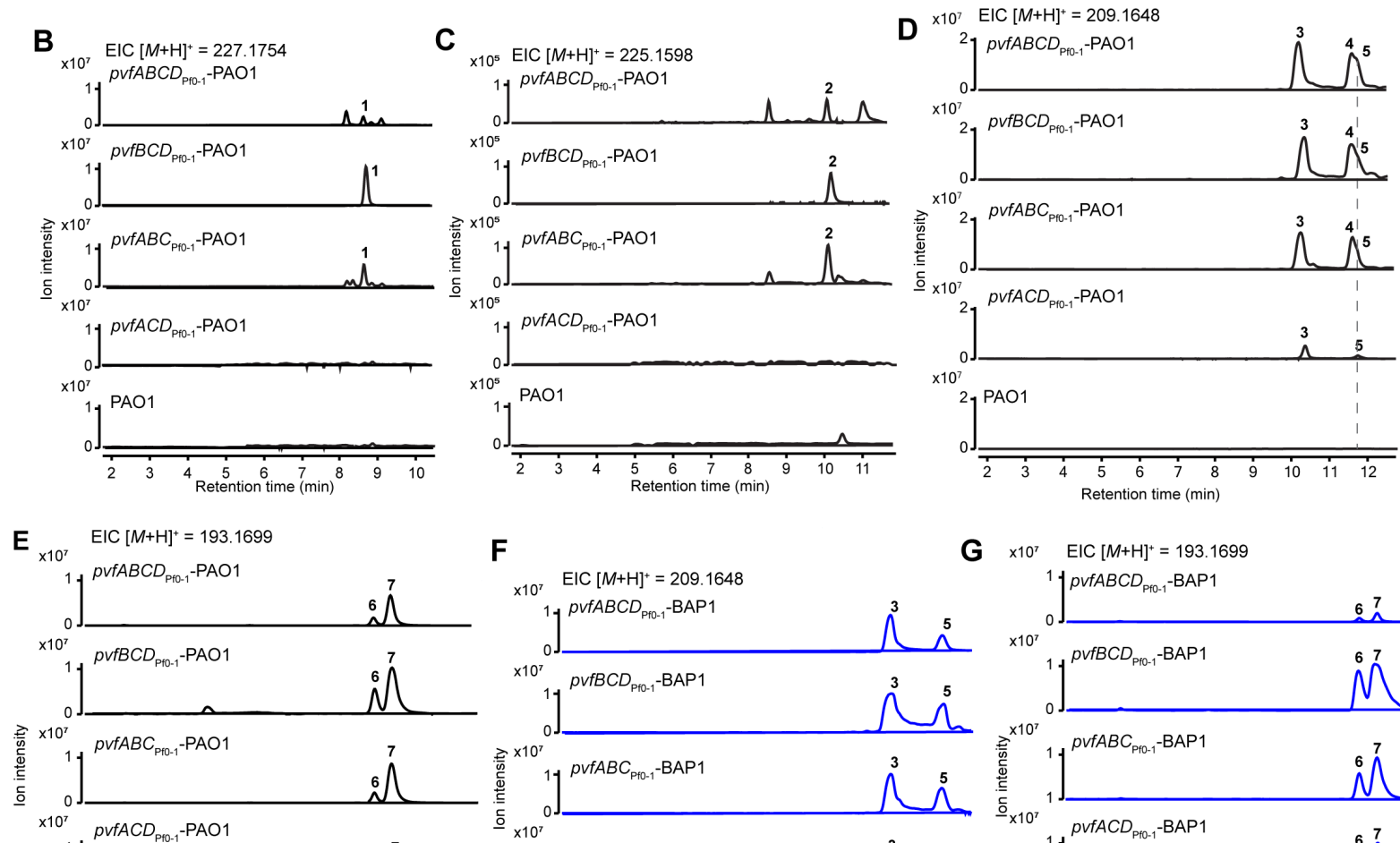

\section{$\mathbf{F}$}

$\times 10^{7} \quad \mathrm{EIC}[M+\mathrm{H}]^{+}=209.1648$ ]$\left._{0}^{1}\right]^{p v f A B C D_{\mathrm{P} 0-1}-\mathrm{BAP} 1}$
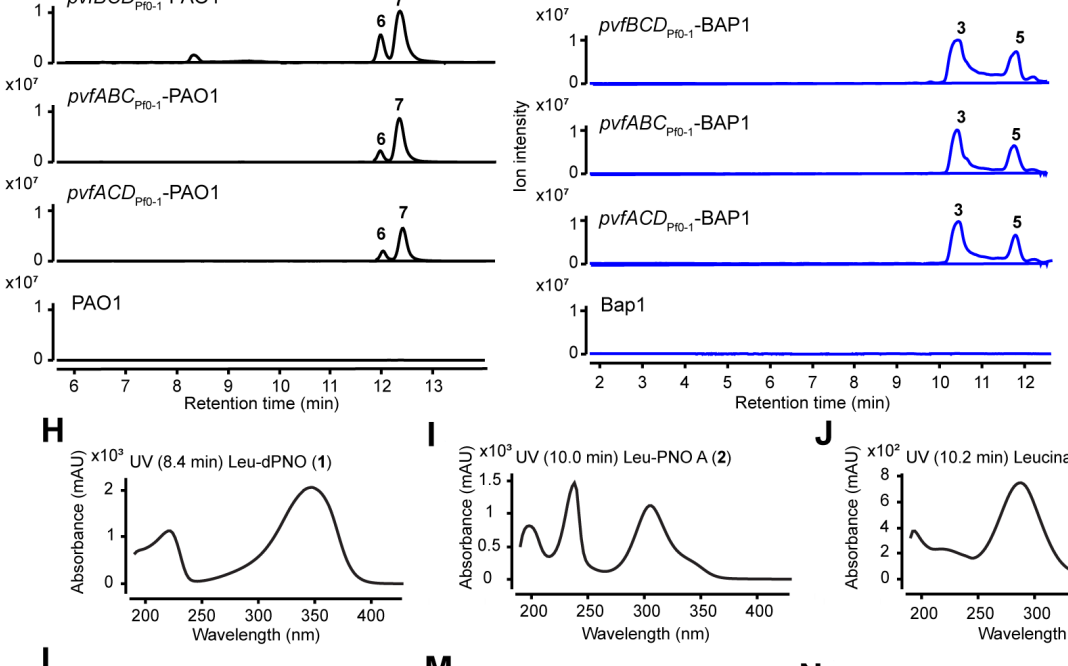

J

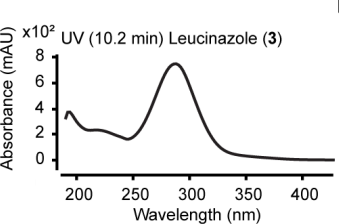

G $\quad x 10^{7} \quad \mathrm{EIC}[M+\mathrm{H}]^{+}=193.1699$

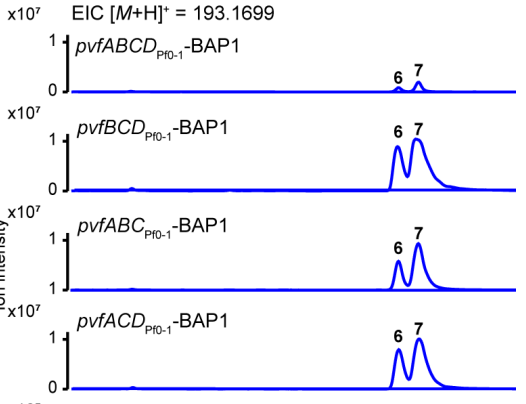

L

M
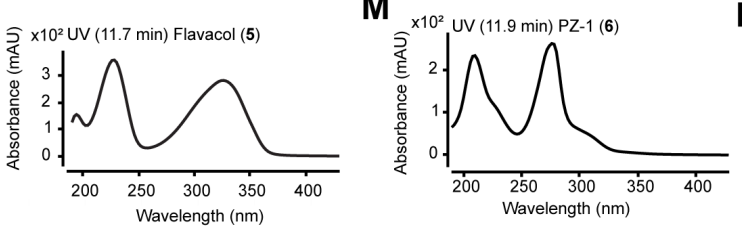

N $\times 10^{2}$ UV (12.3 min) PZ-2 (7)

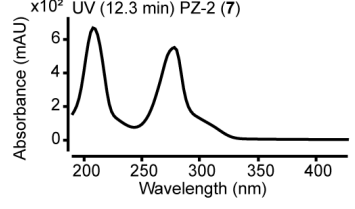


Figure S1. Production of Leu-dPNO, Leu-PNO A, and Leu-PNO B requires expression of $p v f C_{\mathrm{Pf0}-1}$ and $p v f B_{\mathrm{Pfo}-1}$ and production of leucinazole, flavacol, $\mathrm{PZ}-1$, and $\mathrm{PZ}-2$ requires expression of pvfC $_{\mathrm{Pf0}-1}$ in P. aeruginosa PAO1 (black) and E. coli BAP1 (blue).

A) Structures of Leu-dPNO (1), Leu-PNO A (2), leucinazole (3), Leu-PNO B (4), and flavacol (5), PZ-1 (6), and PZ-2 (7).

B-E) LC-HRMS analyses of cell-free culture extracts of $P$. aeruginosa PAO1 expressing pvfABCD Pfo-1, $_{\text {, }}$ pvfBCD pfo-1, pvfABC Pf0-1, pvfACD Pf0-1, or containing the empty pPSV35 vector (top to bottom). B) Extracted ion chromatograms $(\mathrm{EICs})$ of $1\left([\mathrm{M}+\mathrm{H}]^{+}=227.1754\right)$. C) EICs of $2\left([M+\mathrm{H}]^{+}=225.1598\right.$. D) EICs of 3, 4, and $5\left([M+H]^{+}=209.1648\right)$. E) EICs of 6 and $7\left([M+H]^{+}=193.1699\right)$.

F-G) LC-HRMS analyses of cell-free culture extracts of $E$. coli BAP1 expressing $p v f A B C D$ Pf0-1, $p v f B C D$ Pf0-

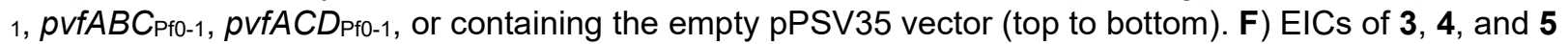
$\left.\left([M+H]^{+}=209.1648\right) . \mathbf{G}\right)$ EICs of 6 and $7\left([M+H]^{+}=193.1699\right)$.

UV-vis spectra of H) Leu-dPNO (1), I) Leu-PNO A (2), J) leucinazole (3), and K) Leu-PNO B (4) from LCHRMS analyses of cell-free culture extracts of $P$. aeruginosa PAO1 expressing $p v f B C D_{\mathrm{Pfo}-1}$. UV-vis spectra of L) flavacol (5), M) PZ-1 (6), and N) PZ-2 (7) from LC-HRMS analyses of cell-free culture extracts of $E$. coli BAP1 cells expressing pvfABCD Pfo-1. UV-vis spectrum of flavacol in the extracts of PAO1 expressing $p v f B C D_{\mathrm{Pfo}-1}$ is masked by Leu-PNO B that co-elutes with flavacol, therefore, is only

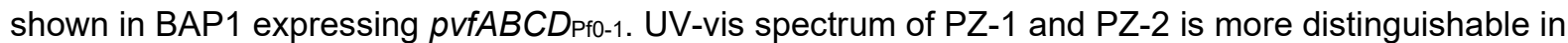
BAP1 expressing pvfABCD Pf0-1 due to reduced background. The UV spectra of these molecules were acquired from LC-HRMS runs under acidic conditions. Metabolites were separated with the LC-HRMS method outlined in "LC-HRMS of metabolomic extracts" 


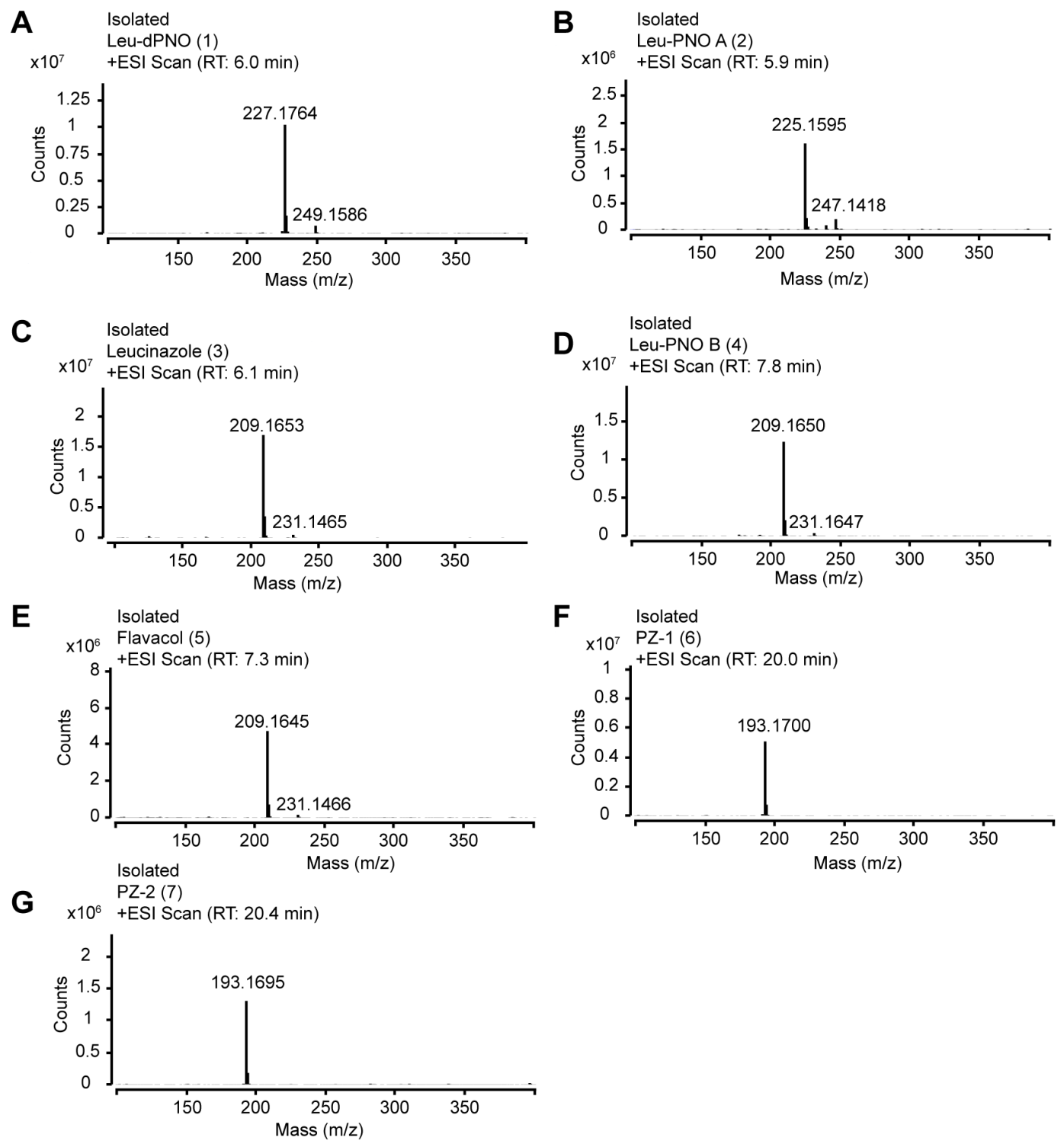

Figure S2. Mass spectra of isolated Leu-dPNO (1), Leu-PNO A (2), leucinazole (3), LeuPNO B (4), flavacol (5), PZ-1 (6), and PZ-2 (7)

Metabolites 1-7 (A-G) were detected in the cell-free extracts of $P$. aeruginosa PAO1 expressing pvfBCD $D_{\text {pfo-1 }}$ and separated on a Hypercarb $5 \mu \mathrm{m}, 100 \times 2.0 \mathrm{~mm}$ column outlined in method "LC-HRMS analysis of isolated metabolites 1-5" 
A $\quad$ pVfBCD $-\mathrm{PAO} 1$

Leu-dPNO (1)

$\times 10^{7}+\mathrm{ESI}$ Scan (RT: $8.5 \mathrm{~min}$ )

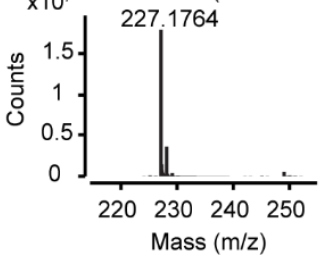

pvfBCD
Flavacol - - - PAO1

+ESI Scan (RT: $11.7 \mathrm{~min})$

$\times 10^{6}$

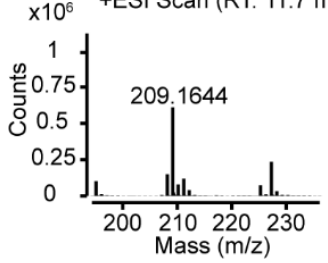

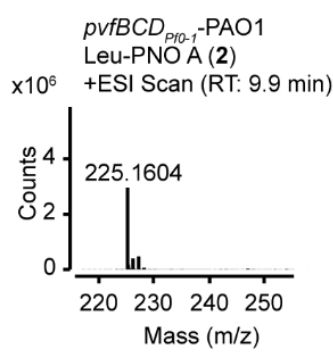
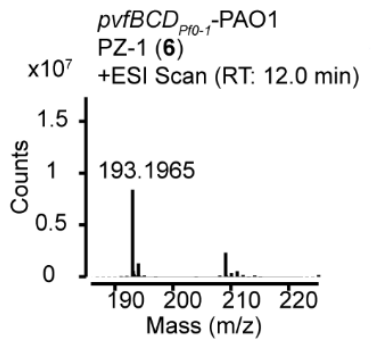
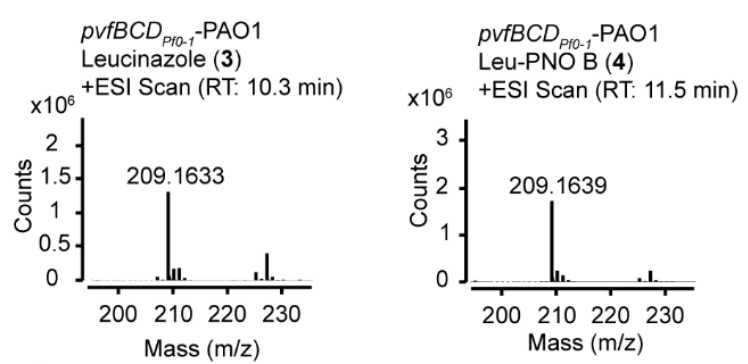
pvfBCD ${ }_{\text {Pfo-1 }}-\mathrm{PAO} 1$
$\mathrm{PZ}-2(\mathbf{7})$
$\times 10^{7} \quad+$ ESI Scan (RT: $12.3 \mathrm{~min}$ )

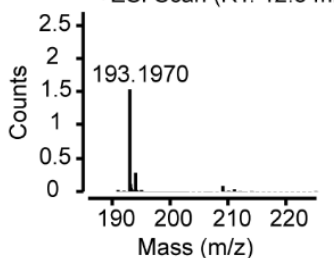

Figure S3. Mass spectra of isolated Leu-dPNO (1), Leu-PNO A (2), leucinazole (3), LeuPNO B (4), flavacol (5), PZ-1 (6), and PZ-2 (7) in metabolomic studies.

Mass spectrum of isolated metabolites A) Leu-dPNO (1), B) Leu-PNO A (2), C) leucinazole (3), D) LeuPNO B (4), E) flavacol (5), F) PZ-1 (6), G) PZ-2 (7). Metabolites were analyzed on a Hypercarb $5 \mu \mathrm{m}, 100$ $x 4.6 \mathrm{~mm}$ column outlined in method "LC-HRMS of metabolomic extracts" 


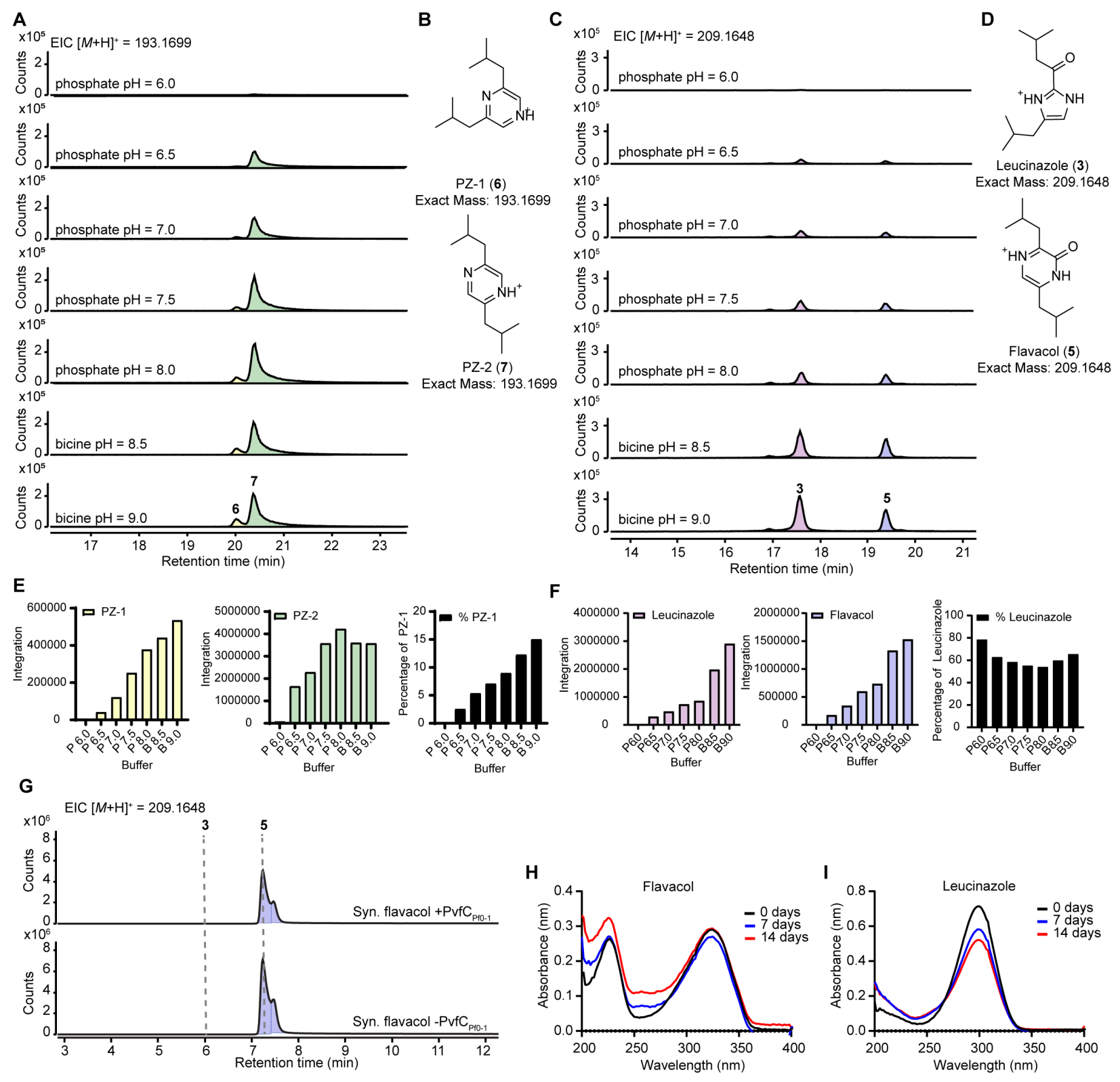

Figure S4. $\mathrm{PvfC}_{\mathrm{Pf0}-1}$ produces more PZ-1, PZ-2, leucinazole, and flavacol with increasing $\mathrm{pH}$.

A) EICs of PZ-1 (6) and PZ-2 (7) $\left([M+H]^{+}=193.1699\right)$ in the reactions including PvfC Pfo-1 $_{1}$ ATP, Sfp, CoA, $\mathrm{MgCl}_{2}, \mathrm{NADPH}$, and L-Leu in phosphate buffer $(\mathrm{pH}=6.0,6.5,7.0,7.5$, or 8.0, top five panels) or in bicine buffer ( $\mathrm{pH}=8.5$ or 9.0, bottom two panels). B) Structures of PZ-1 and PZ-2. C) EICs of leucinazole (3) and flavacol (5) $\left([\mathrm{M}+\mathrm{H}]^{+}=209.1648\right)$ in the reactions including PvfC $\mathrm{Pfo}-1_{1}, \mathrm{ATP}, \mathrm{Sfp}, \mathrm{CoA}, \mathrm{MgCl}_{2}, \mathrm{NADPH}$, and L-Leu in phosphate buffer $(\mathrm{pH}=6.0,6.5,7.0,7.5$, or 8.0 , top five panels $)$ or in bicine buffer $(\mathrm{pH}=8.5$ or 9.0, bottom two panels). D) Structures of leucinazole and flavacol. E) Production of PZ-1 (left, yellow) and PZ-2 (middle, green) in reactions under different buffering conditions $(P=$ phosphate, $B=$ bicine). Peak area integration from MS analysis is shown. Right (black): percentage of PZ-1 in total amount of PZ1 and PZ-2 produced in each reaction calculated using MS peak area integration. F) Production of leucinazole (left, purple) and flavacol (middle, blue) in reactions under different buffering conditions $(P=$ phosphate, $\mathrm{B}=$ bicine). Peak area integration from MS analysis is shown. Right (black): percentage of 
leucinazole in total amount of leucinazole and flavacol produced in each reaction calculated using MS peak area integration. G) EICs of leucinazole and flavacol $\left([M+H]^{+}=209.1648\right)$ in a full reaction containing PvfC $\mathrm{PfO}-1_{1}, \mathrm{ATP}, \mathrm{Sfp}, \mathrm{CoA}, \mathrm{MgCl}_{2}, \mathrm{NADPH}$, and synthetic flavacol (top) and a control reaction excluding $\mathrm{PvfC}_{\mathrm{PfO}-1}$ from full reaction mixture (bottom). $\mathrm{PvfC}_{\mathrm{Pf0}-1}$ does not convert flavacol to leucinazole. H) UV stability of flavacol over 14 days in water. I) UV stability of leucinazole over 14 days in water.

Reactions were separated using method outlined in "LC-HRMS of in vitro reactions separated on a Hypercarb column" in the main text. Reaction in panel $\mathbf{G}$ was separated using method "LC-HRMS of in vitro reactions separated on a C18 column". 
A
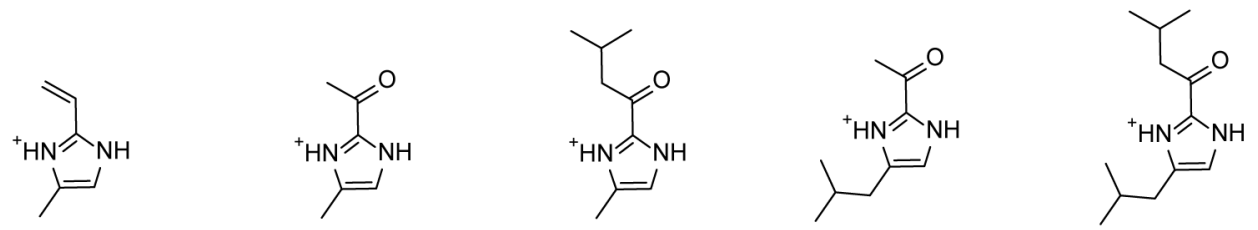

Exact Mass: 109.0760

Exact Mass: 125.0709 Exact Mass: 167.1179

Exact Mass: 167.1179

Exact Mass: 209.1648

B

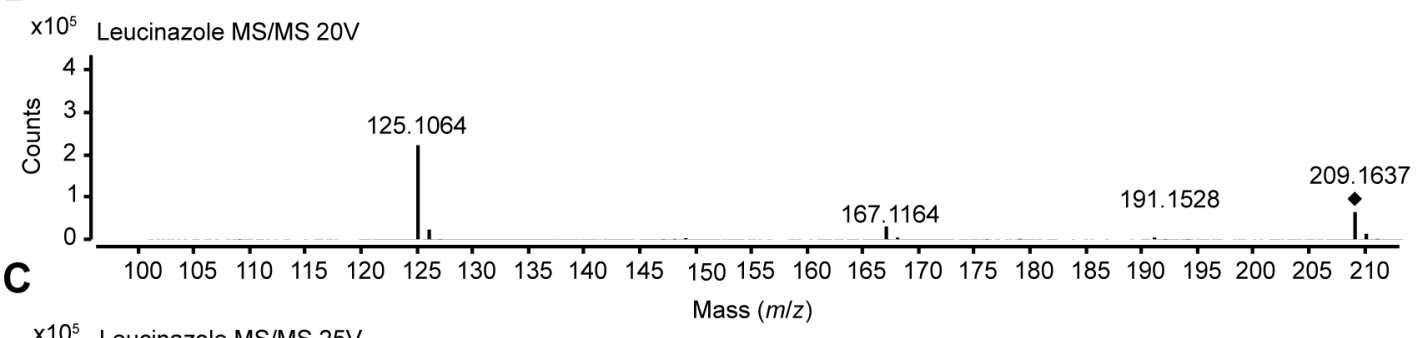

x10 $10^{5}$ Leucinazole MS/MS 25V

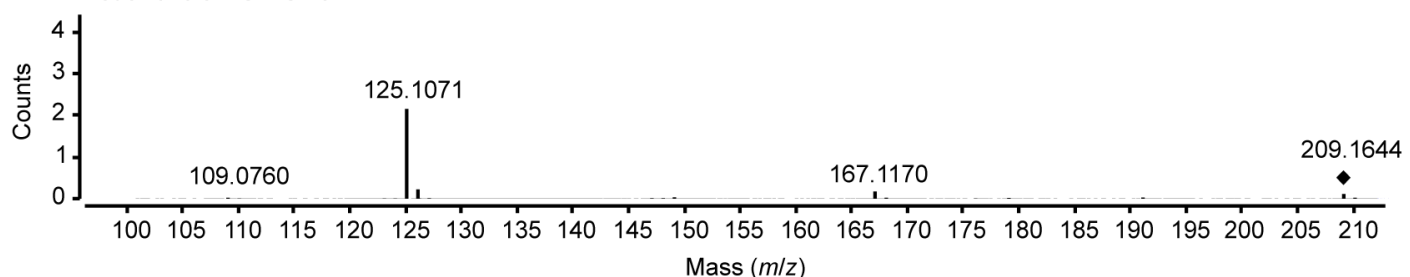

D
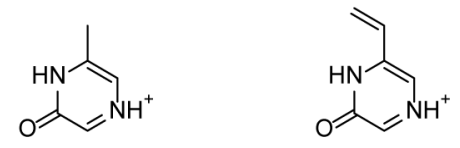

Exact Mass: 111.0553

Exact Mass: 123.0553
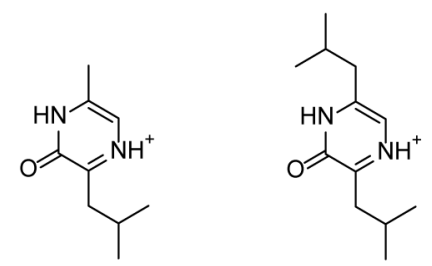

E

x105 Flavacol MS/MS $20 \mathrm{~V}$

$$
\text { F }
$$

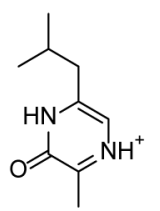

Exact Mass: 167.1179

Exact Mass: 167.1179

Exact Mass: 209.1648

F
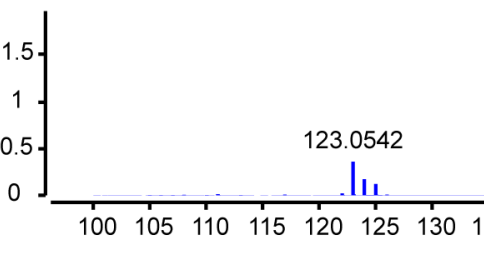

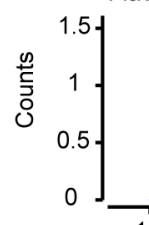

vacol MS/MS 25V

123.0542
IL.

167.1165

209.1635

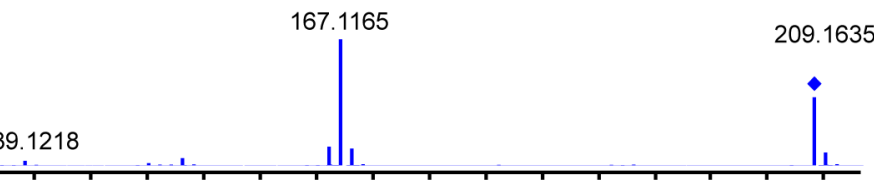

Mass $(\mathrm{m} / \mathrm{z})$

5210

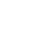

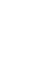


Proposed structures of leucinazole fragments. E) MS/MS spectrum of isolated flavacol with a fragmentor voltage of $20 \mathrm{~V}$. F) MS/MS spectrum of isolated flavacol at a fragmentor voltage of $25 \mathrm{~V}$. 


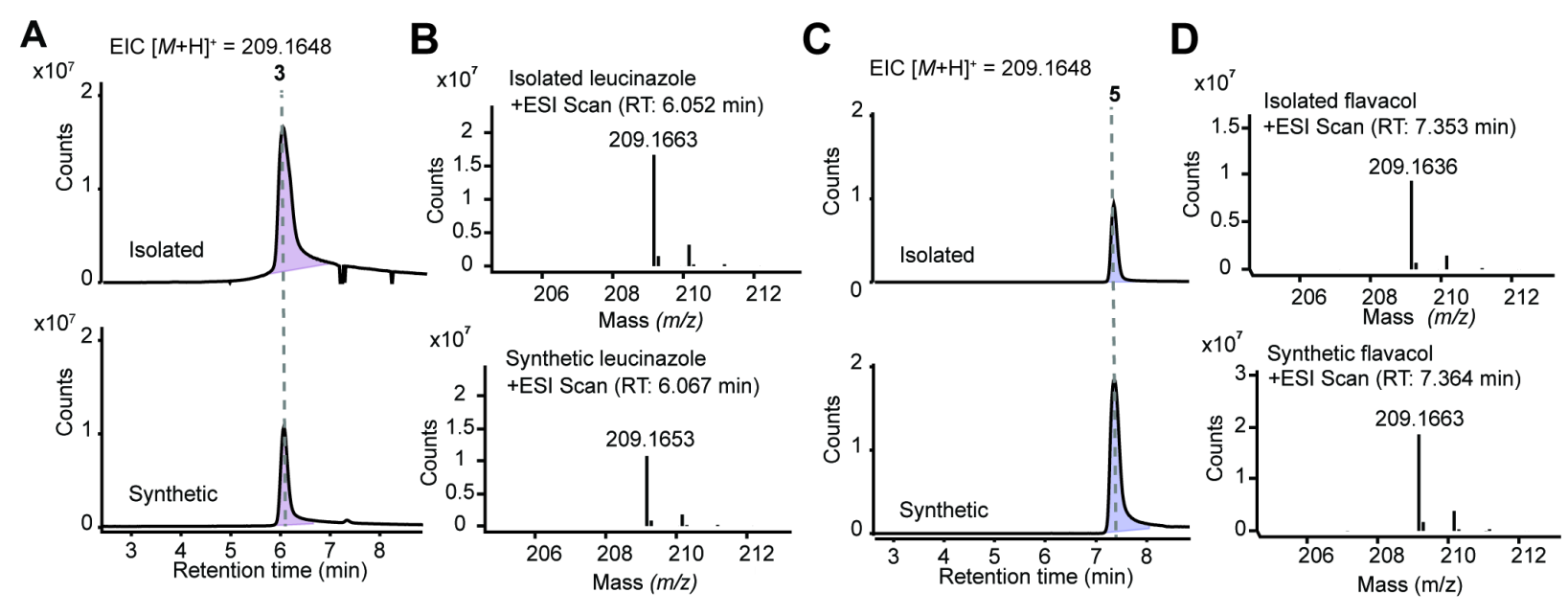

${\text { E } \quad \times 10^{5}}^{\mathrm{EIC}}[M+\mathrm{H}]^{+}=193.1699$

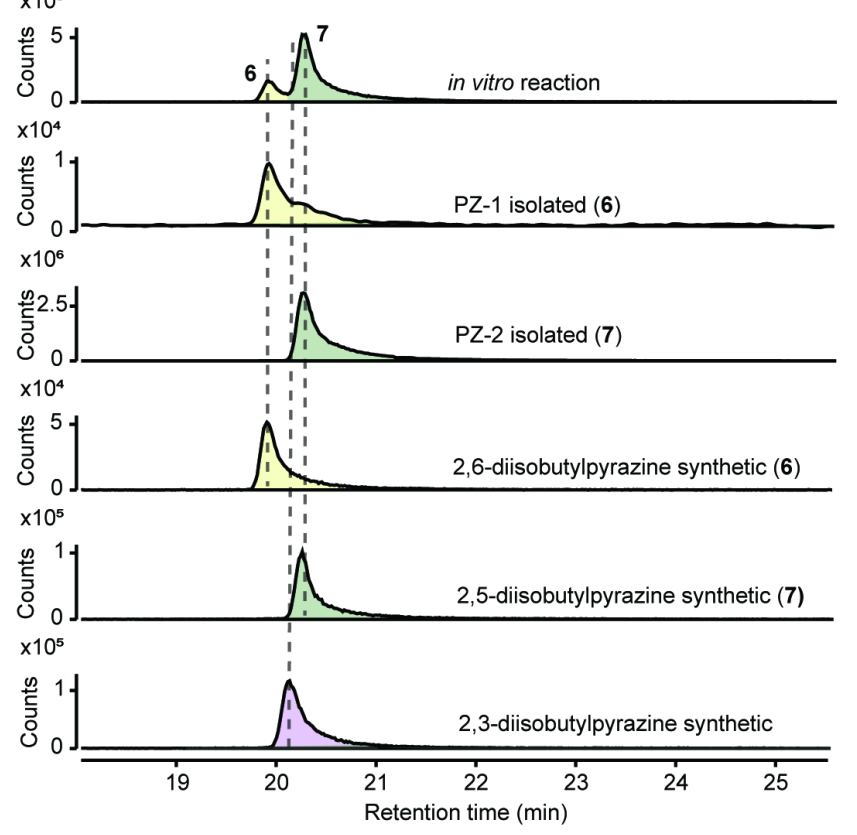

F

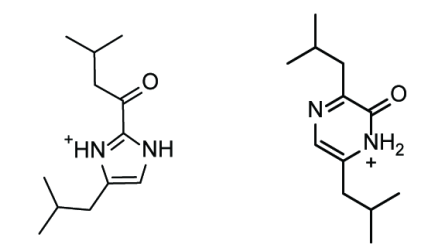

Leucinazole (3) Flavacol (5)

Exact Mass: 209.1648
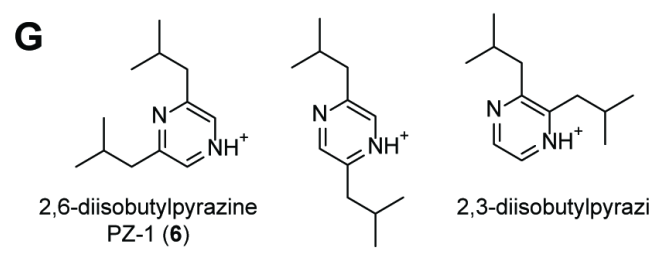

2,5-diisobutylpyrazine

PZ-2 (7)

Exact Mass: 193.1699
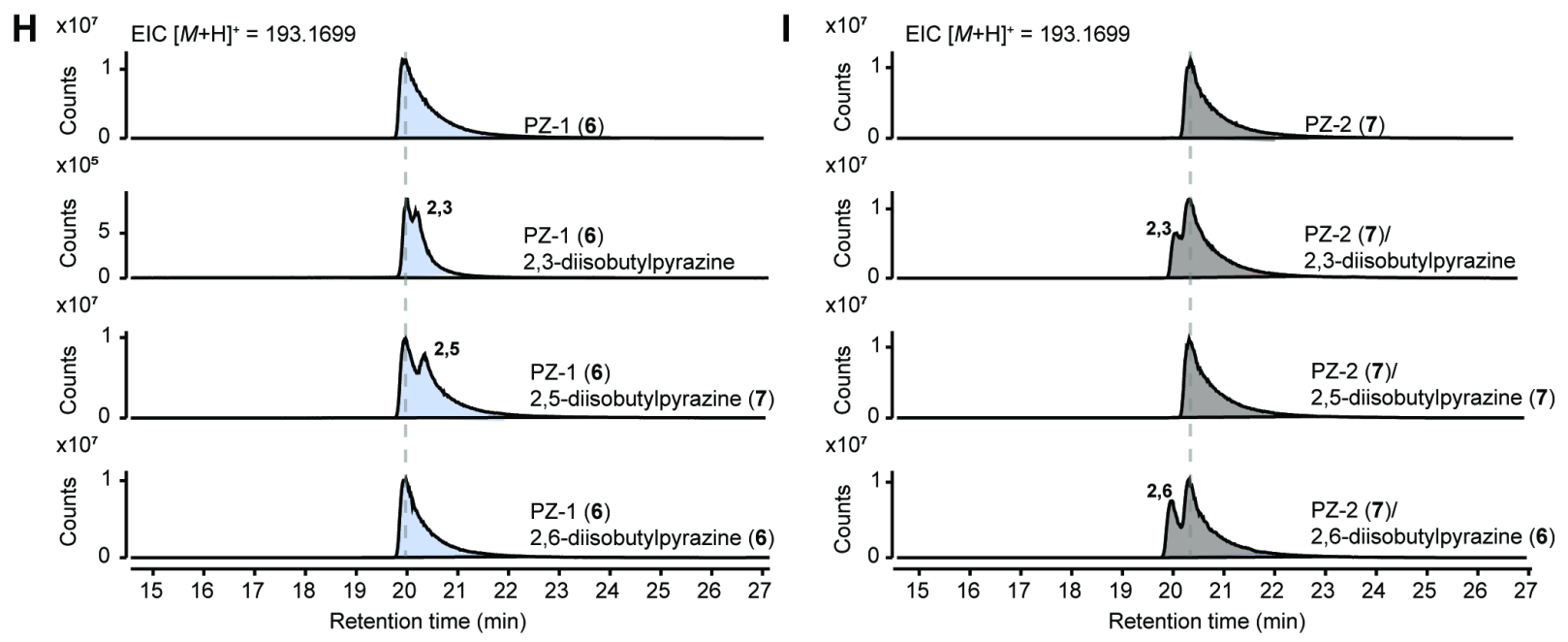
Figure S6. Isolated flavacol, leucinazole, PZ-1, and PZ-2 elute at the same time as their synthetic standards.

\begin{abstract}
A) EICs of leucinazole $\left([M+H]^{+}=209.1648\right)$ in the isolated (top) and synthetic (bottom) samples. B) Mass spectrum of isolated leucinazole (top) and synthetic leucinazole (bottom). C) EICs of flavacol $\left([\mathrm{M}+\mathrm{H}]^{+}=\right.$ 209.1648) in the isolated (top) and synthetic (bottom) samples. D) Mass spectrum of isolated flavacol (top) and synthetic flavacol (bottom). E) EICs of diisobutylpyrazine isomers $\left([M+H]^{+}=193.1699\right)$ in the in vitro PvfC ${ }_{\mathrm{Pfo}-1}$ reaction, isolated PZ-1, isolated PZ-2, synthetic 2,6-diiosbutyl pyrazine, synthetic 2,5diisobutylpyrazine, synthetic 2,3-diisobutylpyrazine (top to bottom). F) Structures of leucinazole (3) and flavacol (5). G) Structures of PZ-1 (2,6-diisobutylpyrazine, 6), PZ-2 (2,5-diisobutylpyrazine, 7), and 2,3diisobutyilpyrazine. $\mathbf{H})$ EICs of diisobutylpyrazine $\left([M+H]^{+}=193.1699\right)$ in samples containing PZ-1, coinjections of PZ-1 and 2,3-diisobutylpyrazine, PZ-1 and 2,5-diisobutylpyrazine, and PZ-1 and 2,6diisobutylpyrazine (top to bottom). I) EICs of diisobutylpyrazine $\left([M+\mathrm{H}]^{+}=193.1699\right)$ in samples containing PZ-2, coinjections of PZ-2 and 2,3-diisobutylpyrazine, PZ-2 and 2,5-diisobutylpyrazine, and PZ-2 and 2,6diisobutylpyrazine (top to bottom).
\end{abstract}

Reactions in panel A--D was separated using method "LC-HRMS of in vitro reactions separated on a C18 column". Reactions in panels E, H, and I were separated using method outlined in "LC-HRMS of in vitro reactions separated on a Hypercarb column" in the main text. 
A

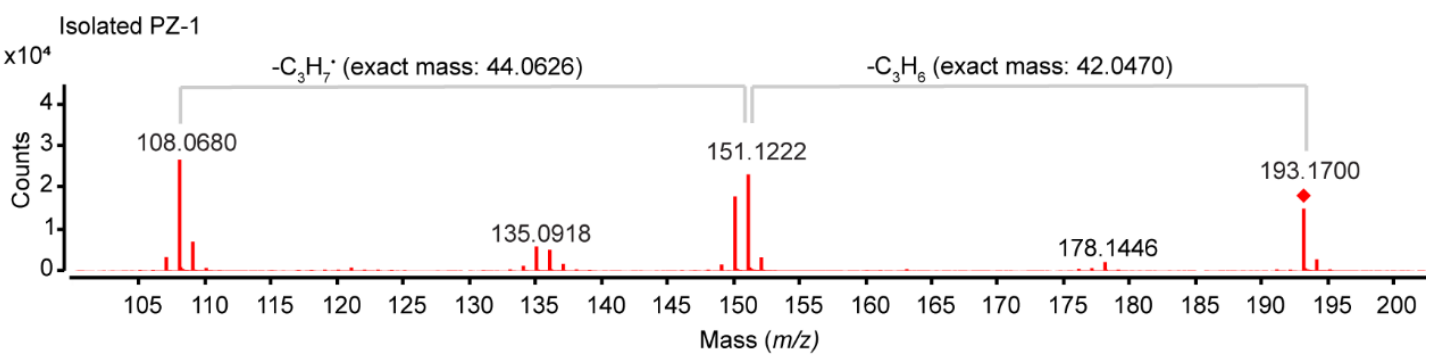

B $\times 10^{4}$ Synthetic 2,6-diisobutylpyrazine

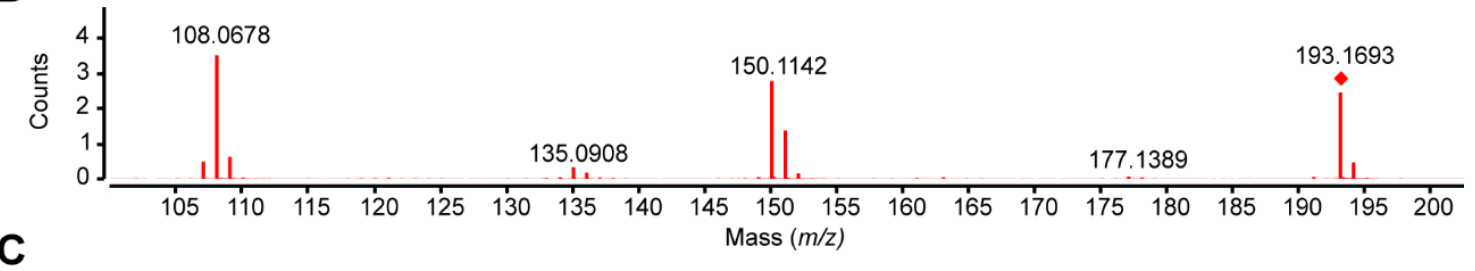

$\times 10^{5}$ Synthetic 2,3-diisobutylpyrazine

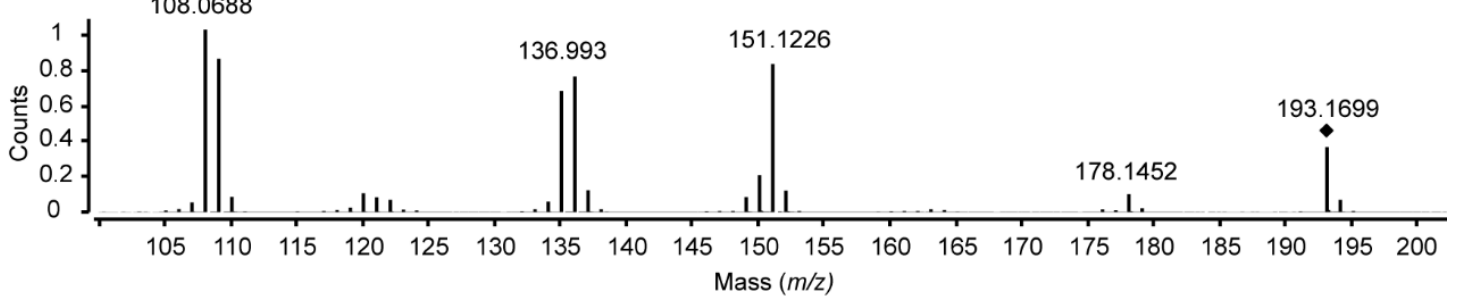

D $_{x 10^{4}}$ Isolated PZ-2

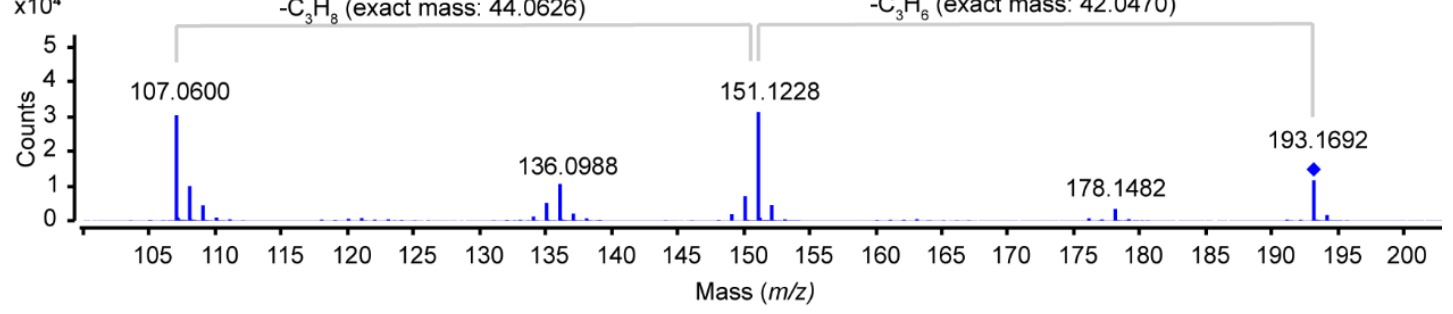

$\mathbf{E}$

x10 Synthetic 2,5-diisobutylpyrazine

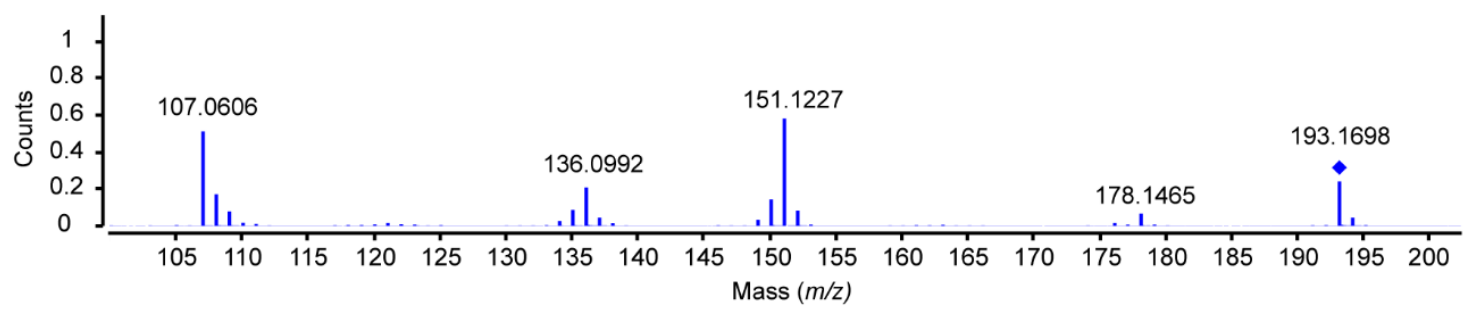

Figure S7. MS fragmentation of isolated PZ-1 and PZ-2 and synthetic 2,6-, 2,3-, and 2,5diisobutylpyrazines.

A) MS/MS spectrum of isolated PZ-1. B) MS/MS spectrum of synthetic 2,6-diisobutylpyrazine. C) MS/MS spectrum of synthetic 2,3-diisobutylpyrazine. D) MS/MS spectrum of isolated PZ-2. E) MS/MS spectrum of synthetic 2,5-diisobutylpyrazine. All MS/MS spectra were obtained at a fragmentor voltage of $25 \mathrm{~V}$. 
A PvfC $_{\text {pfo-1 }}$

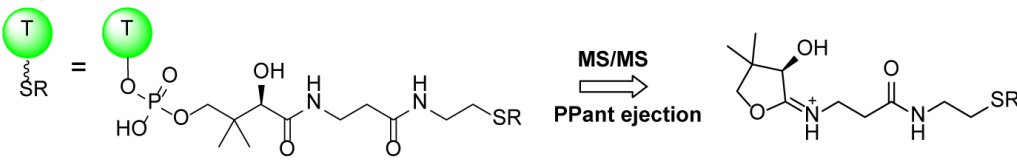

B<smiles>[B]C(C)CC(N)C(=O)SCCNC(=O)CC[NH+]=C1OCC(C)(C)C1O</smiles>

Exact Mass: 374.2108

PPant ejection ion of $\mathrm{PvfC}_{\mathrm{Pf0}-1}-\mathrm{T}$-Leu

D

C $\times 10^{4} \quad \mathrm{MS}^{2} \mathrm{EIC}[M+\mathrm{H}]^{+}=374.2108$
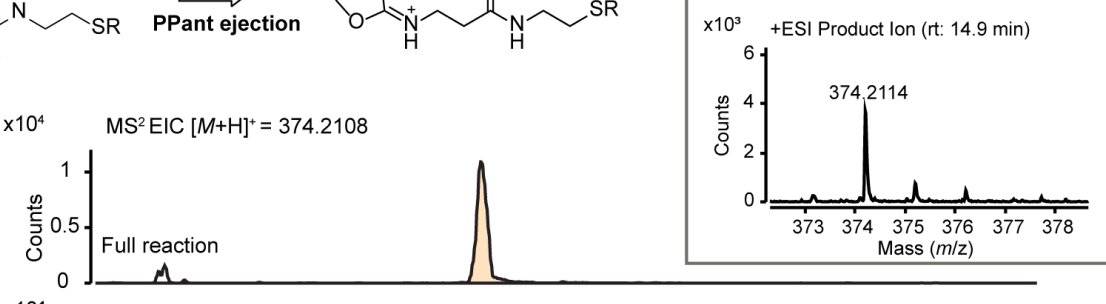

$\times 10^{4}$

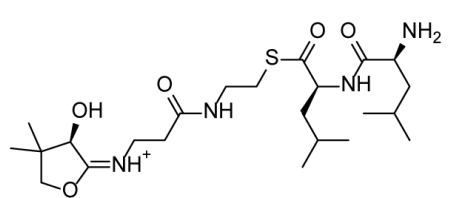

$E$

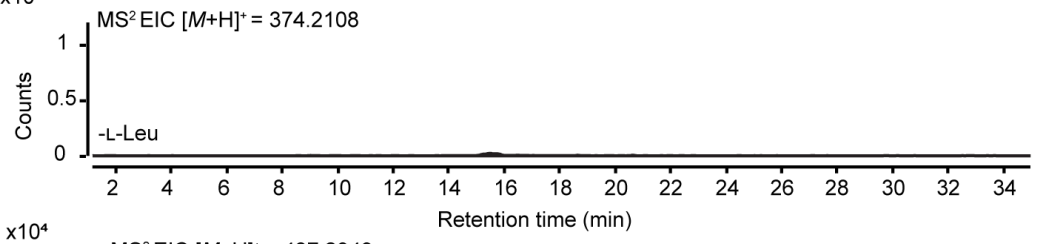

Exact Mass: 487.2949

PPant ejection ion of $\mathrm{PvfC}_{\mathrm{Pf0}-1}-\mathrm{T}$-Leu-Leu

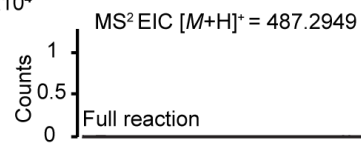

$\times 10^{4}$
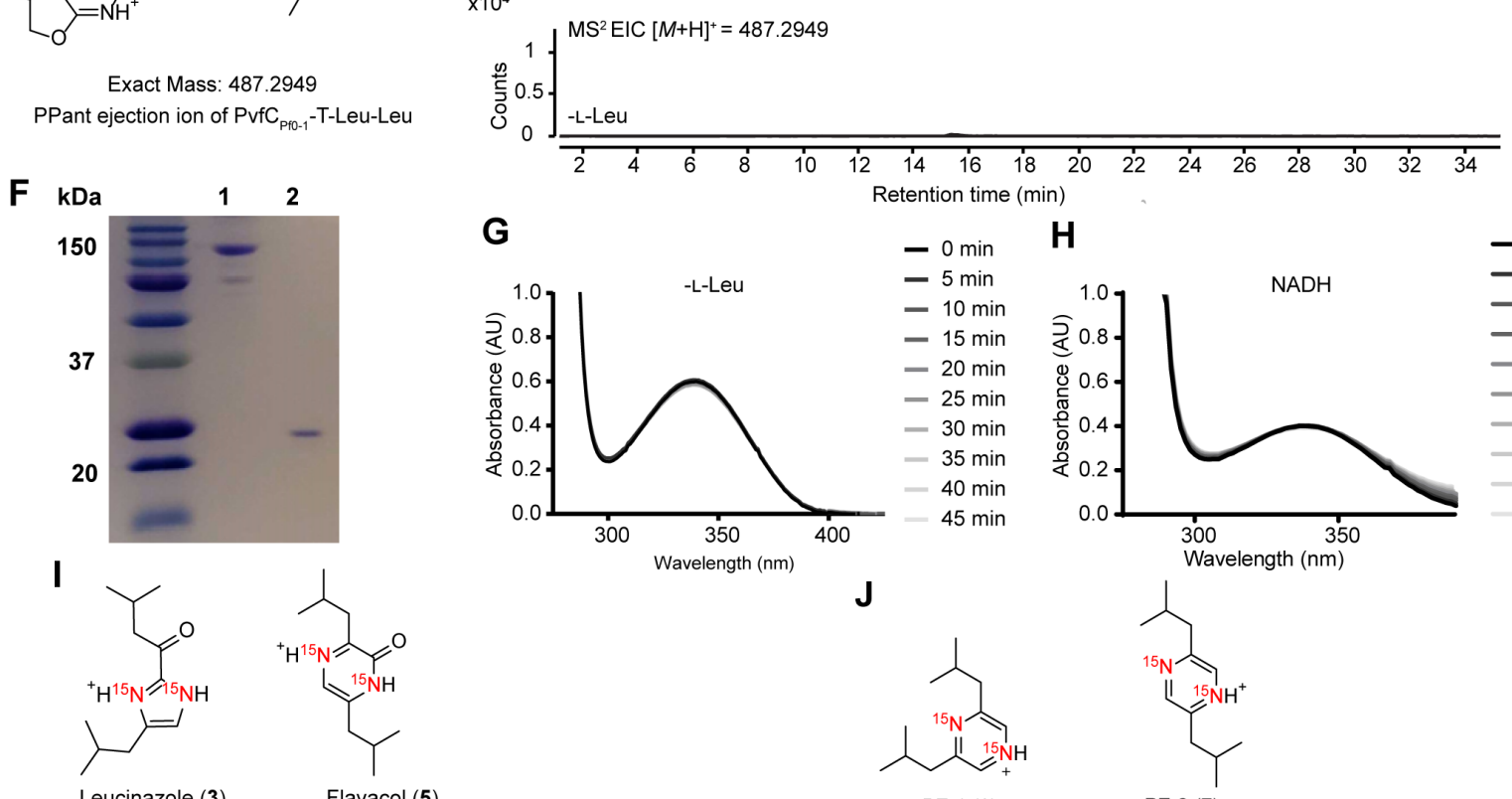

\section{H}
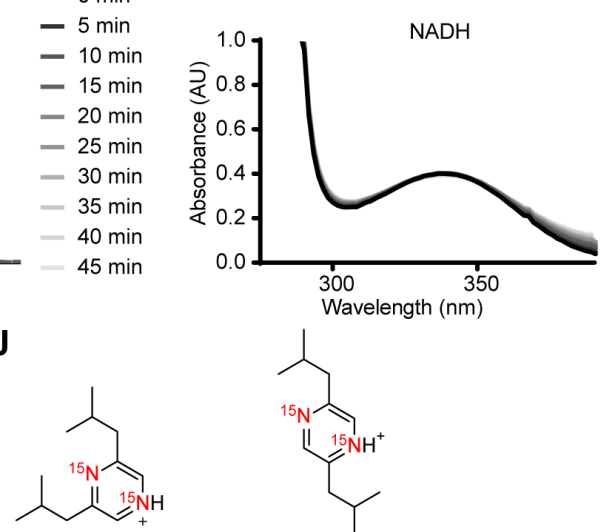

$-0 \mathrm{~min}$

$-5 \mathrm{~min}$

- $10 \mathrm{~min}$

$-15 \mathrm{~min}$

$-20 \mathrm{~min}$

$-25 \mathrm{~min}$

- $30 \mathrm{~min}$

- $35 \mathrm{~min}$

$35 \mathrm{~min}$

$45 \mathrm{~min}$

Leucinazole (3) Exact mass: 211.1589 Exact mass: 211.1589

$\mathrm{PZ}-1$ (6)

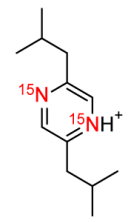

Exact Mass: 195.1640 Exact Mass: 195.1640

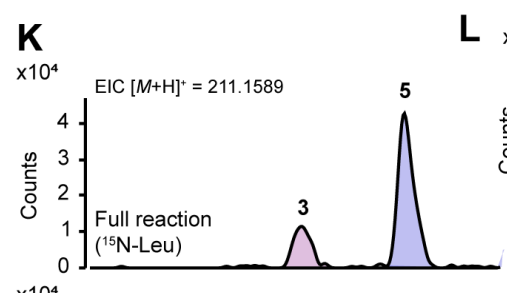

$\times 10^{4} \quad$ Full reaction $\left({ }^{15} \mathrm{~N}\right.$-Leu)

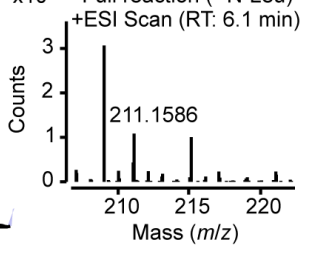

M

$\mathbf{N}$
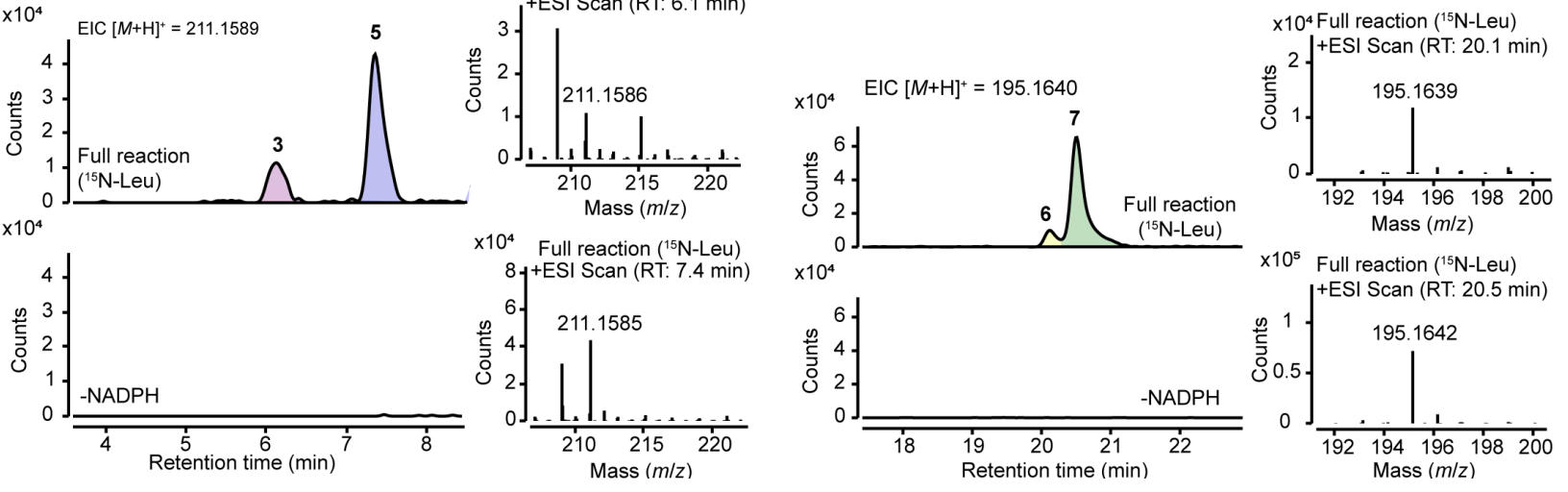
Figure S8. PvfC $\mathrm{Pf0}_{\mathrm{P}-1}$ loads a single leucine on $\mathrm{PvfC}_{\mathrm{Pf0}-1-\mathrm{T}}$ and utilizes an NADPH-dependent reductive release in the biosynthesis of flavacol, leucinazole, PZ-1 and PZ-2.

A) PvfCPf0-1-T was loaded with leucine using full length $\mathrm{PvfC}_{\mathrm{Pf0}-1}$ in trans. MS/MS analysis of leucine-

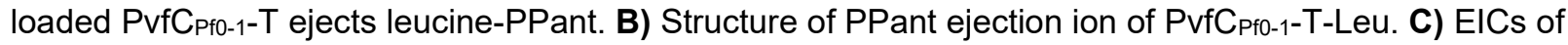
the ion shown in $B\left([M+H]^{+}=374.2108\right.$, mass spectrum shown in inset) from MS/MS analysis of a reaction including PvfC Pfo-1-T, ATP, Sfp, CoA, and L-Leu (top) and the control reaction excluding L-Leu (bottom). D) Structure of PPant ejection ion of PvfC pfo-1-T-Leu-Leu. E) EICs of the ion shown in D ([M+H $]^{+}$ = 487.2949) from MS/MS analysis of a reaction including PvfC Pfo-1-T, ATP, Sfp, CoA, and L-Leu (top) and the control reaction excluding L-Leu (bottom). No Leu-Leu dipeptide was observed on PvfCPf0-1-T. F) SDSPAGE analysis of proteins used in this study. Lane 1, PvfC pf0-1; lane 2, PvfCPf0-1-T. G) UV-vis spectra of

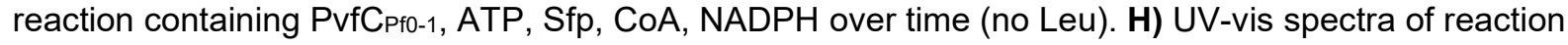
containing PvfC ${ }_{\text {pfo-1 }}$, ATP, L-Leu Sfp, CoA, NADH (instead of NADPH) over time. I) Structures of leucinazole and flavacol with ${ }^{15} \mathrm{~N}-\mathrm{Leu}$ incorporated. J) Structures of PZ-1 and PZ-2 with ${ }^{15} \mathrm{~N}-\mathrm{Leu}$ incorporated. K) EICs of ${ }^{15} \mathrm{~N}$-leucinazole and -flavacol $\left([M+H]^{+}=211.1589\right)$ in reactions containing PvfCpfo-1, ${ }^{15} \mathrm{~N}$-L-Leu, ATP, Sfp, CoA, and $\mathrm{MgCl}_{2}$ in the presence of NADPH (top) or absence of NADPH (bottom). L) Mass spectra of ${ }^{15} \mathrm{~N}$-leucinazole (top) and ${ }^{15} \mathrm{~N}$-flavacol (bottom) in the top reaction in K). M) EICs of ${ }^{15} \mathrm{~N}-\mathrm{PZ}-1$ and $-\mathrm{PZ}-2\left([\mathrm{M+H}]^{+}=195.1640\right)$ in a reaction including PvfC ${ }_{\mathrm{pfo}-1}, \mathrm{ATP}, \mathrm{Sfp}, \mathrm{CoA}, \mathrm{MgCl}_{2}$, $\mathrm{NADPH}$, and ${ }^{15}-\mathrm{N}-\mathrm{L}-\mathrm{Leu}$ (top), and a control reaction excluding NADPH (bottom). N) Mass spectra of ${ }^{15} \mathrm{~N}-$ $\mathrm{PZ}-1$ (top) and ${ }^{15} \mathrm{~N}-\mathrm{PZ}-2$ (bottom) in the top reaction in $\mathrm{M}$ ).

Reactions in panels B-E were separated using method "LC-HRMS analysis of L-leucine loading of

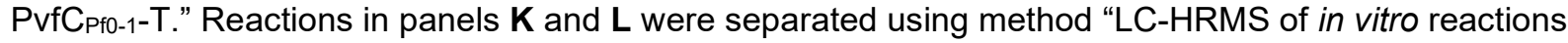
separated on a C18 column." Reactions in panels $\mathbf{M}$ and $\mathbf{N}$ were separated using method outlined in "LCHRMS of in vitro reactions separated on a Hypercarb column" in the main text. 
A
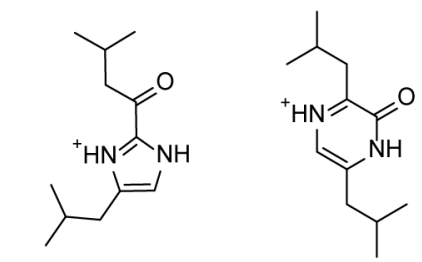

Flavacol (5)

Leucinazole (3)

Exact Mass: 209.1648 Exact Mass: 209.1648

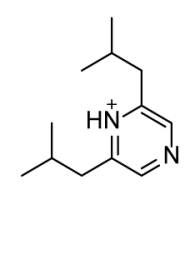

PZ-1 (6)

Exact Mass: 193.1699 Exact Mass: 193.1699

$\begin{array}{ll}\text { B Hypercarb column } \\ \times 10^{5} & \text { Combined EIC }[M+H]^{+}=193.1699,209.1648\end{array}$

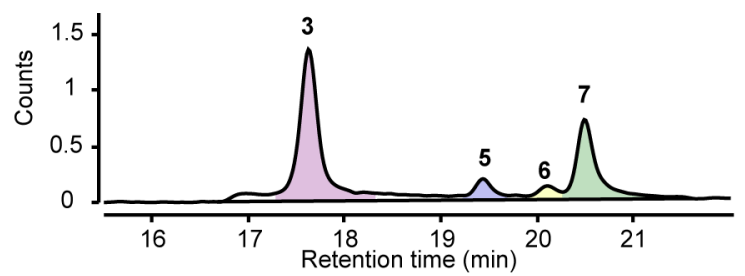

C C18 column

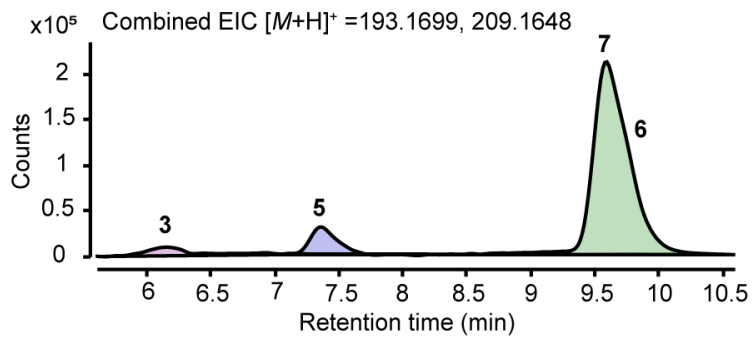

Figure S9. Elution profile of leucinazole, flavacol, PZ-1, PZ-2 in $\mathrm{PvfC}_{\mathrm{Pf0}-1}$ in vitro reaction changes based on the column used for separation.

A) Structures of leucinazole (3), flavacol (5), PZ-1 (6) and PZ-7 (7). B\&C) Combined EICs of leucinazole and flavacol $\left([\mathrm{M}+\mathrm{H}]^{+}=209.1648\right)$, and PZ-1 and PZ-2 $\left([M+\mathrm{H}]^{+}=193.1699\right)$ in an in vitro reaction containing all assay components separated on B) a Hypercarb column or C) a C18 column.

Reaction in panel B was separated using method outlined in "LC-HRMS of in vitro reactions separated on a Hypercarb column" in the main text. Reaction in panel $\mathbf{C}$ was separated using method "LC-HRMS of in vitro reactions separated on a C18 column." 
A

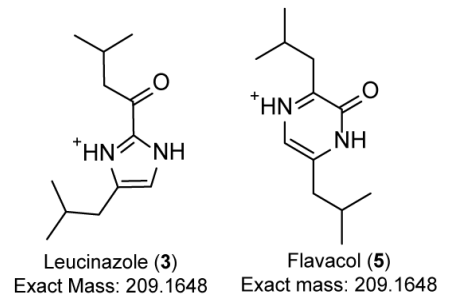

B
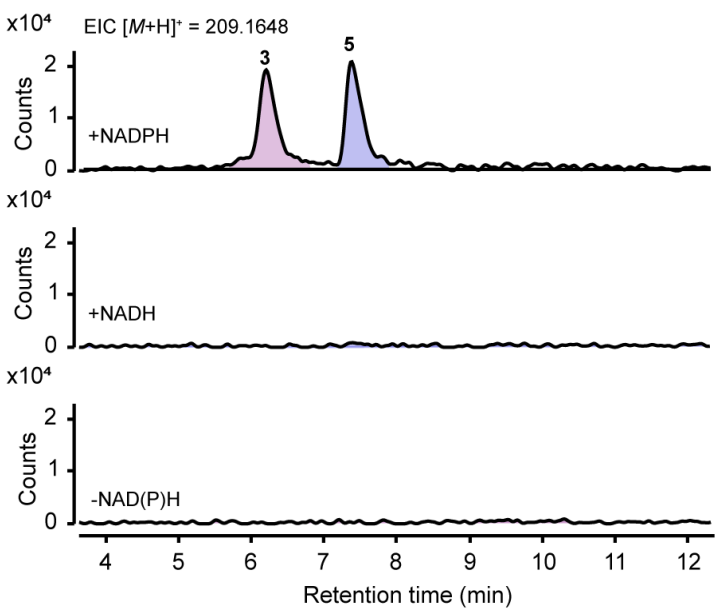

C $+\mathrm{NADPH}$

$\times 10^{4}+$ ESI Scan (RT: $\left.6.2 \mathrm{~min}\right)$

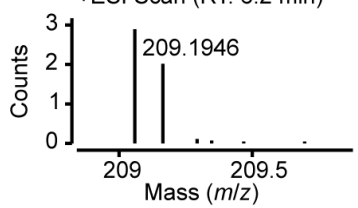

D $+\mathrm{NADPH}$

$\mathrm{x} 10^{4}+\mathrm{ESI} \mathrm{Scan}(\mathrm{RT}: \mathrm{7} .3 \mathrm{~min})$

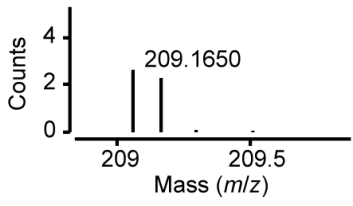

Figure S10. Leucinazole and flavacol are only produced by $\mathrm{PvfC}_{\mathrm{Pf0}-1}$ in the presence of NADPH.

A) Structures of leucinazole (3) and flavacol (5). B) EICs of leucinazole and flavacol $\left([M+\mathrm{H}]^{+}=209.1648\right)$

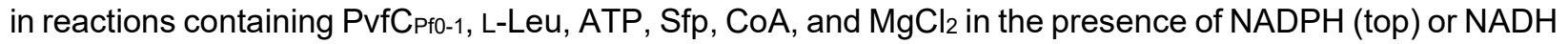
(middle), or in the absence of either NADPH or NADH (bottom). C) Mass spectrum of leucinazole in the top reaction in $\mathbf{B}$ ). D) Mass spectrum of flavacol in the top reaction in $\mathbf{B}$ ).

Reactions were separated using method "LC-HRMS of in vitro reactions separated on a C18 column."

A

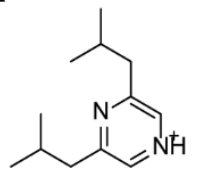

PZ-1 (6) Exact Mass: 193.1699

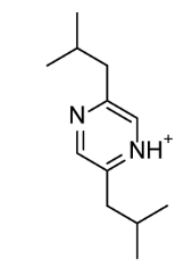

PZ-2 (7)

Exact Mass: 193.1699

\section{B}

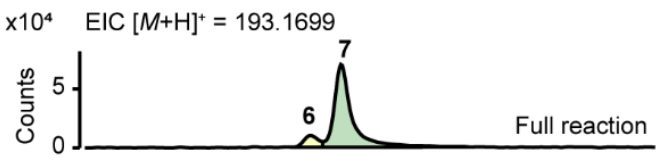

$\mathrm{x} 10^{4}$

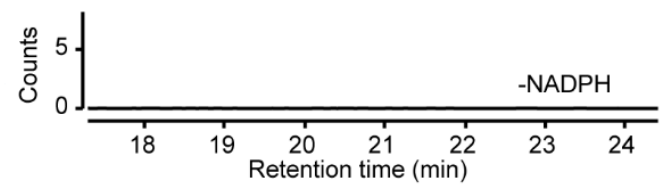

D

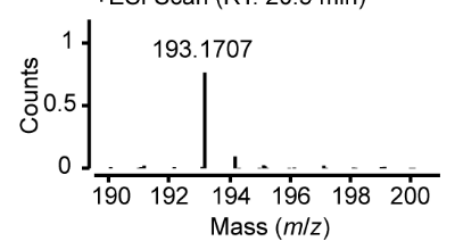

\section{Figure S11. $\mathrm{PvfC}_{\mathrm{Pf0}-1}$ produces both PZ-1 (6) and PZ-2 (7) in vitro.}

A) Structures of PZ-1 and PZ-2. B) EICs of PZ-1 and PZ-2 $\left([M+H]^{+}=193.1699\right)$ in a reaction including $\mathrm{PvfC}_{\mathrm{Pf0}-1}, \mathrm{ATP}, \mathrm{Sfp}, \mathrm{CoA}, \mathrm{MgCl}_{2}, \mathrm{NADPH}$, and L-Leu (top), and a control reaction excluding NADPH (bottom). C) Mass spectrum of PZ-1 in a reaction containing PvfC $\mathrm{Pfo}_{-1}, \mathrm{ATP}, \mathrm{Sfp}, \mathrm{CoA}, \mathrm{MgCl}_{2}, \mathrm{NADPH}$, 
and L-Leu. D) Mass spectrum of PZ-2 in a reaction containing $\mathrm{PvfC}_{\mathrm{Pf0}-1}, \mathrm{ATP}, \mathrm{Sfp}, \mathrm{CoA}, \mathrm{MgCl}_{2}, \mathrm{NADPH}$, and L-Leu. Reaction was separated on a Hypercarb column

Reactions were separated using method outlined in "LC-HRMS of in vitro reactions separated on a Hypercarb column" in the main text.

A

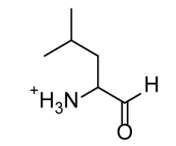

Exact Mass: 116.1070

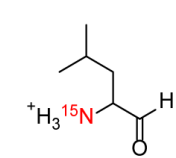

Exact Mass: 117.1040
E

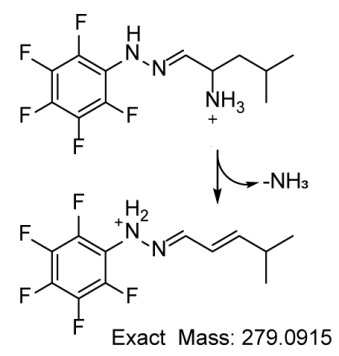

F L-Leu + PFPH

$\times 10^{6}+$ ESI Scan (RT: $5.95 \mathrm{~min}$ )

$\begin{array}{ll}\mathrm{B} 10^{4} & \text { L-Leu -PFPH } \\ & \text { +ESI Scan (RT: } 0.43 \mathrm{~min})\end{array}$

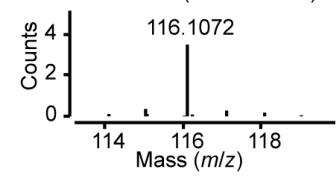

$\mathbf{C}_{\mathrm{x} 10^{4}} \quad \mathrm{EIC}[M+\mathrm{H}]^{+}=116.1070$

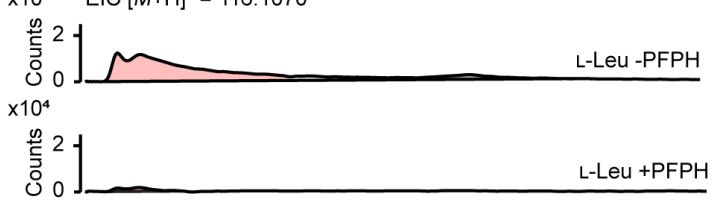

$\times 10^{4}$

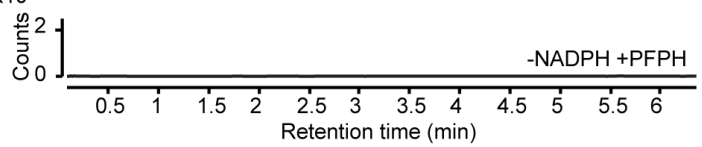

D $\times 10^{4} \quad \mathrm{EIC}[M+H]^{+}=117.1040$

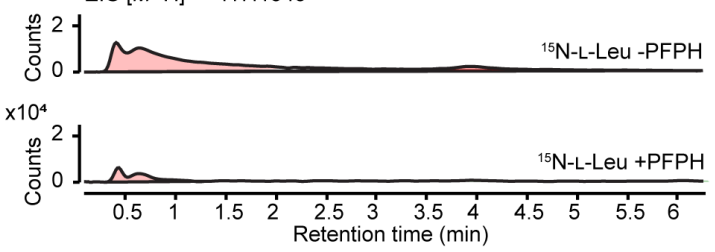

I

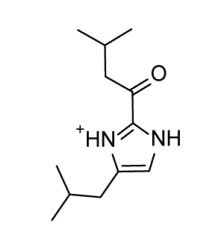

Leucinazole (3) Exact Mass: 209.1648 Exact Mass: 209.1648
Flavacol (5)
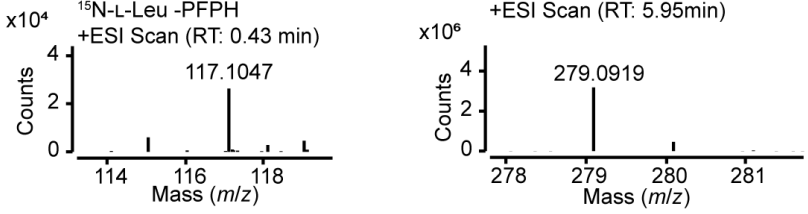

$\mathbf{G}_{\times 10^{6}}$

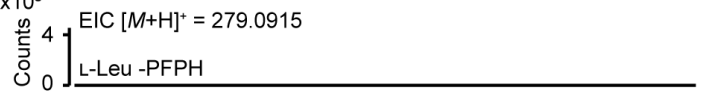

$\mathrm{x} 10^{6}$

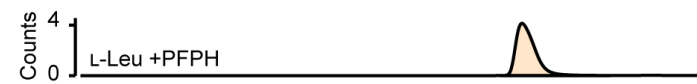

$\mathrm{x} 10^{6}$

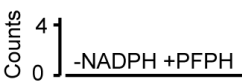

$\begin{array}{llcccccc}1 & 2 & 3 & 4 & 5 & 6 & 7 & 8 \\ \end{array}$

$\mathbf{H}_{\times 10^{\circ}}$

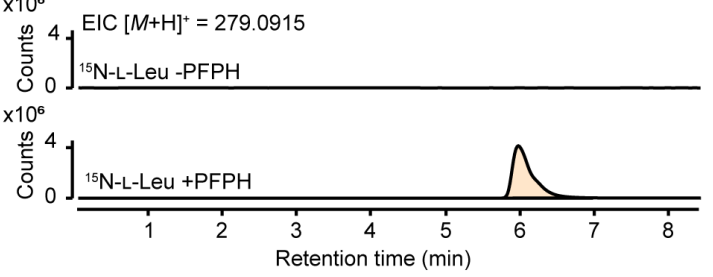

J $\times 10^{4}$ EIC $[M+H]^{+}=209.1648$

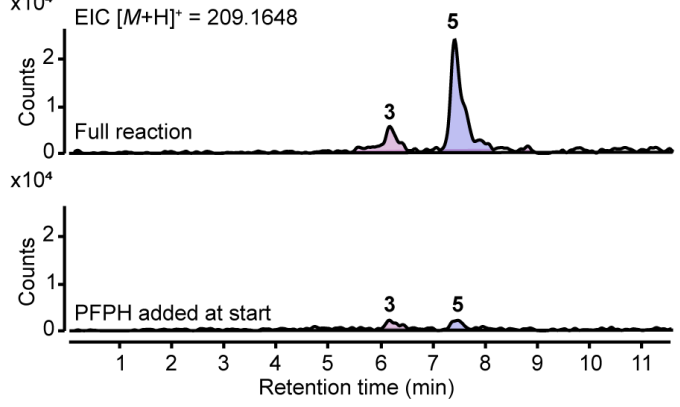

Figure S12. Leu-aldehyde is released by $\mathrm{PvfC}_{\mathrm{Pf0}-1}$ and derivatized by pentafluorophenylhydrazine (PFPH). 
A) Structures of Leu-aldehyde and ${ }^{15} \mathrm{~N}$-Leu-aldehyde. B) Mass spectrum of Leu-aldehyde (left) or ${ }^{15} \mathrm{~N}$ Leu-aldehyde (right) in a reaction containing PvfC $\mathrm{Pf0}_{-1}, \mathrm{ATP}, \mathrm{Sfp}, \mathrm{CoA}, \mathrm{MgCl}_{2}, \mathrm{NADPH}$, and L-Leu (left) or ${ }^{15} \mathrm{~N}-\mathrm{L}-\mathrm{Leu}$ (right). C) EIC of Leu-aldehyde $\left([\mathrm{M}+\mathrm{H}]^{+}=116.1070\right)$ in a full reaction by $\mathrm{PvfC}_{\mathrm{Pfo}-1}$ with L-Leu

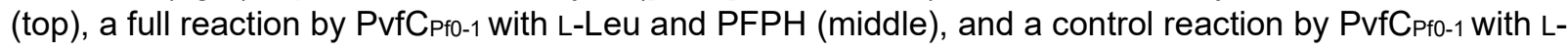
Leu and PFPH and but no NADPH (bottom). D) EIC of ${ }^{15} \mathrm{~N}$-Leu-aldehyde $\left([M+\mathrm{H}]^{+}=117.1040\right)$ in a full reaction with ${ }^{15} \mathrm{~N}$-L-Leu (top) and a full reaction with ${ }^{15} \mathrm{~N}$-L-Leu and PFPH (bottom). E) Structures of PFPH-derivatized Leu-aldehyde (left) and ${ }^{15} \mathrm{~N}$-Leu-aldehyde (right). F) Mass spectrum of PFPHderivatized Leu-aldehyde (left) or ${ }^{15} \mathrm{~N}$-Leu-aldehyde (right) in a reaction with PvfC Pfo-1, ATP, Sfp, CoA, $\mathrm{MgCl}_{2}, \mathrm{NADPH}$, and L-Leu (left) or ${ }^{15} \mathrm{~N}$-L-Leu (right). G) EICs of PFPH-derivatized Leu-aldehyde with loss of $\mathrm{NH}_{3}\left([\mathrm{M}+\mathrm{H}]^{+}=279.0915\right)$ in a full reaction by PvfC $\mathrm{Pf0}-1$ with L-Leu (top), a full reaction with L-Leu and PFPH (middle), and a control reaction with L-Leu and PFPH but no NADPH (bottom). H) EICs of PFPHderivatized ${ }^{15} \mathrm{~N}$-Leu-aldehyde with loss of $\mathrm{NH}_{3}\left([\mathrm{M}+\mathrm{H}]^{+}=279.0915\right)$ in a full reaction by $\mathrm{PvfC}_{\mathrm{Pfo}-1}$ with ${ }^{15} \mathrm{~N}-$ L-Leu (top) and a full reaction with ${ }^{15} \mathrm{~N}-\mathrm{L}-$ Leu and PFPH (bottom). I) Structures of leucinazole and flavacol. J) EICs of leucinazole and flavacol $\left([\mathrm{M}+\mathrm{H}]^{+}=209.1648\right)$ in a reaction containing $\mathrm{PvfC}_{\mathrm{PfO}-1},{ }^{15} \mathrm{~N}-\mathrm{L}-\mathrm{Leu}$, NADPH and all assay components with no PFPH added (top) and a full reaction with PFPH added at the beginning of the reaction (bottom). Reactions were separated using method "LC-HRMS of in vitro reactions separated on a C18 column".

A

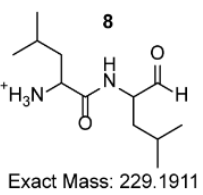

B $10^{4} \quad$ L-Leu - PFPH
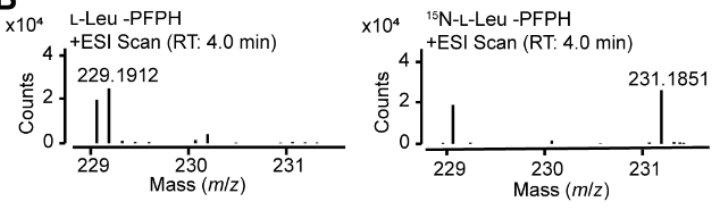

C

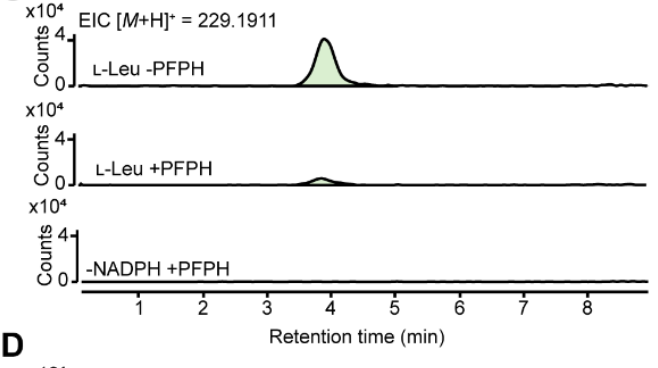

D

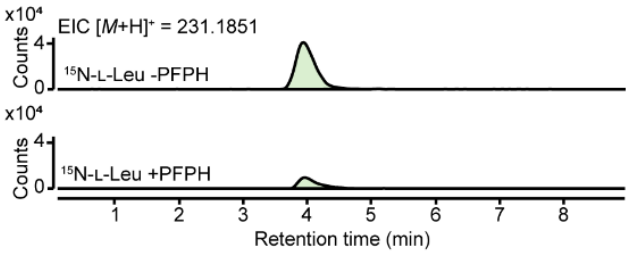

E

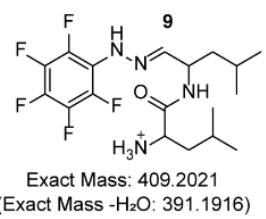

F L-Leu +PFPH

$\times 10^{4} \quad+$ ESI Scan (RT: $7.4 \mathrm{~min}$ )

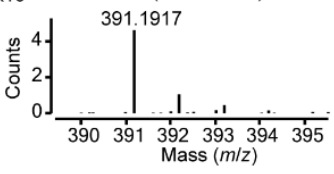

G

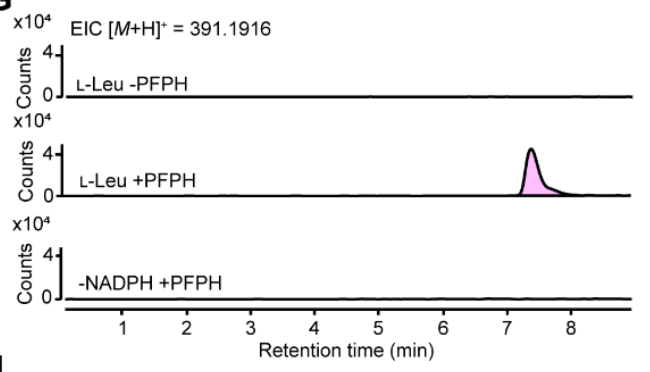

H

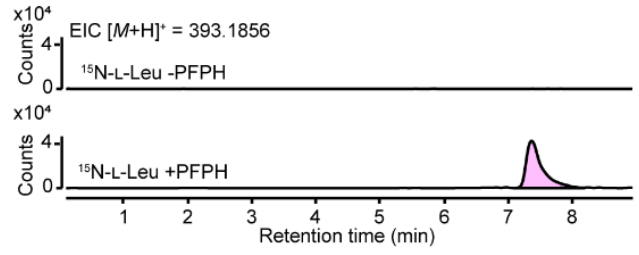

Figure S13. Leu-Leu-aldehyde (8) is released by $\mathrm{PvfC}_{\mathrm{Pf0}-1}$ and derivatized by PFPH. 
A) Structures of Leu-Leu-aldehyde (left) and ${ }^{15} \mathrm{~N}$-Leu-Leu-aldehyde (right). B) Mass spectrum of Leu-Leu aldehyde (left) or ${ }^{15} \mathrm{~N}$-Leu-Leu-aldehyde (right) in a reaction with PvfC ${ }_{\mathrm{pfo}-1}, \mathrm{ATP}, \operatorname{Sfp}, \mathrm{CoA}, \mathrm{MgCl}_{2}$, NADPH, and L-Leu (left) or ${ }^{15} \mathrm{~N}-\mathrm{L}-L e u$ (right). C) EIC of Leu-Leu-aldehyde $\left([M+\mathrm{H}]^{+}=229.1911\right)$ in a full

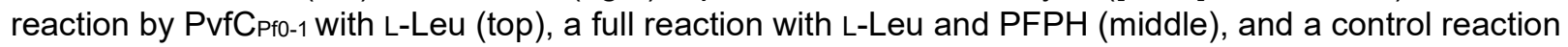
with L-Leu and PFPH but no NADPH (bottom). D) EIC of ${ }^{15} \mathrm{~N}$-Leu-Leu-aldehyde $\left([M+H]^{+}=231.1851\right)$ in a full reaction by $\mathrm{PvfC}_{\mathrm{Pf0}-1}$ with ${ }^{15} \mathrm{~N}$-L-Leu (top) and a full reaction with ${ }^{15} \mathrm{~N}-\mathrm{L}-\mathrm{Leu}$ and PFPH (bottom). E) Structures of PFPH-derivatized Leu-Leu-aldehyde (left) and ${ }^{15} \mathrm{~N}$-Leu-Leu-aldehyde (right). F) Mass spectrum of PFPH-derivatized Leu-Leu-aldehyde (left) or ${ }^{15} \mathrm{~N}$-Leu-Leu-aldehyde (right) in a reaction with PvfC ${ }_{P f 0-1}, A T P, S f p, C o A, M C_{2}, \mathrm{NADPH}$, and L-Leu (left) or ${ }^{15} \mathrm{~N}$-L-Leu (right). G) EIC of PFPH-derivatized Leu-Leu-aldehyde with loss of $\mathrm{H}_{2} \mathrm{O}\left([\mathrm{M}+\mathrm{H}]^{+}=391.1916\right)$ in a full reaction by PvfC Pf0-1 with L-Leu (top), a full reaction with L-Leu and PFPH (middle), and a control reaction with L-Leu and PFPH but no NADPH (bottom). H) EIC of PFPH-derivatized ${ }^{15} \mathrm{~N}$-Leu-Leu-aldehyde with loss of $\mathrm{H}_{2} \mathrm{O}\left([\mathrm{M}+\mathrm{H}]^{+}=393.1856\right)$ in a full reaction by PvfC Pfo-1 with ${ }^{15} \mathrm{~N}$-L-Leu (top) and a full reaction with ${ }^{15} \mathrm{~N}$-L-Leu and PFPH (bottom). Reactions were separated using method "LC-HRMS of in vitro reactions separated on a C18 column."

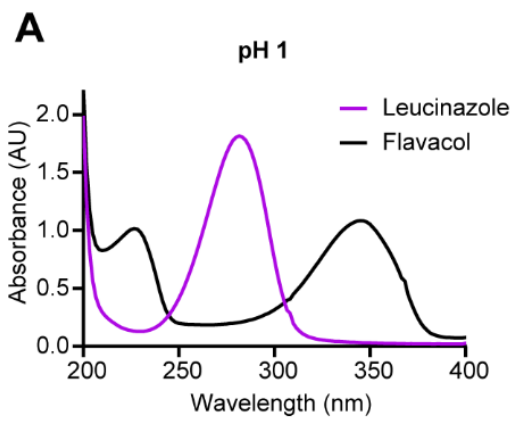

B

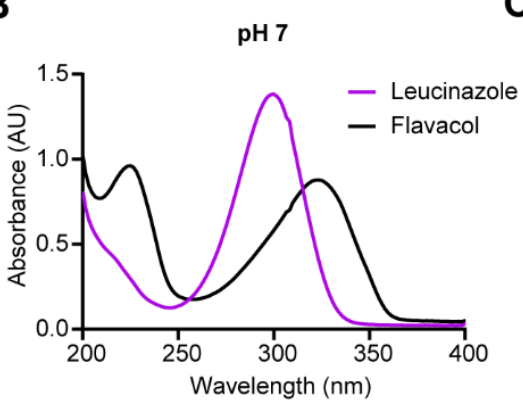

C

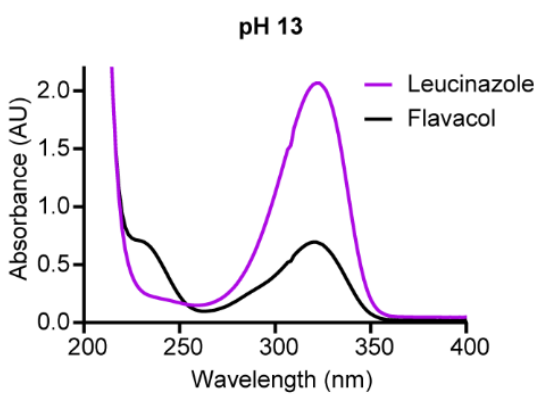

D
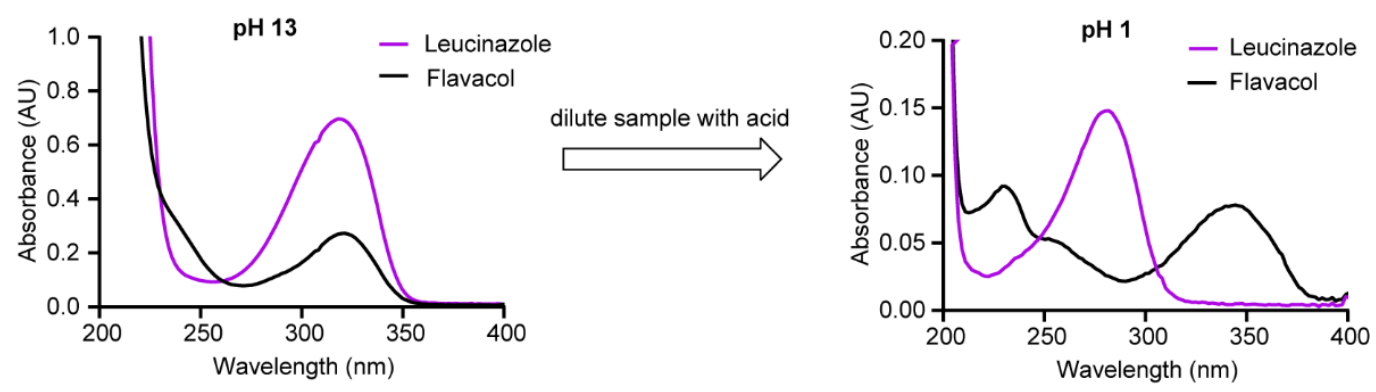

E $\quad x 10^{7}$ Total ion chromatogram of flavacol treated at $\mathrm{pH} 13$

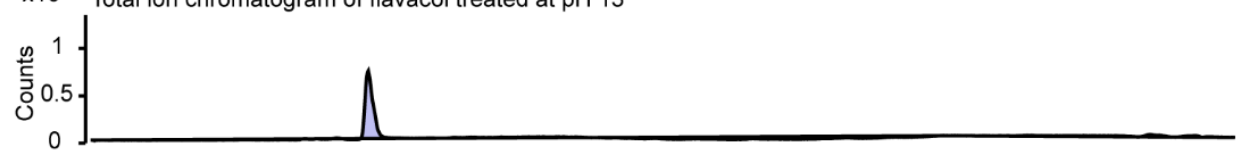

$\mathrm{x} 10^{7}$ Total ion chromatogram of leucinazole treated at $\mathrm{pH} 13$

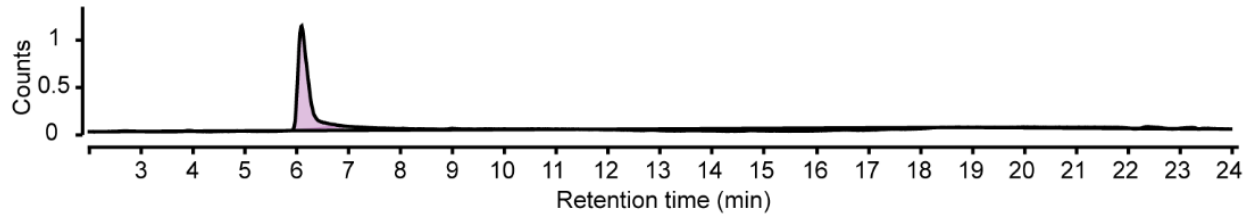

Figure S14. $\lambda_{\max }$ of flavacol and leucinazole changes at different pHs. 
UV spectra of flavacol (black) and leucinazole (purple) in aqueous solution at a $\mathrm{pH}$ of A) 1, B) 7, C) and 13. D) $\mathrm{pH} 13$ sample diluted with sample until a pH 1. E) Total ion chromatograms of flavacol (top, blue) and leucinazole (bottom, purple) after treatment at $\mathrm{pH}=13$. 


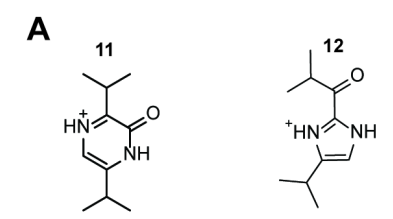

Exact Mass: 181.1335 Exact Mass: 181.1335

D

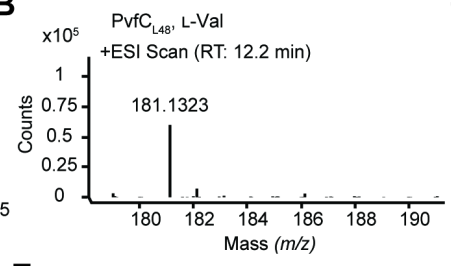<smiles></smiles>

Exact Mass: 165.1386

13 and 14

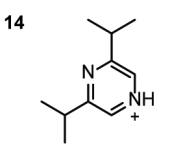

E

E ${ }_{x 10^{4}} \quad$ PvfC $_{\text {L48 }}$, L-Val

x10 $\quad+$ ESI Scan (RT: $10.2 \mathrm{~min}$ )

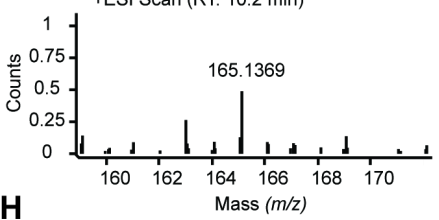

H

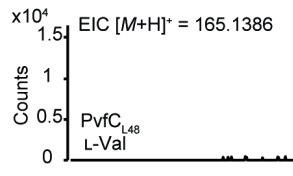

$\mathbf{x}_{10^{4}}$ EIC $[M+H]^{+}=181.1335$

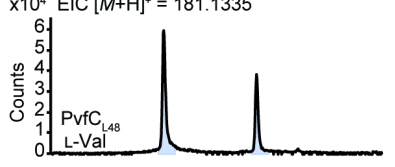

$\times 10^{4}$
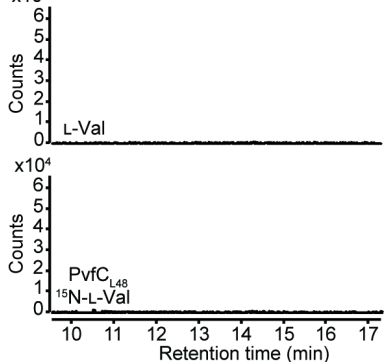

I

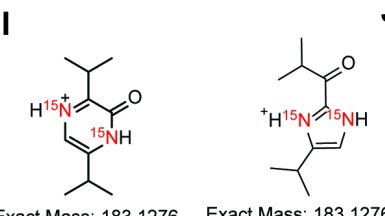

C ${ }_{\times 10^{4}} \mathrm{PvfC}_{\mathrm{L} 48}, \mathrm{~L}$-Val

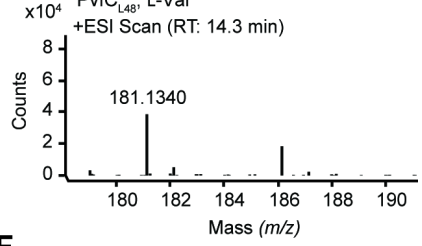

F $\quad \mathrm{PvfC}_{\mathrm{L} 48}, \mathrm{~L}-\mathrm{Val}$

$\mathrm{x} 10^{4}+\mathrm{ESI}$ Scan (RT: $18.2 \mathrm{~min}$ )

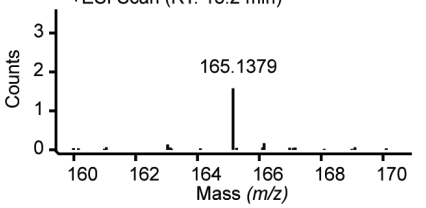
Mass $(\mathrm{m} / \mathrm{z})$
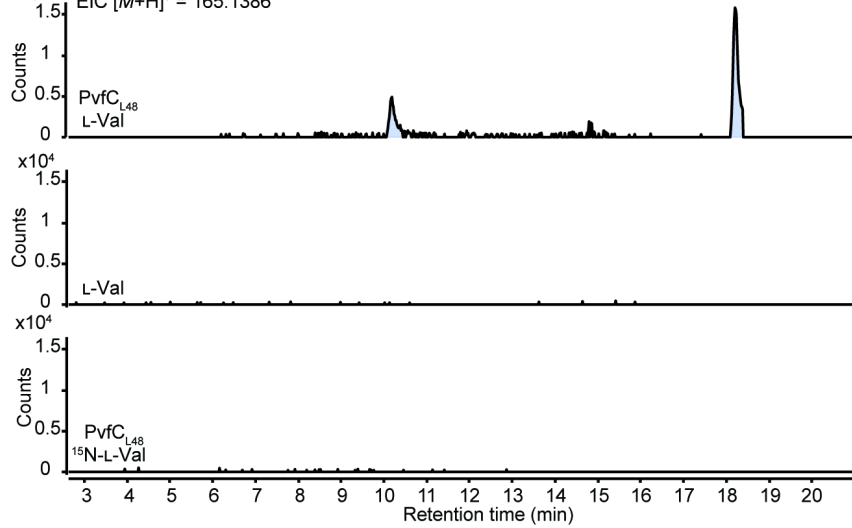

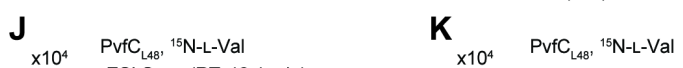

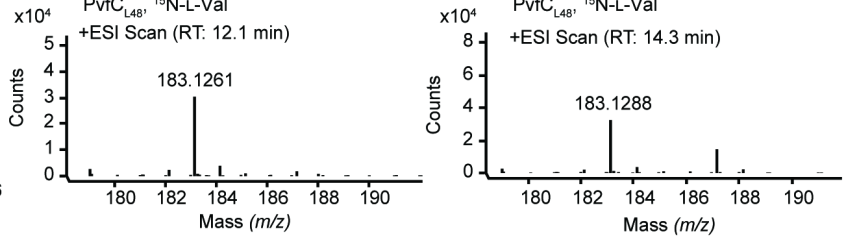

$\mathbf{L}$

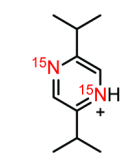

Exact Mass: $167.1327 \quad$ Exact Mass: 167.1327

M PvfC $1{ }^{15} \mathrm{~N}-\mathrm{L}-\mathrm{Val}$

N $\quad \mathrm{PvfC}_{\mathrm{L} 48},{ }^{15} \mathrm{~N}-\mathrm{L}-\mathrm{Val}$
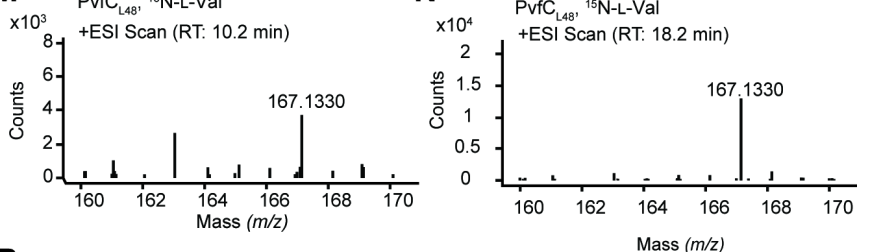

0

$P_{\times 10^{4}}$
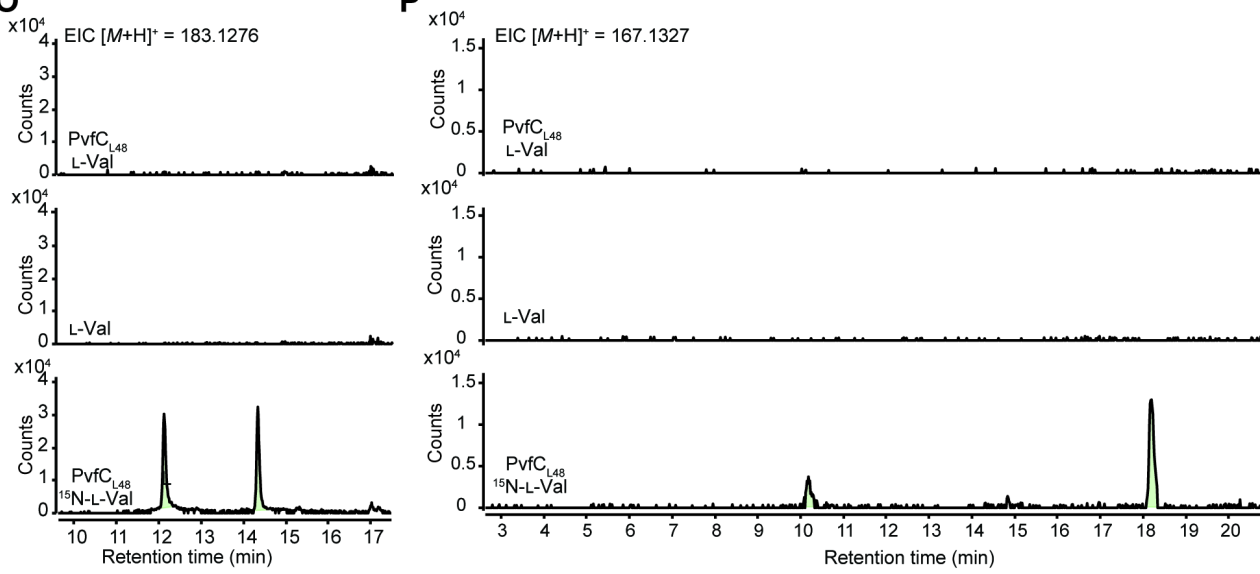
Figure S15. PvfC $\mathrm{L}_{48}$ produces valine-derived molecules corresponding to Val-pyrazinone, Valimidazole, and Val-pyrazines in vitro.

A) Structures of the proposed Val-pyrazinone (11) and Val-imidazole (12). B \& C) Mass spectra of product ions corresponding to Val-pyrazinone (11) and Val-imidazole (12) in a reaction containing $\mathrm{PVfC}_{\mathrm{L} 48}, \mathrm{ATP}, \mathrm{Sfp}, \mathrm{CoA}, \mathrm{MgCl}_{2}, \mathrm{NADPH}$, and L-Val. D) Structures of the proposed Val-pyrazines (13 and 14). E \& F) Mass spectra of product ions corresponding to Val-pyrazines (13 and 14) in a reaction containing PvfC $\mathrm{L}_{48}$, ATP, Sfp, CoA, $\mathrm{MgCl}_{2}, \mathrm{NADPH}$, and L-Val. G) EICs of Val-pyrazinone and Valimidazole $\left([M+H]^{+}=181.1335\right)$ in the full reaction by $\mathrm{PvfC}_{\llcorner 48}$ with L-Val (top), in a control reaction without

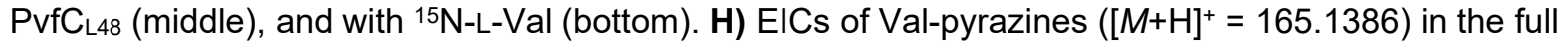
reaction by $\mathrm{PvfC}_{\llcorner 48}$ with $\mathrm{L}-\mathrm{Val}$ (top), in a control reaction without $\mathrm{P}_{\mathrm{VfC}} \mathrm{L}_{\llcorner 8}$ (middle), and with ${ }^{15} \mathrm{~N}-\mathrm{L}-\mathrm{Val}$ (bottom).

I) Structures of the proposed ${ }^{15} \mathrm{~N}-\mathrm{Val}$-pyrazinone and ${ }^{15} \mathrm{~N}-\mathrm{Val}$-imidazole. J \& K) Mass spectra of product ions corresponding to Val-pyrazinone and Val-imidazole in a reaction containing $\mathrm{PvfC}_{\llcorner 48}$, ATP, Sfp, CoA, $\mathrm{MgCl}_{2}, \mathrm{NADPH}$, and ${ }^{15} \mathrm{~N}-\mathrm{L}-$ Val. L) Structures of the proposed ${ }^{15} \mathrm{~N}-$ Val-pyrazines (Val-PZ-1 and -PZ-2). M \& N) Mass spectra of product ions corresponding to Val-pyrazines in a reaction containing PvfC $\llcorner 48$, ATP, Sfp, CoA, $\mathrm{MgCl}_{2}, \mathrm{NADPH}$, and ${ }^{15} \mathrm{~N}-\mathrm{L}-\mathrm{Val}$. O) EICs of ${ }^{15} \mathrm{~N}-$ Val-pyrazinone and ${ }^{15} \mathrm{~N}-$ Val-imidazole $\left([\mathrm{M}+\mathrm{H}]^{+}=\right.$ 183.1276) in the full reaction by $\mathrm{PvfC}_{\llcorner 48}$ with L-Val (top), in a control reaction without $\mathrm{PvfC}_{\llcorner 48}$ (middle), and with ${ }^{15} \mathrm{~N}-\mathrm{L}-\mathrm{Val}$ (bottom). P) EICs of ${ }^{15} \mathrm{~N}-\mathrm{Val}-$ pyrazine $\left([\mathrm{M}+\mathrm{H}]^{+}=167.1327\right)$ in the full reaction by PvfC $\mathrm{L48}$ with L-Val (top), in a control reaction without $\mathrm{PvfC}_{\llcorner 48}$ (middle), and with ${ }^{15} \mathrm{~N}-\mathrm{L}-\mathrm{Val}$ (bottom). Reactions were analyzed using method "LC-HRMS and MS/MS analysis of $\mathrm{PvfC}_{\llcorner 48}$ in vitro reactions." 
A
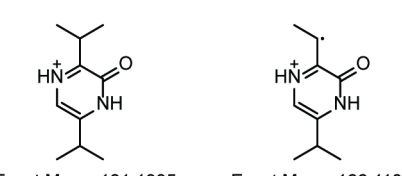

B

Exact Mass: 181.1335

Exact Mass: 166.1101

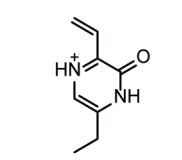

Exact Mass: 151.0866

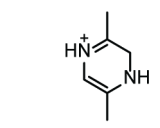

Exact Mass: 111.0917

$\times 10^{4} \quad \mathrm{PvfC}_{\text {L48 }}$, L-Val

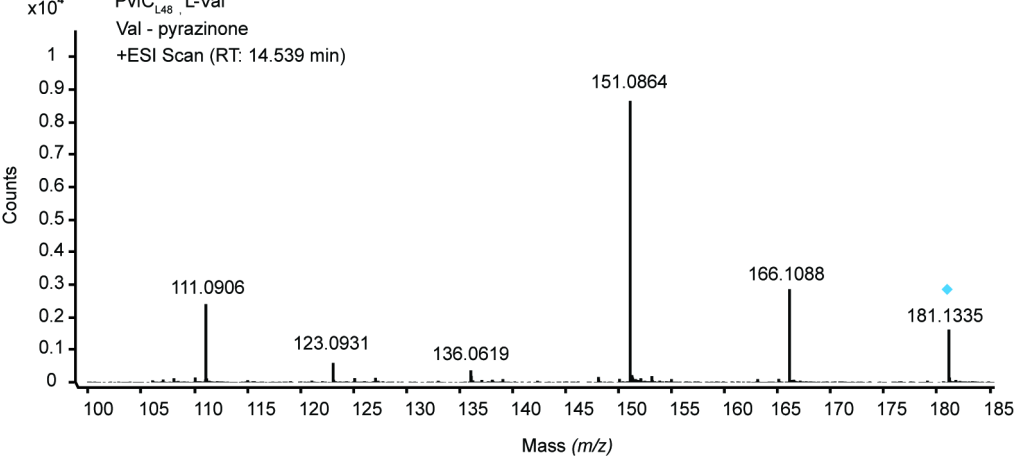

C

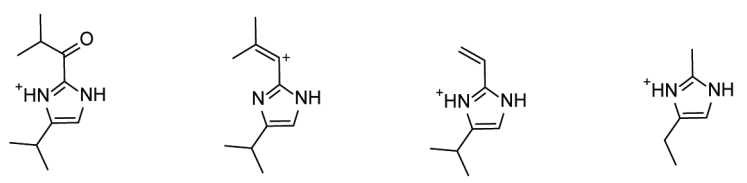

Exact Mass: 181.1335 Exact Mass: 163.1230 Exact Mass: 137.1073 Exact Mass: 111.0917

D

PvfC $_{\text {L48 }}$, L-Val

Val - imidazole

+ESI Scan (RT: $12.300 \mathrm{~min}$ )

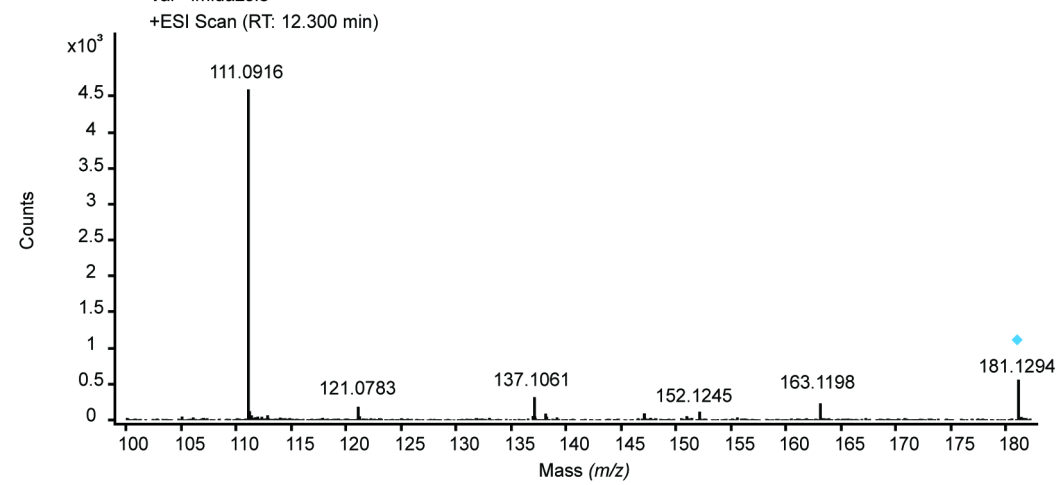

E
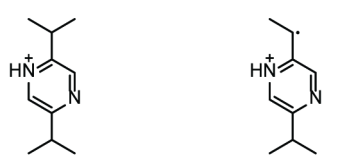

Exact Mass: $150.1151 \quad$ Exact Mass: 135.0917
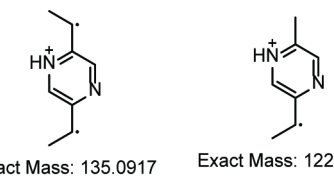

Exact Mass: 165.1386

Exact Mass: 122.0838

$\mathbf{F}$

$\mathrm{PufC}_{\text {L48 }}$, L-Val

Val - pyrazine

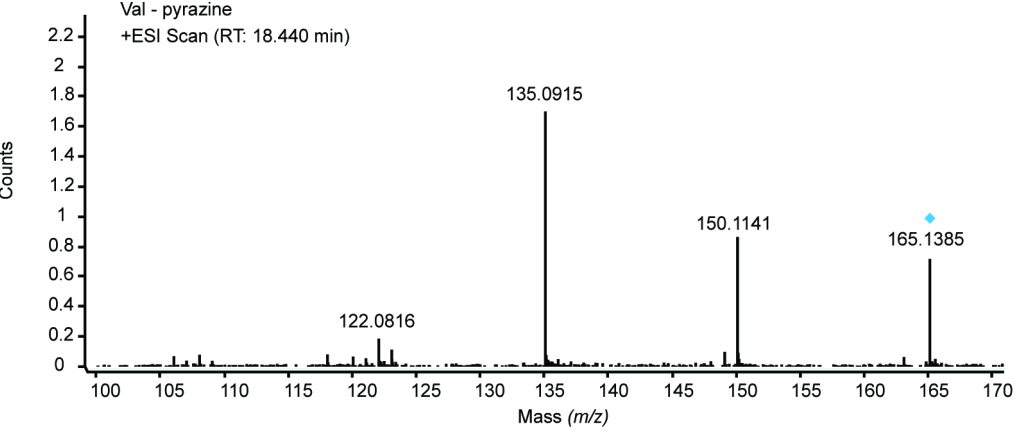


Figure S16. MS fragmentation of $\mathrm{PvfC}_{\mathrm{L} 48}$ in vitro products.

A) Proposed fragments of Val-pyrazinone. B) MS/MS spectrum of Val-pyrazinone in a reaction containing PvfC L48, ATP, Sfp, CoA, MgCl $2, \mathrm{NADPH}$, and L-Val. C) Proposed fragments of Val-imidazole. D) MS/MS spectrum of Val-imidazole in a reaction containing PvfC $\mathrm{L}_{48}, \mathrm{ATP}, \mathrm{Sfp}, \mathrm{CoA}, \mathrm{MgCl}_{2}, \mathrm{NADPH}$, and L-Val. E) Proposed fragments of a Val-pyrazine (2,5-disopropylpyrazine). F) MS/MS spectrum of Val-pyrazine in a reaction containing $\mathrm{PvfC}_{\mathrm{L} 48}, \mathrm{ATP}, \mathrm{Sfp}, \mathrm{CoA}, \mathrm{MgCl}_{2}, \mathrm{NADPH}$, and L-Val. All MS/MS were obtained using a fragmentor voltage of $25 \mathrm{~V}$.

*Peak at 10 min that shares a mass with Val-pyrazine was produced in too low of abundance to produce a fragmentation pattern. Only the Val-pyrazine at $18.4 \mathrm{~min}$ is shown.

Reactions were analyzed using method "LC-HRMS and MS/MS analysis of $\mathrm{PvfC}_{\llcorner 48}$ in vitro reactions". 
A

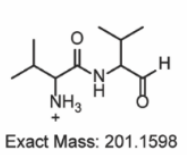

C
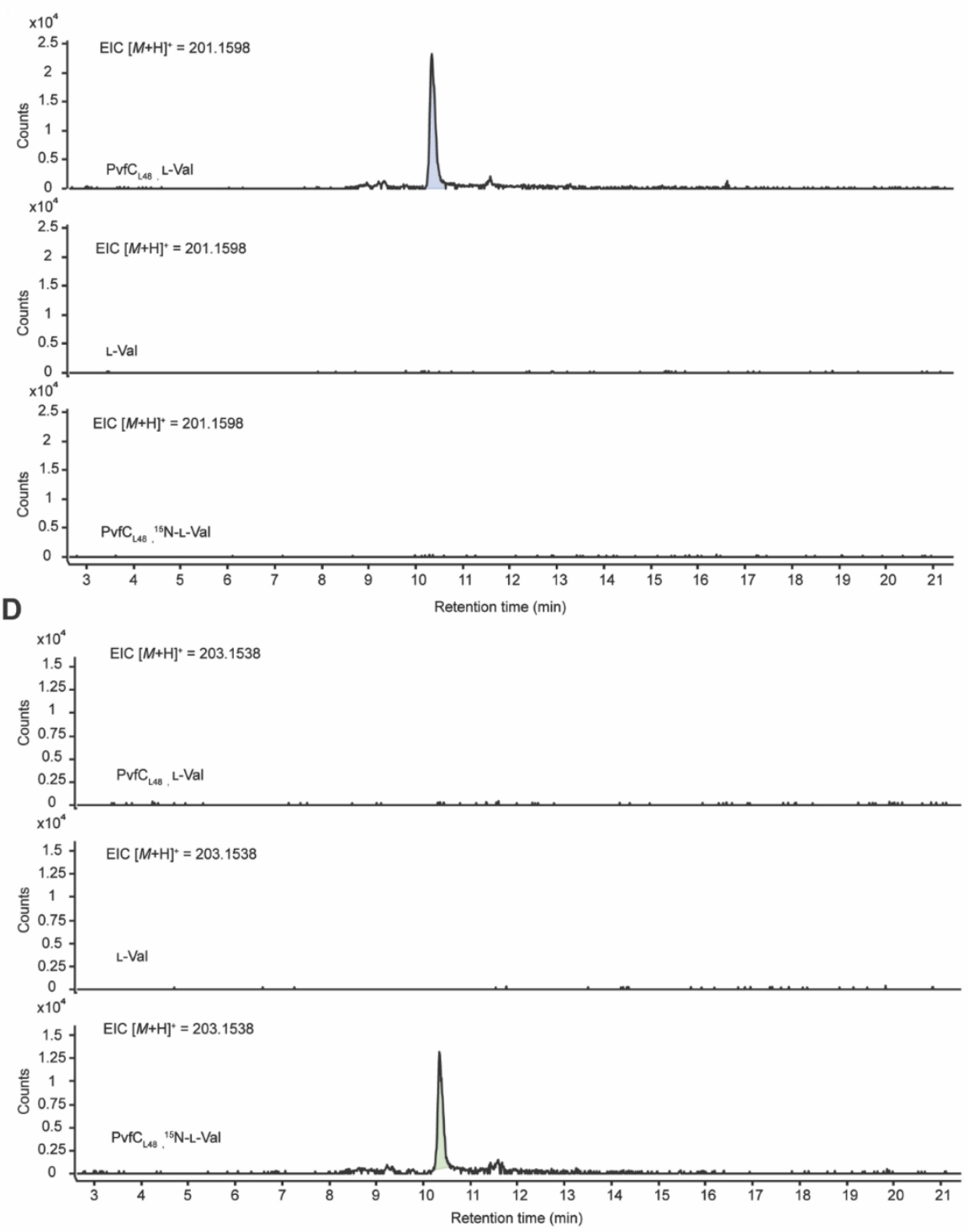

Figure S17. $\mathrm{PvfC}_{\mathrm{L} 48}$ produces Val-Val-aldehyde in vitro.

A) Structures of Val-Val-aldehyde both with and without ${ }^{15} \mathrm{~N}-\mathrm{Val}$ incorporated. B) Mass spectrum of ValVal-aldehyde in a reaction containing PvfCL48, ATP, Sfp, CoA, $\mathrm{MgCl}_{2}, \mathrm{NADPH}$, and L-Val (left) or ${ }^{15} \mathrm{~N}-\mathrm{L}-\mathrm{Val}$ (right). C) EIC of Val-Val-aldehyde $\left([M+H]^{+}=201.1598\right)$ in the full reaction by $\mathrm{PvfC}_{\llcorner 48}$ with L-Val (top), in a control reaction without $\mathrm{PVfC}_{\mathrm{L} 48}$ (middle), and with ${ }^{15} \mathrm{~N}-\mathrm{L}-\mathrm{Val}$ (bottom). D) EIC of Val-Val-aldehyde with ${ }^{15} \mathrm{~N}-\mathrm{Val}$ incorporated $\left([\mathrm{M}+\mathrm{H}]^{+}=203.1538\right)$ in the full reaction by $\mathrm{PvfC}_{\llcorner 48}$ with $\mathrm{L}-\mathrm{Val}$ (top), in a control reaction without $\mathrm{PvfC}_{\llcorner 48}$ (middle), and with ${ }^{15} \mathrm{~N}-\mathrm{L}-\mathrm{Val}$ (bottom).

Reaction were analyzed using method "LC-HRMS and MS/MS analysis of $\mathrm{PvfC}_{\llcorner 48}$ in vitro reactions". 
A
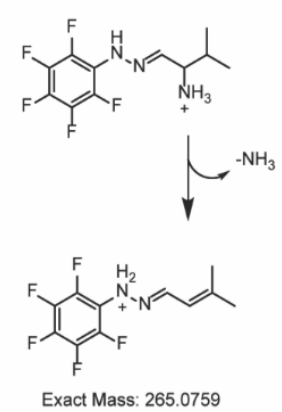

C
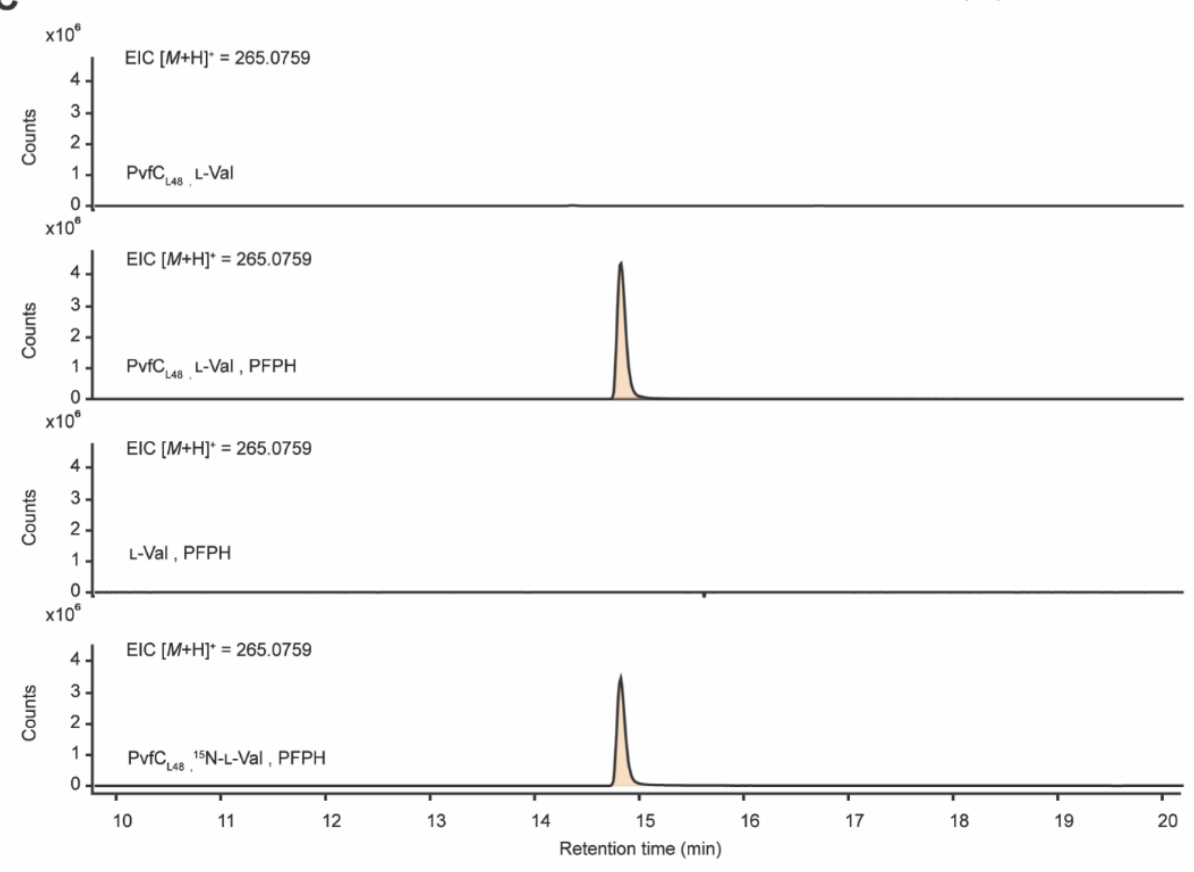

Figure S18. Val-aldehyde is released from $\mathrm{PvfC}_{\mathrm{L} 48}$ and captured by $\mathrm{PFPH}$ in vitro.

A) Structures of PFPH-derivatized Val-aldehyde (left) and ${ }^{15} \mathrm{~N}-\mathrm{Val}$-aldehyde (right). B) Mass spectrum of PFPH-derivatized Val-aldehyde in a reaction containing PvfC $\mathrm{L48}_{4}, \mathrm{ATP}, \mathrm{Sfp}, \mathrm{CoA}, \mathrm{MgCl}_{2}, \mathrm{NADPH}, \mathrm{PFPH}$, and L-Val (top) or ${ }^{15} \mathrm{~N}-\mathrm{L}-$ Val (bottom). C) EIC of PFPH-derivatized Val-aldehyde with loss of $\mathrm{NH}_{3}\left([\mathrm{M}+\mathrm{H}]^{+}=\right.$ 265.0759) in the reaction by $\mathrm{PvfC}_{\llcorner 48}$ while excluding $\mathrm{PFPH}$, including $\mathrm{PFPH}$, a control reaction without $\mathrm{PvfC}_{\llcorner 48}$, and a reaction including PFPH while utilizing ${ }^{15} \mathrm{~N}-\mathrm{L}-\mathrm{V}$ al as the enzyme substrate.

Reactions were analyzed using method "LC-HRMS and MS/MS analysis of $\mathrm{PvfC}_{\llcorner 48}$ in vitro reactions". 

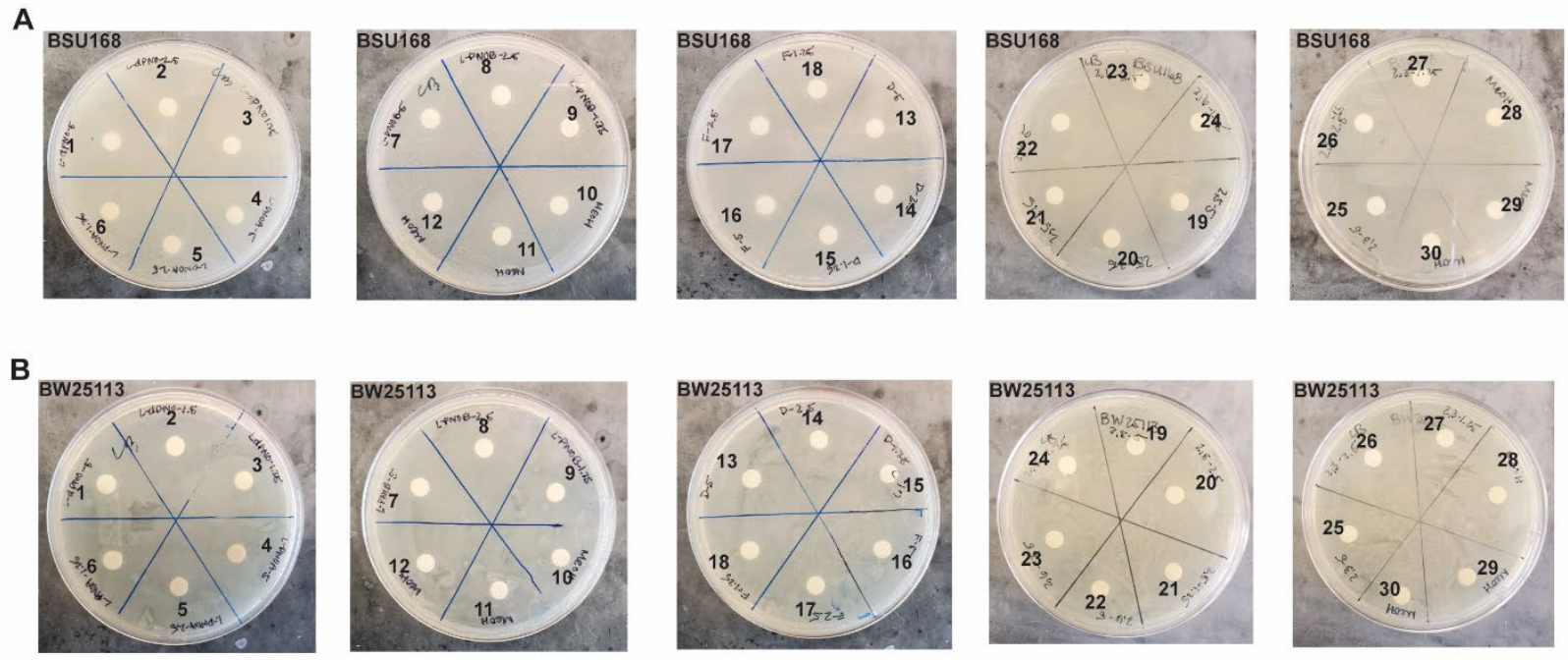

Figure S19. Leu-(d)PNOs, flavacol, leucinazole, PZ-1, PZ-2, and 2,3-diisobutylpyrazine do not inhibit growth of Bacillus subtilis or Escherichia coli.

For disk diffusion assays, $3 \mu \mathrm{L}$ of a compound in $\mathrm{MeOH}$ was applied in each lane, including 1) $5 \mathrm{mM}$ LeudPNO, 2) $2.5 \mathrm{mM}$ Leu-dPNO, 3) $1.25 \mathrm{mM}$ Leu-dPNO, 4) $5 \mathrm{mM}$ Leu-PNO A, 5) $2.5 \mathrm{mM}$ Leu-PNO A, 6) 1.25 $\mathrm{mM}$ Leu-PNO A, 7) $5 \mathrm{mM}$ Leu-PNO B, 8) $2.5 \mathrm{mM}$ Leu-PNO B, 9) $1.25 \mathrm{mM}$ Leu-PNO B, 10-12) MeOH control, 13) $5 \mathrm{mM}$ leucinazole, 14) $2.5 \mathrm{mM}$ leucinazole, 15) $1.25 \mathrm{mM}$ leucinazole, 16) $5 \mathrm{mM}$ flavacol, 17) $2.5 \mathrm{mM}$ flavacol, 18) $1.25 \mathrm{mM}$ flavacol, 19) $5 \mathrm{mM}$ 2,5-diisobutylpyrazine (PZ-2), 20) $2.5 \mathrm{mM} \mathrm{2,5-}$ diisobutylpyrazine (PZ-2), 21) $1.25 \mathrm{mM}$ 2,5-diisobutylpyrazine (PZ-2), 22) $5 \mathrm{mM}$ 2,6-diisobutylpyrazine (PZ1), 23) $2.5 \mathrm{mM}$ 2,6-diisobutylpyrazine (PZ-1), 24) $1.25 \mathrm{mM} \mathrm{2,6-diisobutylpyrazine} \mathrm{(PZ-1),} \mathrm{25)} 5 \mathrm{mM} \mathrm{2,3-}$ diisobutylpyrazine, 26) $2.5 \mathrm{mM}$ 2,3-diisobutylpyrazine, 27) $1.25 \mathrm{mM}$ 2,3-diisobutylpyrazine, 28-30) MeOH control.

B. subtilis BSU168 (A) or E. coli BW25113 (B) were used as an indicator strain. Synthetic standards of each compound were used in lane 19-27. 


\section{Extended Data}

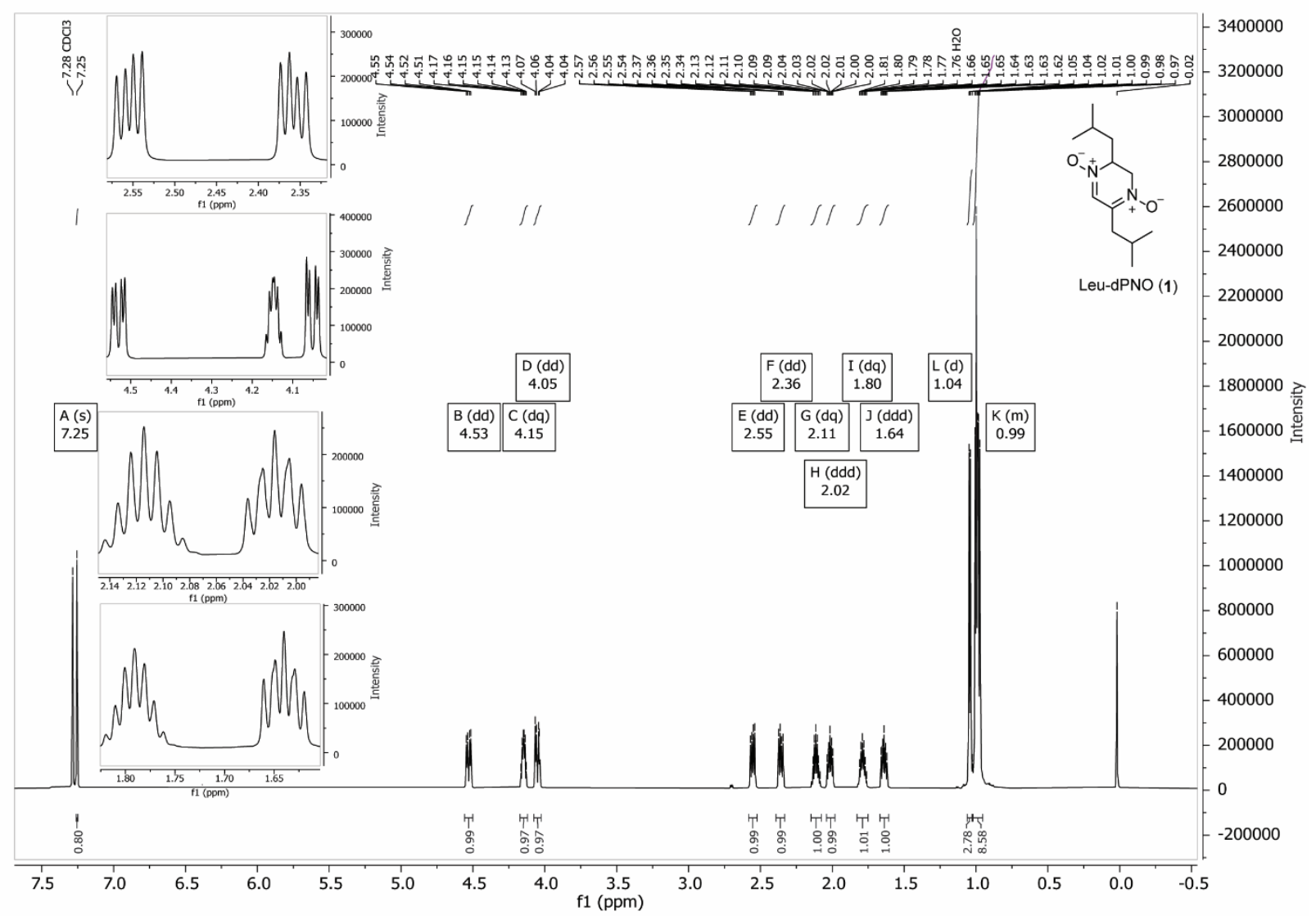

Extended Data 1. ${ }^{1} \mathrm{H}$ NMR spectrum of isolated Leu-dPNO (1) in $\mathrm{CDCl}_{3}(700 \mathrm{MHz})$. 


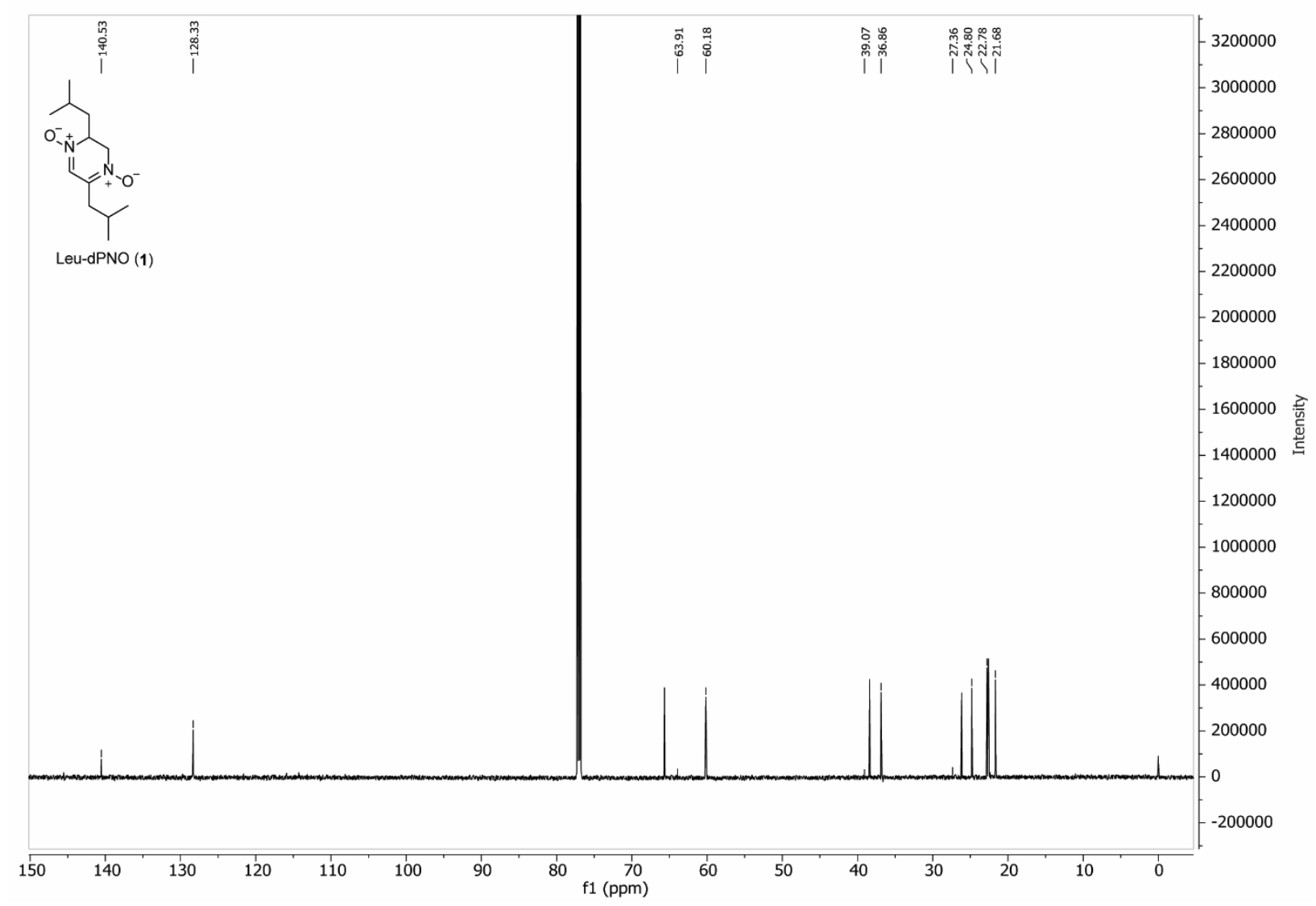

Extended Data $2 .{ }^{13} \mathrm{C}$ NMR spectrum of isolated Leu-dPNO (1) in $\mathrm{CDCl}_{3}$ (176 $\mathrm{MHz}$ ). 


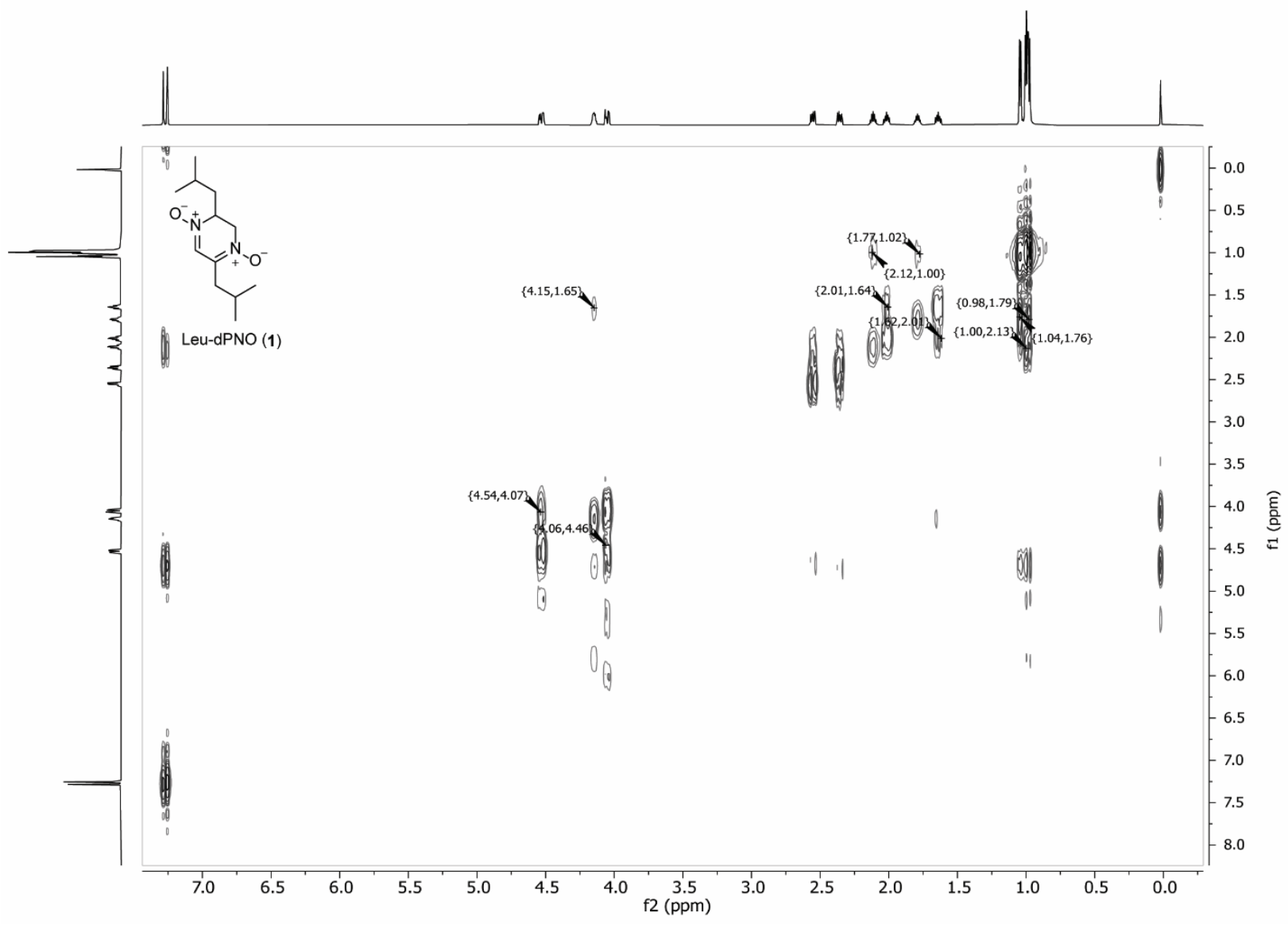

Extended Data 3. $\left({ }^{1} \mathrm{H},{ }^{1} \mathrm{H}\right)$ COSY NMR spectrum of isolated Leu-dPNO (1) in $\mathrm{CDCl}_{3}(700$ $\mathrm{MHz}$ ). 


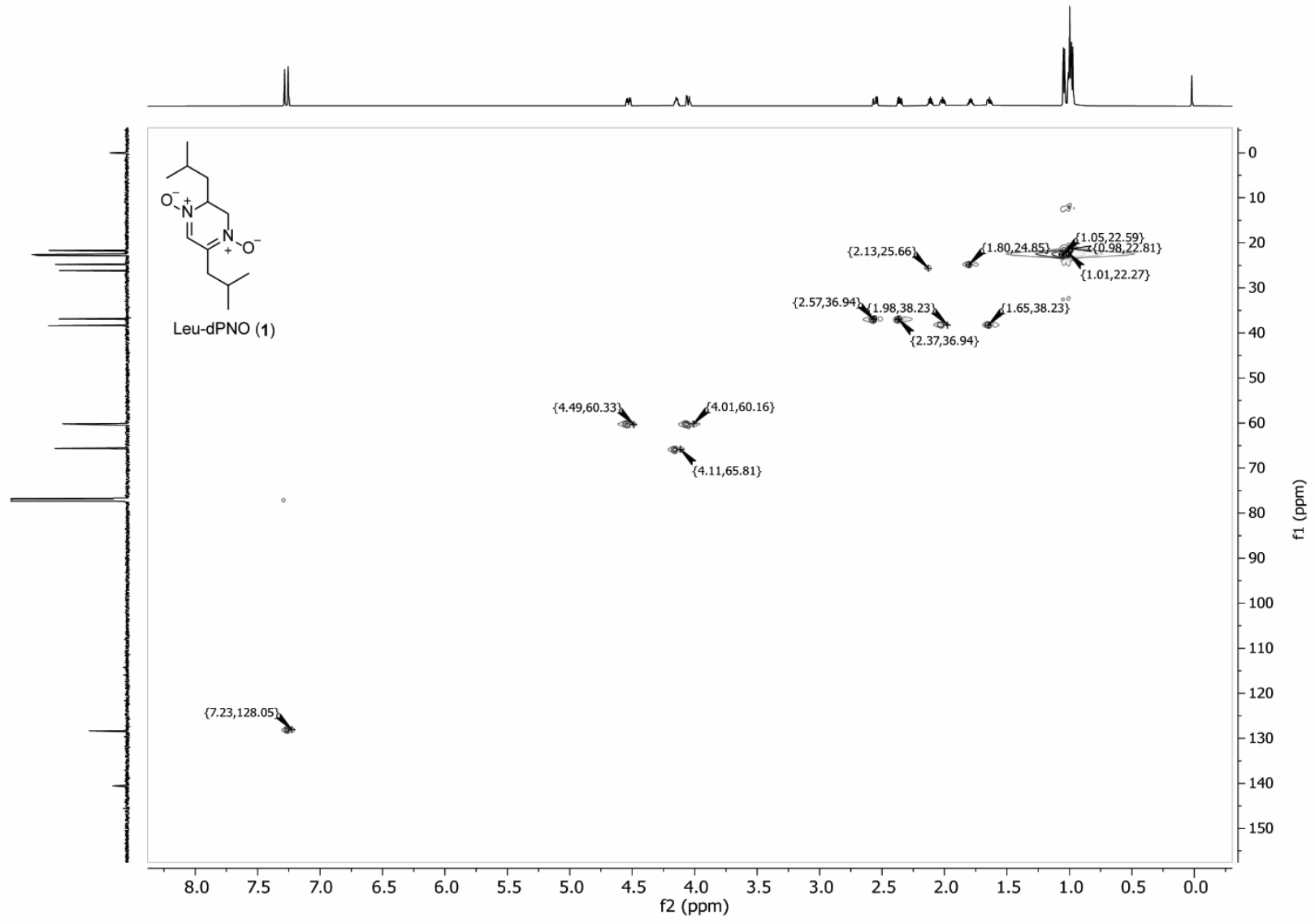

Extended Data 4. $\left({ }^{1} \mathrm{H},{ }^{13} \mathrm{C}\right) \mathrm{HSQC}$ NMR spectrum of isolated Leu-dPNO (1) in $\mathrm{CDCl}_{3}\left({ }^{1} \mathrm{H}\right.$, $700 \mathrm{MHz},{ }^{13} \mathrm{C}, 176 \mathrm{MHz}$ ). 


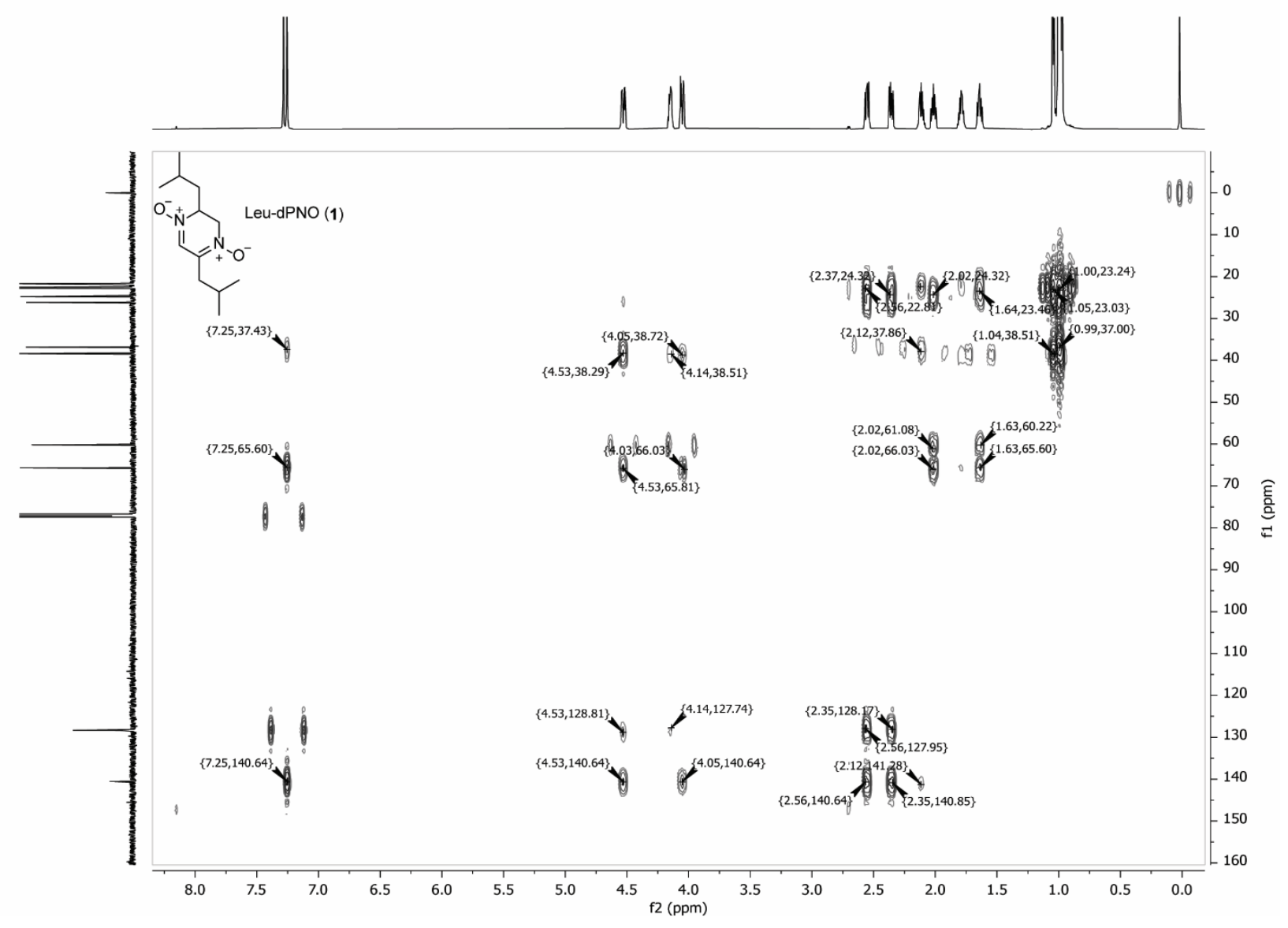

Extended Data 5. $\left({ }^{1} \mathrm{H},{ }^{13} \mathrm{C}\right) \mathrm{HMBC}$ NMR spectrum of isolated Leu-dPNO (1) in $\mathrm{CDCl}_{3}\left({ }^{1} \mathrm{H}\right.$, $\left.700 \mathrm{MHz},{ }^{13} \mathrm{C}, 176 \mathrm{MHz}\right)$. 

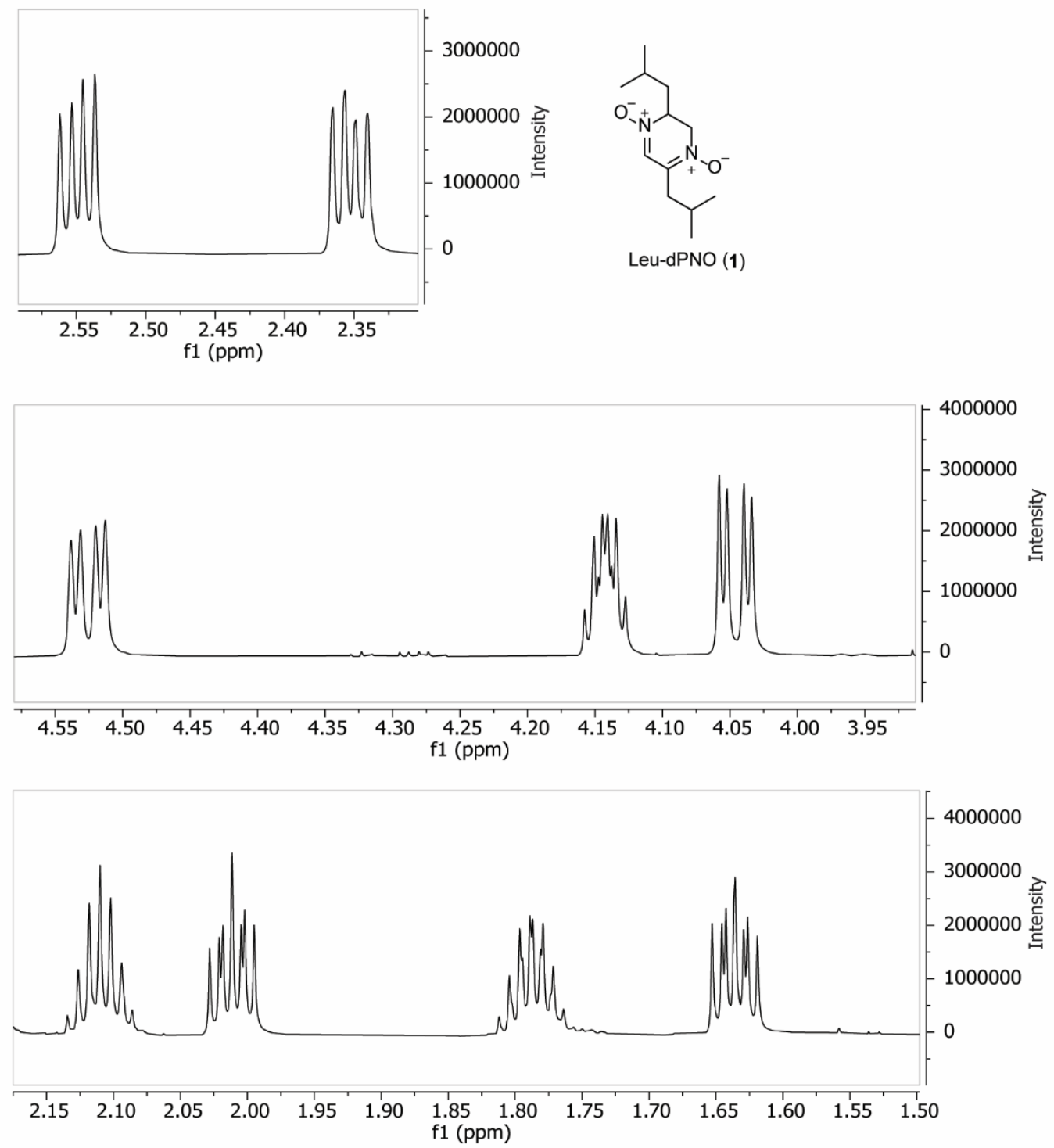

Extended Data 6. ${ }^{1} \mathrm{H}$ NMR spectrum of select peaks of isolated Leu-dPNO (1) in $\mathrm{CDCl}_{3}\left({ }^{1} \mathrm{H}\right.$, $850 \mathrm{MHz}$ ) to show fine splitting. 


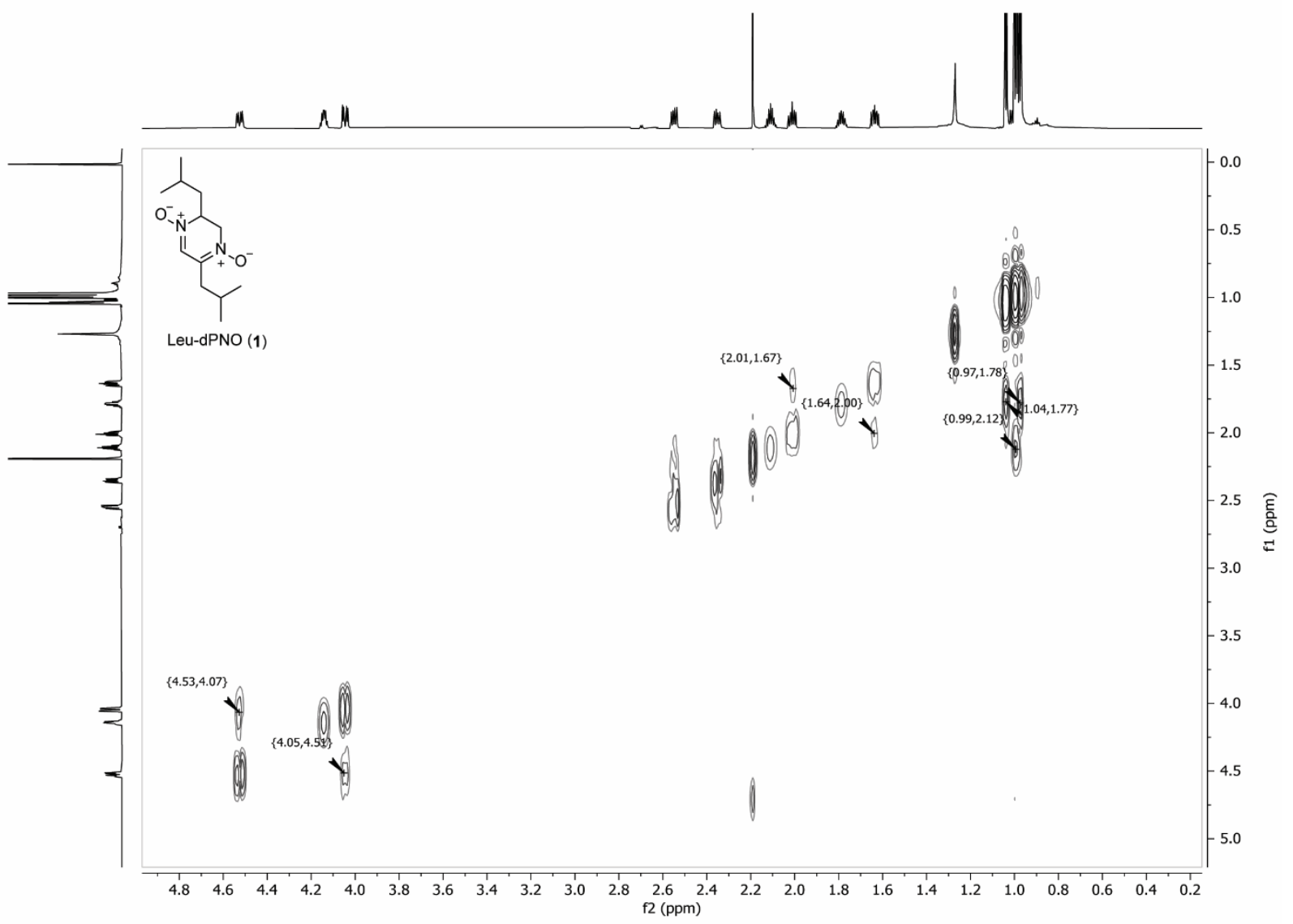

Extended Data 7. $\left({ }^{1} \mathrm{H},{ }^{1} \mathrm{H}\right)$ COSY NMR spectrum of isolated Leu-dPNO (1) in $\mathrm{CDCl}_{3}\left({ }^{1} \mathrm{H}, 850\right.$ $\mathrm{MHz})$. 


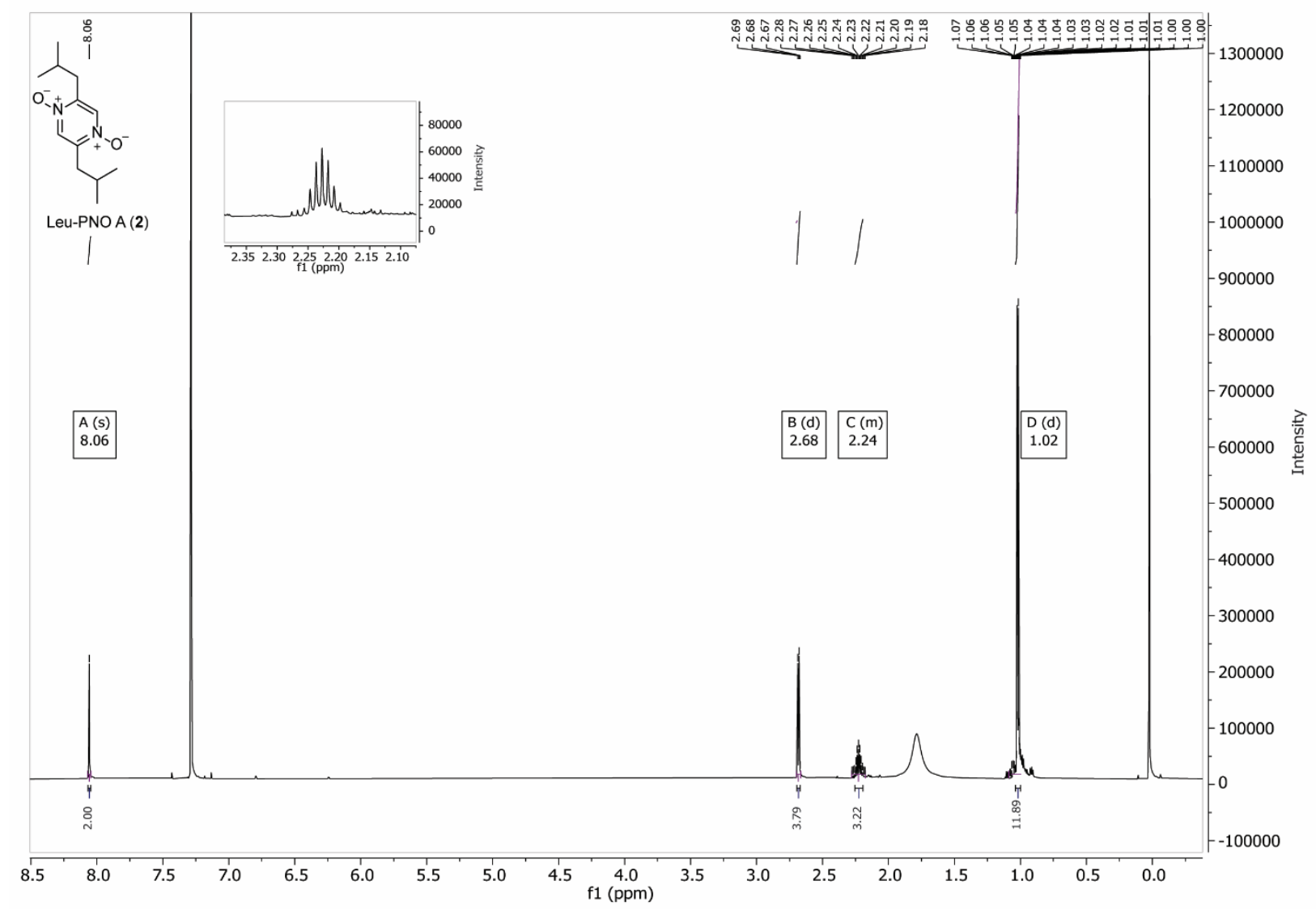

Extended Data 8. ${ }^{1} \mathrm{H}$ NMR spectrum of isolated Leu-PNO A (2) in $\mathrm{CDCl}_{3}(700 \mathrm{MHz})$. 


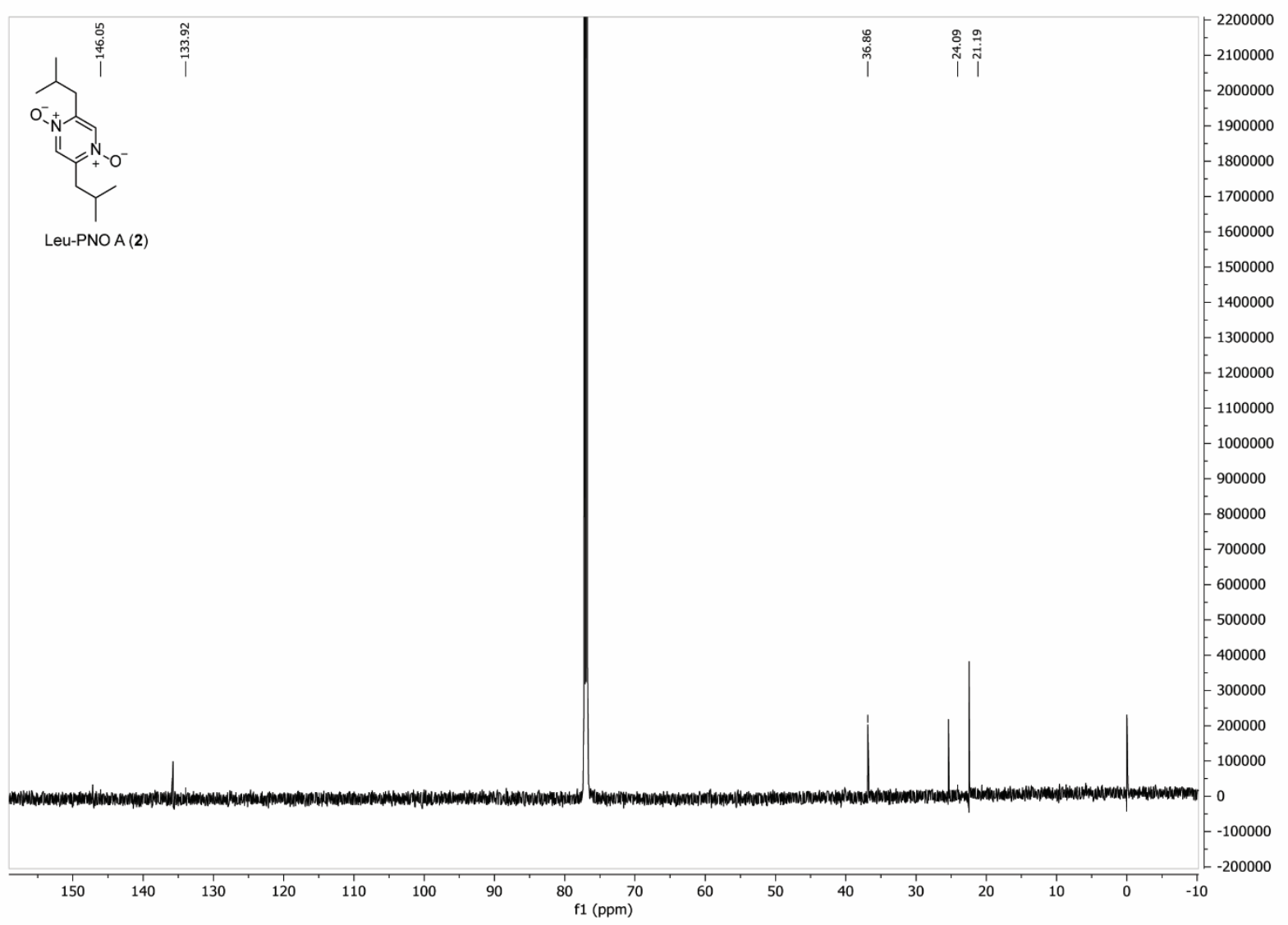

Extended Data 9. ${ }^{13} \mathrm{C}$ NMR spectrum of isolated Leu-PNO A (2) in $\mathrm{CDCl}_{3}(176 \mathrm{MHz}$ ). 


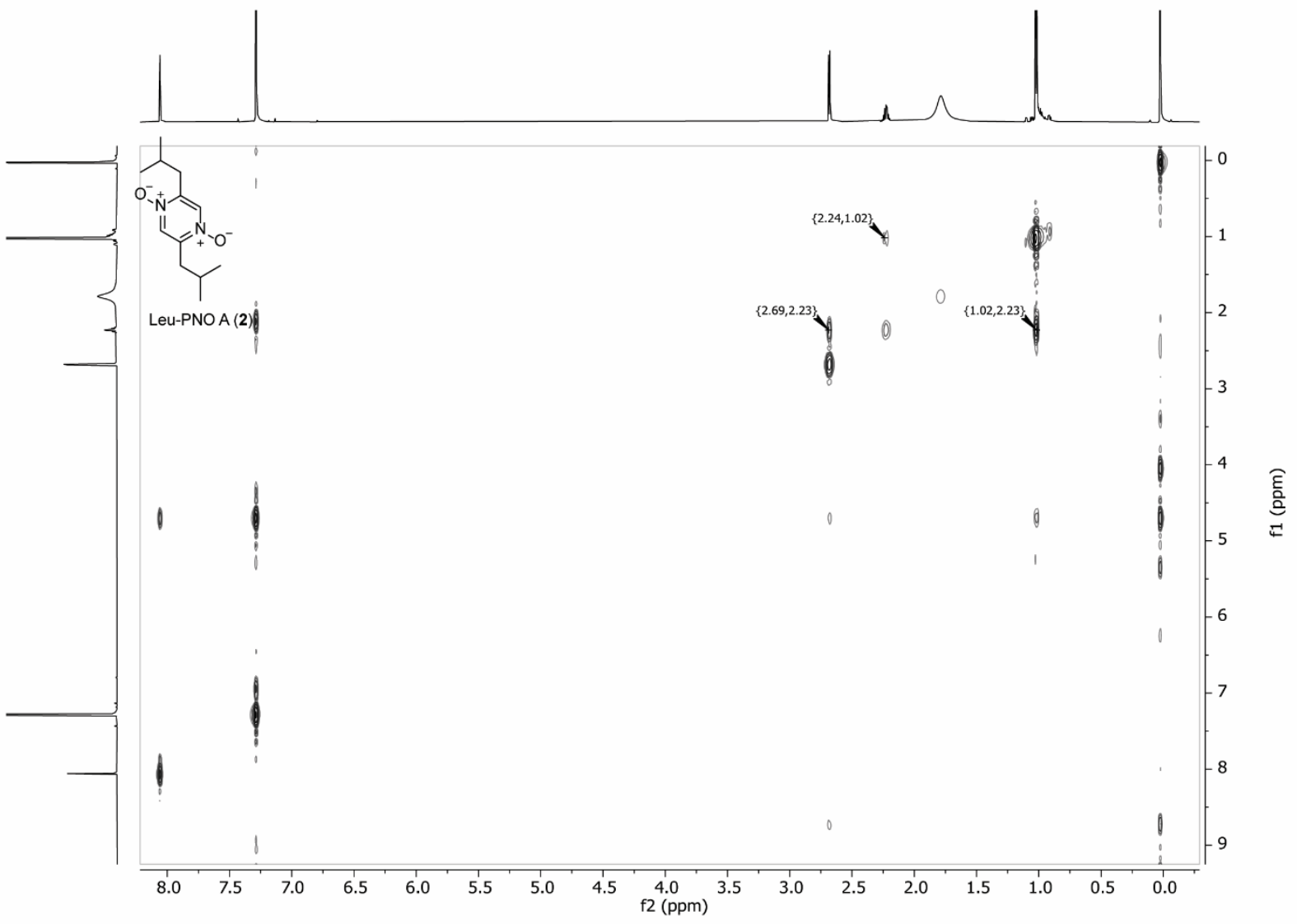

Extended Data 10. $\left({ }^{1} \mathrm{H},{ }^{1} \mathrm{H}\right)$ COSY NMR spectrum of isolated Leu-PNO A (2) in $\mathrm{CDCl}_{3}(700$ $\mathrm{MHz}$ ). 


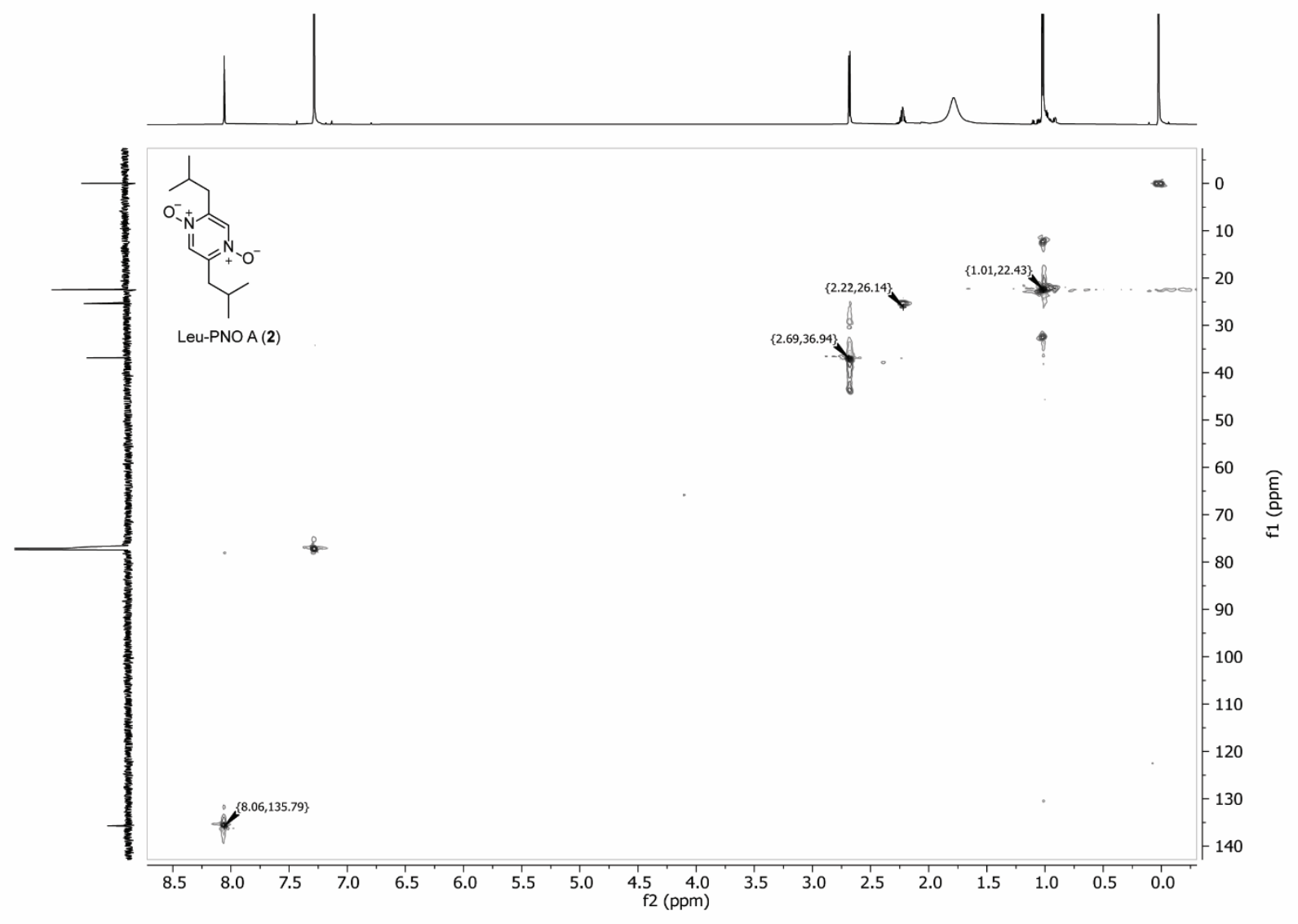

Extended Data 11. $\left({ }^{1} \mathrm{H},{ }^{13} \mathrm{C}\right) \mathrm{HSQC}$ NMR spectrum of isolated Leu-PNO A (2) in $\mathrm{CDCl}_{3}\left({ }^{1} \mathrm{H}\right.$, $700 \mathrm{MHz},{ }^{13} \mathrm{C}, 176 \mathrm{MHz}$ ). 


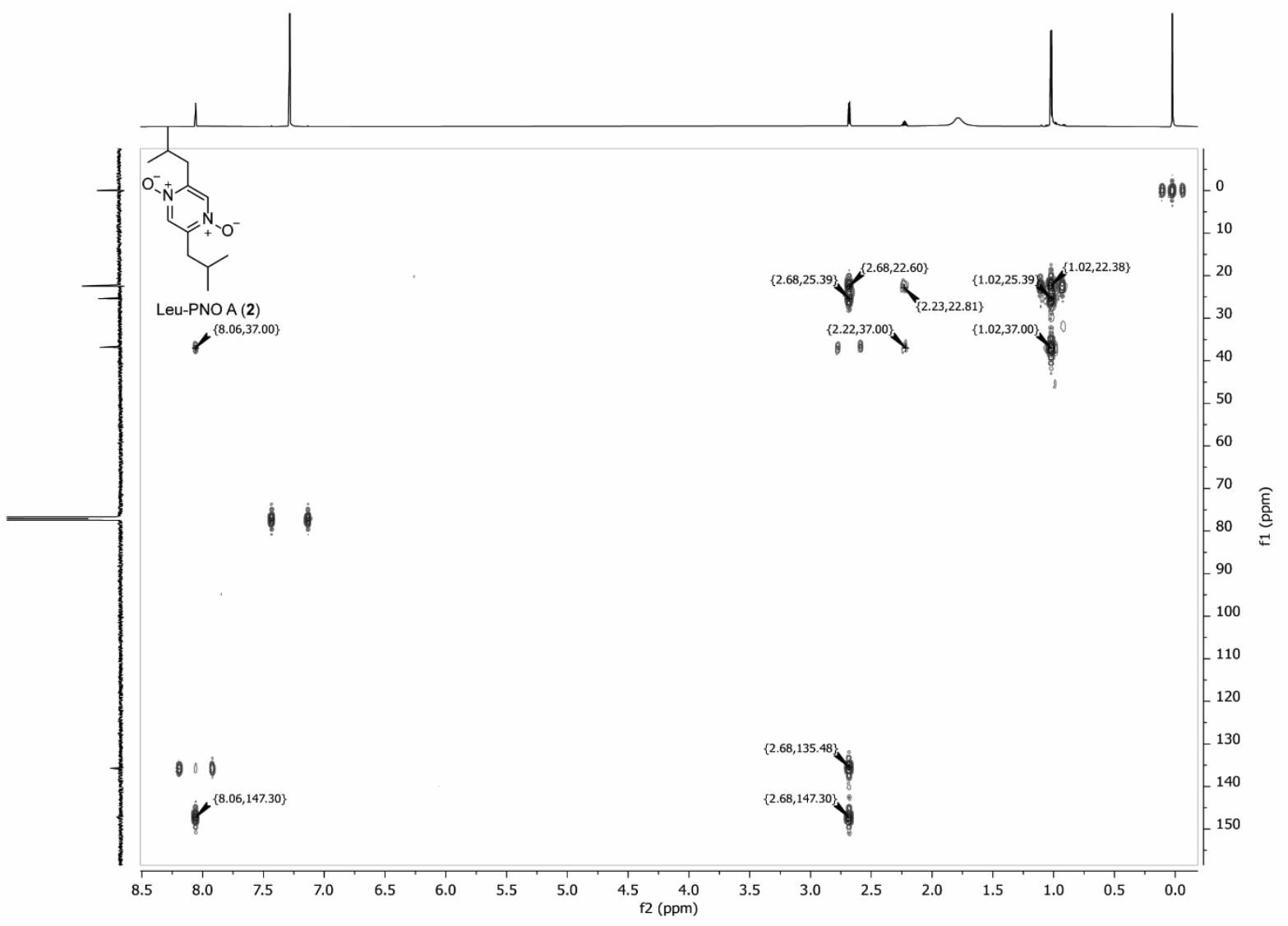

Extended Data 12. $\left({ }^{1} \mathrm{H},{ }^{13} \mathrm{C}\right) \mathrm{HMBC}$ NMR spectrum of isolated Leu-PNO A (2) in $\mathrm{CDCl}_{3}\left({ }^{1} \mathrm{H}, 700 \mathrm{MHz}\right.$, $\left.{ }^{13} \mathrm{C}, 176 \mathrm{MHz}\right)$. 


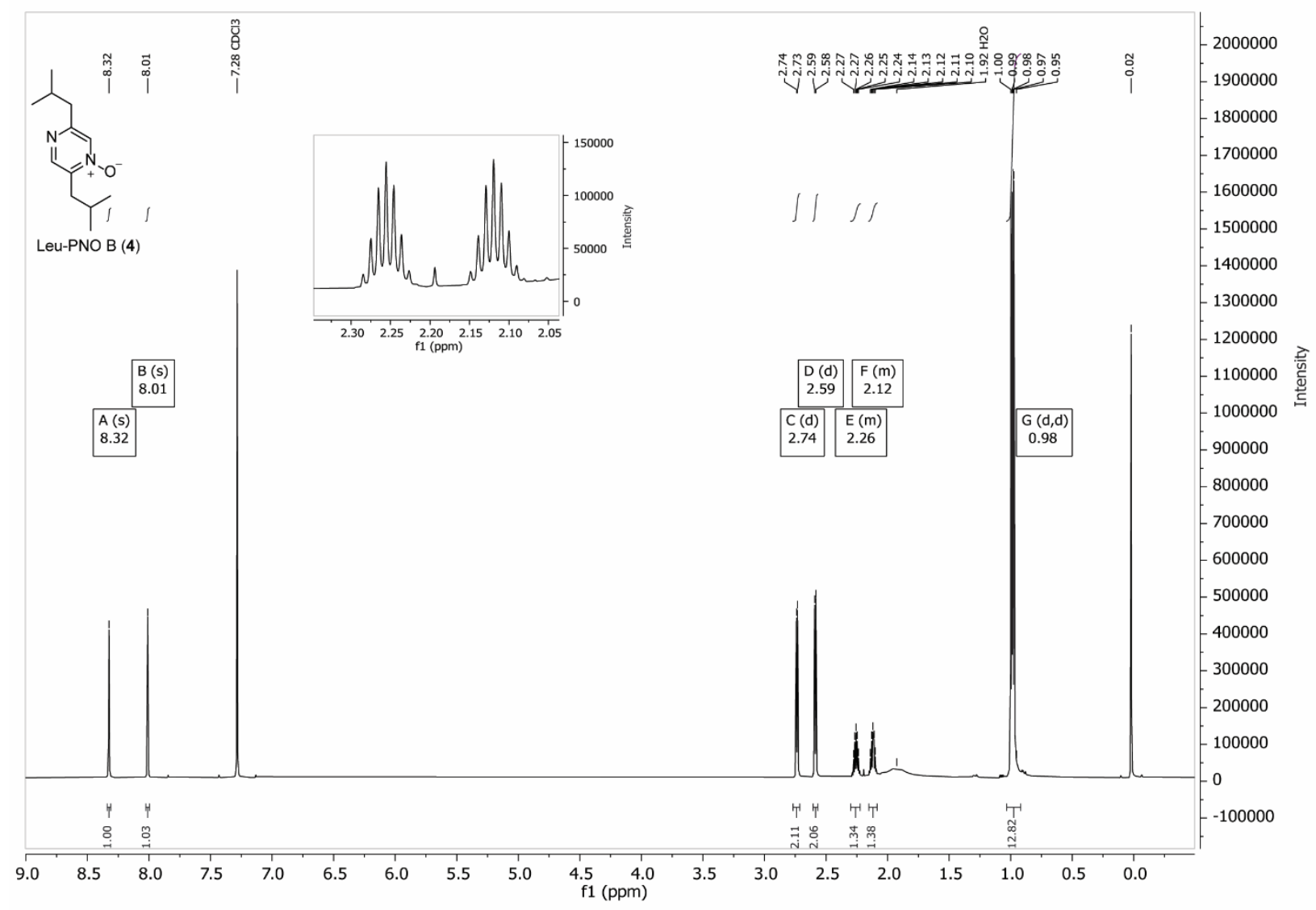

Extended Data 13. ${ }^{1} \mathrm{H}$ NMR spectrum of isolated Leu-PNO B (4) in $\mathrm{CDCl}_{3}(700 \mathrm{MHz})$. 


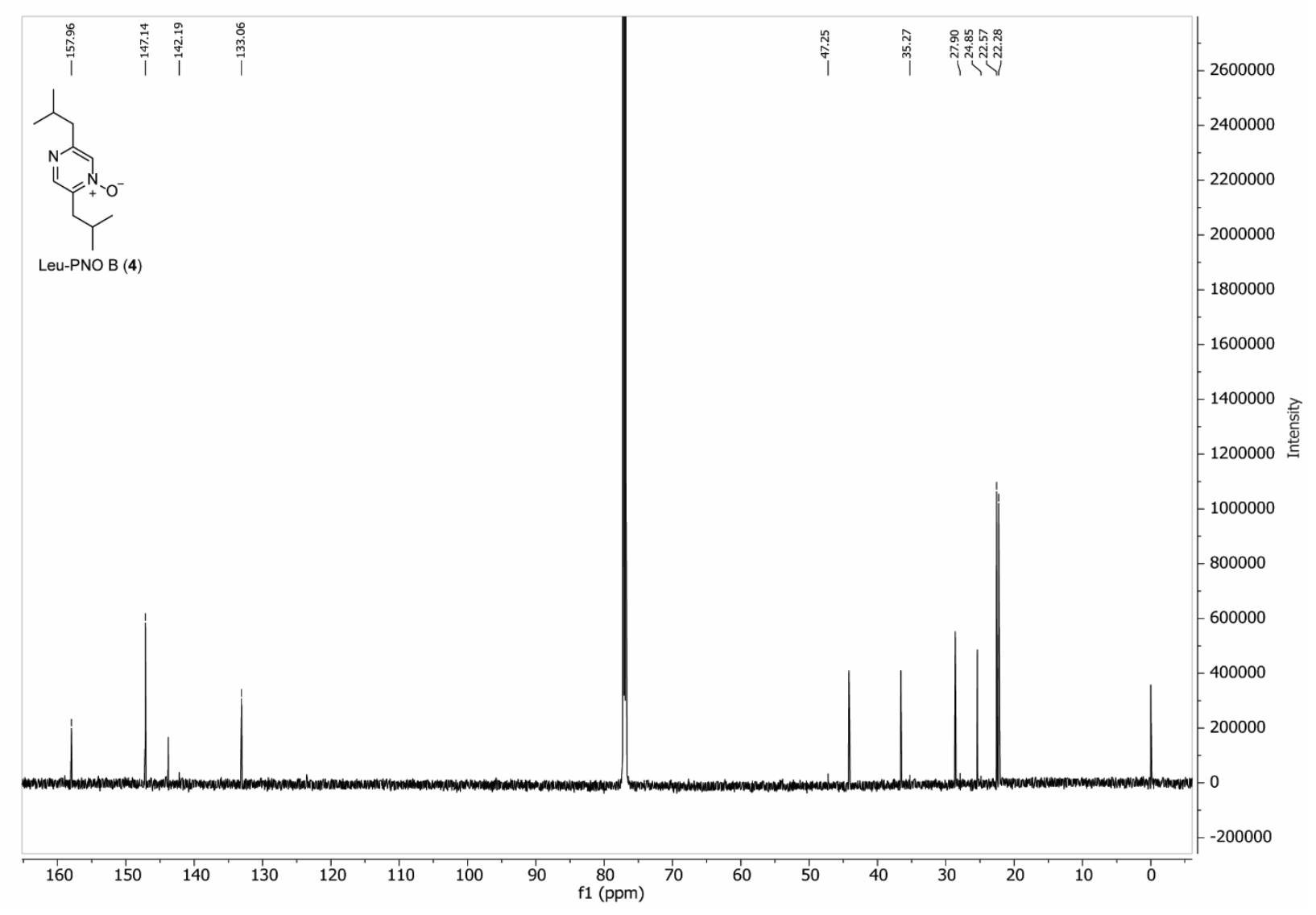

Extended Data 14. ${ }^{13} \mathrm{C}$ NMR spectrum of isolated Leu-PNO B (4) in $\mathrm{CDCl}_{3}(176 \mathrm{MHz}$ ). 


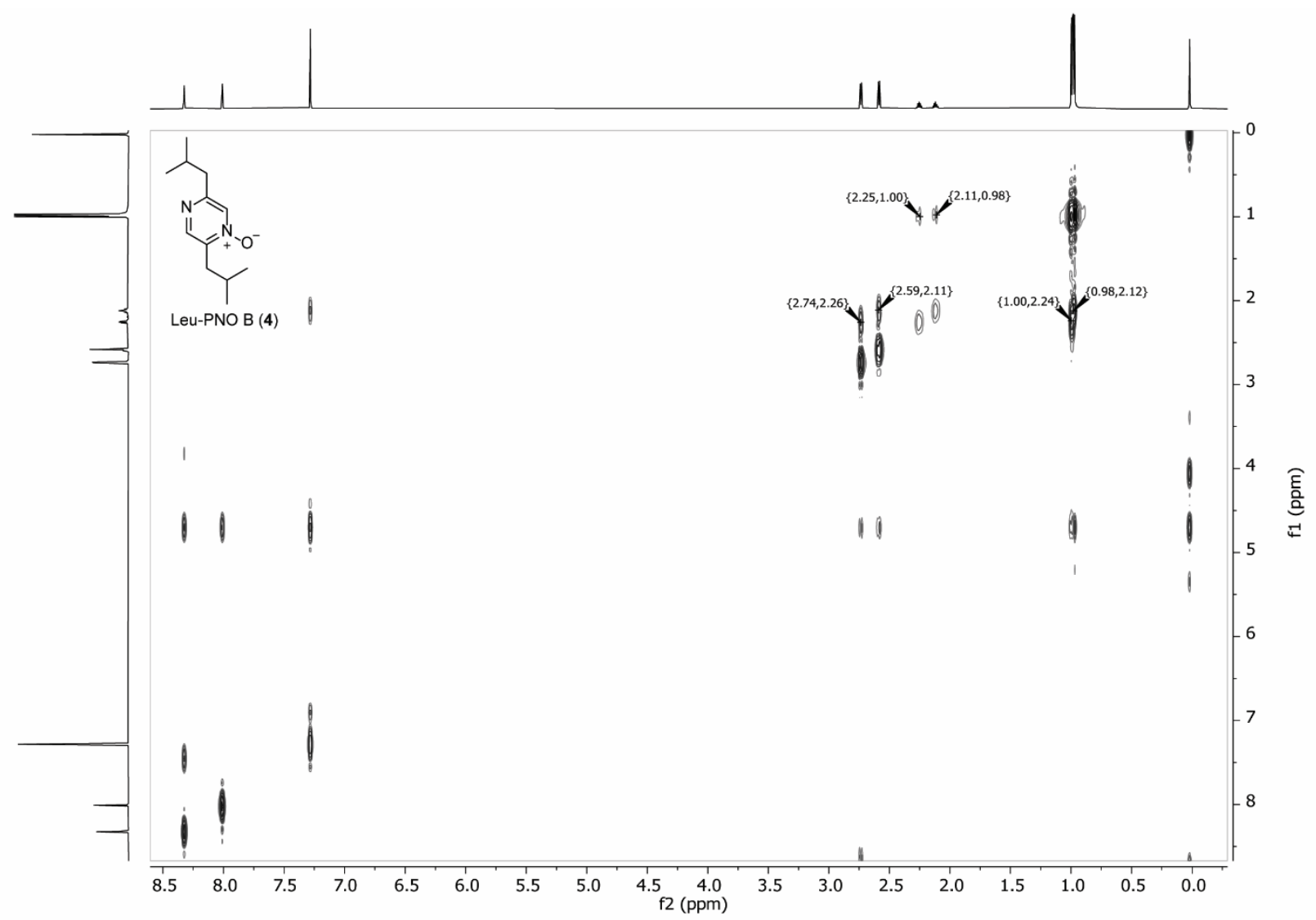

Extended Data 15. $\left({ }^{1} \mathrm{H},{ }^{1} \mathrm{H}\right)$ COSY NMR spectrum of isolated Leu-PNO $\mathrm{B}(4)$ in $\mathrm{CDCl}_{3}(700$ $\mathrm{MHz}$ ). 


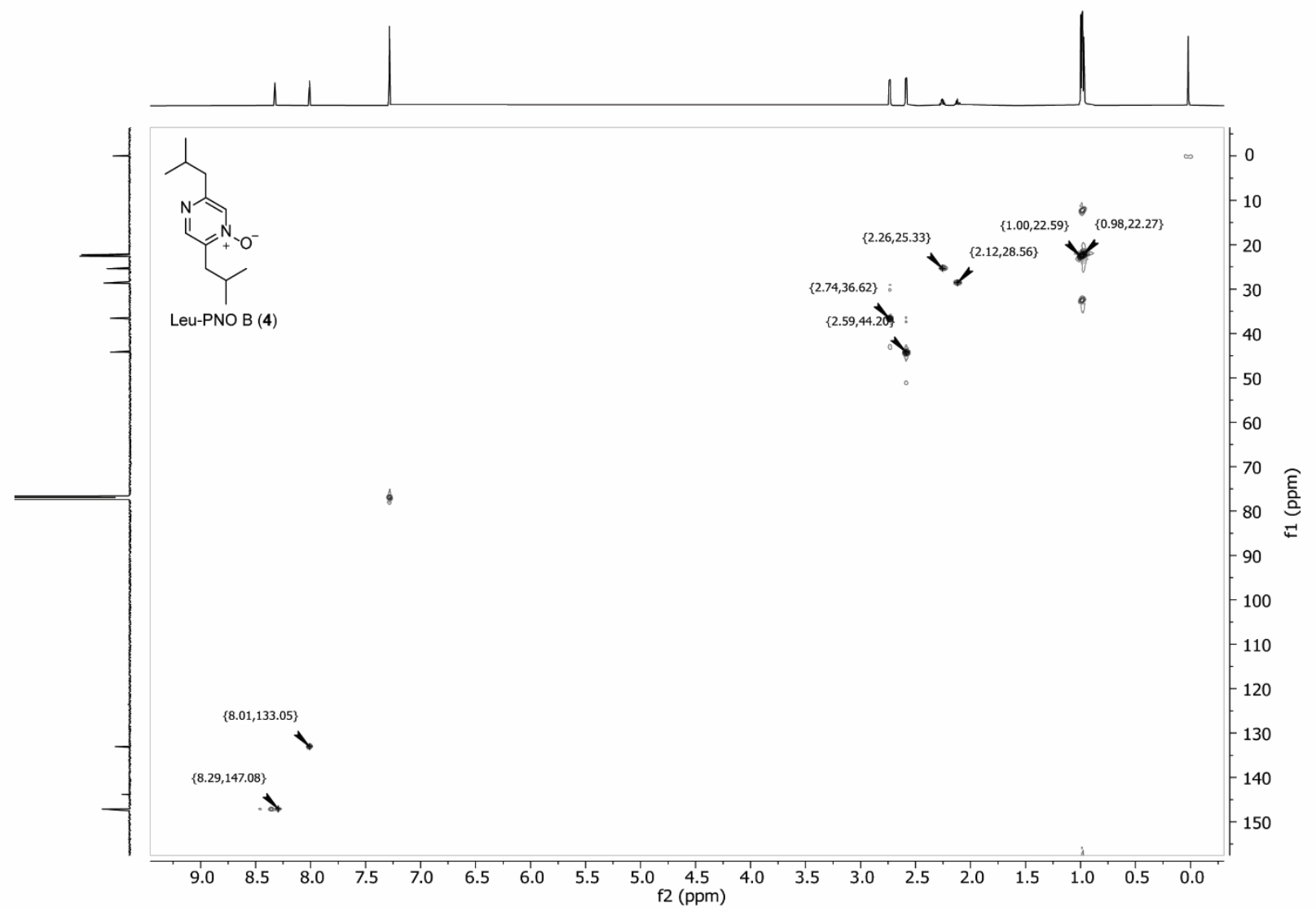

Extended Data 16. $\left({ }^{1} \mathrm{H},{ }^{13} \mathrm{C}\right) \mathrm{HSQC}$ NMR spectrum of isolated Leu-PNO B (4) in $\mathrm{CDCl}_{3}\left({ }^{1} \mathrm{H}, 700 \mathrm{MHz}\right.$, ${ }^{13} \mathrm{C}, 176 \mathrm{MHz}$ ). 


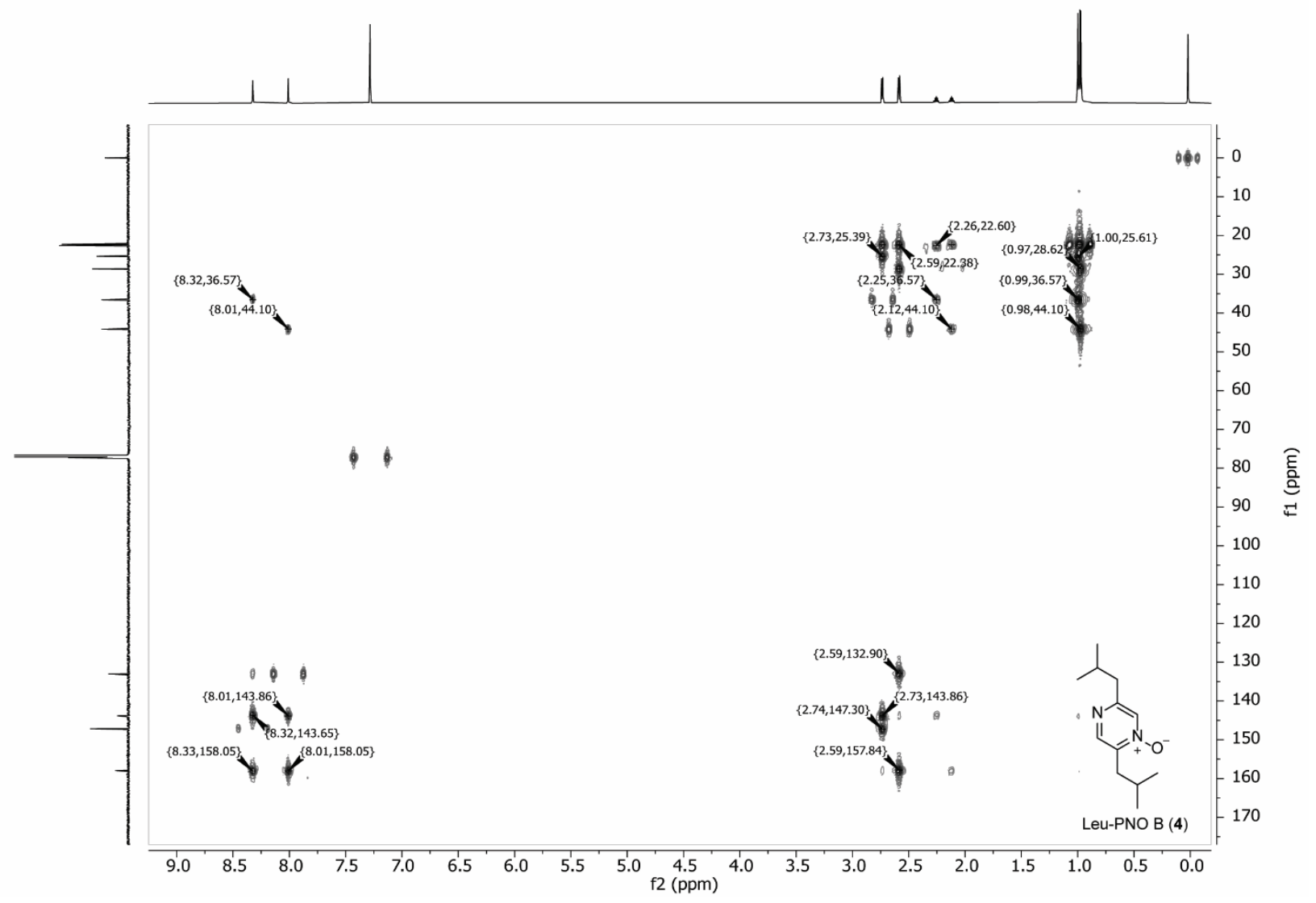

Extended Data 17. $\left({ }^{1} \mathrm{H},{ }^{13} \mathrm{C}\right) \mathrm{HMBC}$ NMR spectrum of isolated Leu-PNO B (4) in $\mathrm{CDCl}_{3}\left({ }^{1} \mathrm{H}, 700 \mathrm{MHz}\right.$, $\left.{ }^{13} \mathrm{C}, 176 \mathrm{MHz}\right)$. 


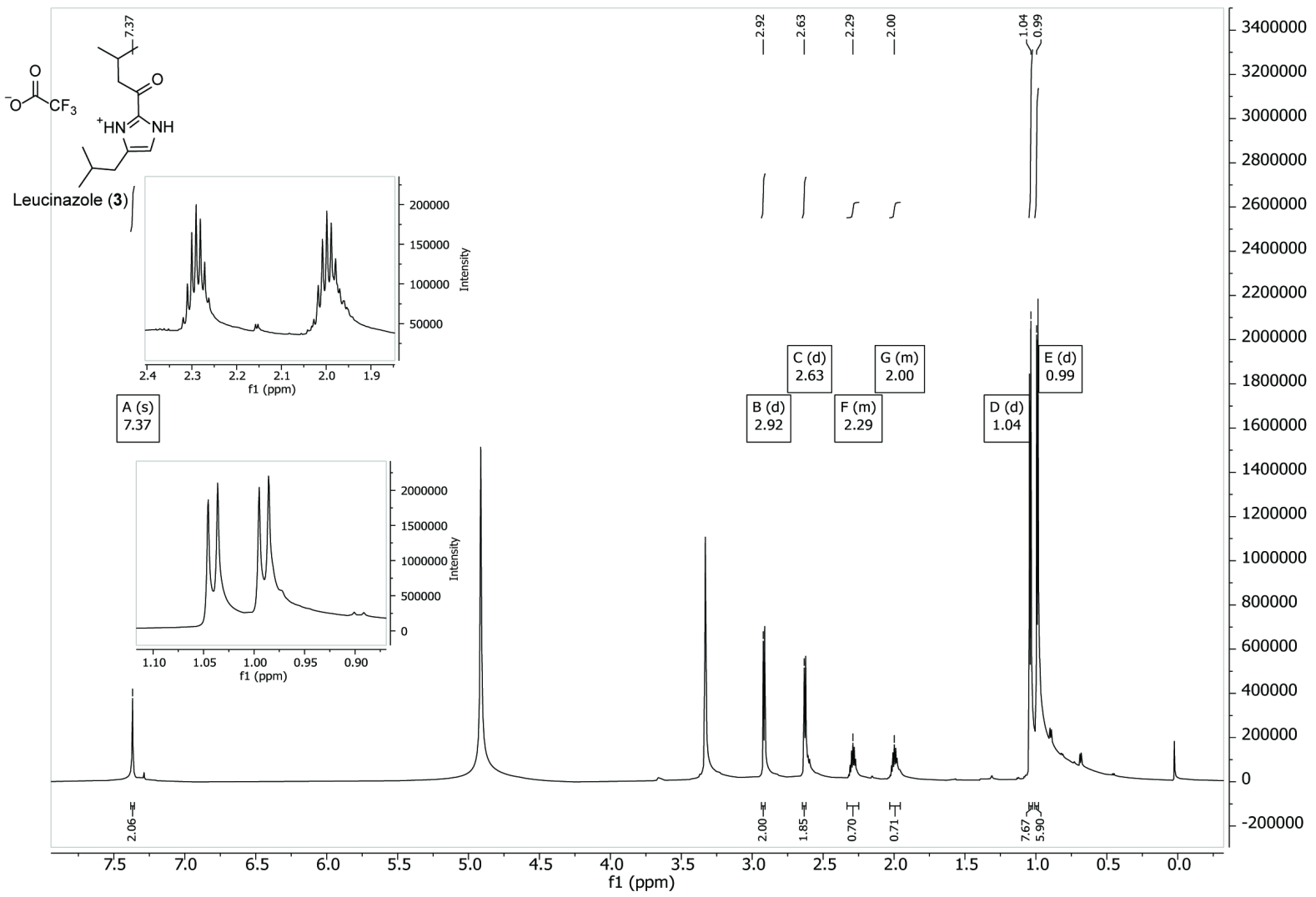

Extended Data 18. ${ }^{1} \mathrm{H}$ NMR spectrum of isolated leucinazole (3) in MeOD (700 MHz).

Isolated as TFA salt. 


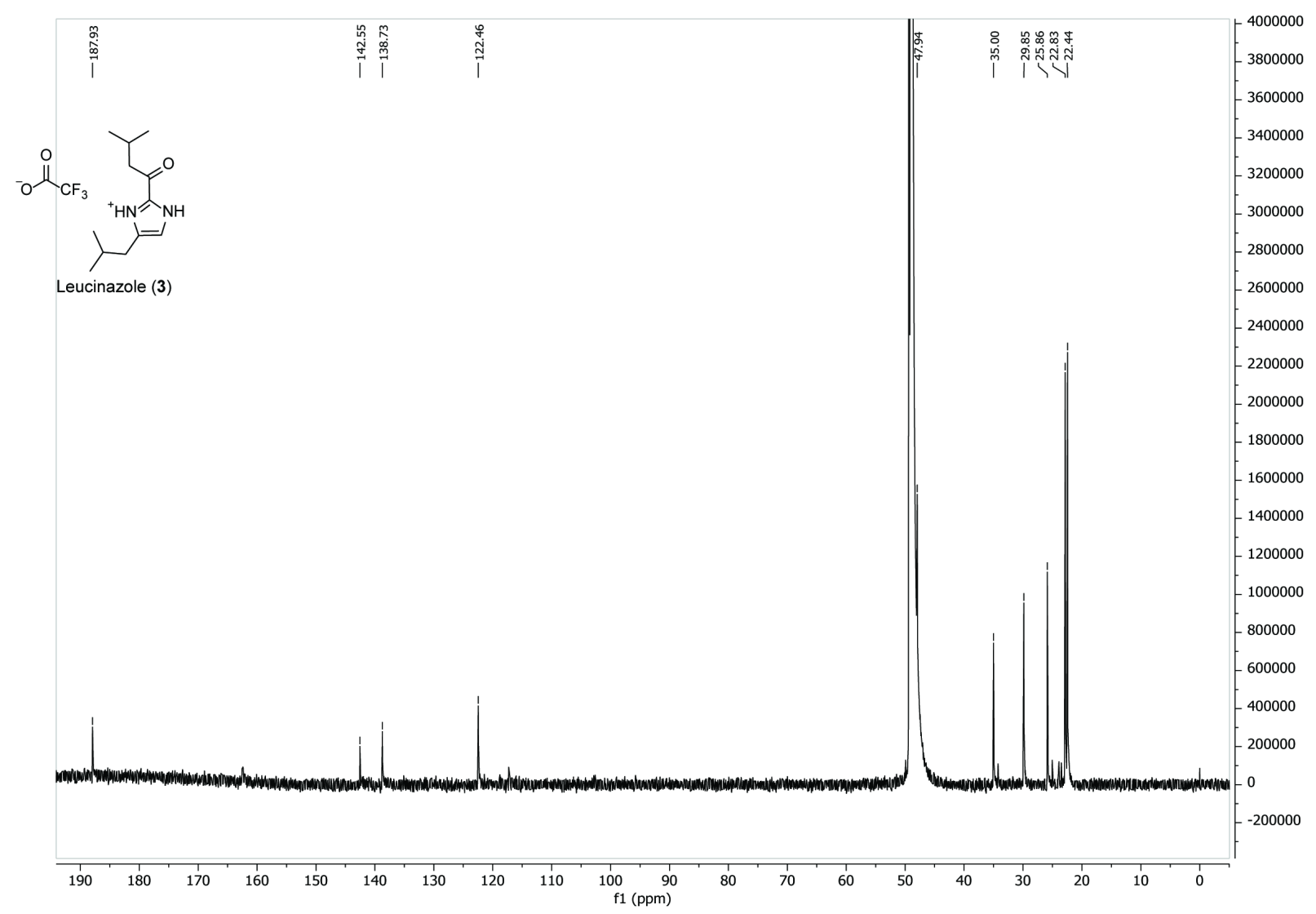

Extended Data 19. ${ }^{13} \mathrm{C}$ NMR spectrum of isolated leucinazole (3) in MeOD (700 MHz).

Isolated as TFA salt. 


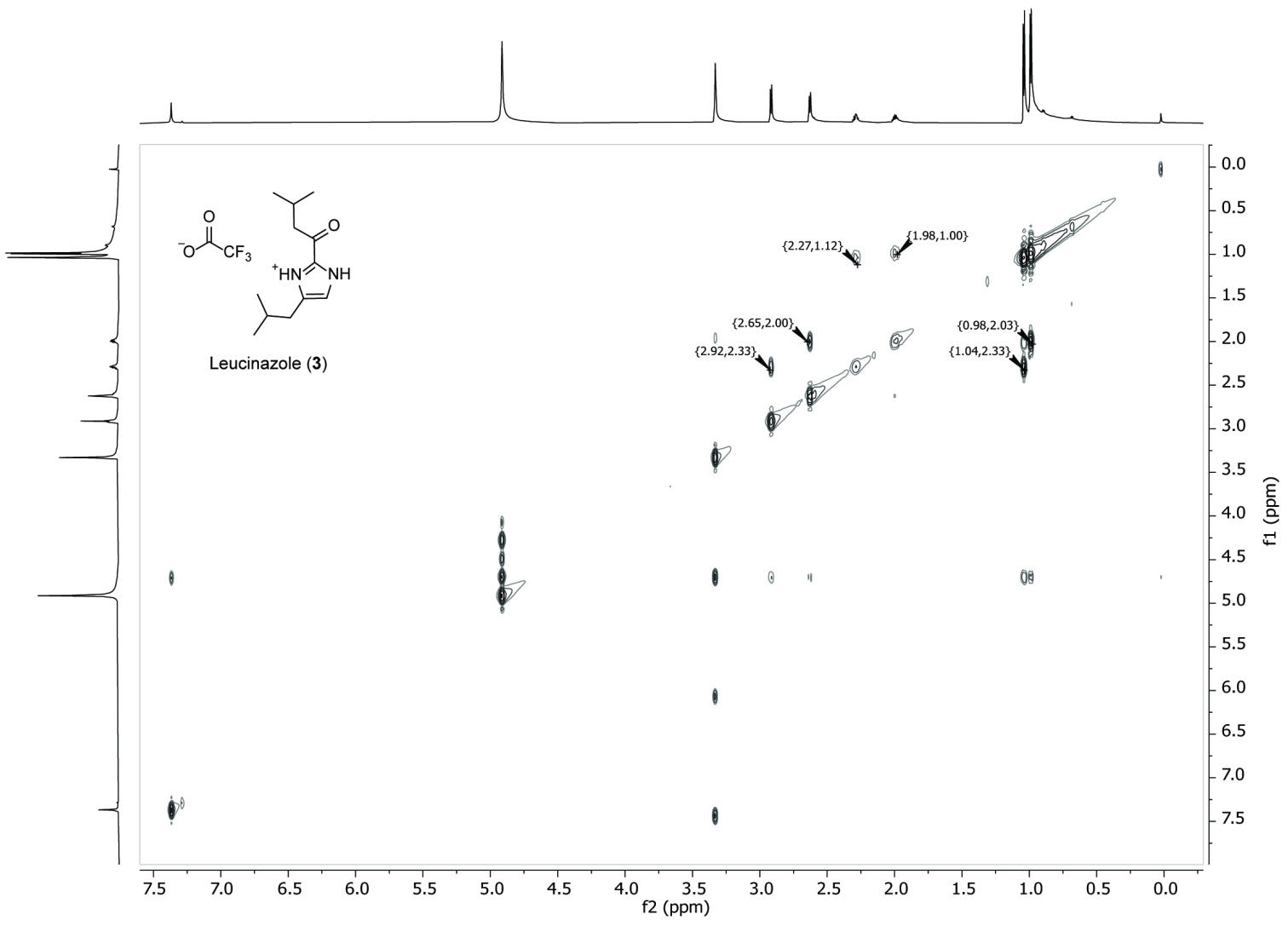

Extended Data 20. $\left({ }^{1} \mathrm{H},{ }^{1} \mathrm{H}\right)$ COSY NMR spectrum of isolated leucinazole (3) in MeOD $(700 \mathrm{MHz})$. Isolated as TFA salt. 


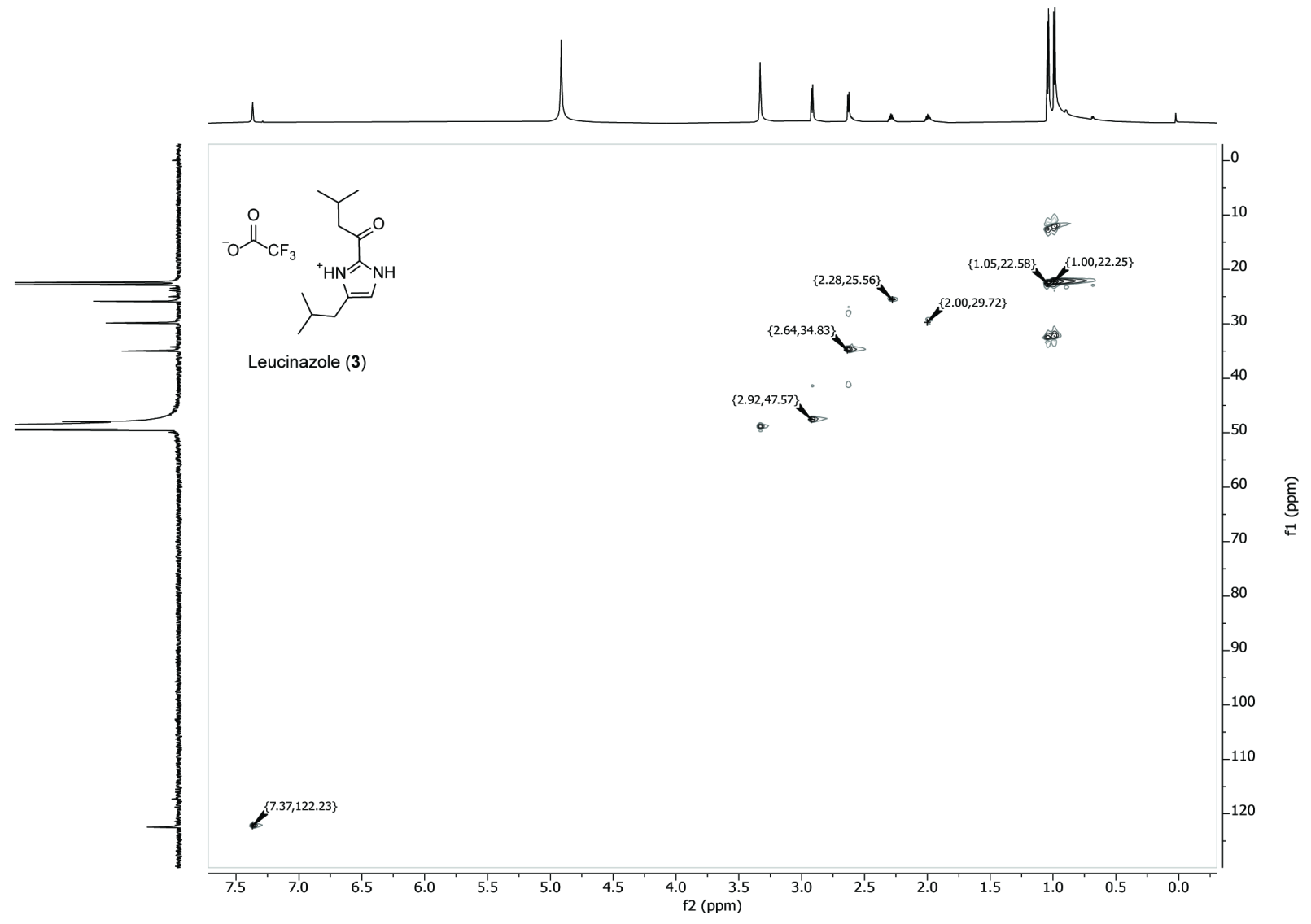

Extended Data 21. $\left({ }^{1} \mathrm{H},{ }^{13} \mathrm{C}\right) \mathrm{HSQC}$ NMR spectrum of isolated leucinazole (3) in MeOD $\left({ }^{1} \mathrm{H}, 700 \mathrm{MHz}\right.$, ${ }^{13} \mathrm{C}, 176 \mathrm{MHz}$ ).

Isolated as TFA salt. 


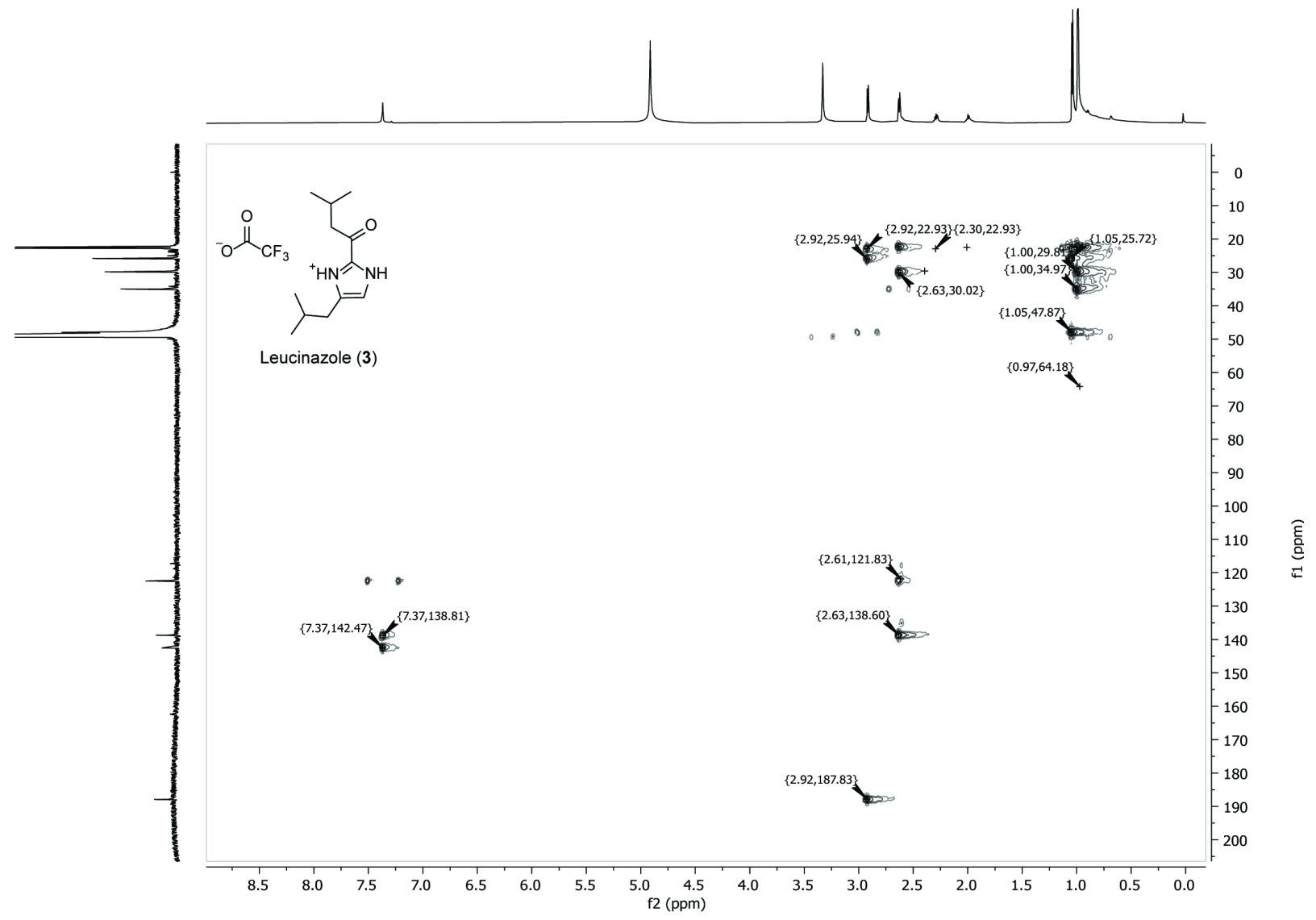

Extended Data 22. $\left({ }^{1} \mathrm{H},{ }^{13} \mathrm{C}\right) \mathrm{HMBC}$ NMR spectrum of isolated leucinazole (3) in MeOD $\left({ }^{1} \mathrm{H}, 700 \mathrm{MHz}\right.$, ${ }^{13} \mathrm{C}, 176 \mathrm{MHz}$ ).

Isolated as TFA salt. 


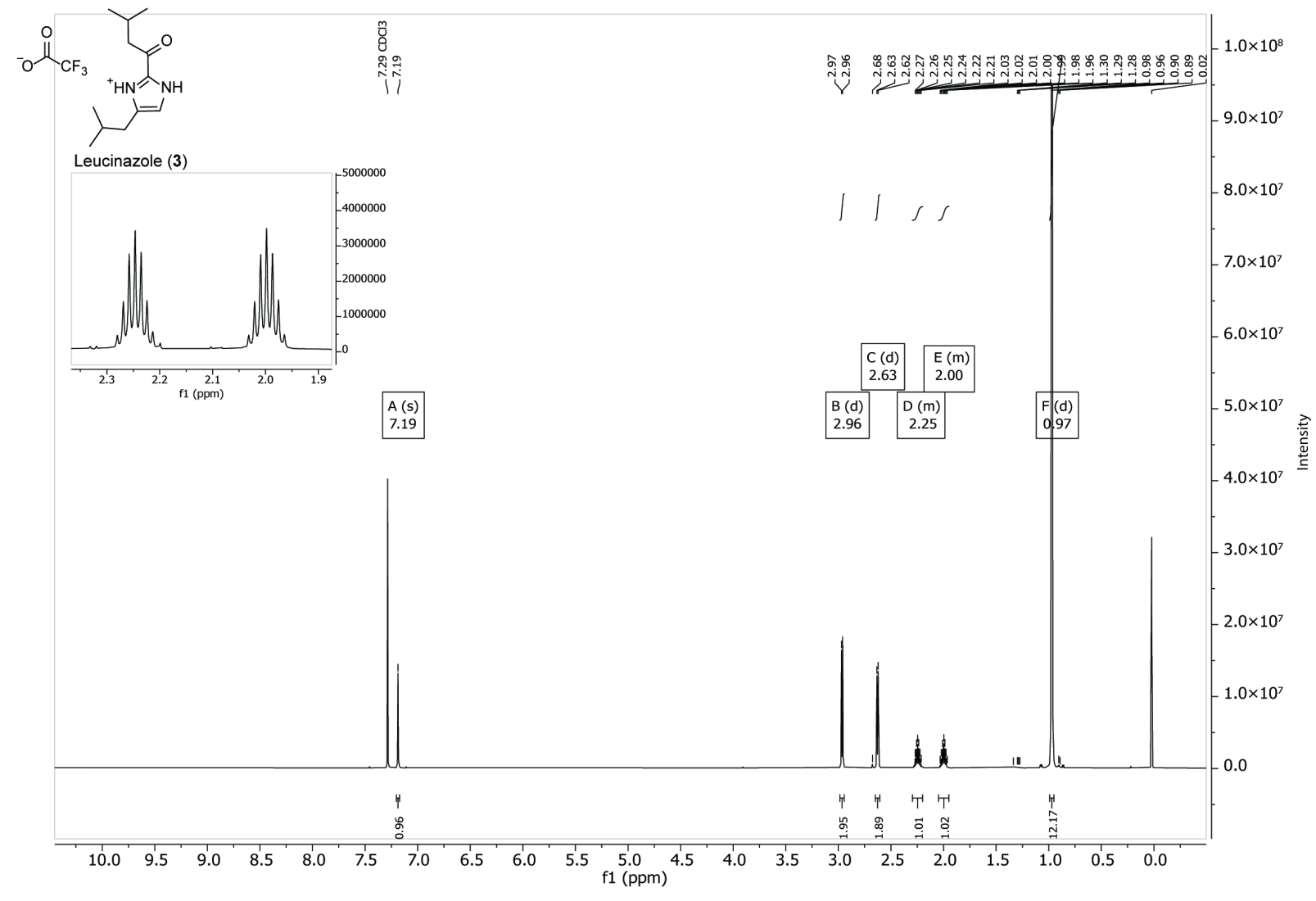

Extended Data 23. ${ }^{1} \mathrm{H}$ NMR spectrum of isolated leucinazole (3) in $\mathrm{CDCl}_{3}(700 \mathrm{MHz})$.

Isolated as TFA salt. 


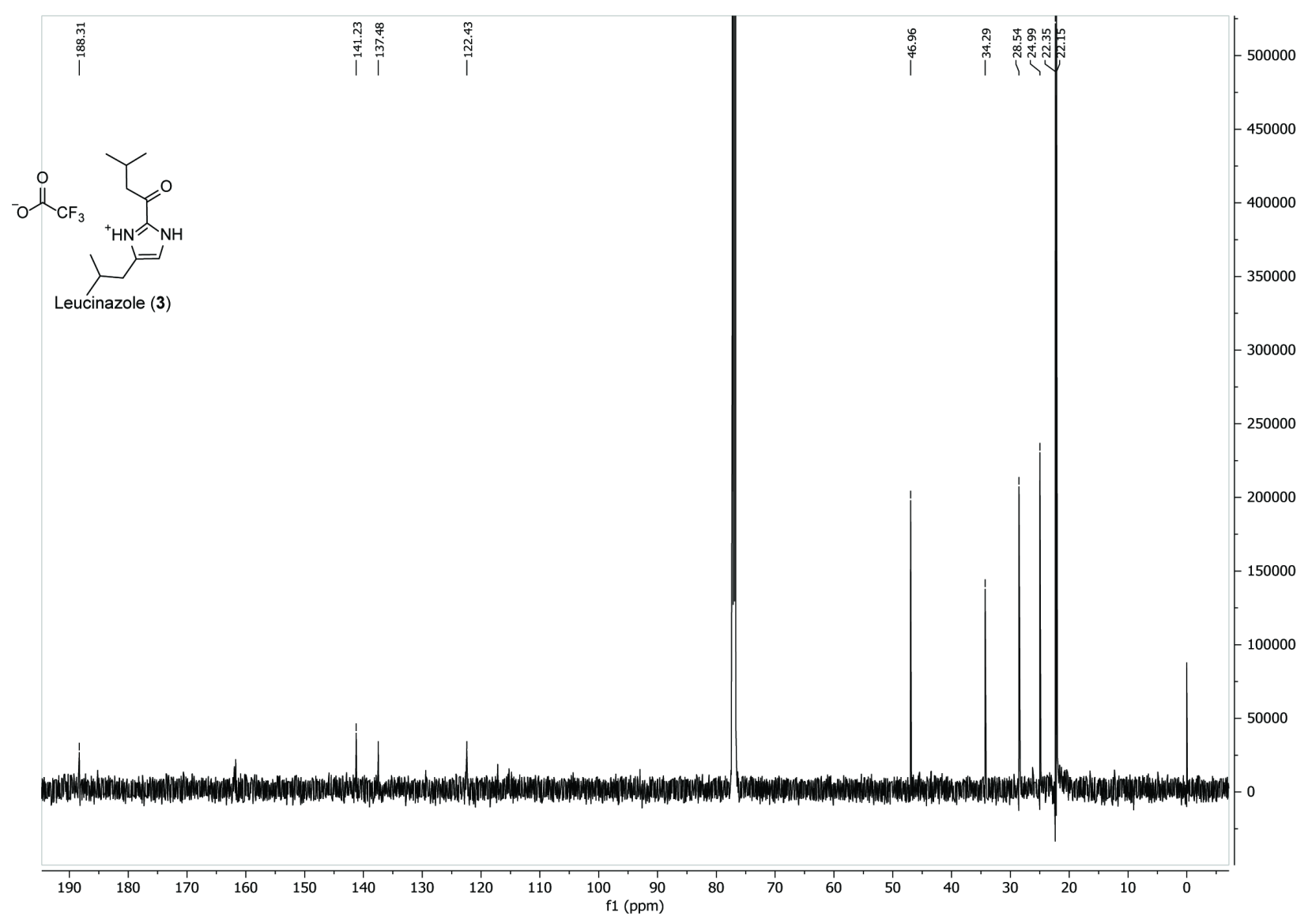

Extended Data $24 .{ }^{13} \mathrm{C}$ NMR spectrum of isolated leucinazole (3) in $\mathrm{CDCl}_{3}(700 \mathrm{MHz})$. Isolated as TFA salt. 


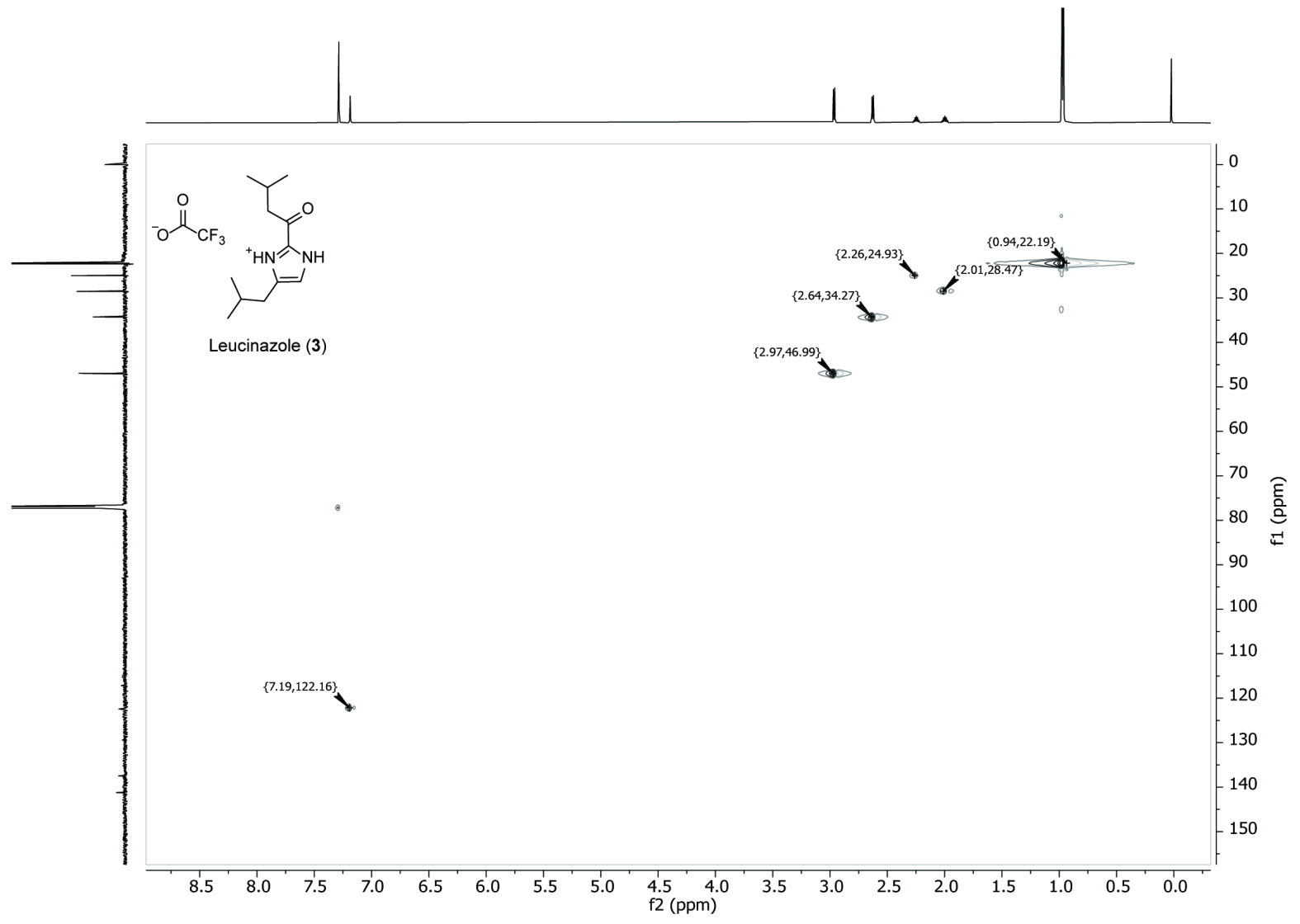

Extended Data 25. $\left({ }^{1} \mathrm{H},{ }^{13} \mathrm{C}\right) \mathrm{HSQC}$ NMR spectrum of isolated leucinazole (3) in $\mathrm{CDCl}_{3}\left({ }^{1} \mathrm{H}, 700 \mathrm{MHz}\right.$, $\left.{ }^{13} \mathrm{C}, 176 \mathrm{MHz}\right)$.

Isolated as TFA salt. 


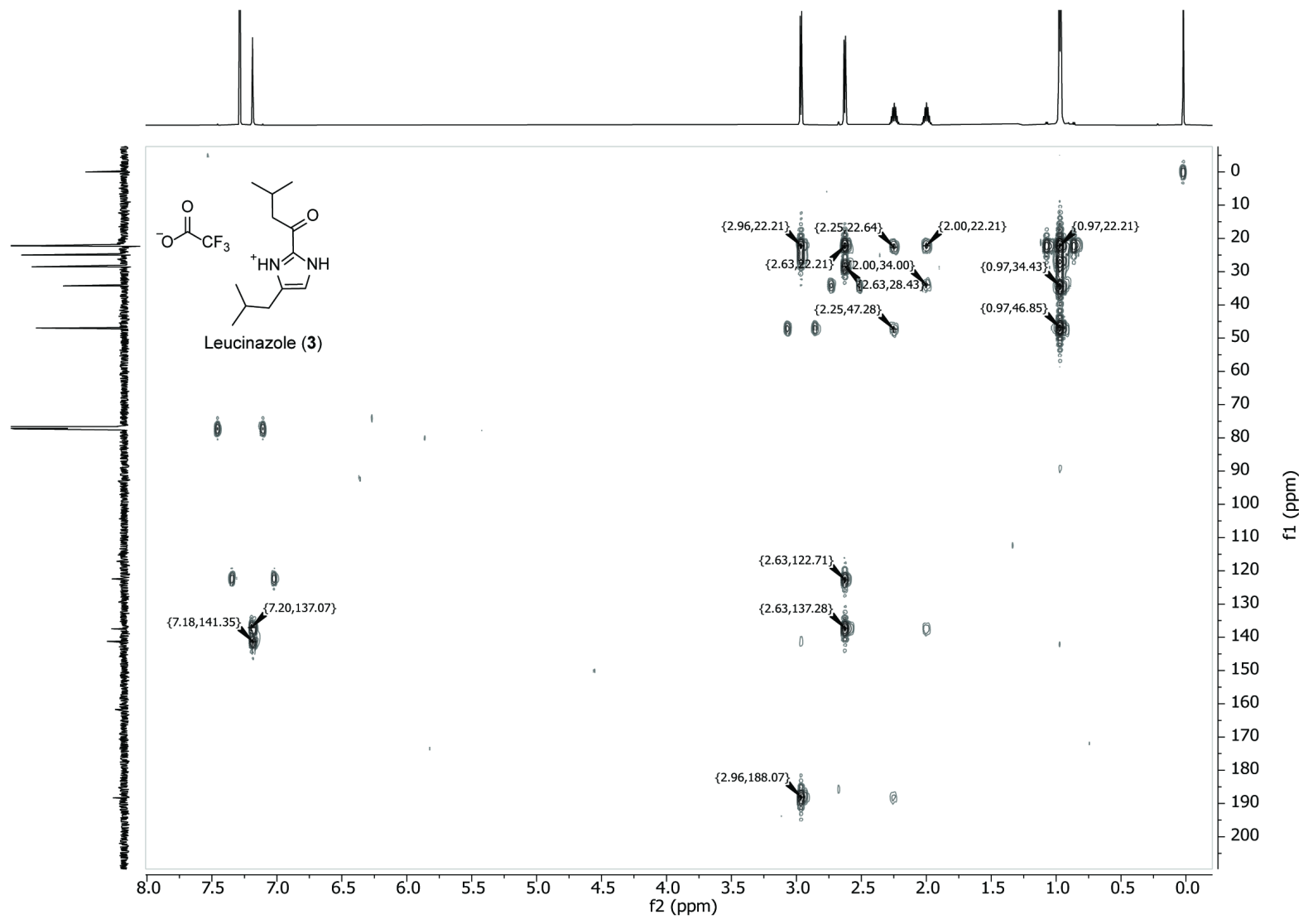

Extended Data 26. $\left({ }^{1} \mathrm{H},{ }^{13} \mathrm{C}\right) \mathrm{HMBC}$ NMR spectrum of isolated leucinazole (3) in $\mathrm{CDCl}_{3}\left({ }^{1} \mathrm{H}, 700 \mathrm{MHz}\right.$, ${ }^{13} \mathrm{C}, 176 \mathrm{MHz}$ ).

Isolated as TFA salt. 


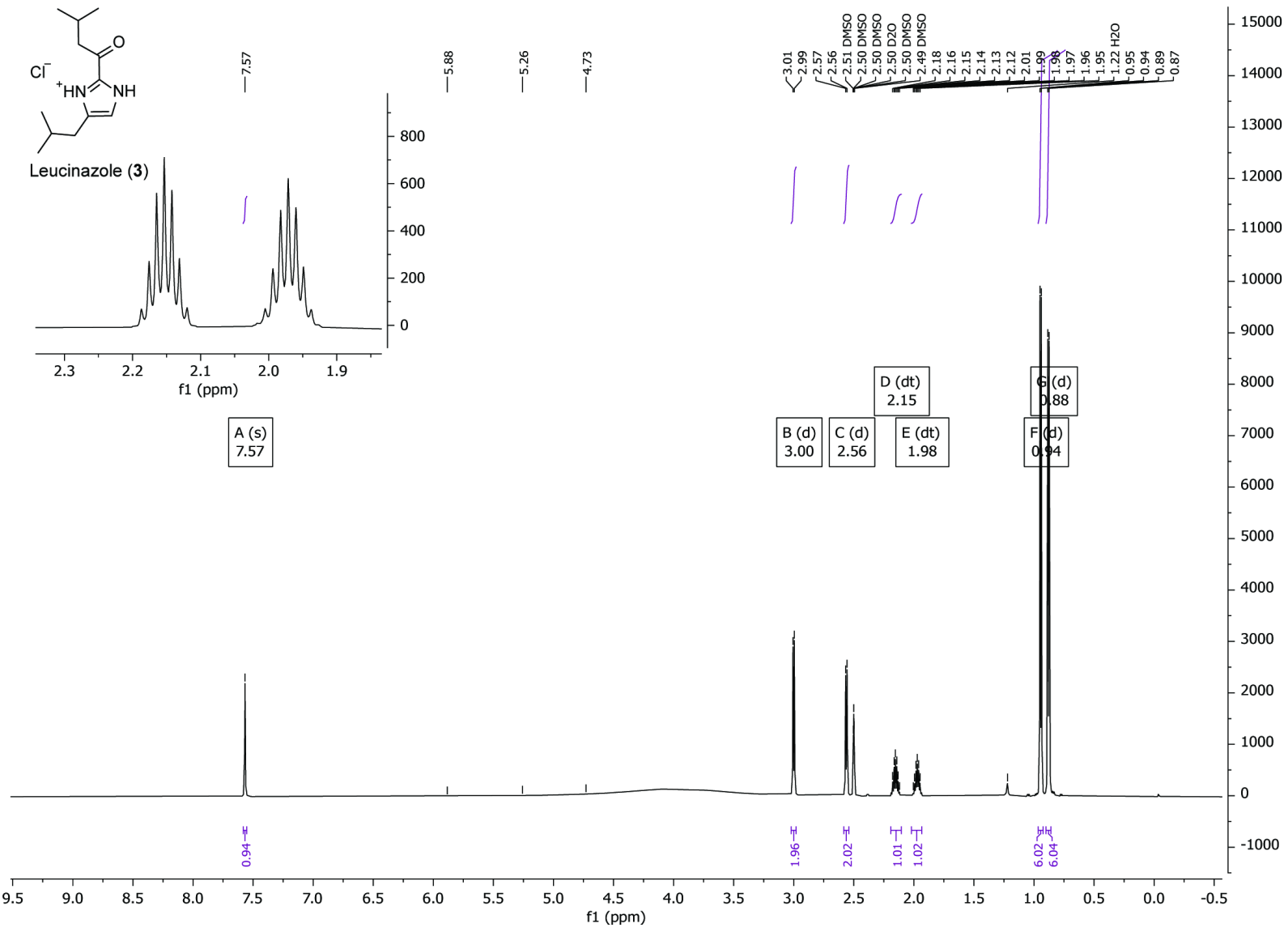

Extended Data 27. ${ }^{1} \mathrm{H}$ NMR spectrum of isolated leucinazole (3) in DMSO (500 MHz).

Isolated as $\mathrm{HCl}$ salt. 


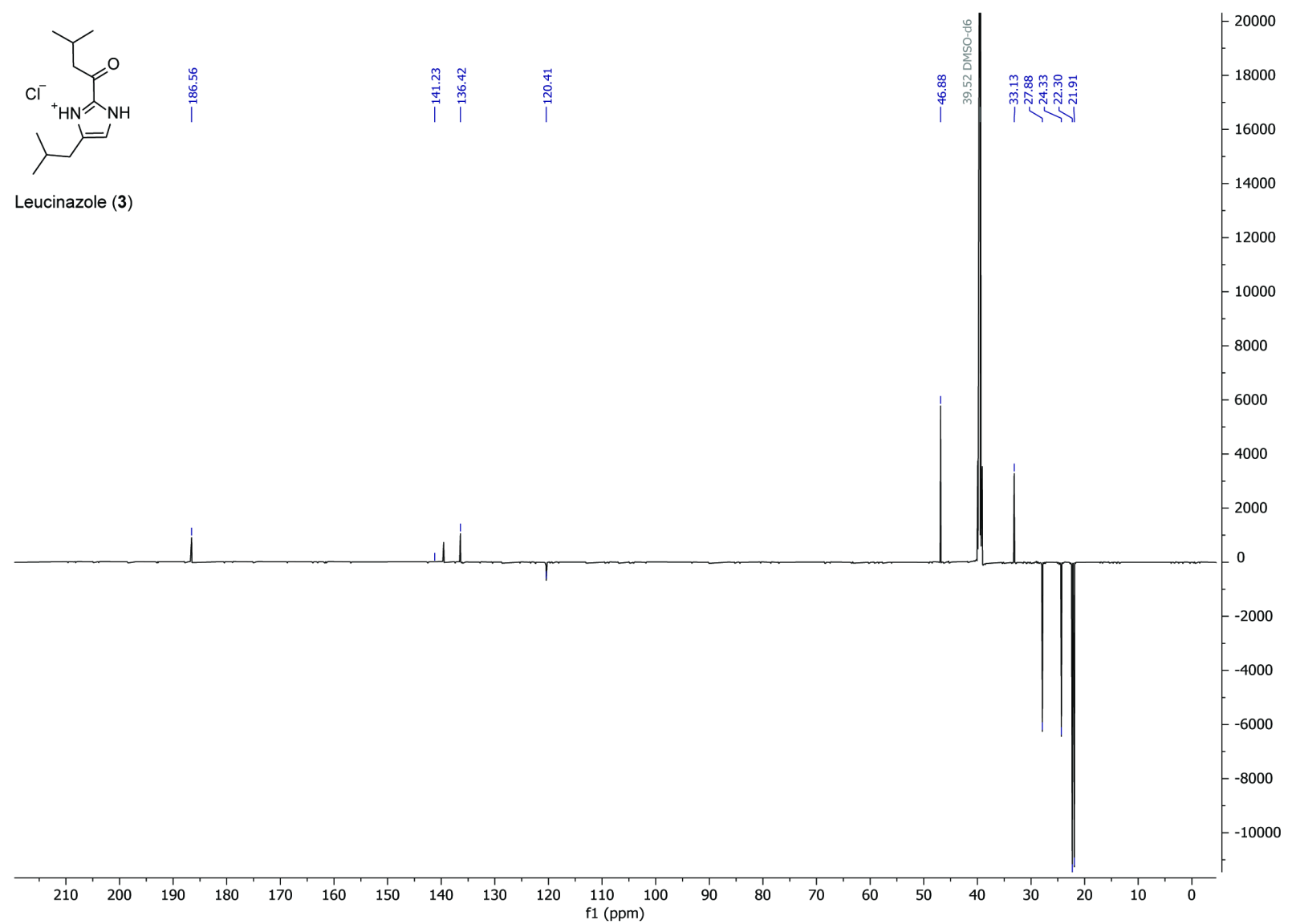

Extended Data 28. DEPT-135 ${ }^{13} \mathrm{C}$ NMR spectrum of isolated leucinazole (3) in DMSO (500 MHz). Isolated as $\mathrm{HCl}$ salt. 


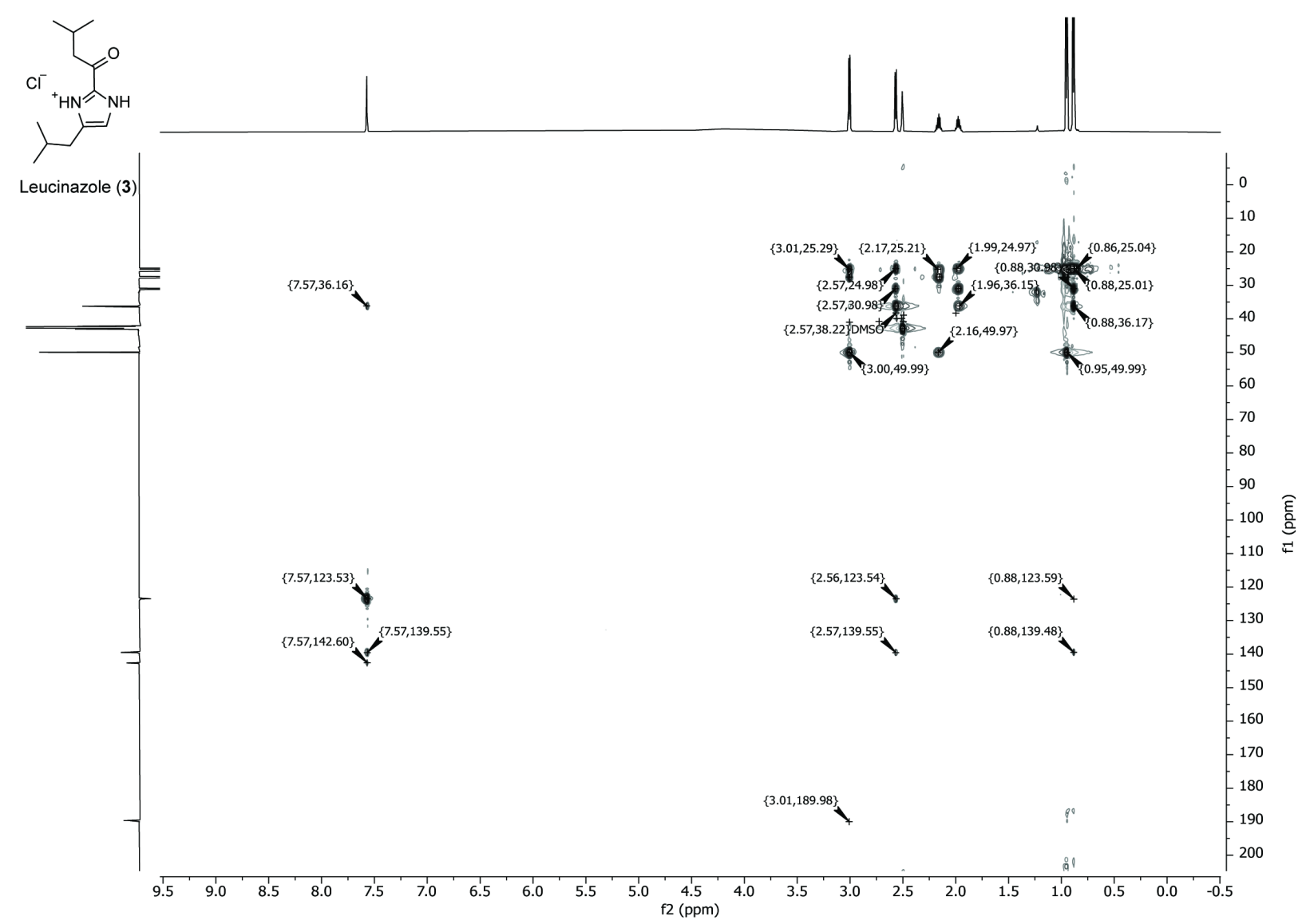

Extended Data 29. ${ }^{1} \mathrm{H}-{ }^{13} \mathrm{C}$ HSQC-TOCSY NMR spectrum of isolated leucinazole (3) in DMSO (500 MHz).

Isolated as $\mathrm{HCl}$ salt. 


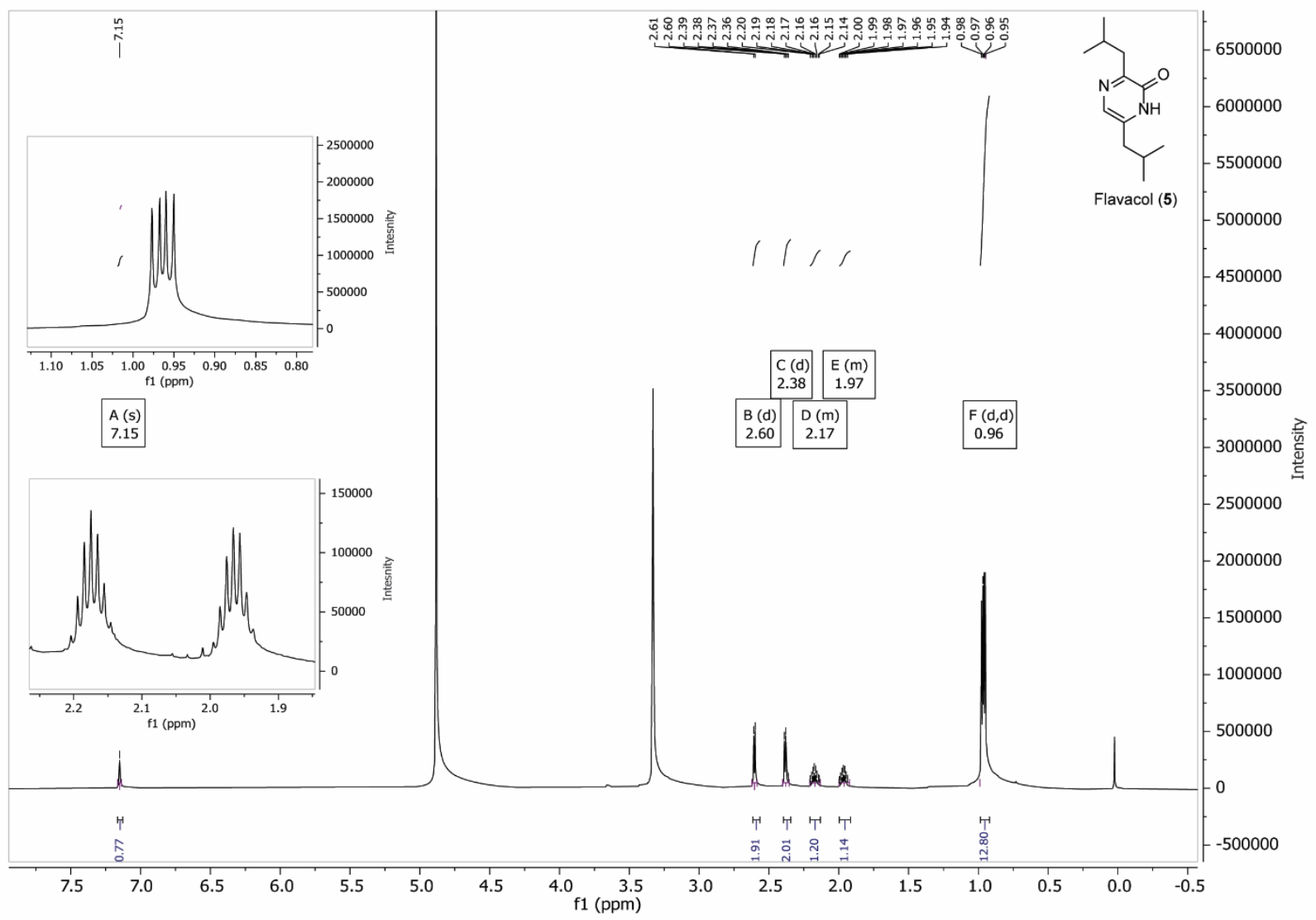

Extended Data 30. ${ }^{1} \mathrm{H}$ NMR spectrum of isolated flavacol (5) in MeOD (700 MHz). 


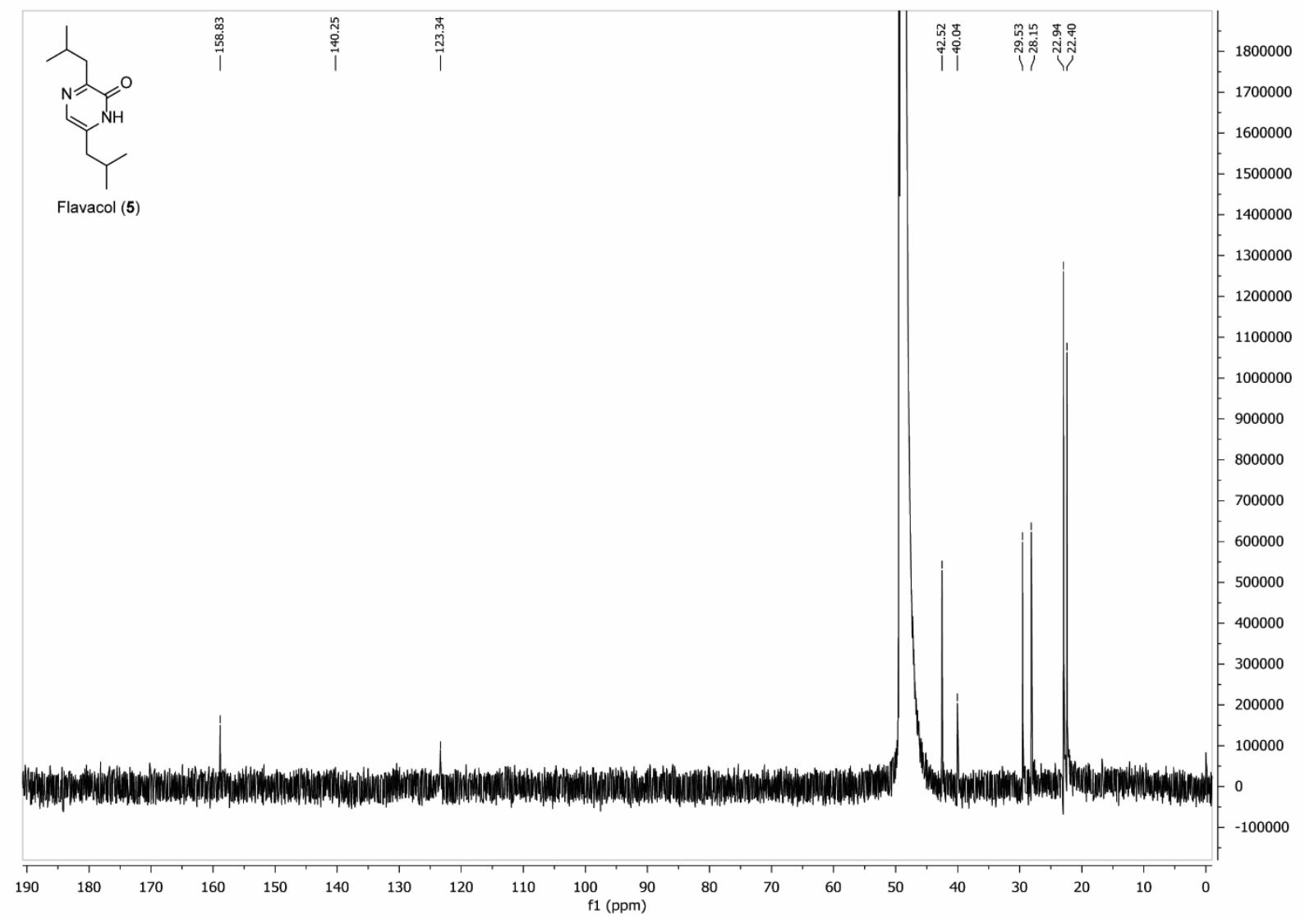

Extended Data $31 .{ }^{13} \mathrm{C}$ NMR spectrum of isolated flavacol (5) in MeOD (700 MHz). 


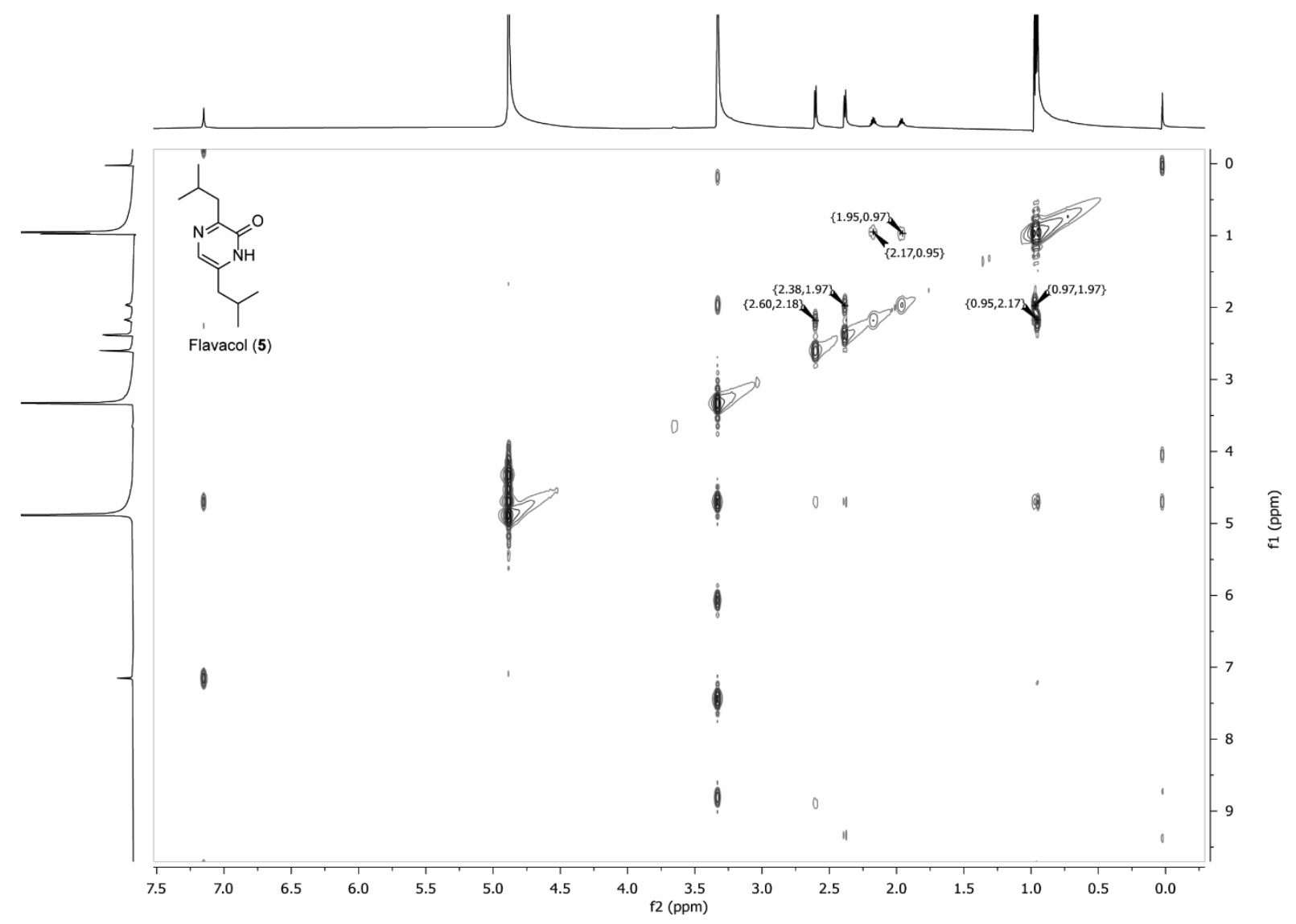

Extended Data 32. $\left({ }^{1} \mathrm{H},{ }^{1} \mathrm{H}\right)$ COSY NMR spectrum of isolated flavacol (5) in MeOD (700 MHz). 


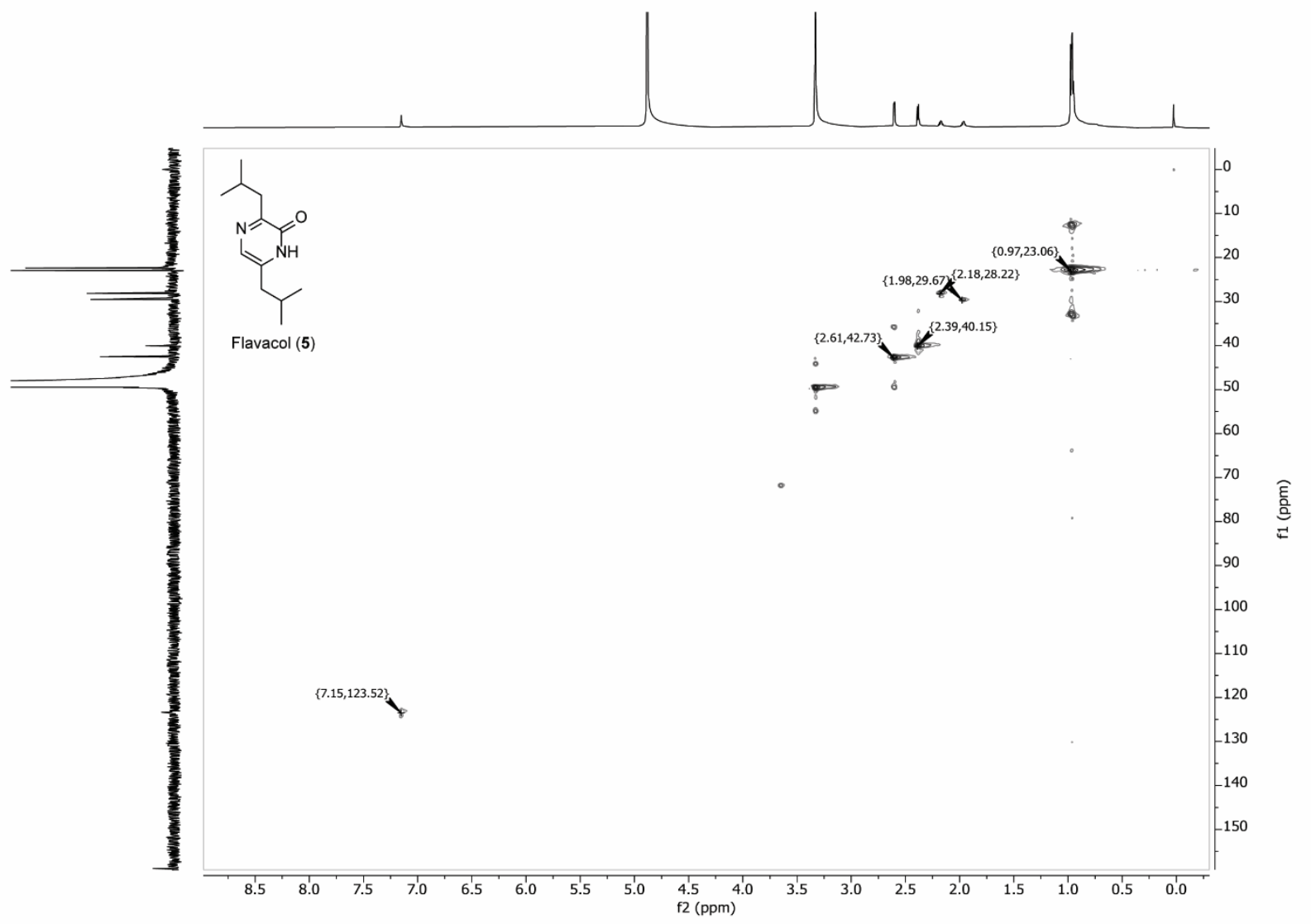

Extended Data 33. $\left({ }^{1} \mathrm{H},{ }^{13} \mathrm{C}\right) \mathrm{HSQC}$ NMR spectrum of isolated flavacol $(5)$ in MeOD $\left({ }^{1} \mathrm{H}, 700 \mathrm{MHz},{ }^{13} \mathrm{C}\right.$, $176 \mathrm{MHz}$ ). 


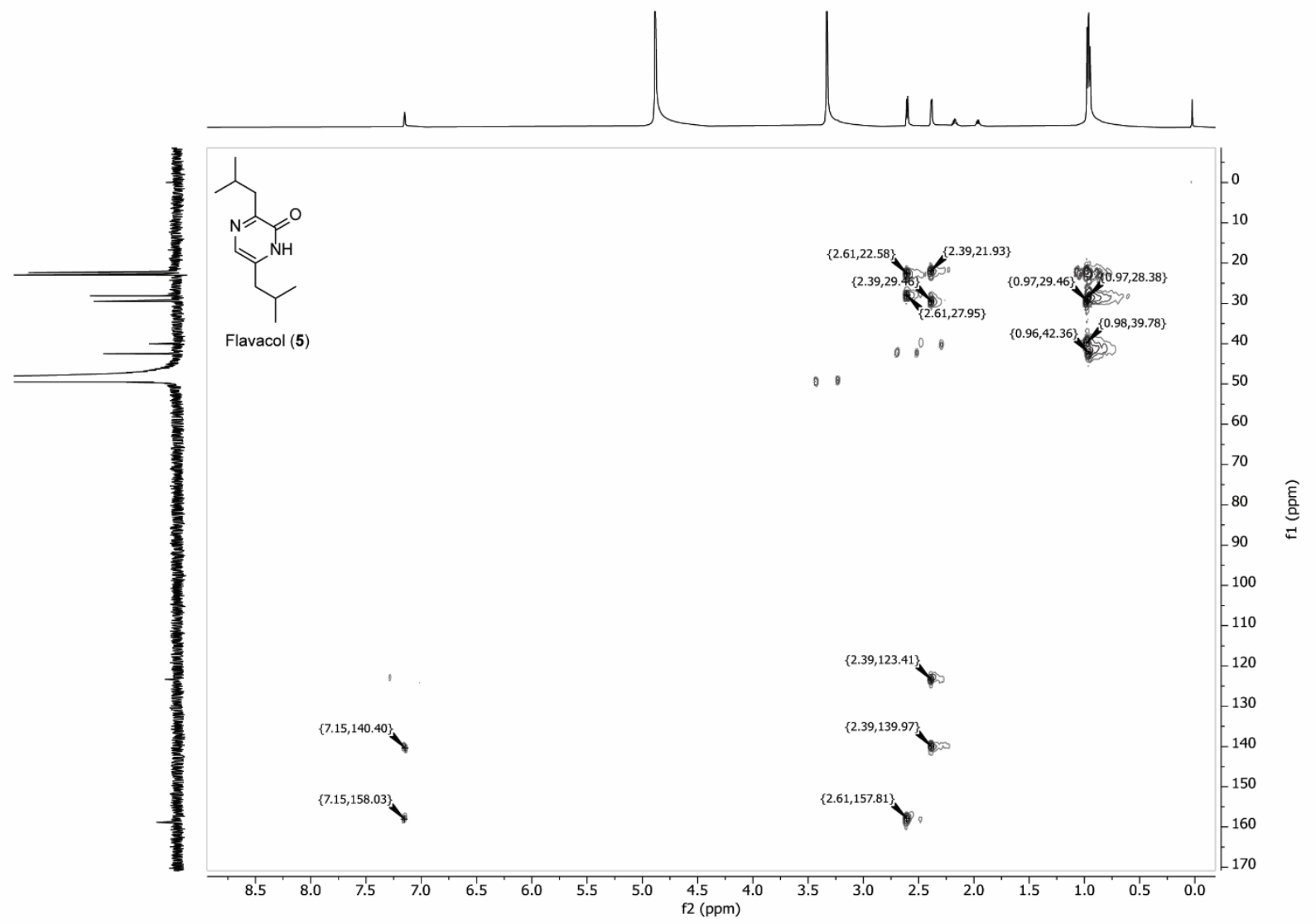

Extended Data 34. $\left({ }^{1} \mathrm{H},{ }^{13} \mathrm{C}\right) \mathrm{HMBC}$ NMR spectrum of isolated flavacol $(5)$ in MeOD $\left({ }^{1} \mathrm{H}, 700 \mathrm{MHz}\right.$, ${ }^{13} \mathrm{C}, 176 \mathrm{MHz}$ ). 


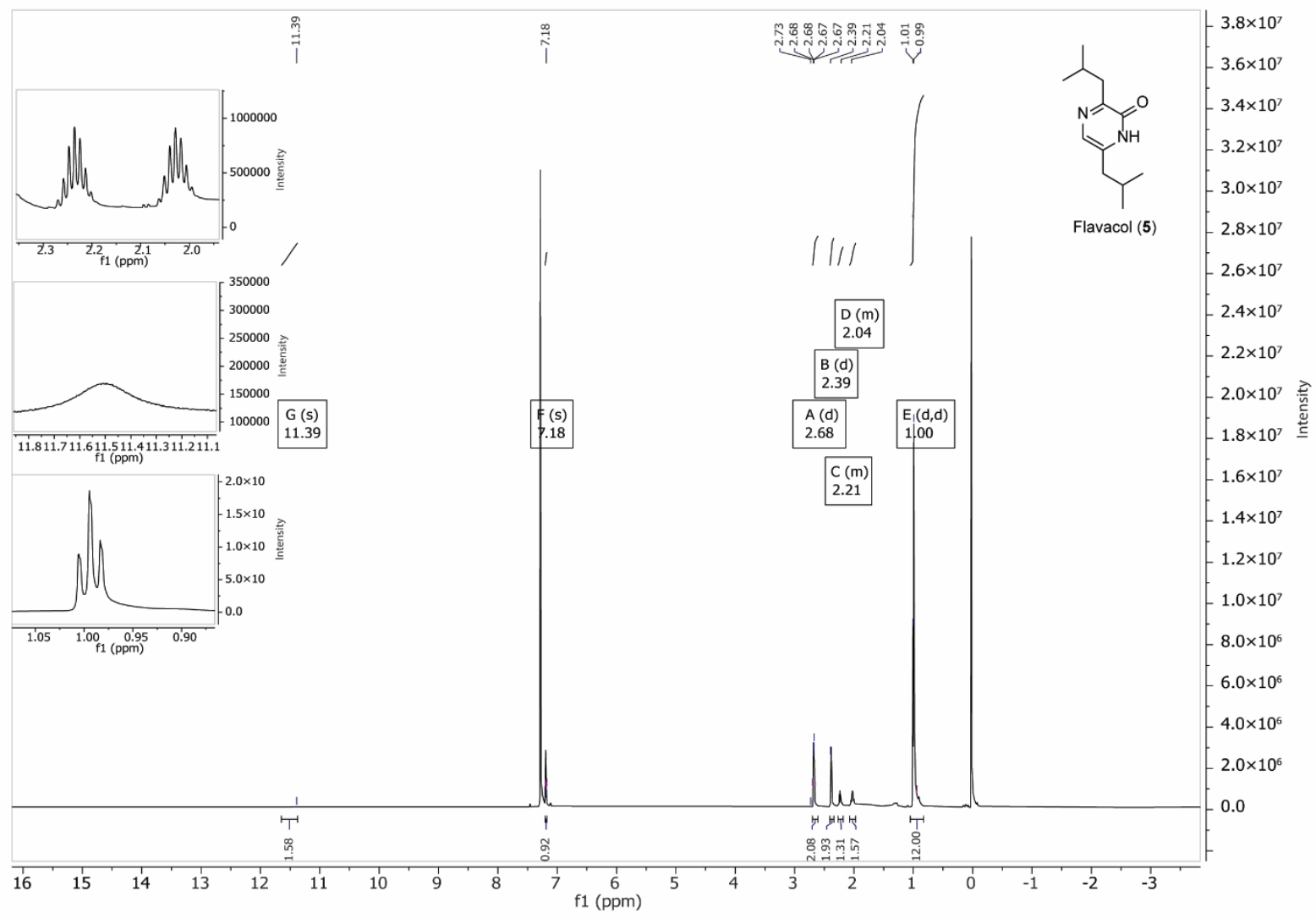

Extended Data $35 .{ }^{1} \mathrm{H}$ NMR spectrum of isolated flavacol (5) in $\mathrm{CDCl}_{3}(700 \mathrm{MHz})$. 


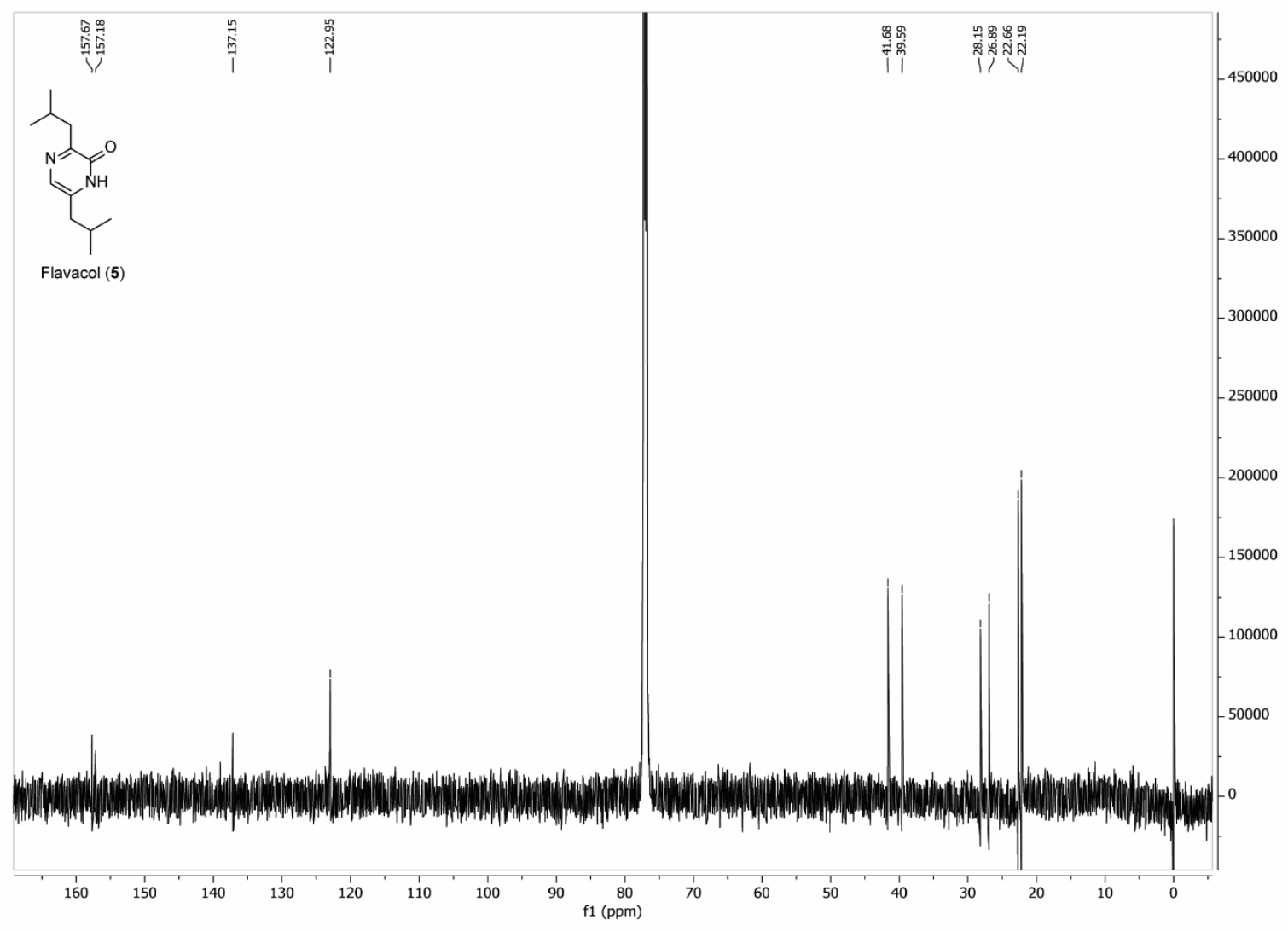

Extended Data 36. ${ }^{13} \mathrm{C}$ NMR spectrum of isolated flavacol (5) in $\mathrm{CDCl}_{3}(700 \mathrm{MHz})$. 

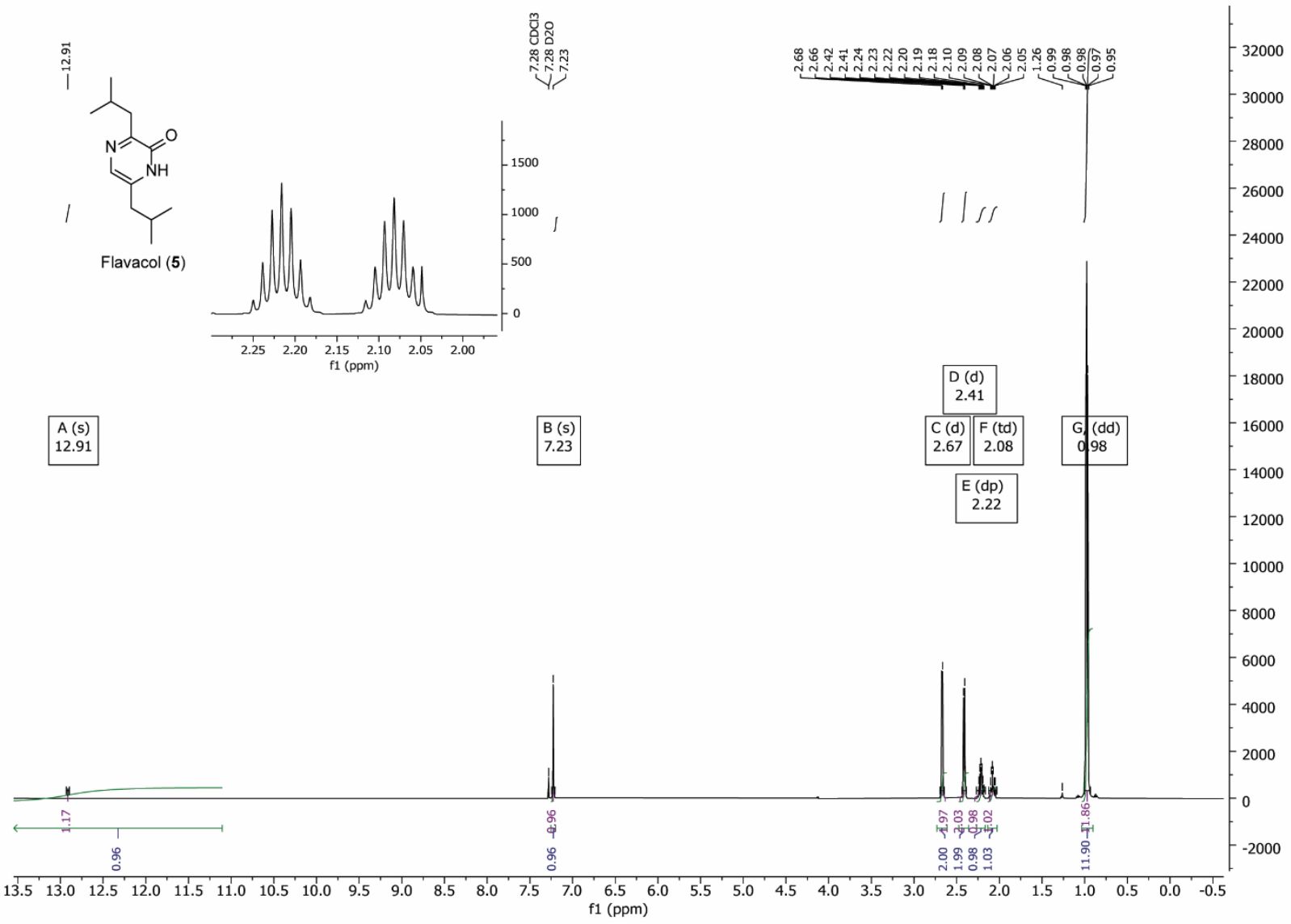

Extended Data 37. ${ }^{1} \mathrm{H}$ NMR spectrum of synthetic flavacol (5) in $\mathrm{CDCl}_{3}(500 \mathrm{MHz})$. 


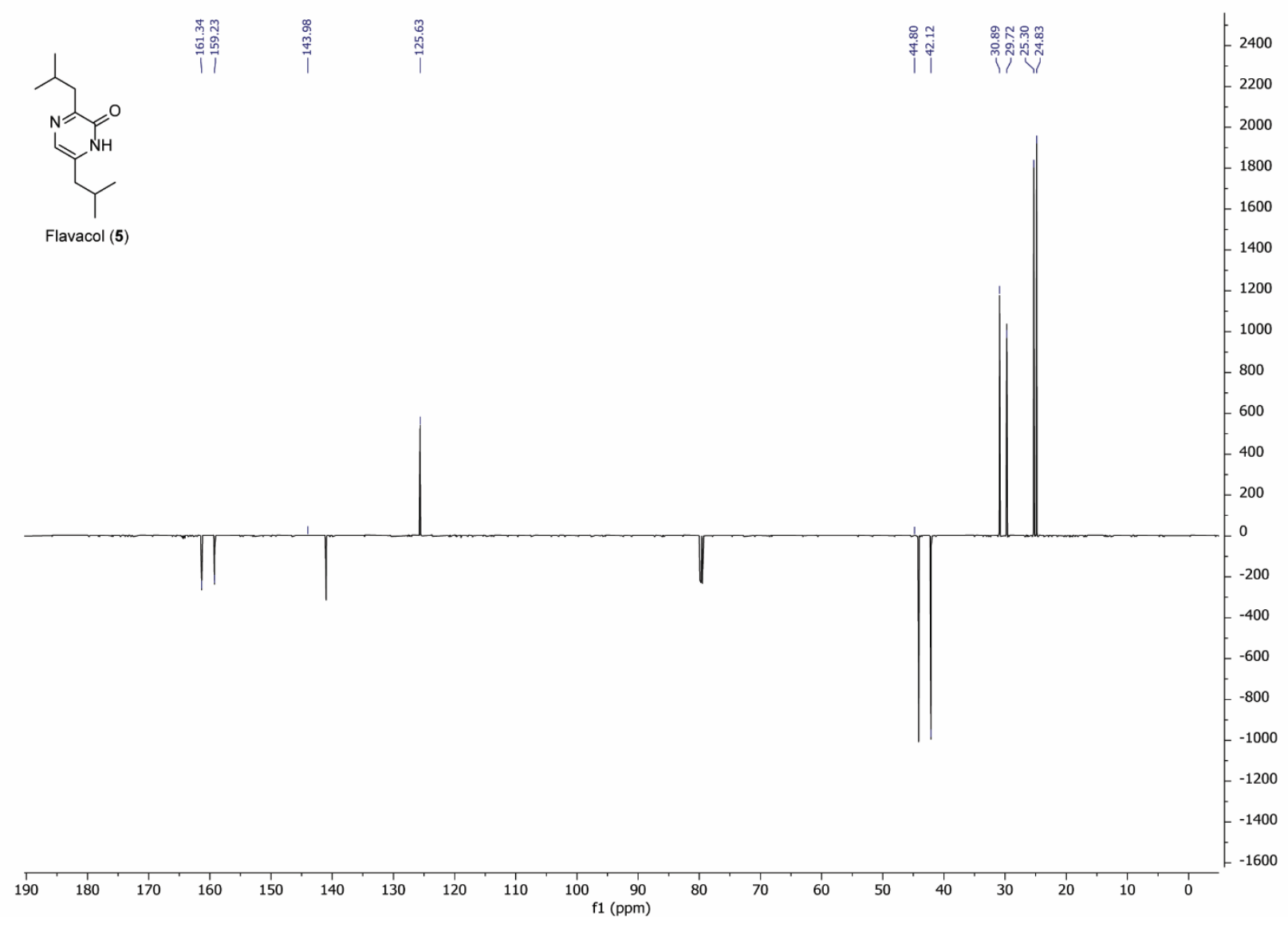

Extended Data 38. DEPT-135 ${ }^{13} \mathrm{C}$ NMR spectrum of synthetic flavacol (5) in $\mathrm{CDCl}_{3}(500 \mathrm{MHz})$. 


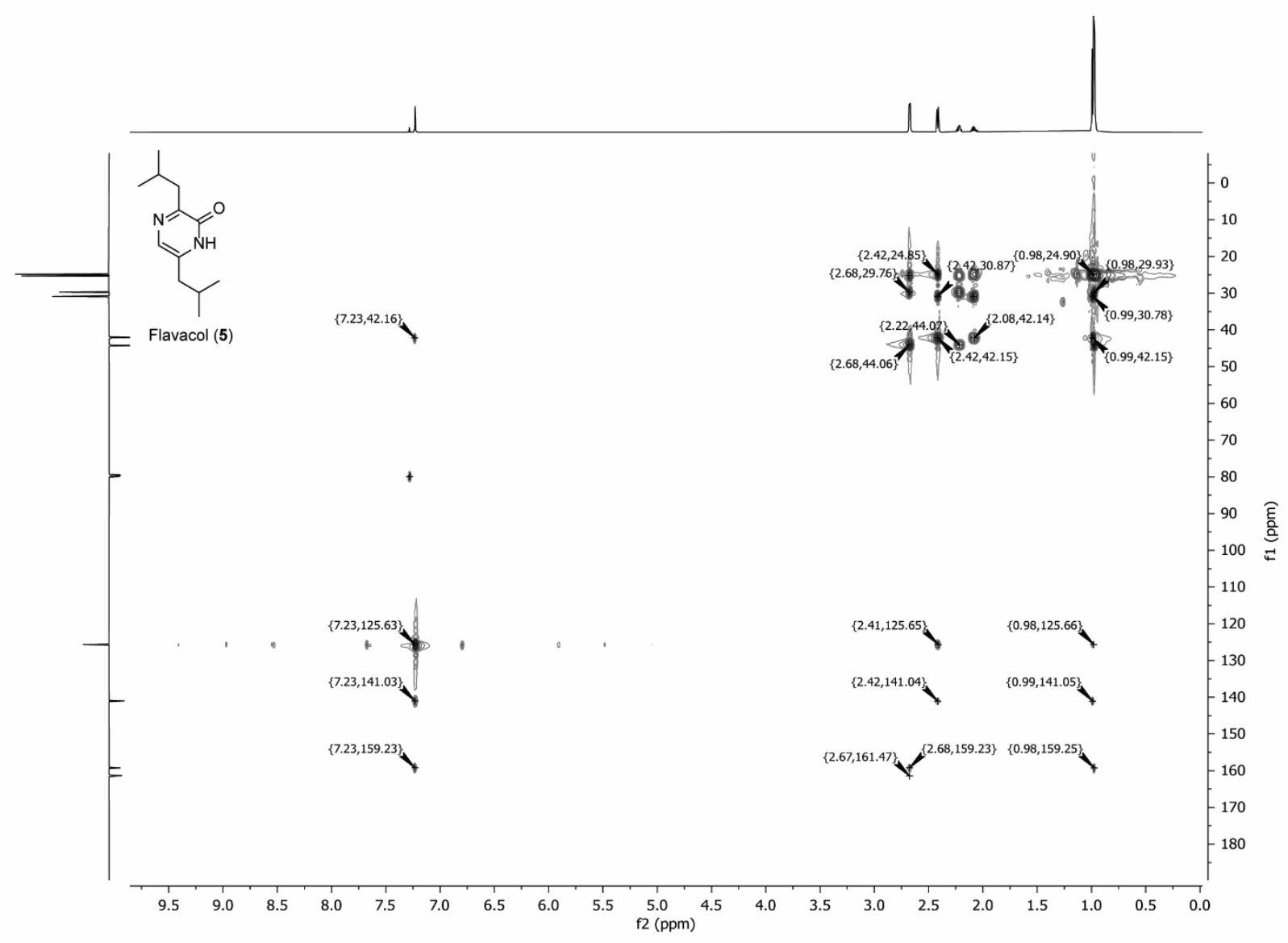

Extended Data 39. $\left({ }^{1} \mathrm{H},{ }^{13} \mathrm{C}\right) \mathrm{HSQC}-T O C S Y$ NMR spectrum of synthetic flavacol $(5)$ in $\mathrm{CDCl}_{3}(500$ $\mathrm{MHz}$ ). 


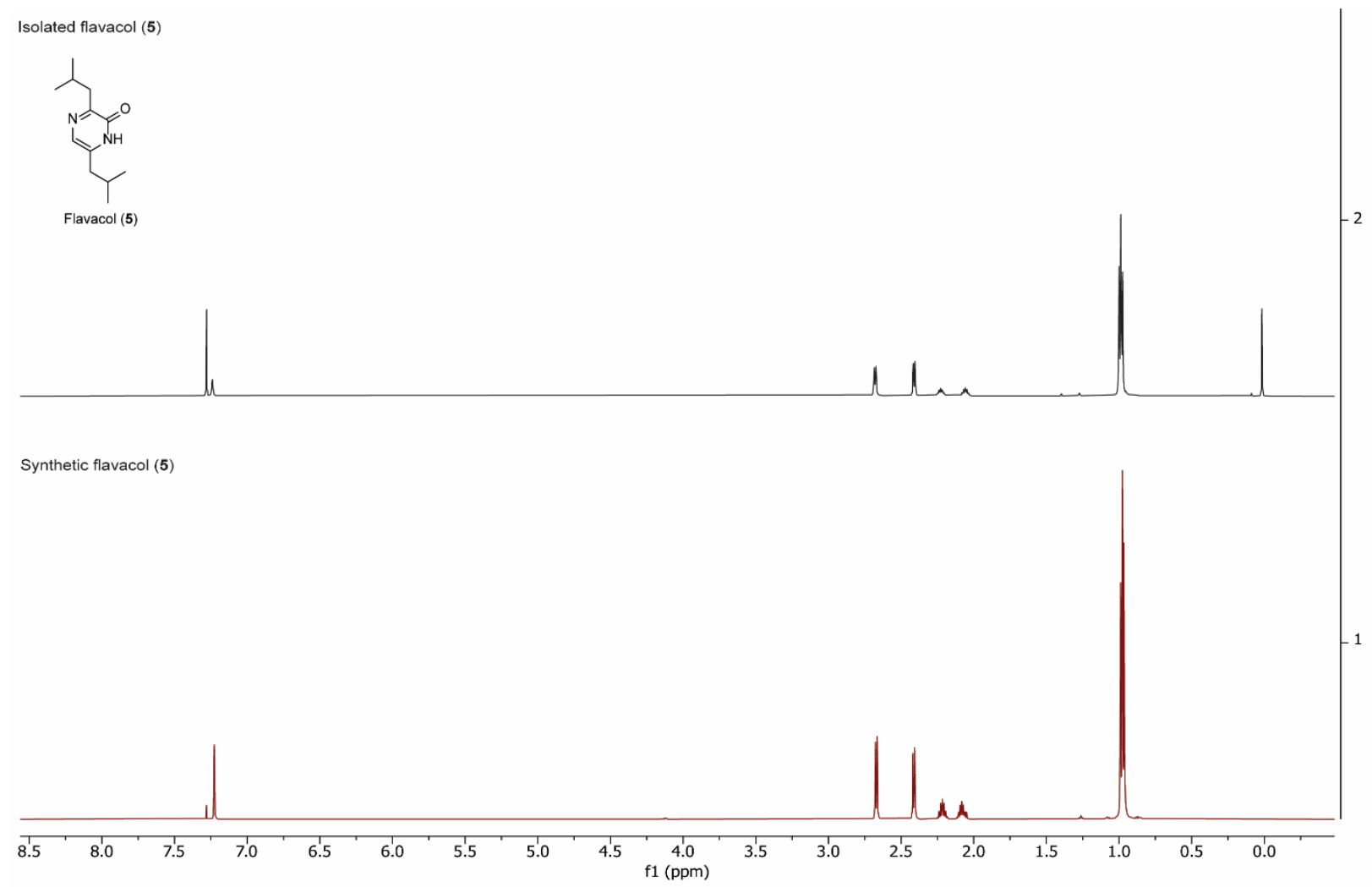

Extended Data 40. ${ }^{1} \mathrm{H}$ NMR spectrum of isolated (top) and synthetic (bottom) flavacol in DMSO-d 6 (500 MHz). 


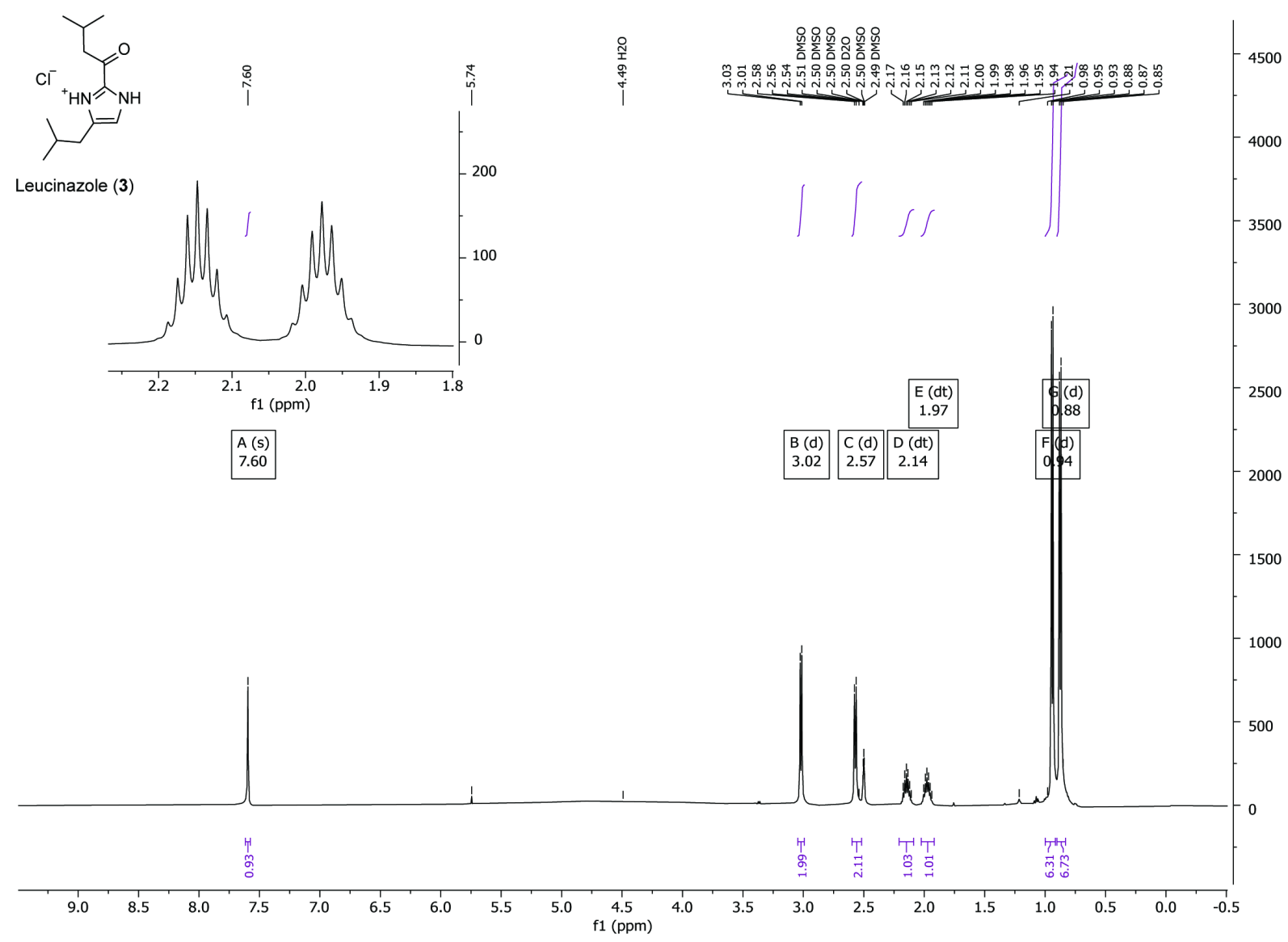

Extended Data 41. ${ }^{1} \mathrm{H}$ NMR spectrum of synthetic leucinazole (3) in DMSO (500 MHz).

Synthesized as $\mathrm{HCl}$ salt. 


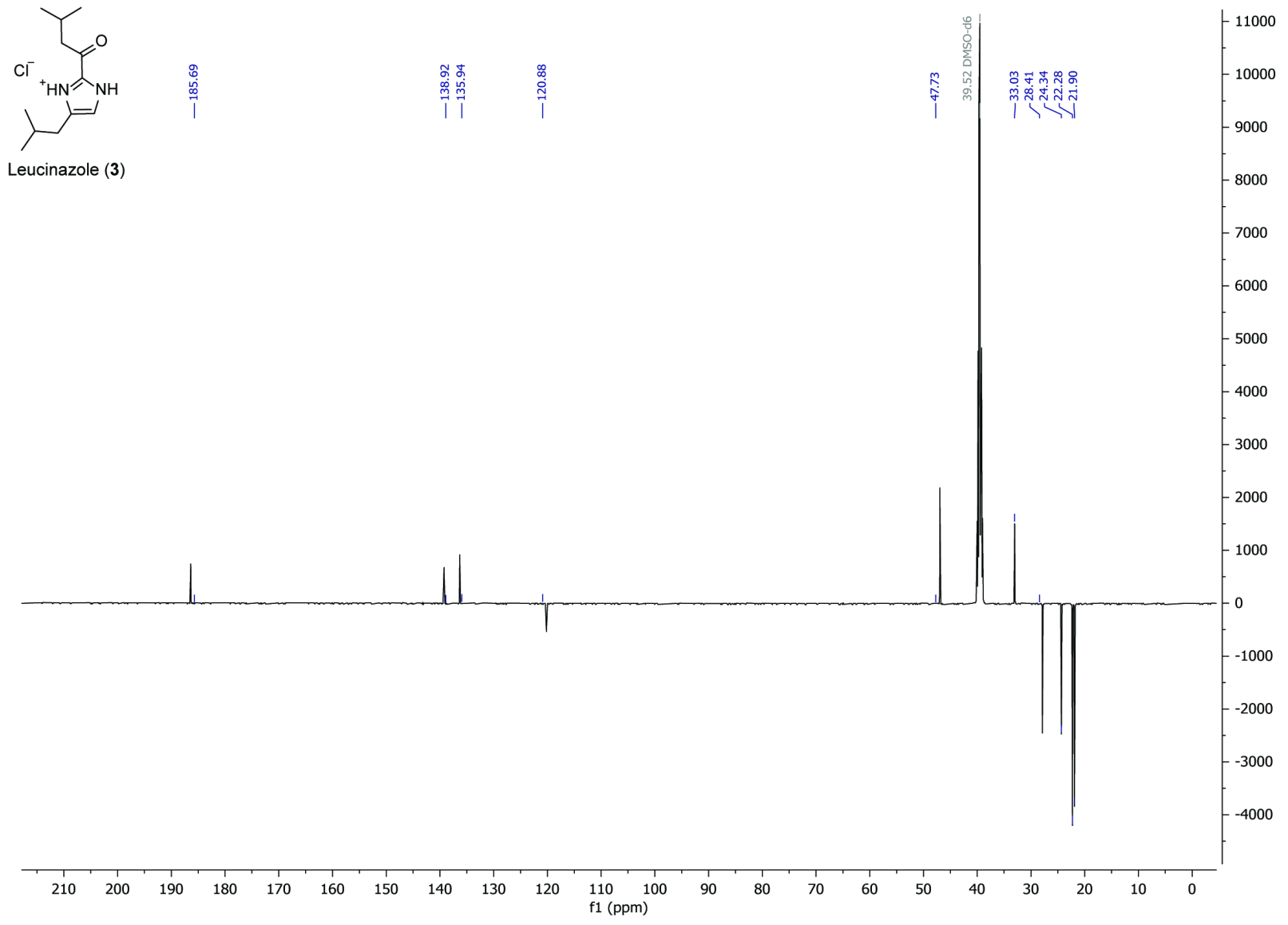

Extended Data 42. DEPT $135{ }^{13} \mathrm{C}$ NMR spectrum of synthetic leucinazole (3) in DMSO (500 MHz).

Synthesized as $\mathrm{HCl}$ salt. 


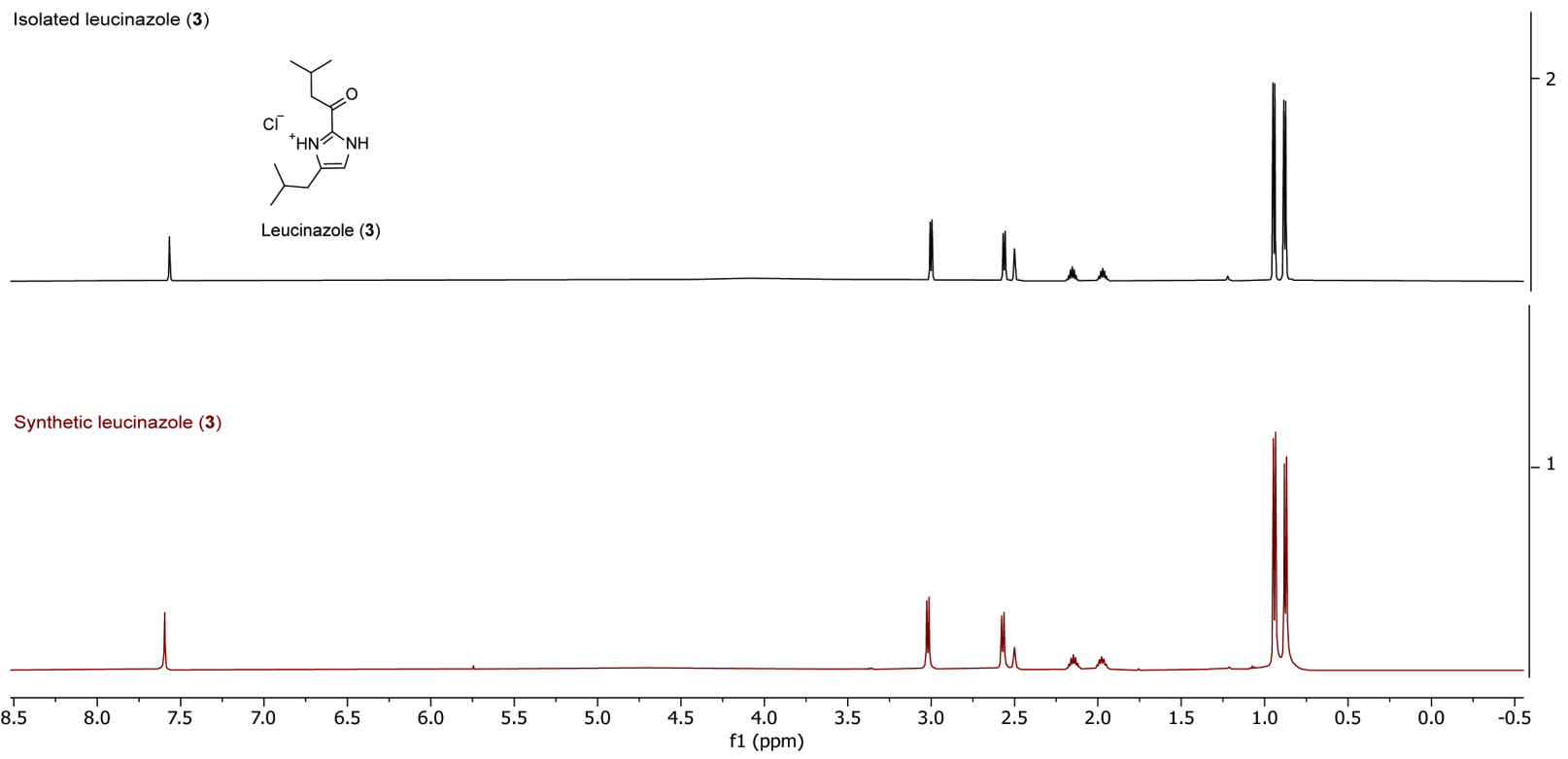

Extended Data 43. ${ }^{1} \mathrm{H}$ NMR spectrum of isolated (top) and synthetic (bottom) leucinazole in DMSO $(500 \mathrm{MHz})$

Synthesized as $\mathrm{HCl}$ salt. 


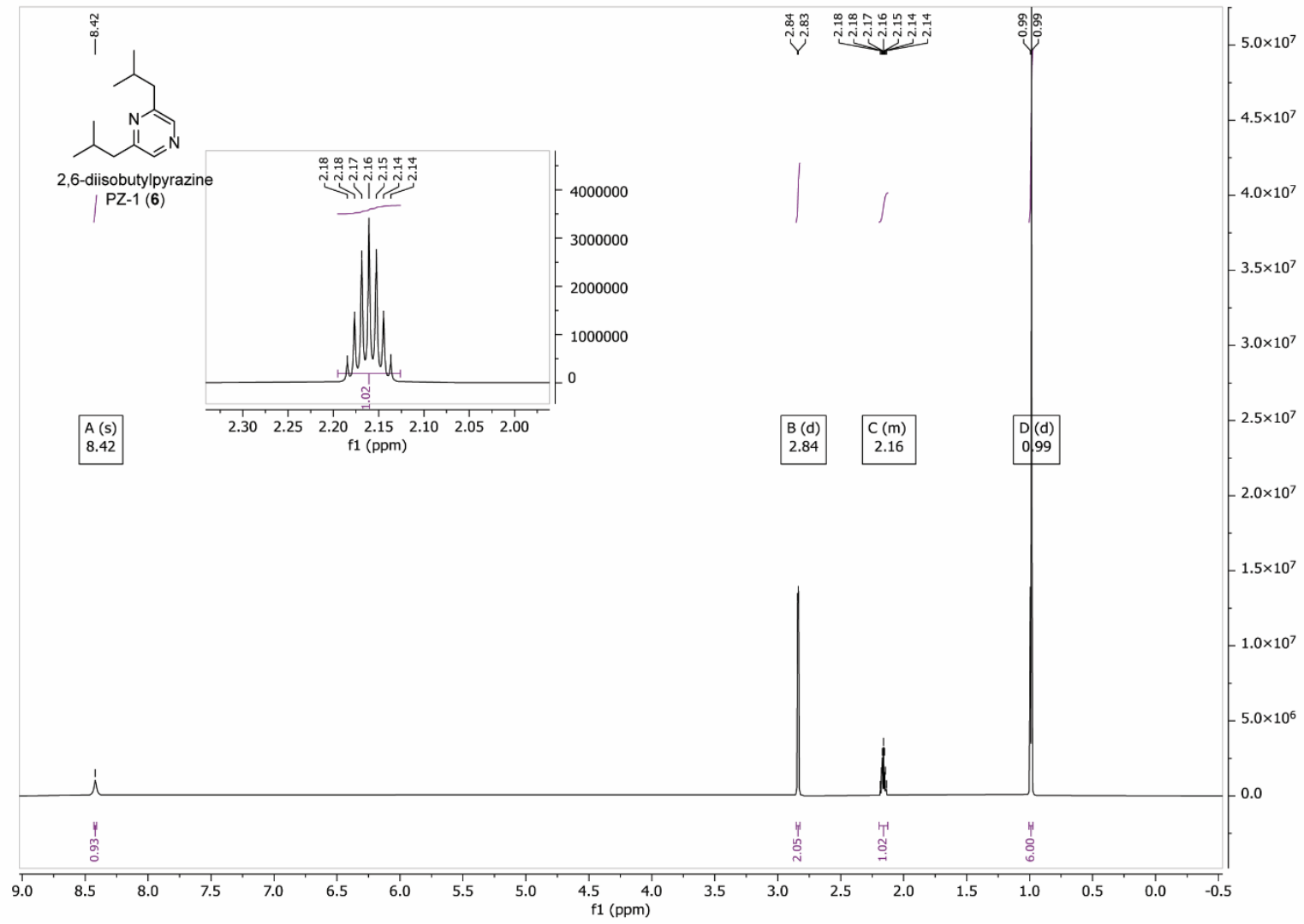

Extended Data 44. ${ }^{1} \mathrm{H}$ NMR spectrum of isolated PZ-1 (6) in $\mathrm{CDCl}_{3}(850 \mathrm{MHz})$. Solvent impurities were removed for clarity. 


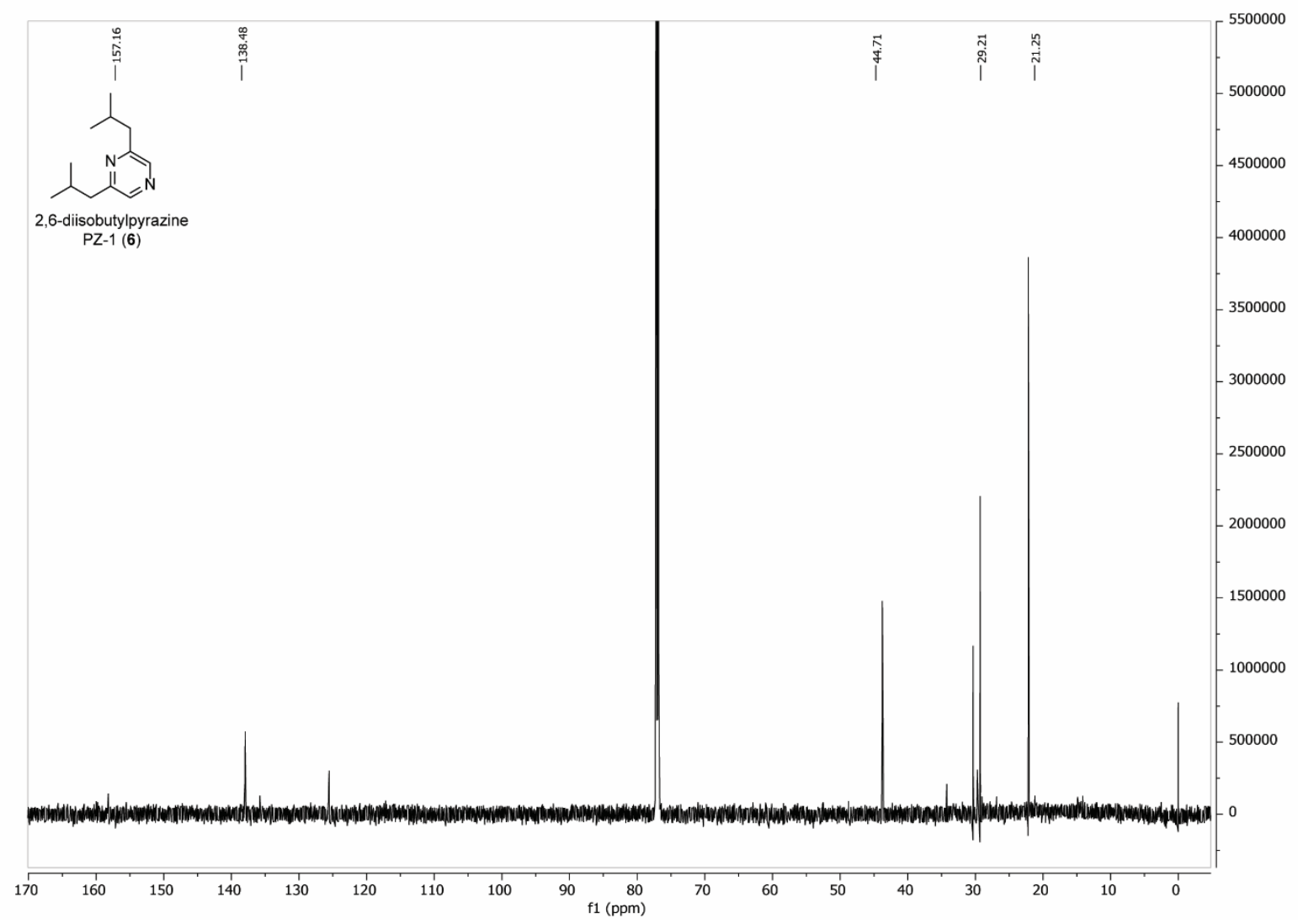

Extended Data $45 .{ }^{13} \mathrm{C}$ NMR spectrum of isolated $\mathrm{PZ}-1$ (6) in $\mathrm{CDCl}_{3}(214 \mathrm{MHz})$. 


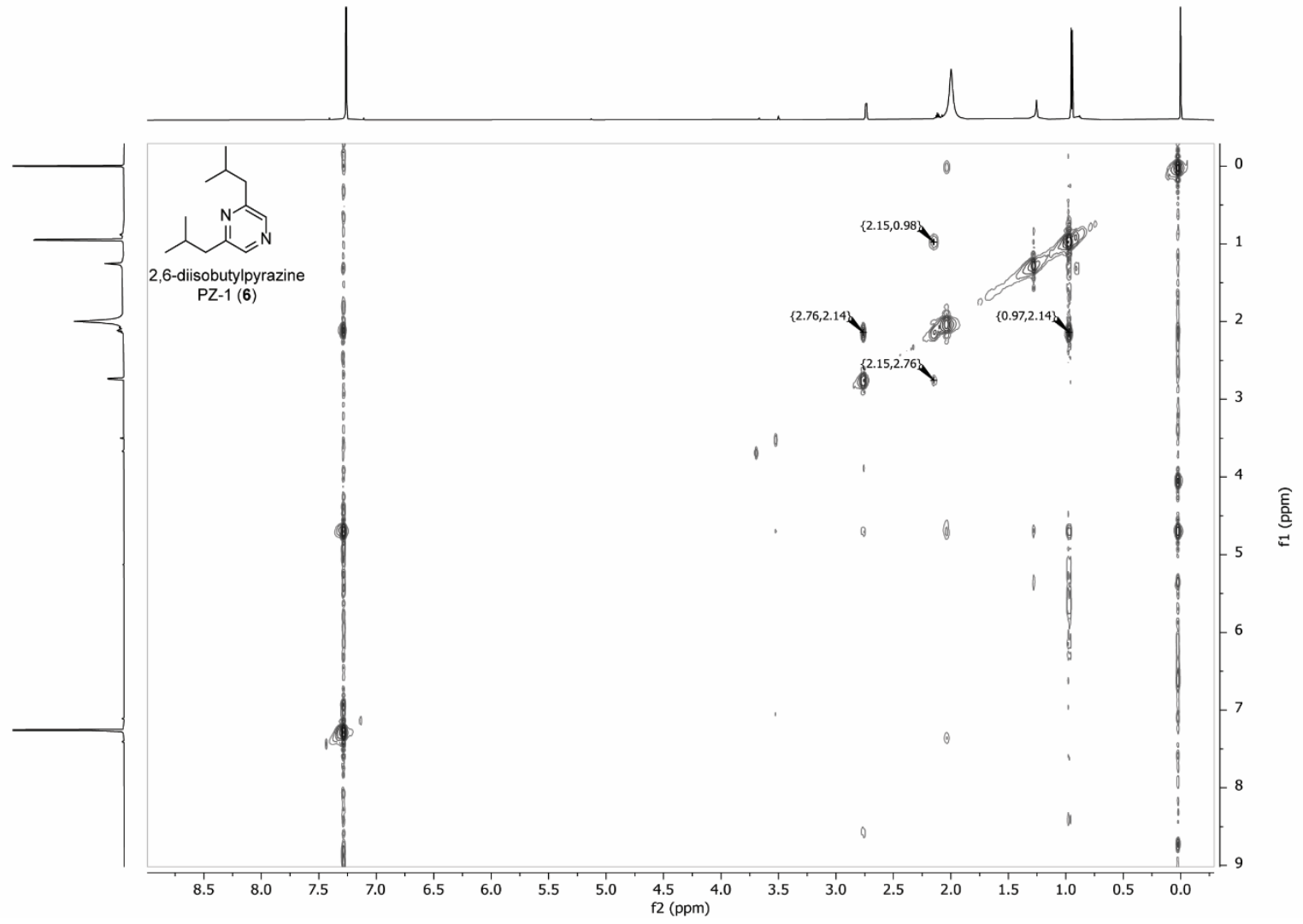

Extended Data 46. $\left({ }^{1} \mathrm{H},{ }^{1} \mathrm{H}\right)$ COSY NMR spectrum of isolated $\mathrm{PZ}-1(6)$ in $\mathrm{CDCl}_{3}(700 \mathrm{MHz})$. 


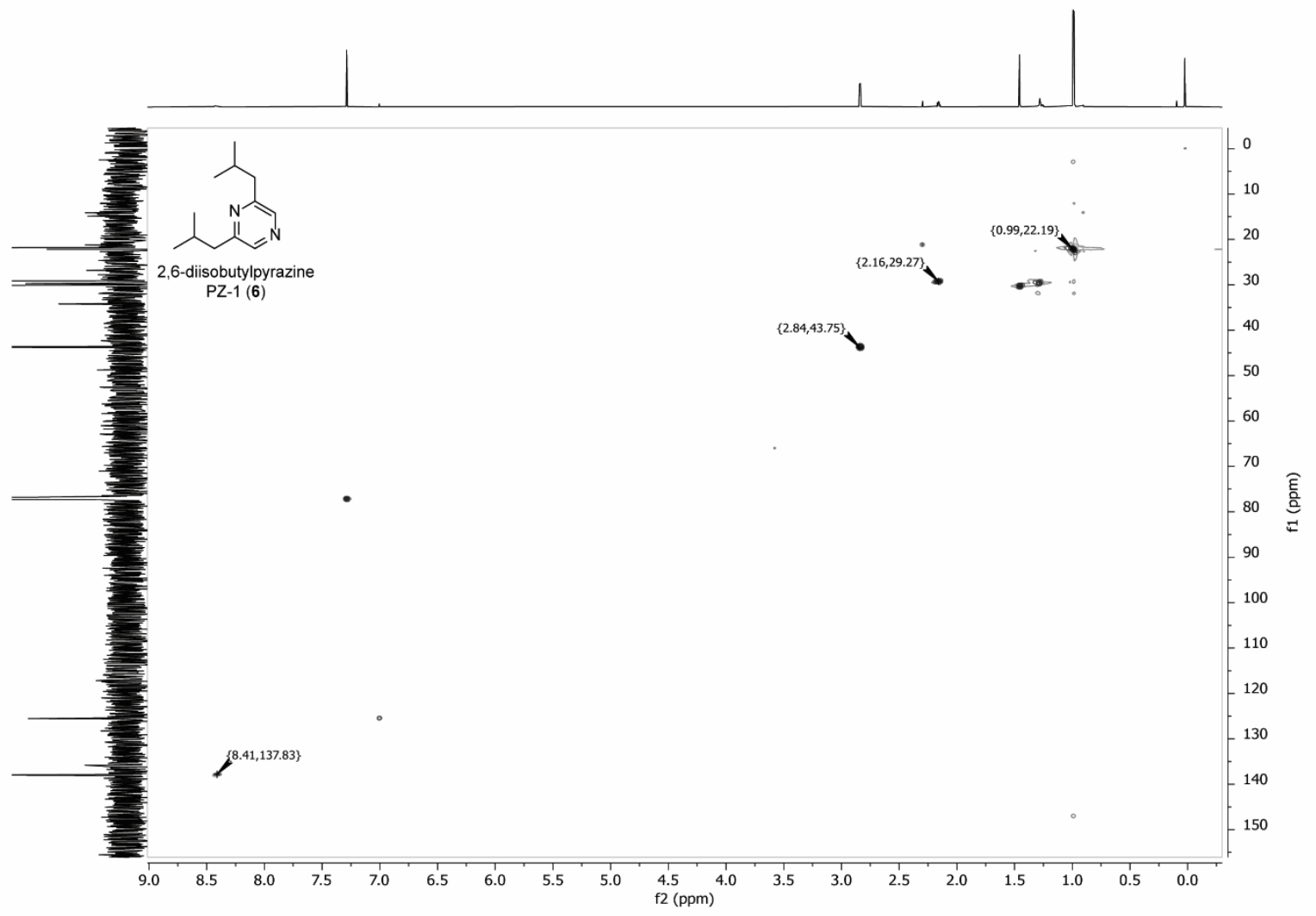

Extended Data 47. $\left({ }^{1} \mathrm{H},{ }^{13} \mathrm{C}\right) \mathrm{HSQC}$ NMR spectrum of isolated $\mathrm{PZ}-1(6)$ in $\mathrm{CDCl}_{3}\left({ }^{1} \mathrm{H}, 850 \mathrm{MHz},{ }^{13} \mathrm{C}\right.$, $214 \mathrm{MHz}$ ). 


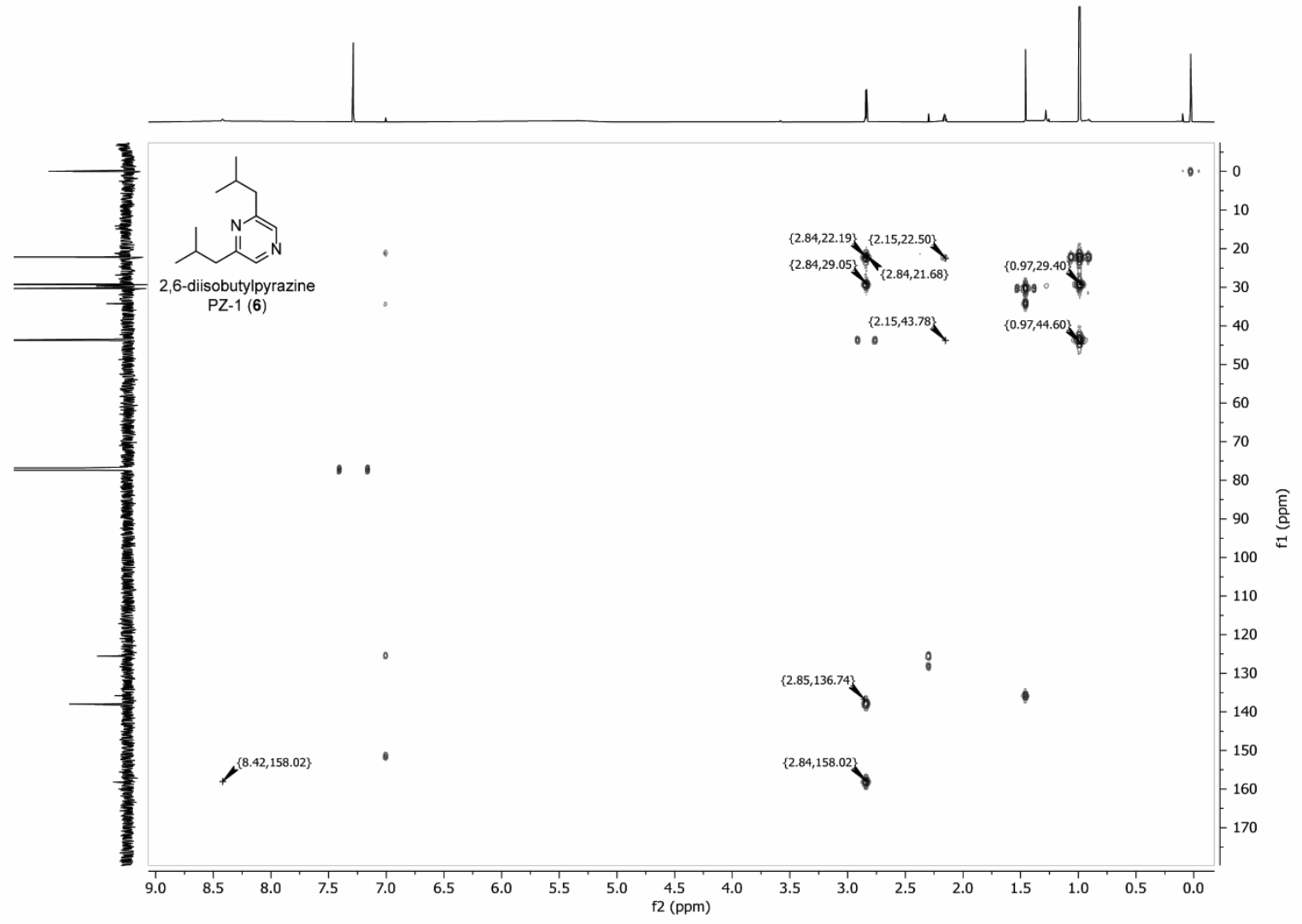

Extended Data 48. $\left({ }^{1} \mathrm{H},{ }^{13} \mathrm{C}\right) \mathrm{HMBC}$ NMR spectrum of isolated $\mathrm{PZ}-1(6)$ in $\mathrm{CDCl}_{3}\left({ }^{1} \mathrm{H}, 850 \mathrm{MHz},{ }^{13} \mathrm{C}\right.$, $214 \mathrm{MHz}$ ). 


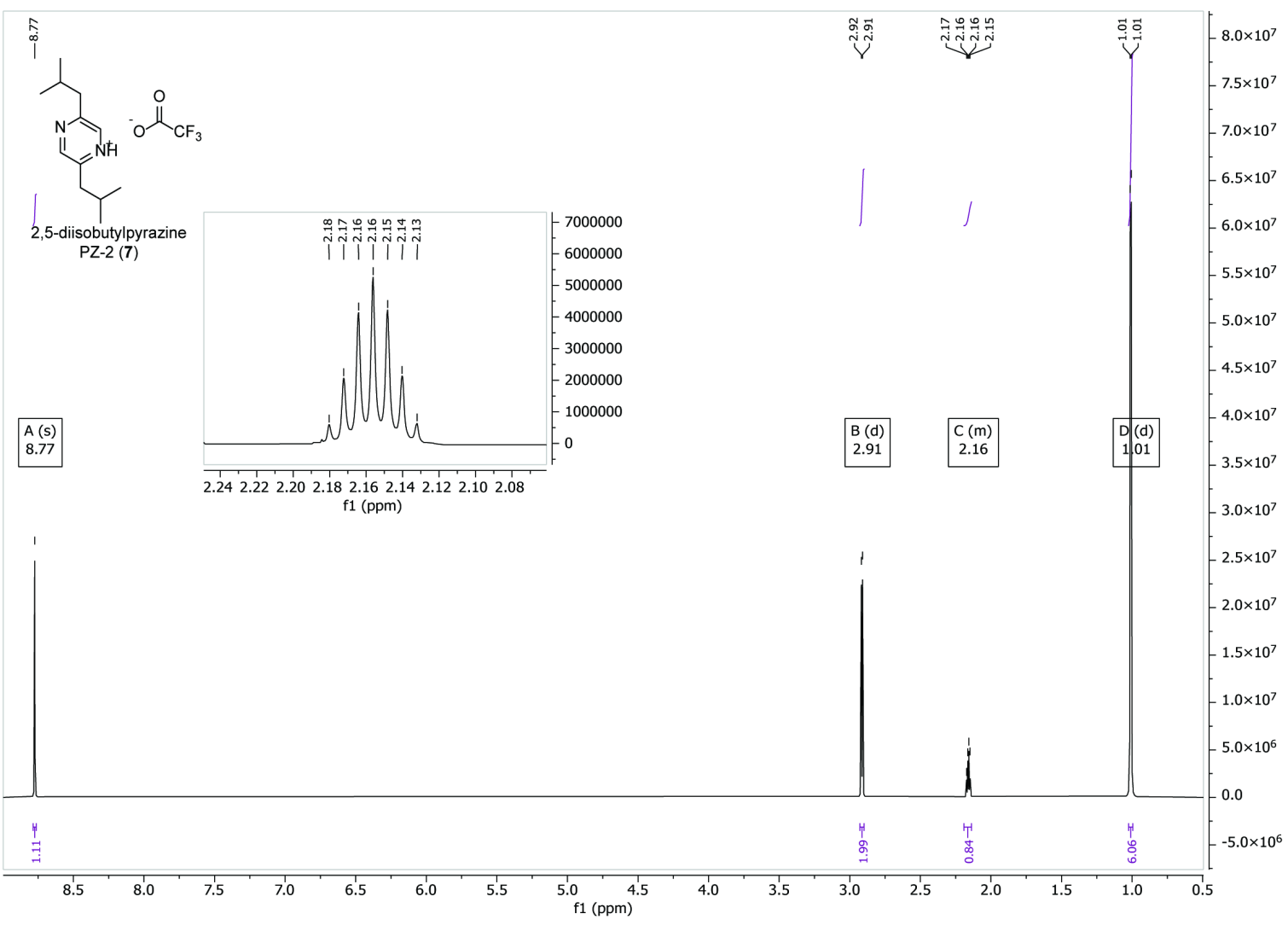

Extended Data 49. ${ }^{1} \mathrm{H}$ NMR spectrum of isolated PZ-2 (7) in $\mathrm{CDCl}_{3}(850 \mathrm{MHz})$. Solvent impurities were removed for clarity.

Isolated as TFA salt. 


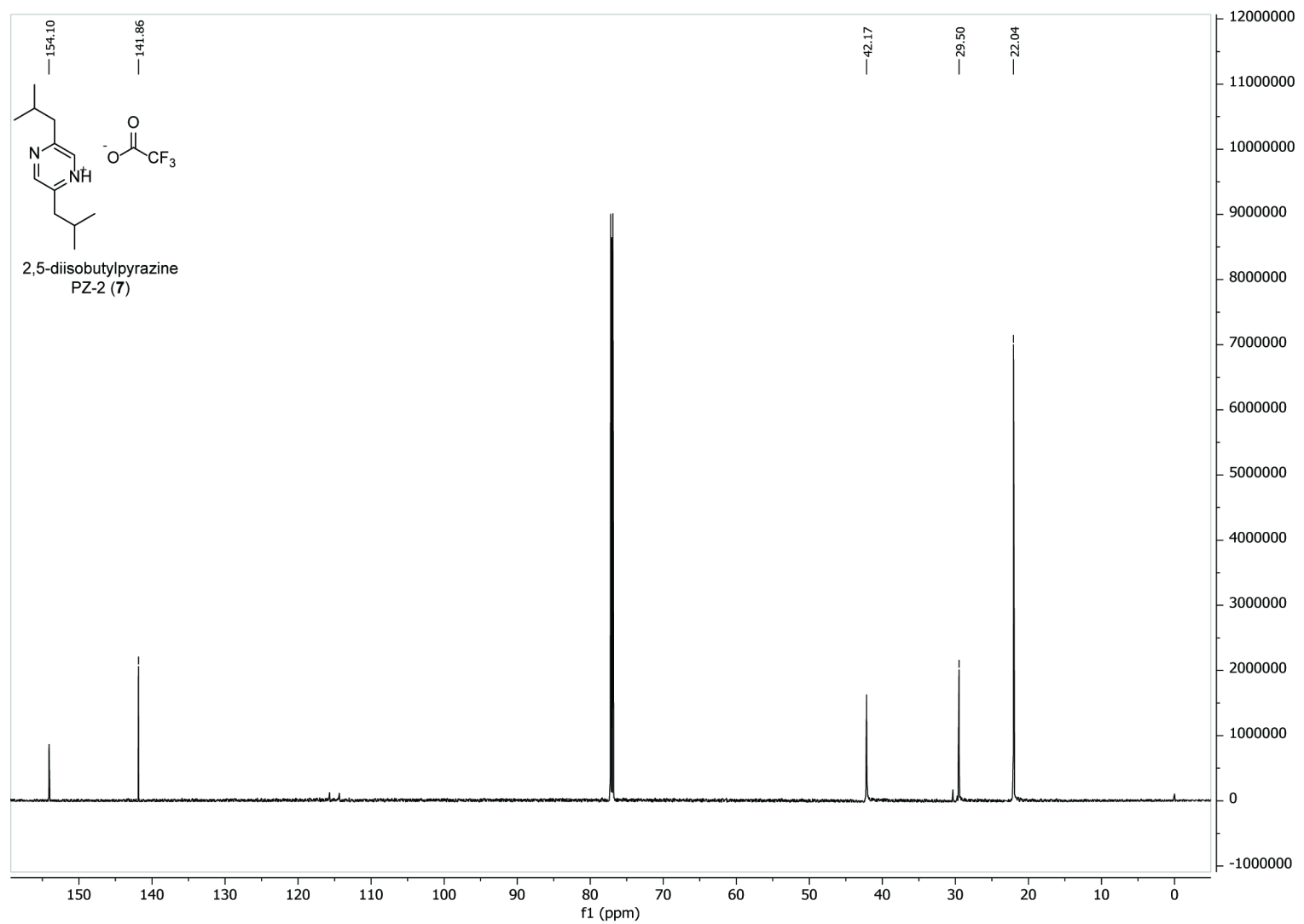

Extended Data 50. ${ }^{13} \mathrm{C}$ NMR spectrum of isolated PZ-2 (7) in $\mathrm{CDCl}_{3}(214 \mathrm{MHz})$.

Isolated as TFA salt. 


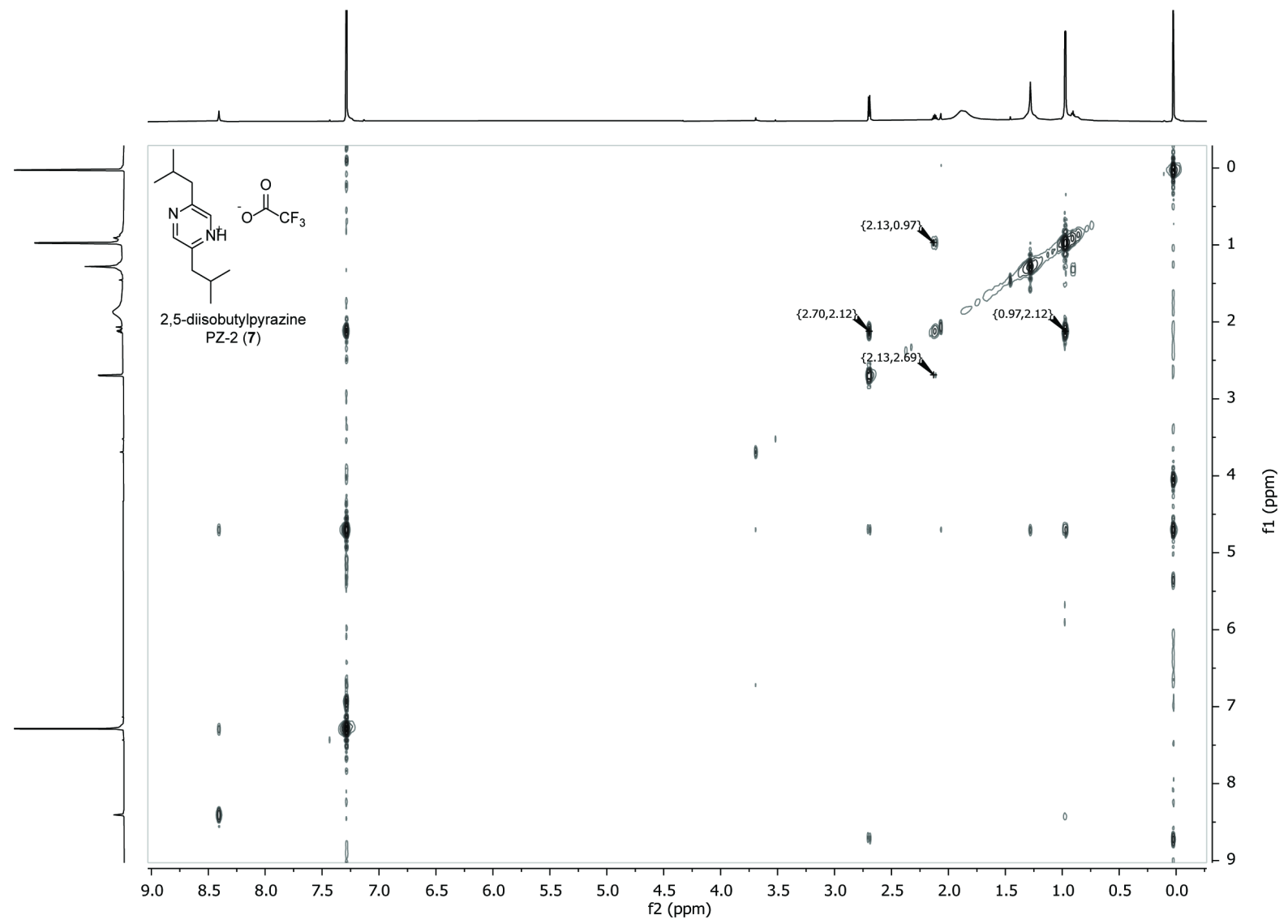

Extended Data 51. $\left({ }^{1} \mathrm{H},{ }^{1} \mathrm{H}\right)$ COSY NMR spectrum of isolated PZ-2 (7) in $\mathrm{CDCl}_{3}(700 \mathrm{MHz})$.

Isolated as TFA salt. 


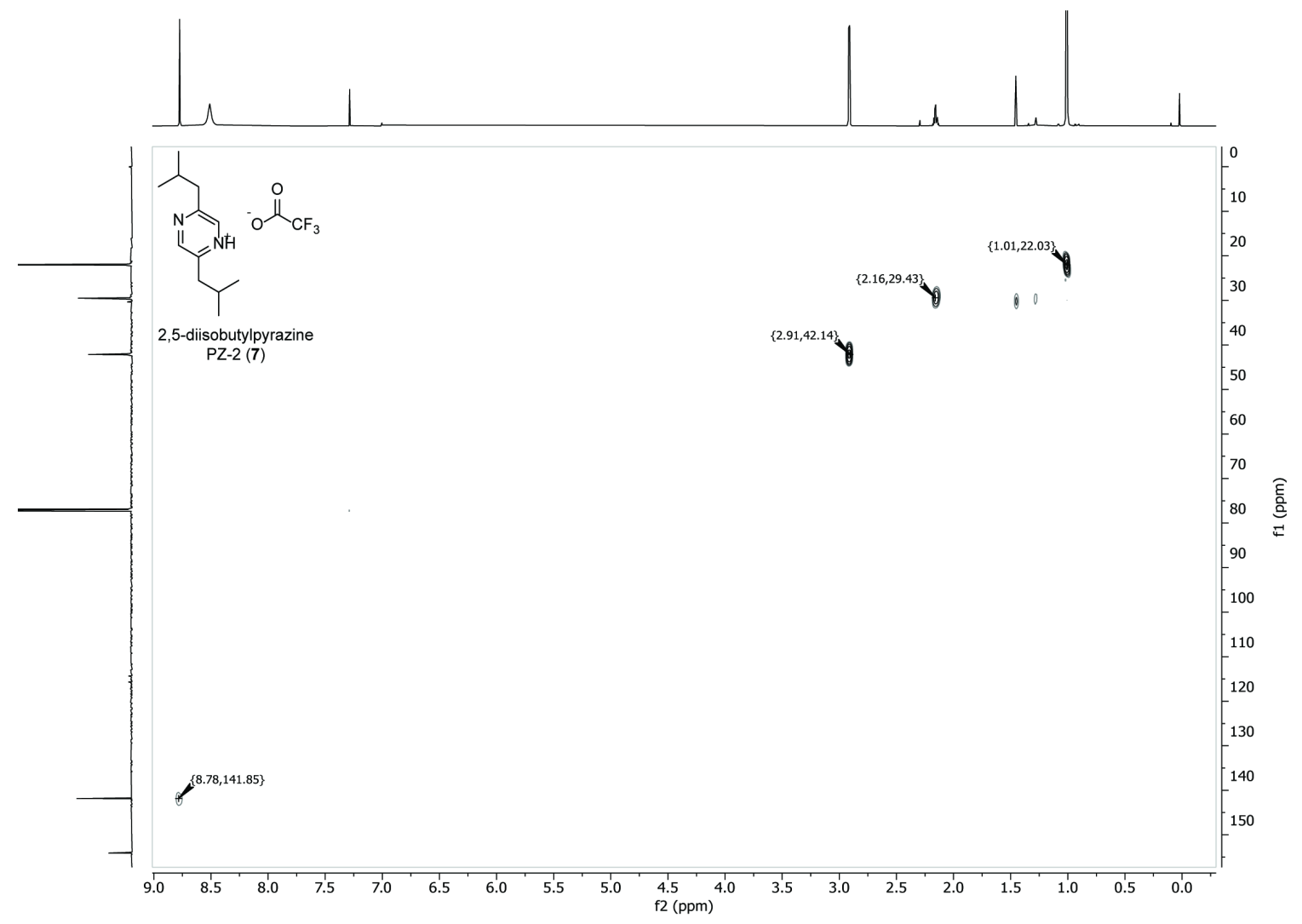

Extended Data 52. $\left({ }^{1} \mathrm{H},{ }^{13} \mathrm{C}\right) \mathrm{HSQC}$ NMR spectrum of isolated $\mathrm{PZ}-2(7)$ in $\mathrm{CDCl}_{3}\left({ }^{1} \mathrm{H}, 850 \mathrm{MHz},{ }^{13} \mathrm{C}\right.$, $214 \mathrm{MHz}$ ).

Isolated as TFA salt. 


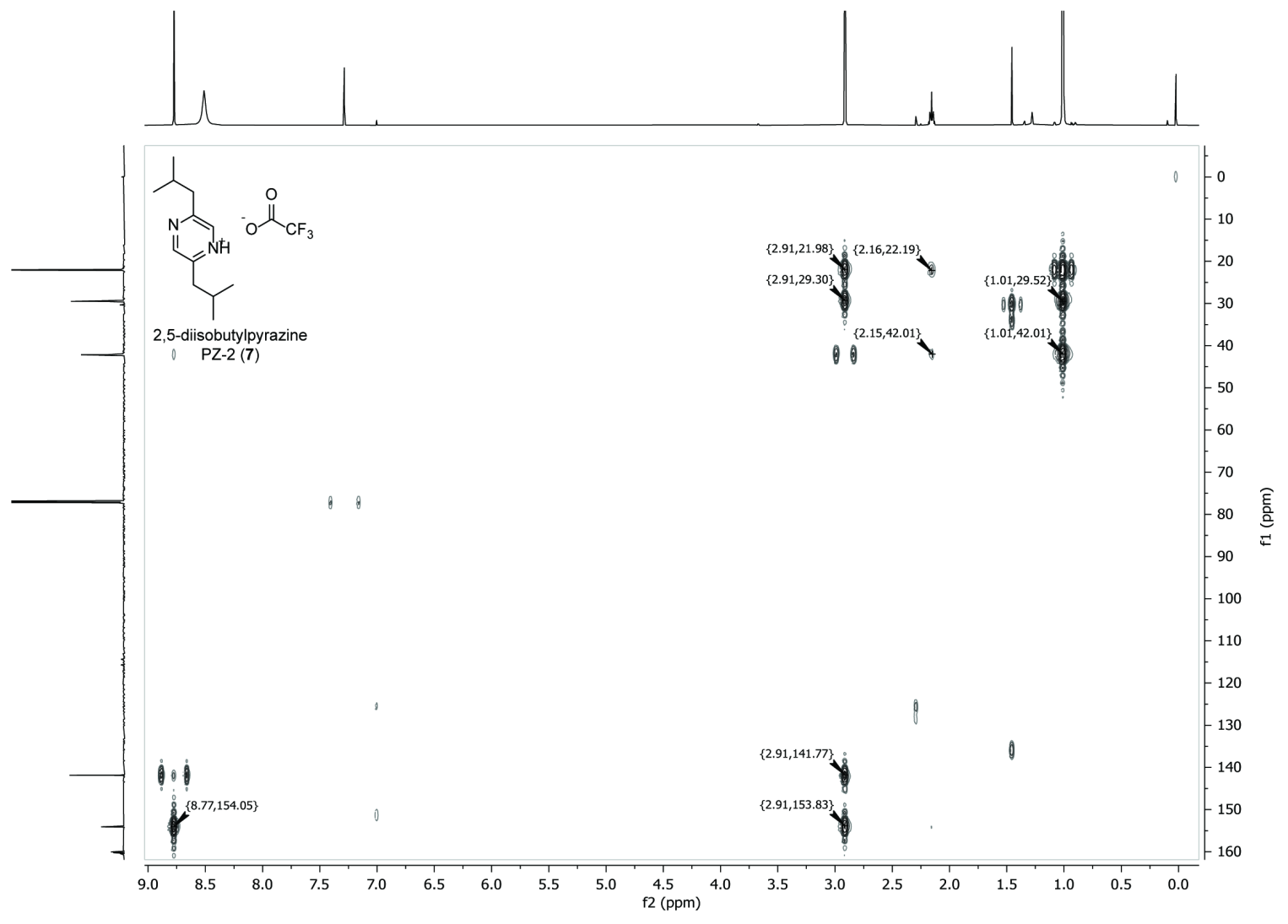

Extended Data 53. $\left({ }^{1} \mathrm{H},{ }^{13} \mathrm{C}\right) \mathrm{HMBC}$ NMR spectrum of isolated $\mathrm{PZ}-2(7)$ in $\mathrm{CDCl}_{3}\left({ }^{1} \mathrm{H}, 850 \mathrm{MHz},{ }^{13} \mathrm{C}\right.$, $214 \mathrm{MHz}$ ).

Isolated as TFA salt. 


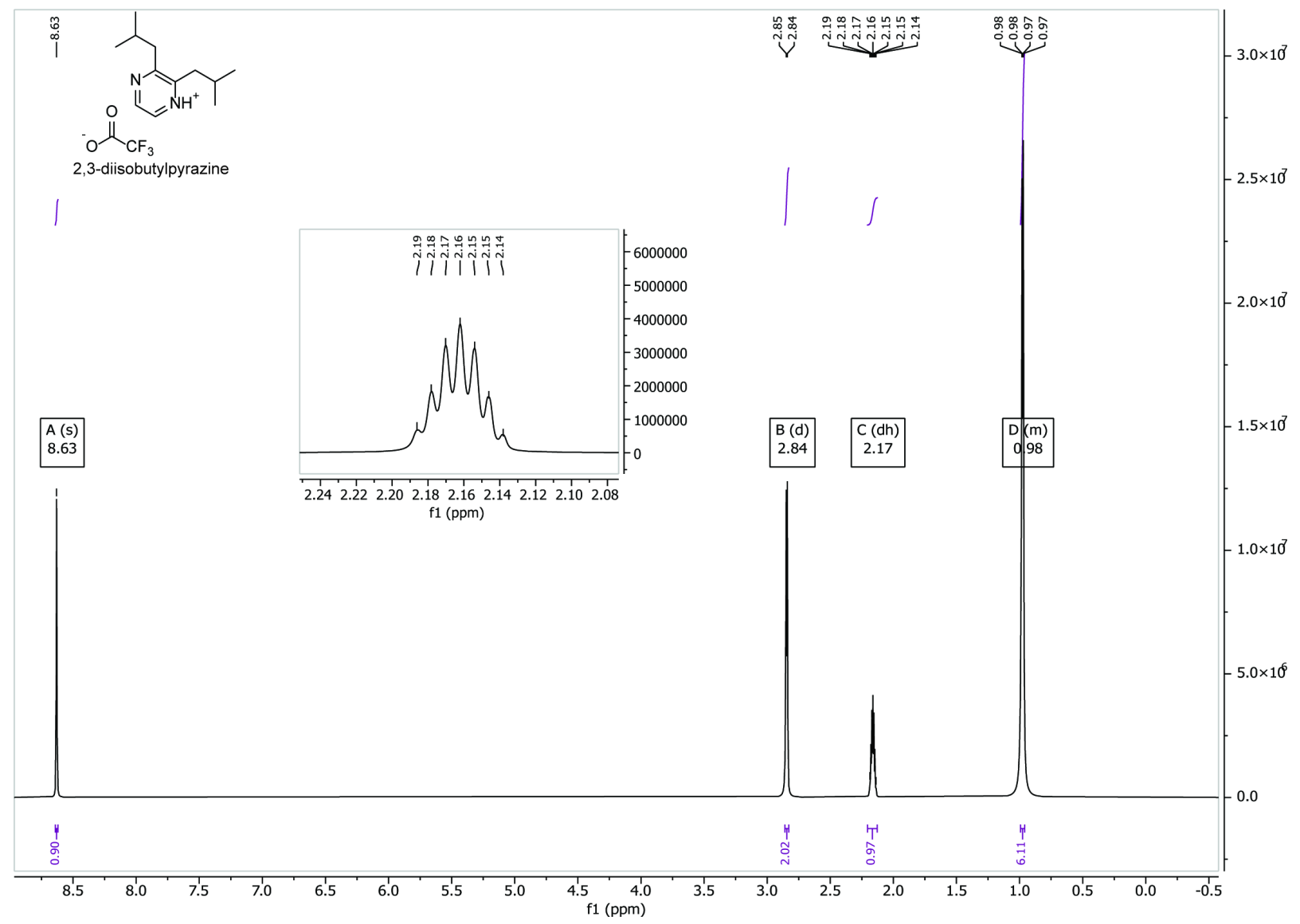

Extended Data 54. ${ }^{1} \mathrm{H}$ NMR spectrum of synthetic 2,3-diisobutylpyrazine in $\mathrm{CDCl}_{3}(850 \mathrm{MHz})$. Solvent impurities were removed for clarity.

Synthesized as TFA salt 


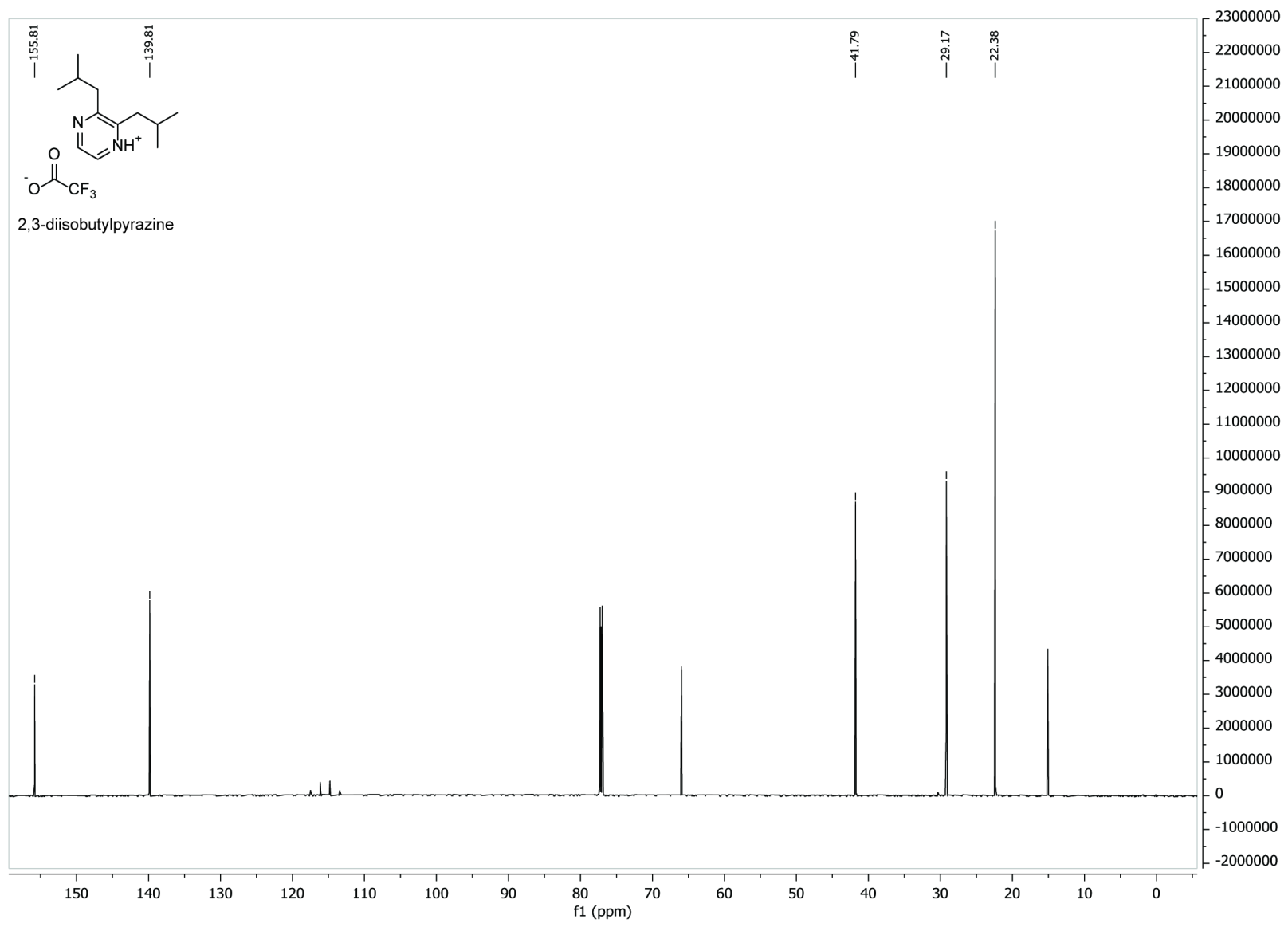

Extended Data 55. ${ }^{13} \mathrm{C}$ NMR spectrum of synthetic 2,3-diisobutylpyrazine in $\mathrm{CDCl}_{3}(214 \mathrm{MHz})$.

Synthesized as TFA salt 


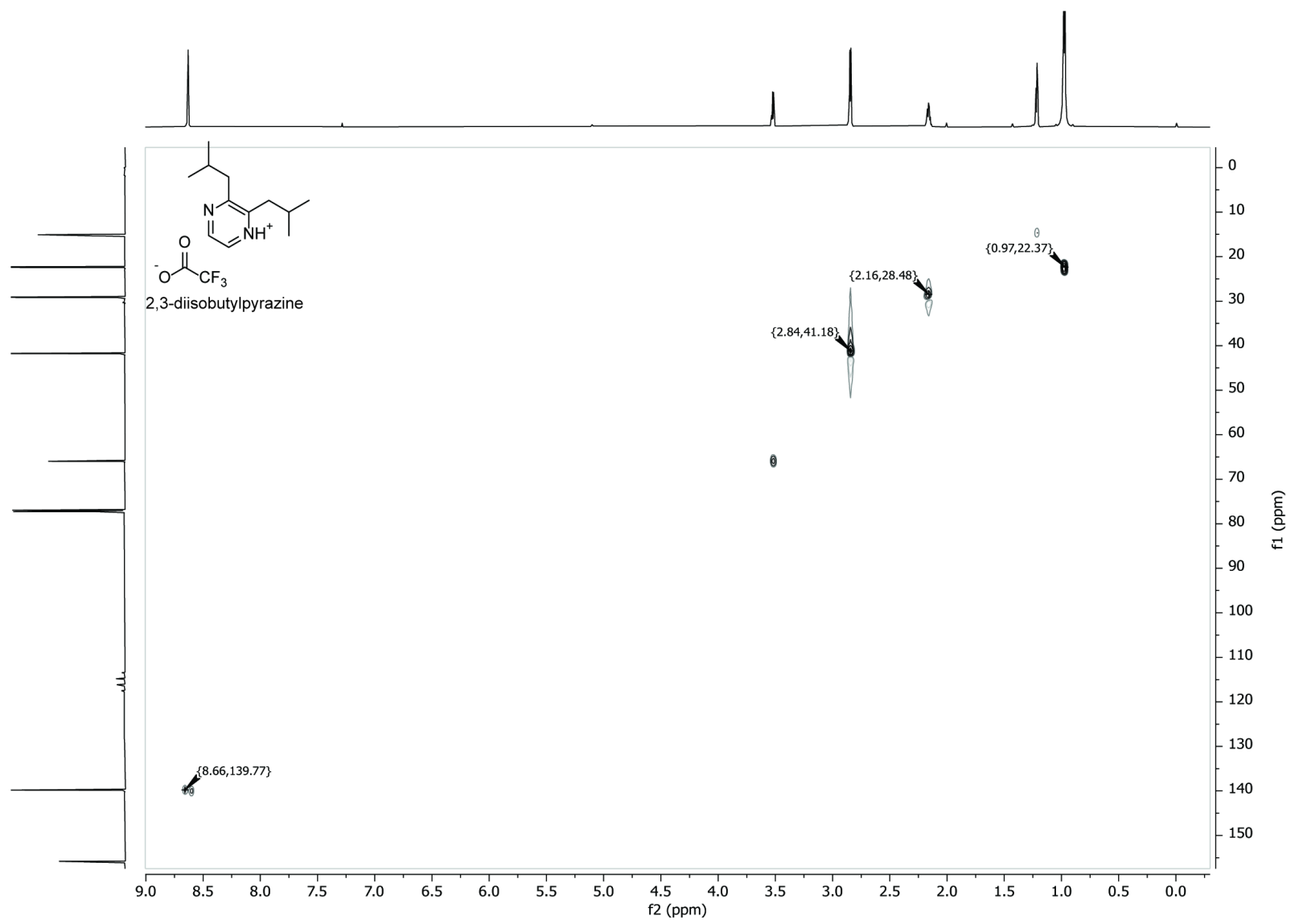

Extended Data 56. $\left({ }^{1} \mathrm{H},{ }^{13} \mathrm{C}\right) \mathrm{HSQC}$ NMR spectrum of synthetic 2,3-diisobutylpyrazine in $\mathrm{CDCl}_{3}\left({ }^{1} \mathrm{H}\right.$, $850 \mathrm{MHz},{ }^{13} \mathrm{C}, 214 \mathrm{MHz}$ ).

Synthesized as TFA salt. 


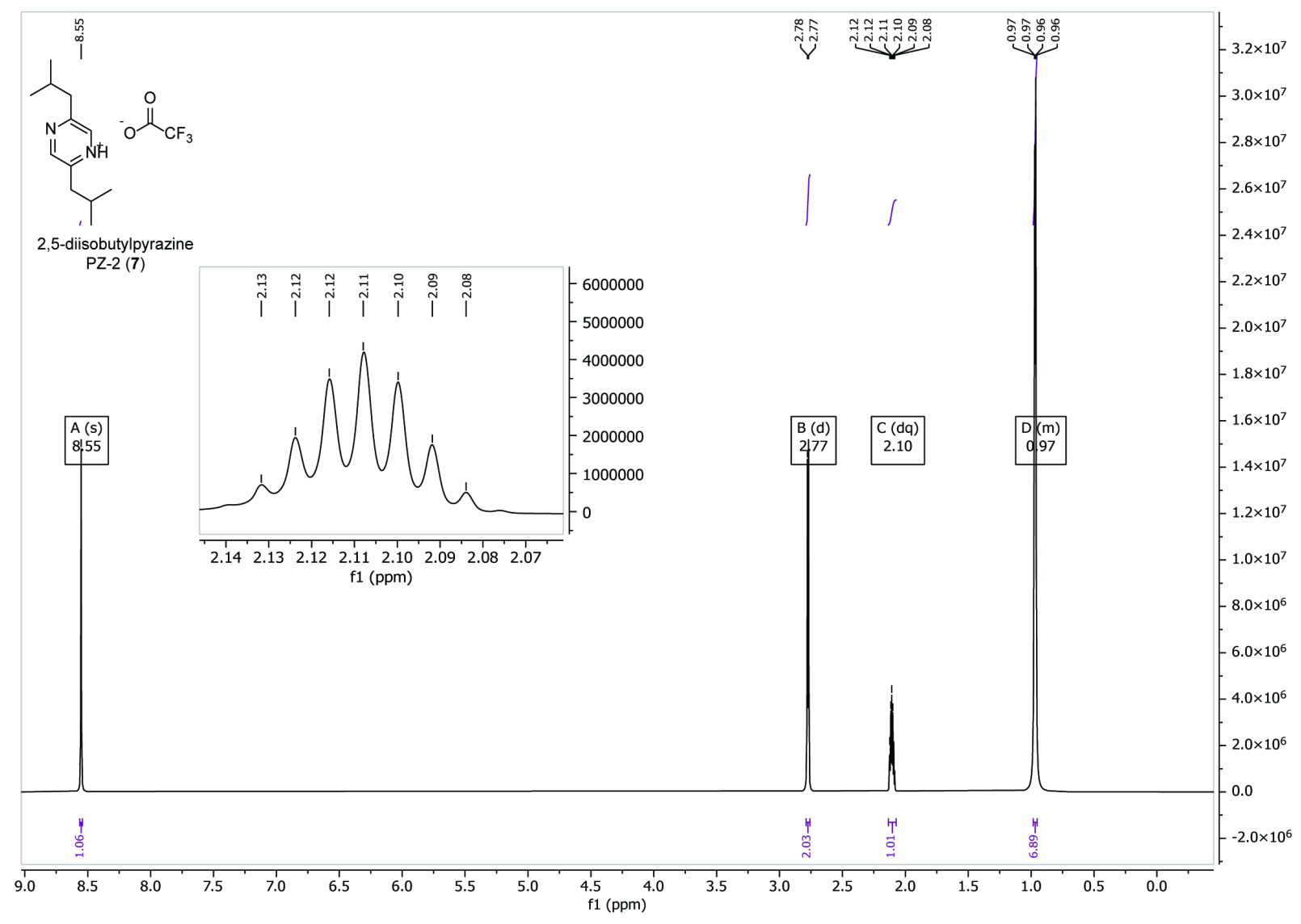

Extended Data 57. ${ }^{1} \mathrm{H}$ NMR spectrum of synthetic 2,5 -diisobutylpyrazine (7) in $\mathrm{CDCl}_{3}(850 \mathrm{MHz})$. Solvent impurities were removed for clarity.

Synthesized as TFA salt 


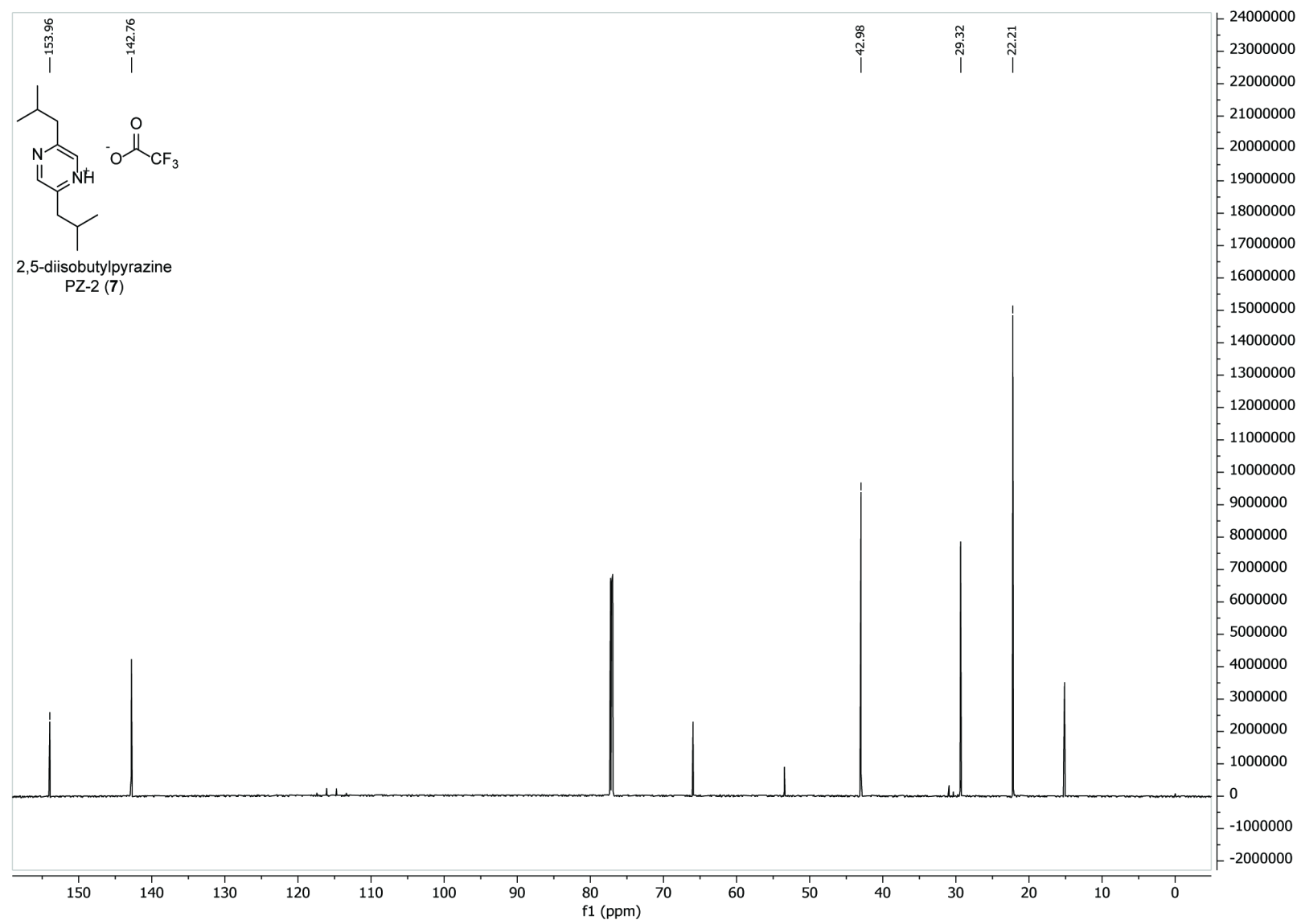

Extended Data 58. ${ }^{13} \mathrm{C}$ NMR spectrum of synthetic 2,5-diisobutylpyrazine (7) in $\mathrm{CDCl}_{3}(214 \mathrm{MHz})$.

Synthesized as TFA salt 


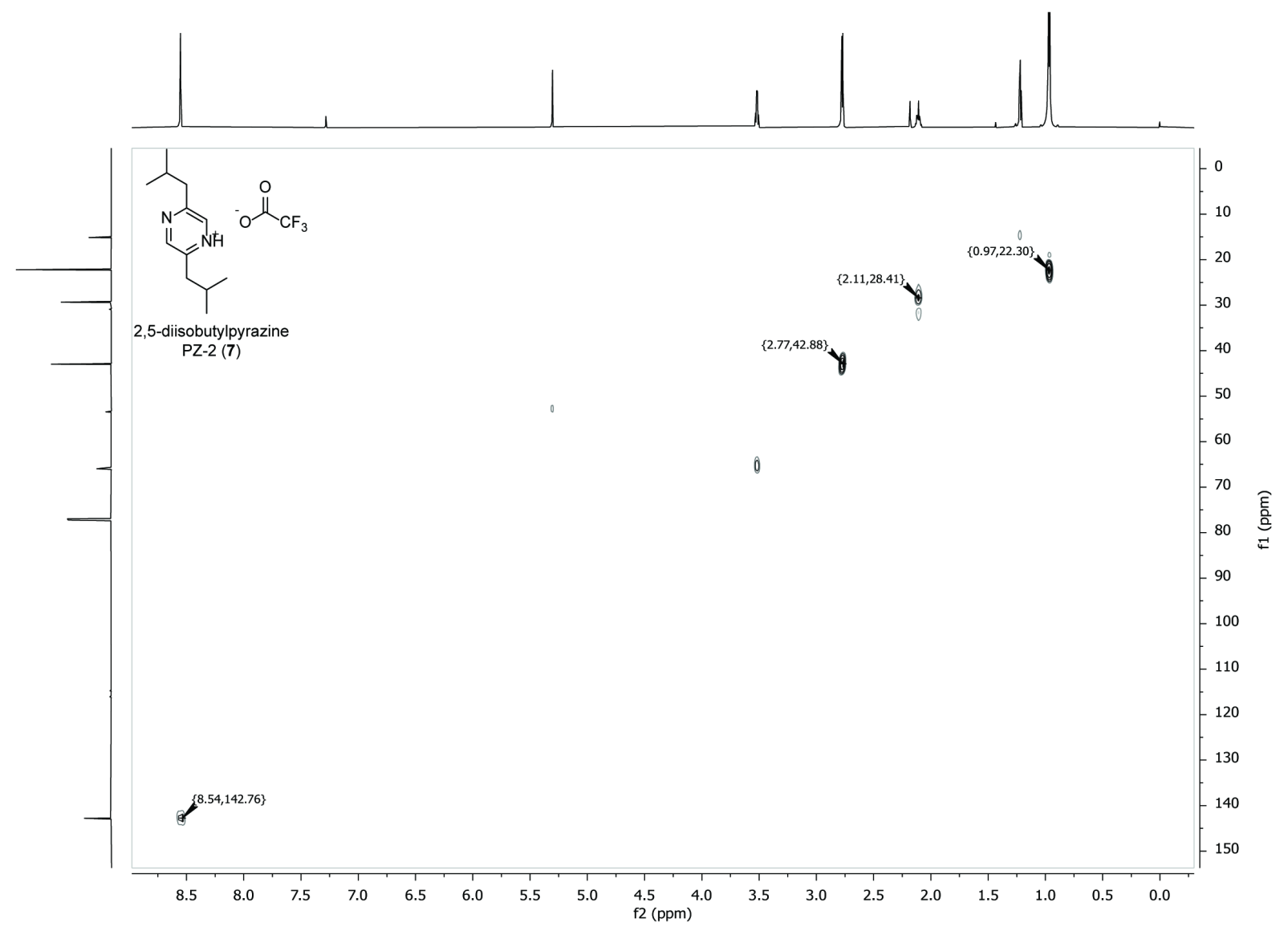

Extended Data 59. $\left({ }^{1} \mathrm{H},{ }^{13} \mathrm{C}\right) \mathrm{HSQC}$ NMR spectrum of synthetic 2,5-diisobutylpyrazine (7) in $\mathrm{CDCl}_{3}$ $\left({ }^{1} \mathrm{H}, 850 \mathrm{MHz},{ }^{13} \mathrm{C}, 214 \mathrm{MHz}\right)$.

Synthesized as TFA salt 


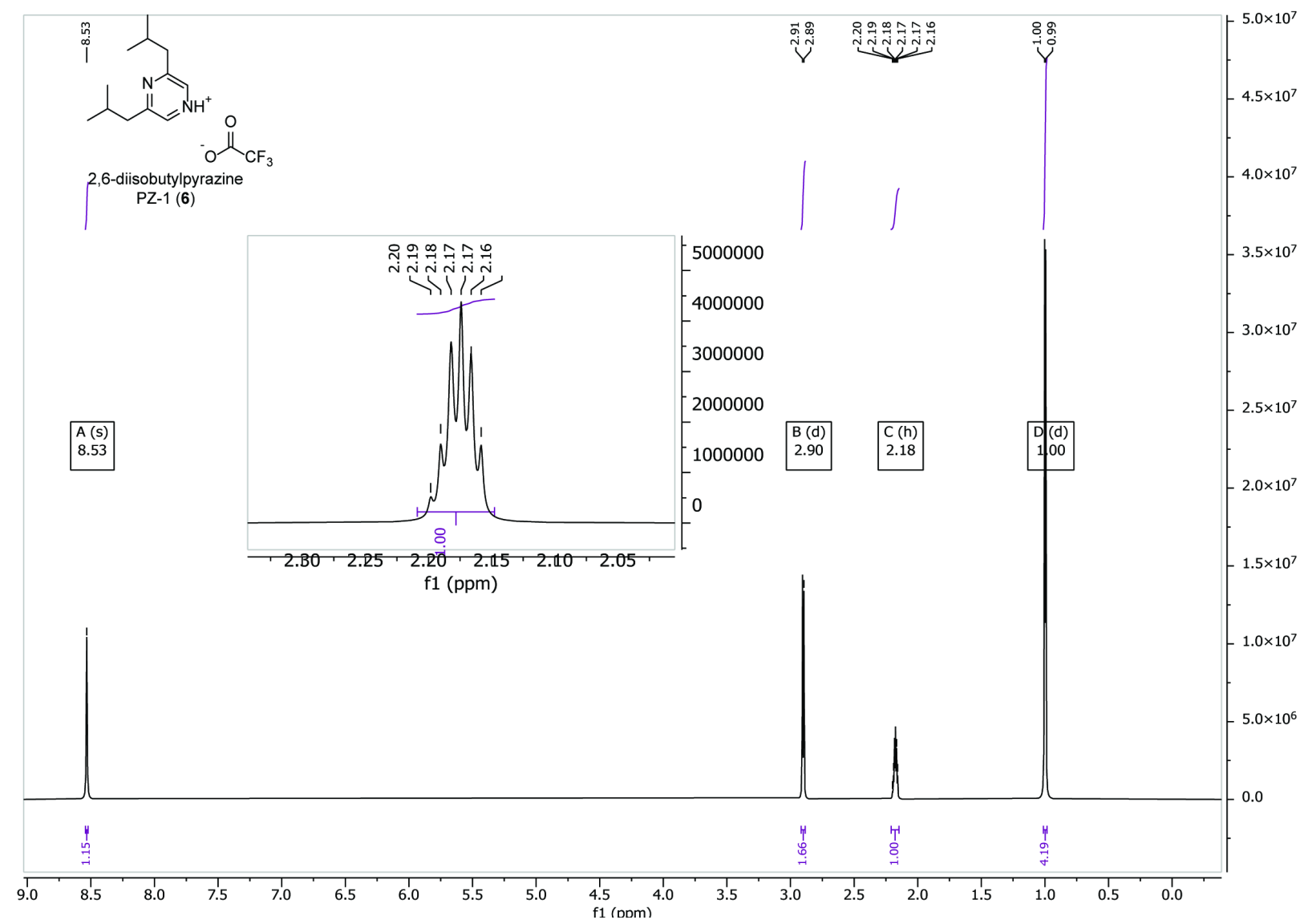

Extended Data 60. ${ }^{1} \mathrm{H}$ NMR spectrum of synthetic 2,6-diisobutylpyrazine in $\mathrm{CDCl}_{3}(850 \mathrm{MHz})$. Solvent impurities were removed for clarity.

Synthesized as TFA salt. 


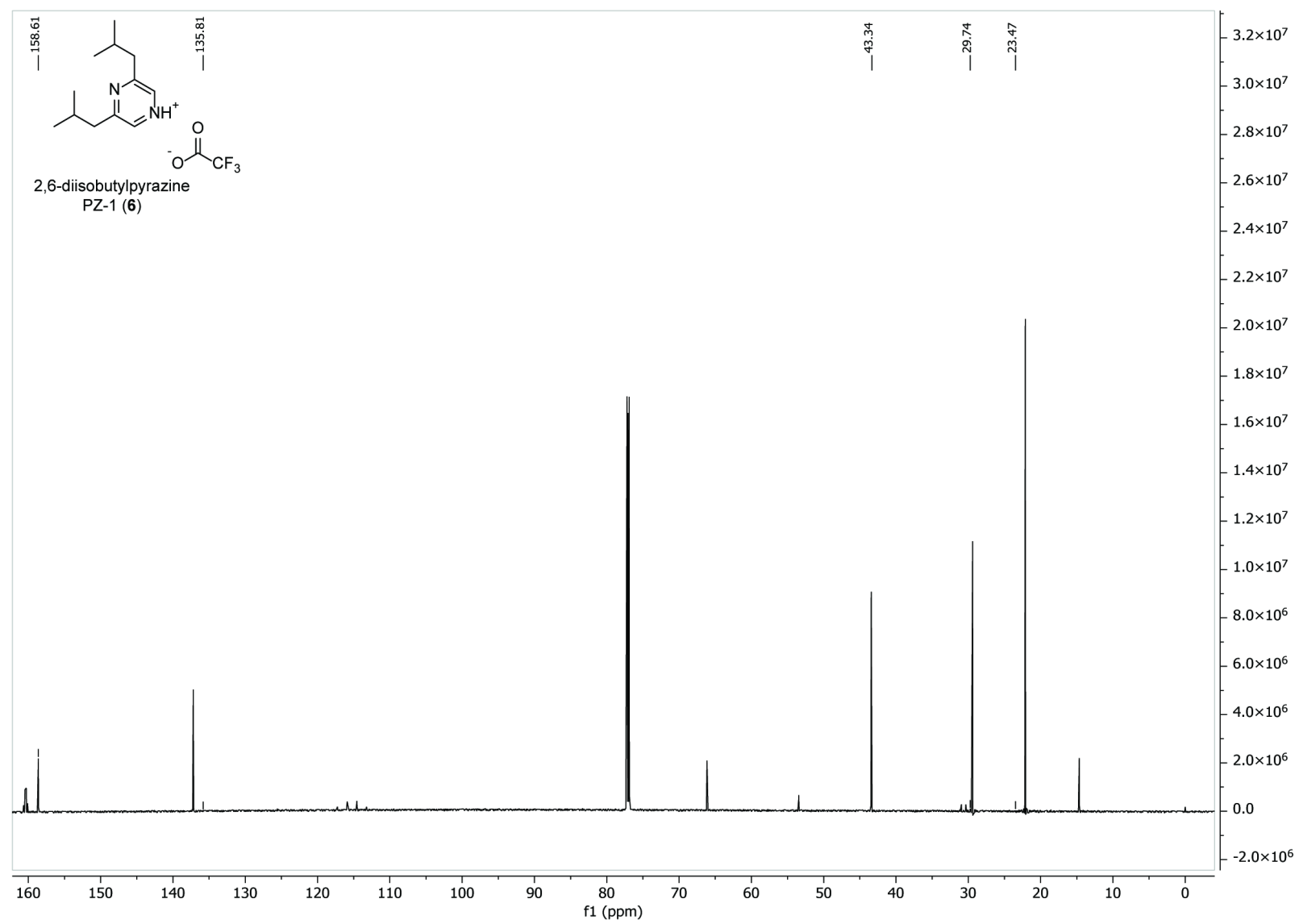

Extended Data $61 .{ }^{13} \mathrm{C}$ NMR spectrum of synthetic 2,6-diisobutylpyrazine in $\mathrm{CDCl}_{3}(214 \mathrm{MHz})$.

Synthesized as TFA salt 


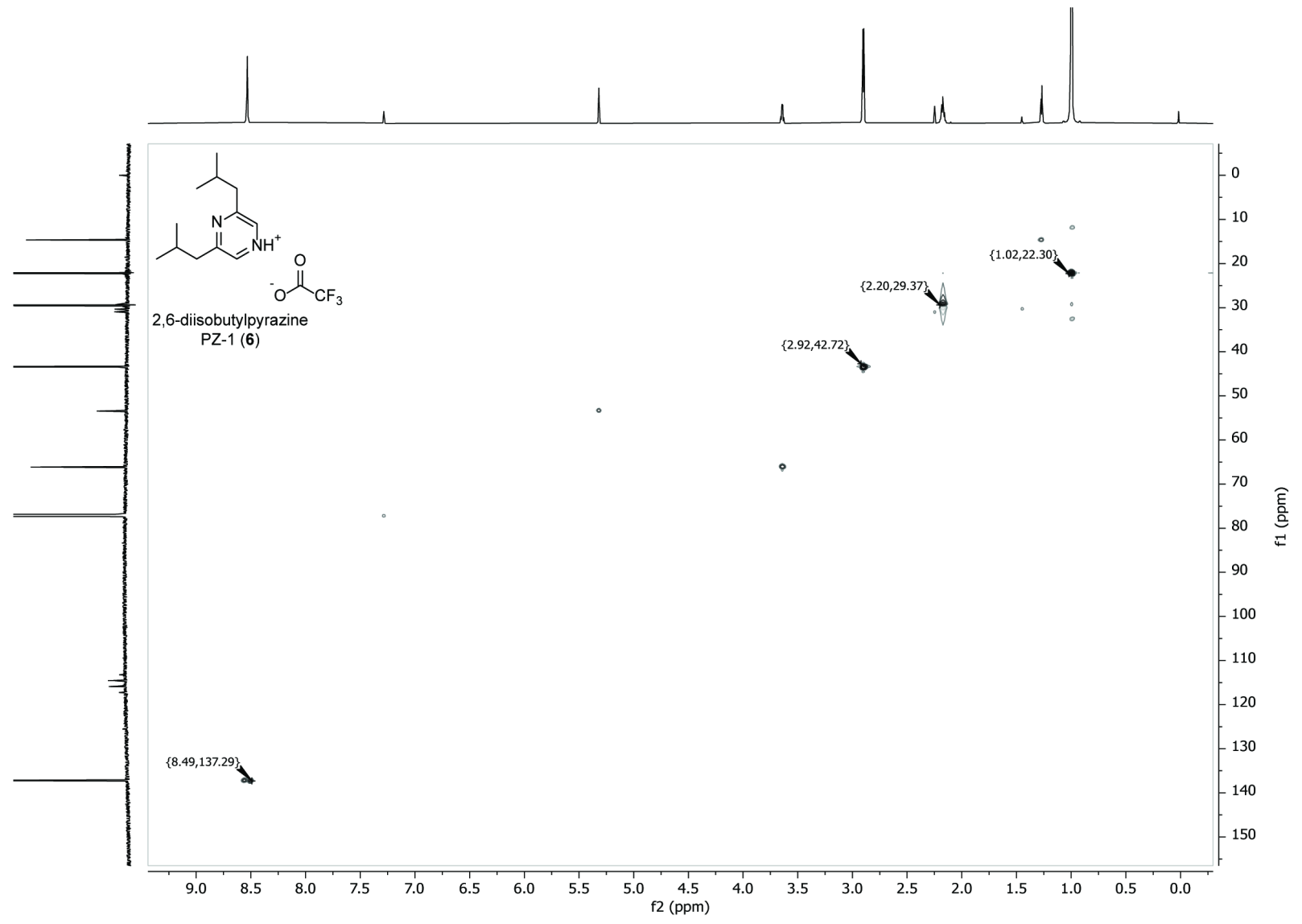

Extended Data 62. $\left({ }^{1} \mathrm{H},{ }^{13} \mathrm{C}\right) \mathrm{HSQC}$ NMR spectrum of synthetic 2,6-diisobutylpyrazine in $\mathrm{CDCl}_{3}\left({ }^{1} \mathrm{H}\right.$, $850 \mathrm{MHz},{ }^{13} \mathrm{C}, 214 \mathrm{MHz}$ ).

Synthesized as TFA salt 


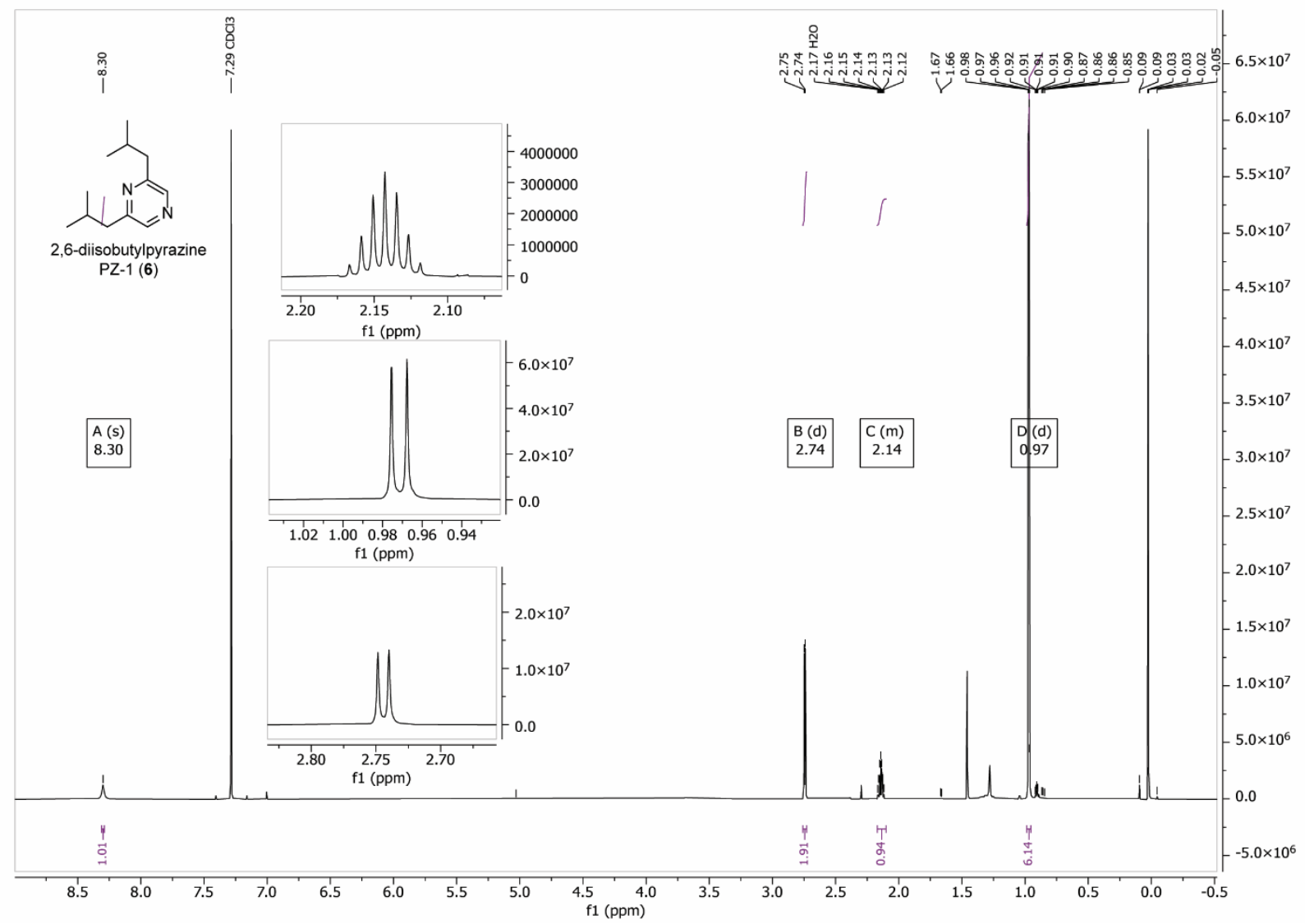

Extended Data 63. ${ }^{1} \mathrm{H}$ NMR spectrum of a combined sample of isolated PZ-1 (6) and synthetic 2,6diisobutylpyrazine in $\mathrm{CDCl}_{3}(850 \mathrm{MHz})$. 


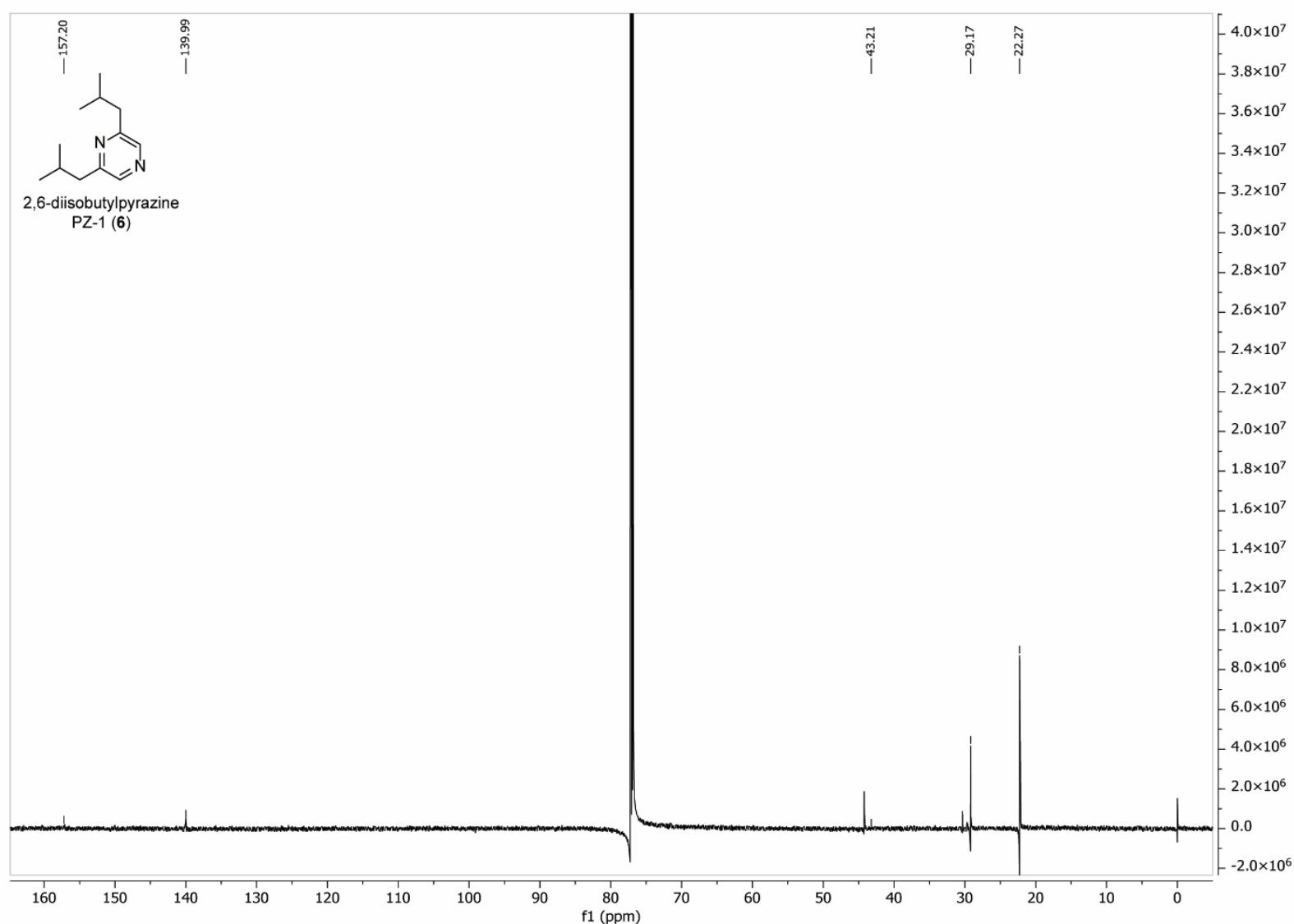

Extended Data $64 .{ }^{13} \mathrm{C}$ NMR spectrum of a combined sample of isolated PZ-1 (6) and synthetic 2,6diisobutylpyrazine in $\mathrm{CDCl}_{3}(214 \mathrm{MHz})$. 


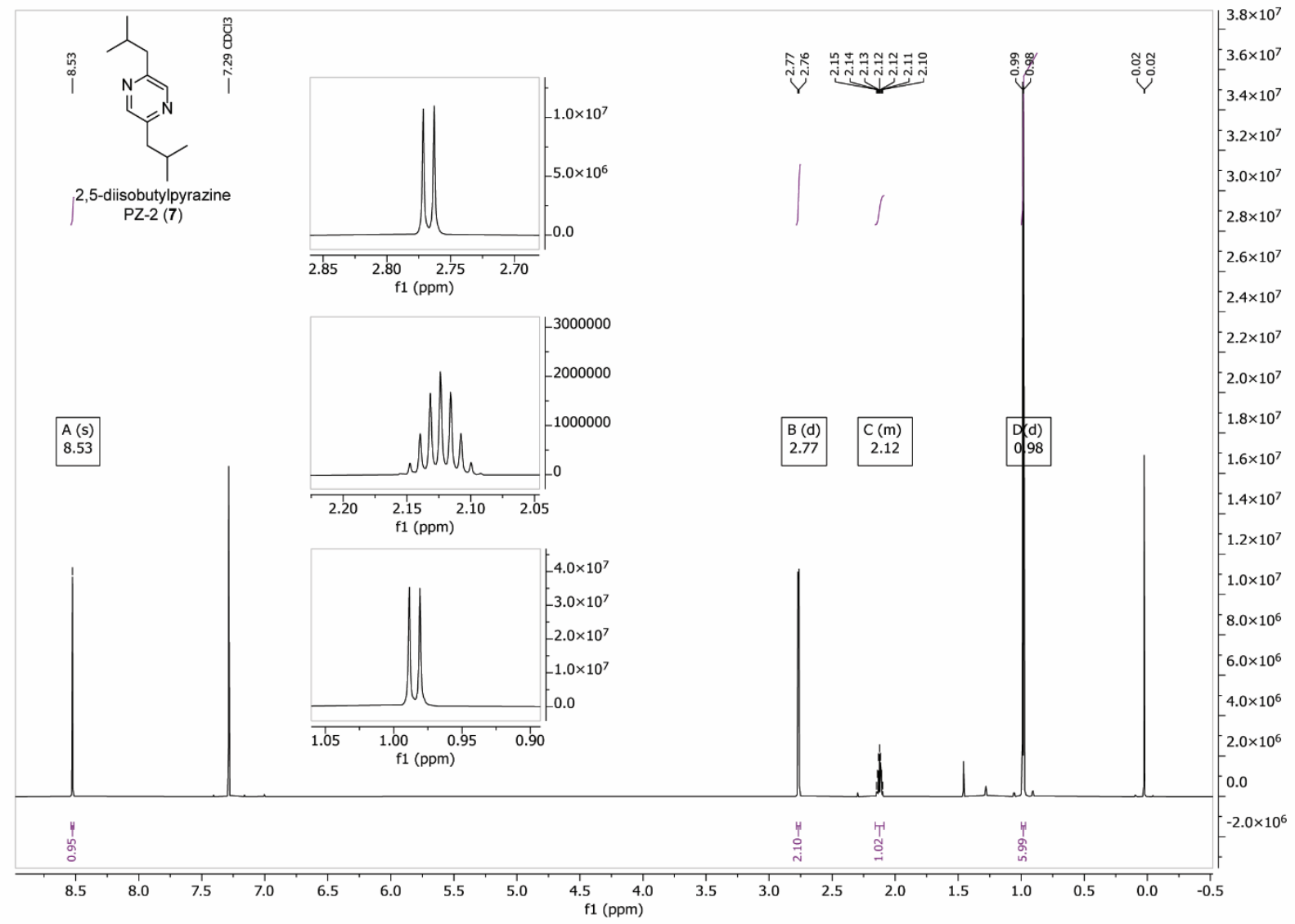

Extended Data 65. ${ }^{1} \mathrm{H}$ NMR spectrum of a combined sample of isolated PZ-2 (7) and synthetic 2,5diisobutylpyrazine in $\mathrm{CDCl}_{3}(850 \mathrm{MHz})$. 


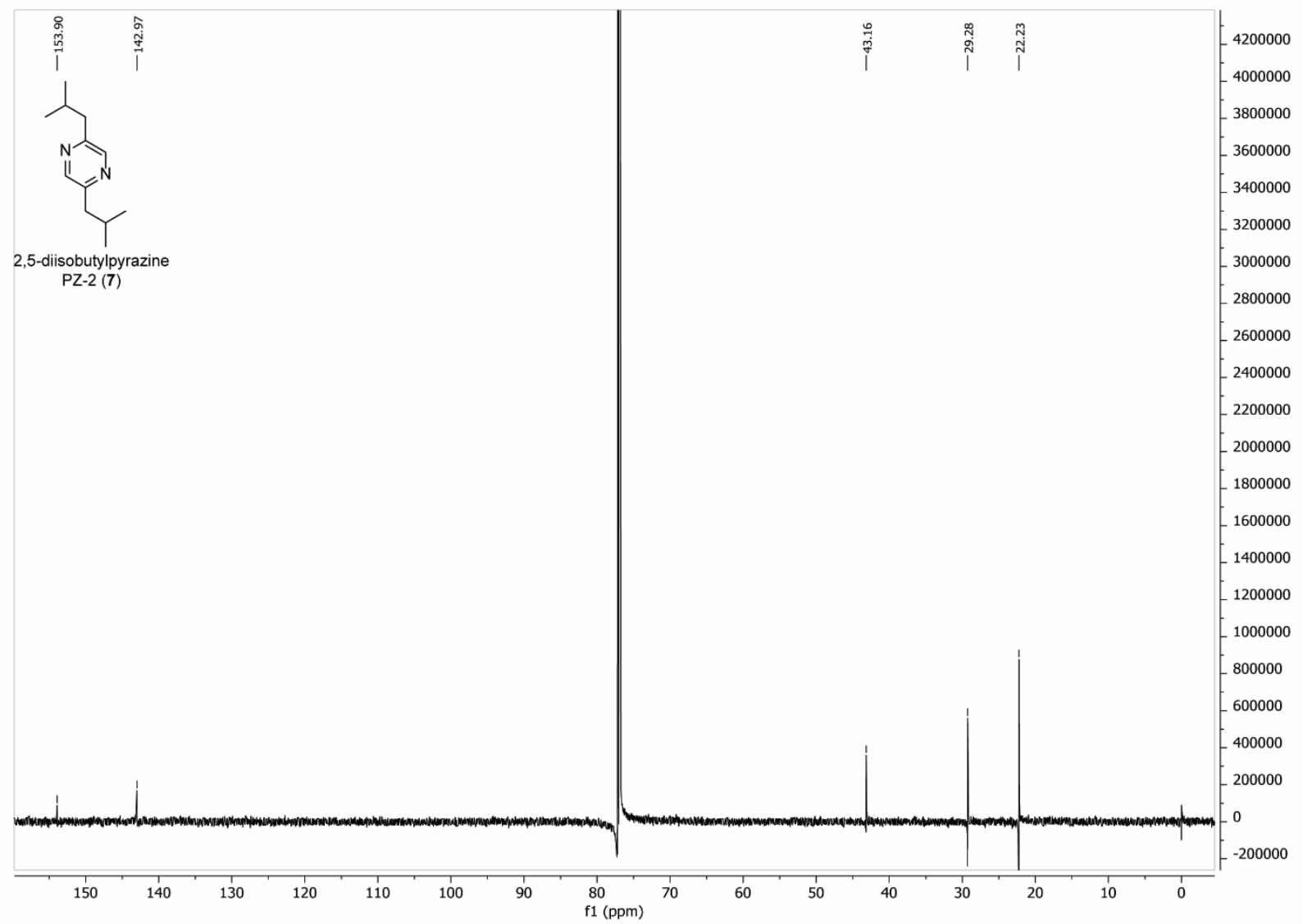

Extended Data 66. ${ }^{13} \mathrm{C}$ NMR spectrum of a combined sample of isolated PZ-2 (7) and synthetic 2,5diisobutylpyrazine in $\mathrm{CDCl}_{3}(214 \mathrm{MHz})$. 


\section{References}

(1) Hou-jin, L., Yong-tong, C., Yun-yun, C., Chi-keung, L., and Wen-jian, L. (2010) Metabolites of marine fungus aspergillus sp. Collected from soft coral sarcophyton tortuosum, Chem. Res. Chinese Universities 26, 415-419.

(2) Choi, K. H., Kumar, A., and Schweizer, H. P. (2006) A 10-min method for preparation of highly electrocompetent pseudomonas aeruginosa cells: Application for DNA fragment transfer between chromosomes and plasmid transformation, J. Microbiol. Methods 64, 391-397.

(3) Ramesh, R., Bovino, M. T., Zeng, Y., and Aubé, J. (2019) Synthesis of the nonribosomal peptide phevalin and analogs, J Org Chem 84, 3647-3651.

(4) Zav'yalov, S. I. S., I. V.; Ezhova, G. I. (1989) Synthesis of imidazoles Izvestiya Akademii Nauk SSSR, Seriya Khimicheskaya 1, 140-143.

(5) Chen, D., Franklin, C. L., Guzzo, P. R., Lin, L. S., Liu, J., Lo, M. M.-C., Nargund, R. P., and Sebhat, I. K. (2008) Substtuted imidazoles as bombesin receptor subtype-3 modulators, In WO2008051404A2.

(6) Lipshutz, B. H. V., W.; Huff, B. (1986) Protection of imidazoles as their betatrimethylsilylethoxymethyl (sem) derivatives, Tetrahedron Letters 27, 4095-4098.

(7) Dickschat, J. S., Reichenbach, H., Wagner-Dobler, I., and Schulz, S. (2005) Novel pyrazines from the myxobacterium chondromyces crocatus and marine bacteria, European Journal of Organic Chemistry, 4141-4153.

(8) Morgan, G. L., Kretsch, A. M., Santa Maria, K. C., Weeks, S. J., and Li, B. (2019) Specificity of nonribosomal peptide synthetases in the biosynthesis of the pseudomonas virulence factor, Biochemistry 58, 5249-5254.

(9) Morgan, G. L., and Li, B. (2020) In vitro reconstitution reveals a central role for the noxygenase pvfb in (dihydro)pyrazine-n-oxide and valdiazen biosynthesis, Angew Chem Int Ed Engl.

(10) Ohta. A., and Ohta, M. (1984) Convenient $n$-oxidation of pyrazines, Synthesis 2, 216-217.

(11) Matsuo, M., Matsmuoto, S., Kurihara, T., Akita, Y., Watanabe, T., and A., O. $(1980){ }^{13} \mathrm{C} \mathrm{nmr}$ spectra of alkyl- and phenylpyrazines and their $n$-oxides, Organic Magnetic Resonance 13, 172-179.

(12) Dunn, G., Newbold, G. T., and Spring, F. S. (1949) Synthesis of flavacol, a metabolic product of aspergillus flavus, Journal of the Chemical Society, 2586-2587.

(13) Xu, X., He, F., Zhang, X., Bao, J., and Qi, S. (2013) New mycotoxins from marine-derived fungus aspergillus sp. Scsgaf0093, Food Chem Toxicol 53, 46-51.

(14) O'Neill, E. M., Mucyn, T. S., Patteson, J. B., Finkel, O. M., Chung, E. H., Baccile, J. A., Massolo, E., Schroeder, F. C., Dangl, J. L., and Li, B. (2018) Phevamine a, a small molecule that suppresses plant immune responses, Proc. Natl. Acad. Sci. U. S. A. 115, E9514-E9522. 